\title{
SOLAR ADOPTION IN THE RURAL MIDWEST: \\ THE DIFFUSION OF SOLAR PHOTOVOLTAIC TECHNOLOGY \\ IN TWO MIDWESTERN STATES
}

A Dissertation
presented to
the Faculty of the Graduate School
at the University of Missouri-Columbia
In Partial Fulfillment
of the Requirements for the Degree
Doctor of Philosophy

by

HEATH A. PICKERILL

Dr. Benyamin Schwarz, Dissertation Supervisor

December 2018 
Running Head: SOLAR ADOPTION IN THE RURAL MIDWEST

The undersigned, appointed by the Dean of the Graduate School at the University of Missouri, have examined the dissertation entitled

\author{
SOLAR ADOPTION IN THE RURAL MIDWEST: \\ THE DIFFUSION OF SOLAR PHOTOVOLTAIC TECHNOLOGY \\ IN TWO MIDWESTERN STATES
}

presented by Heath Allen Pickerill, a candidate for the degree of Doctor of Philosophy, and hereby certify that, in their opinion, it is worthy of acceptance.

Benyamin Schwarz, $\mathrm{PhD}$

Ruth Brent Tofle, $\mathrm{PhD}$

Laura Cole, PhD

Anna Ball, PhD 


\section{SOLAR ADOPTION IN THE RURAL MIDWEST}

\section{DEDICATION}

As I reflect back on this experience and those who have offered support, I recognize all that has changed around me in both my life and the world during this time. At times this has been an intellectual journey and at others a struggle and pure test of endurance. I dedicate this achievement to those who have given me the confidence in myself through their reassurance that I could accomplish what I started four and a half years.

Above everyone, I dedicate this to my parents, who throughout my life have demonstrated the strength and persistence that I needed to stay focused on achieving what I set out to do. I am very fortunate to have such loving and supportive parents. During the time I spent working on my PhD, both my Dad and Mom faced cancer diagnoses. Enduring surgery and treatment with the same dogged determination they have shown in everything they tackled throughout their lives, they remained steadfast in their encouragement to me regardless of the discomfort they may have been experiencing at the time. Someone said to me that one of the challenges of finishing a $\mathrm{PhD}$ is that things in life happen around you along the way. They certainly do! In view of that, I also dedicate this to the fighting spirit of my dear friend Sarah Attea-Griffin. Her humor and wit have been a constant source of laughter. I only hope that I can return the favor in her darkest hour.

Finally, I dedicate this to the aspirations of that little boy who stood staring out the classroom window watching his classmates play in the bright spring sunshine as the teacher broke the news that she and his parents thought it was best if he repeat the second grade the following year. Ultimately, she said, it was his decision. Somewhere inside me, 


\section{SOLAR ADOPTION IN THE RURAL MIDWEST}

as that little boy, I understood then as I do now that ultimately I control what I learn and achieve through education. This is dedicated to that little boy in me who believed in the power of learning. 


\section{ACKNOWLEDGEMENTS}

The gratifying part of acknowledging all those who have supported me through this process is that it signifies I have neared the end of what has, at most times, seemed like an insurmountable task. From the first time I walked into Dr. Benyamin Schwarz's office, he has offered his continued support and guidance. At moments of panic and feeling overwhelmed, he would put a hand on my shoulder and say, "Stop worrying! You know what you are doing. You've got this.” From enlightening me on the latest book he read to discussing the latest happenings in our world, I always walked out of his office believing I was capable of coming through this adventure in one piece.

I want to thank my other committee members as well. Dr. Ruth Tofle always had a kind word and useful suggestion. Her passion and caring attitude are contagious. Each summer, the graduate workshop left me hopeful about the coming semester and thankful that I was a part of such as dedicated group of academics. Dr. Laura Cole challenged me to explore concepts and theories that at the time seemed complex and unrelated. In hindsight, I realize they provided me with the understanding of environmental conservation and behavior change I needed to offer a thorough analysis of solar adoption. Dr. Anna Ball guided me through my first study and provided a wealth of knowledge on qualitative research. It provided a sound foundation I have built on over the past three years and will continue to rely on as I move forward as a researcher.

I owe a huge debt of gratitude to my longtime friend, RoseAnne Hobbs, who answered her phone at all hours of the night. From feedback on the structure of a single sentence to countless lengthy discussions over word choices, her advice has been invaluable. My guess is she never imagined as she proofread term papers for an anxious 
high school senior that nearly thirty years later she would spend countless days of her summer vacation in an office editing a dissertation that seemed to never end. I would be remiss not to mention my close friend and confidant, Dr. Sean Harris. Without Sean's drive and ambition to pursue his own doctorate degree, I may never have taken that first, scary step on this path. He has been a voice of reason when I was at my wits' end and a worthy sparring partner in debating the approaches to research. His fortitude is a constant source of motivation. 


\section{TABLE OF CONTENTS}

ACKNOWLEDGEMENTS ......................................................................... ii

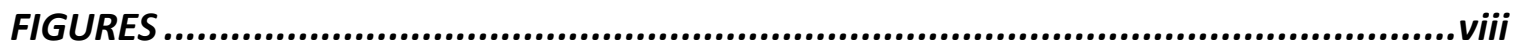

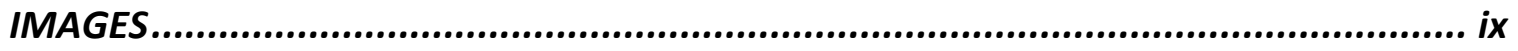

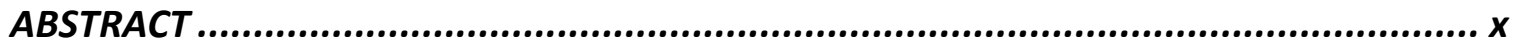

CHAPTER ONE: INTRODUCTION.................................................................. 1

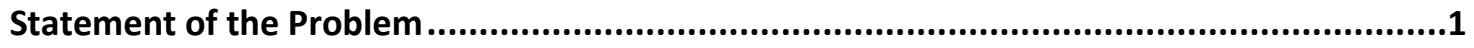

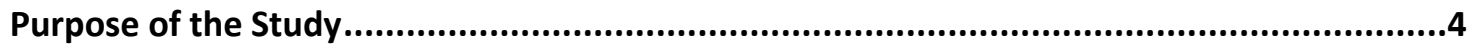

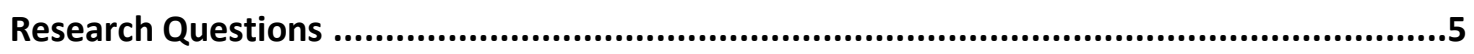

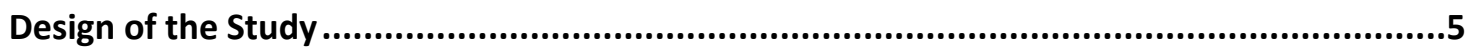

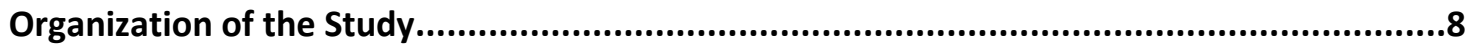

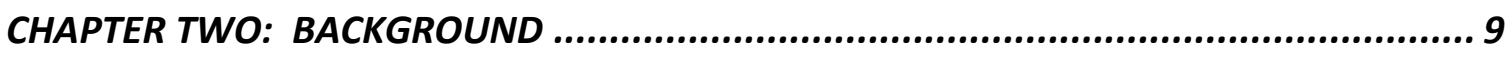

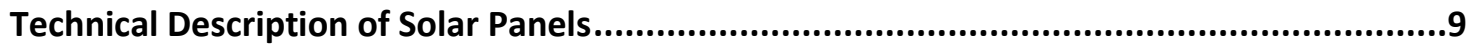

Adoption of Renewable Energy Technologies.............................................................12

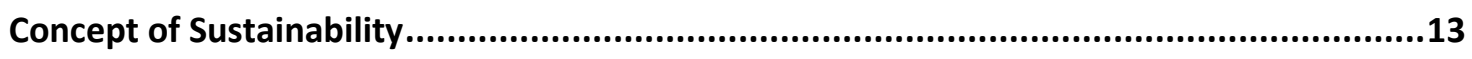

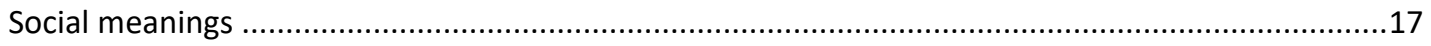

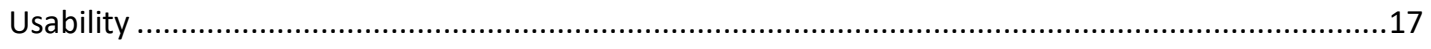

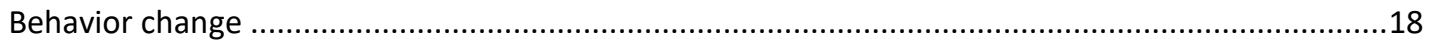

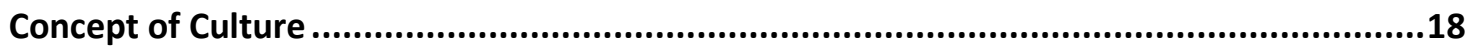

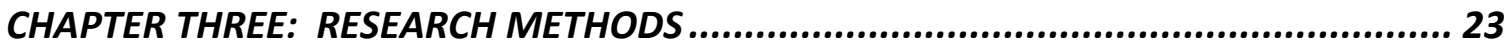

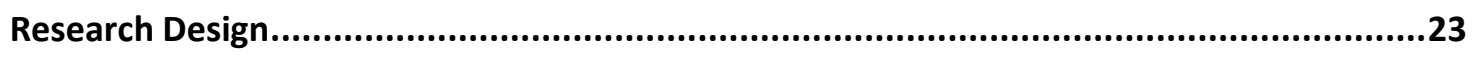

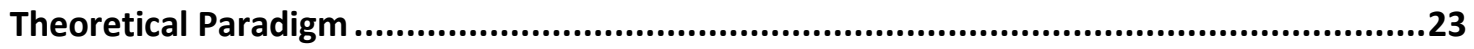

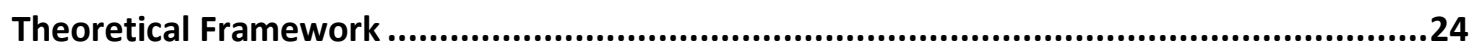




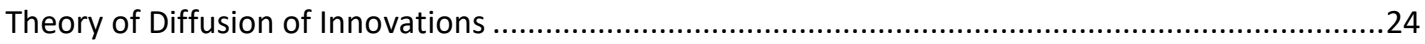

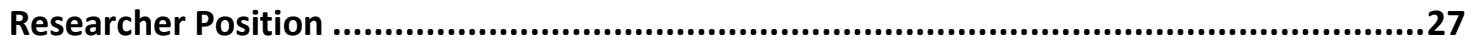

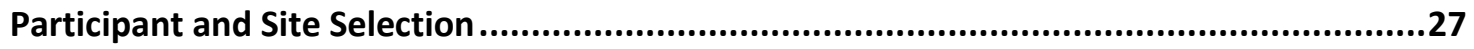

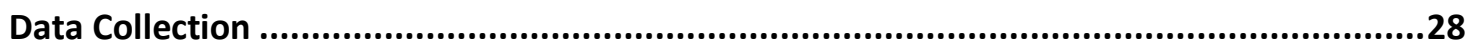

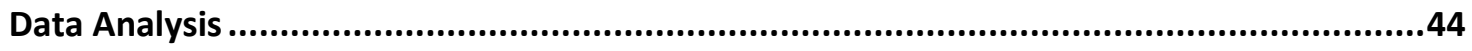

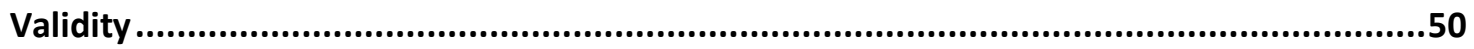

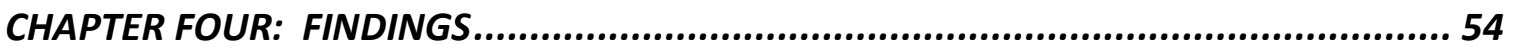

Theme One - Factors and Motivations of Adoption.............................................54

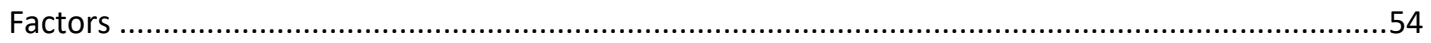

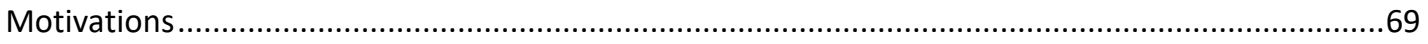

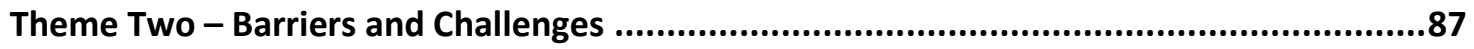

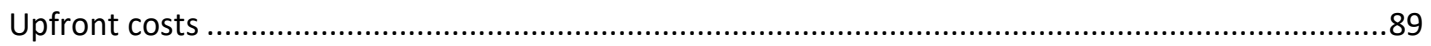

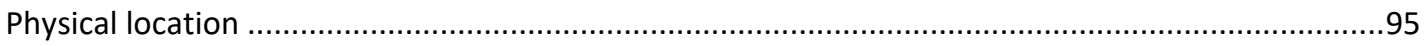

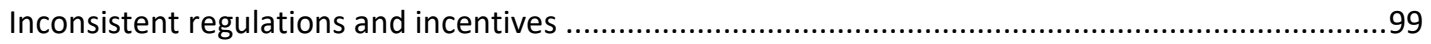

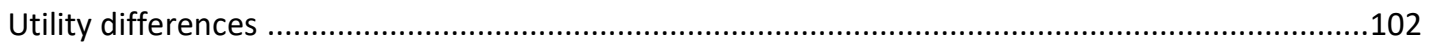

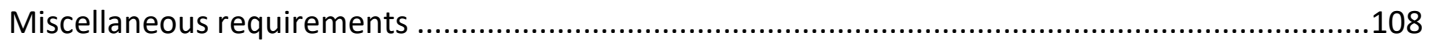

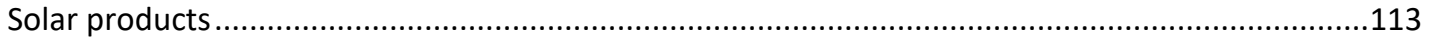

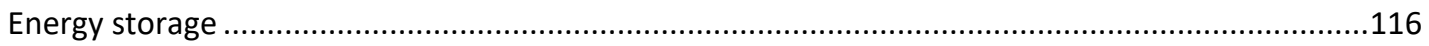

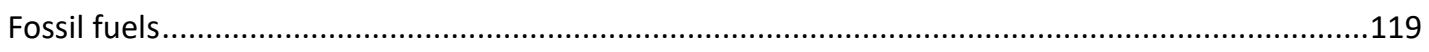

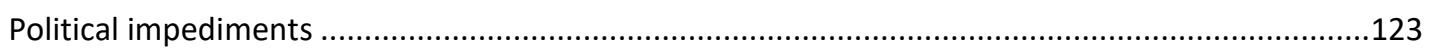

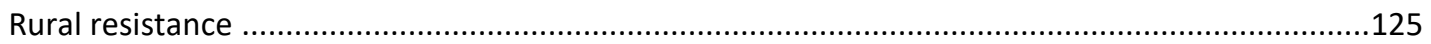

Theme Three - Electric Utilities .......................................................................131

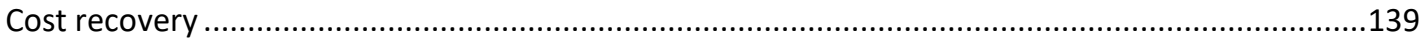

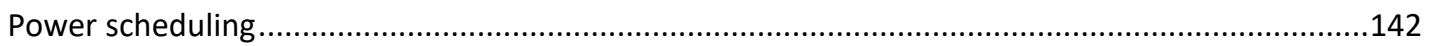

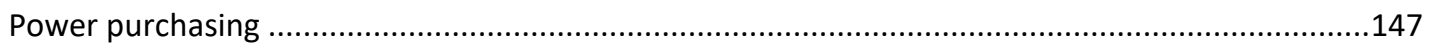

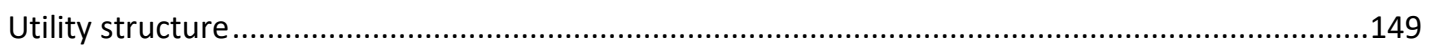




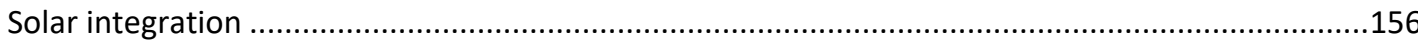

Theme Four - Renewable Portfolio/Energy Standards...............................................160

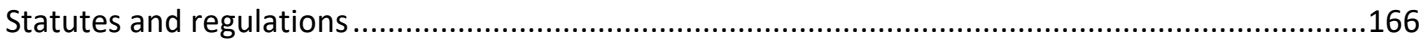

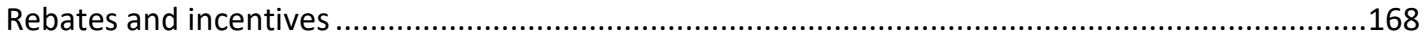

Theme Five - Growth of Rural Solar Adoption...........................................................172

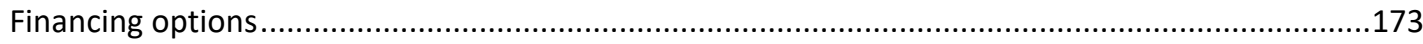

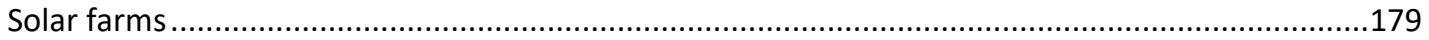

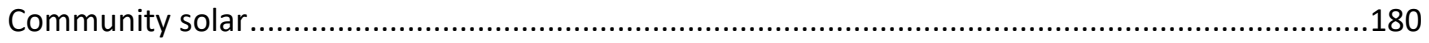

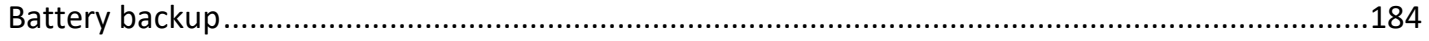

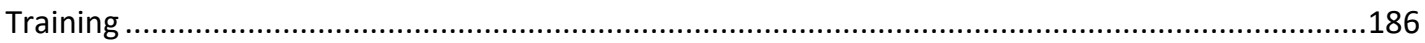

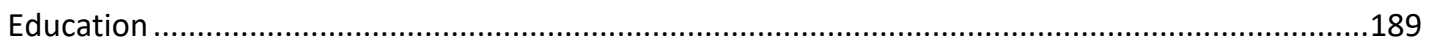

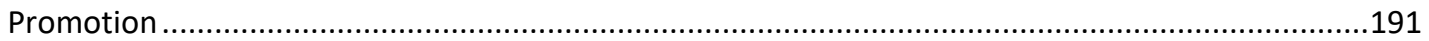

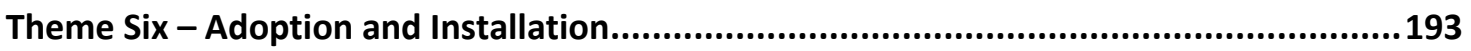

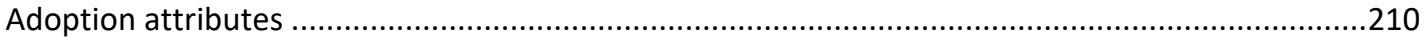

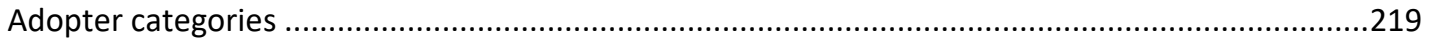

CHAPTER FIVE: DISCUSSION - SUMMARY \& REFLECTIONS ............................... 226

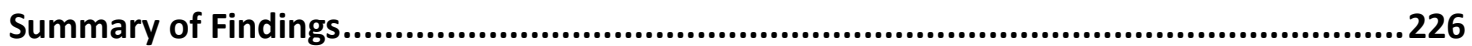

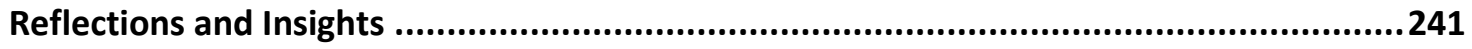

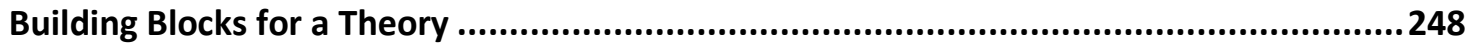

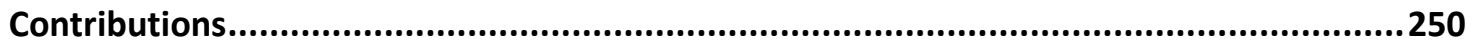

CHAPTER SIX: CONCLUSIONS \& RECOMMENDATIONS ................................. 252

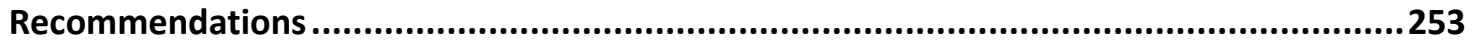

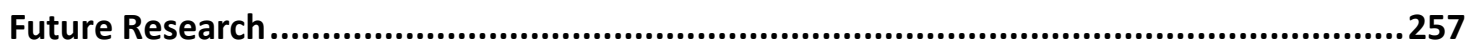

Appendix A - Interview questions for solar adopters ...................................... 261

Appendix B - Interview questions for cooperative utilities ................................ 263 
Appendix C - Participant-coding table example ..................................................... 264

Appendix D - Combined-coding table example ..................................................... 270

Appendix $E$ - Theme prioritization table example ............................................... 272

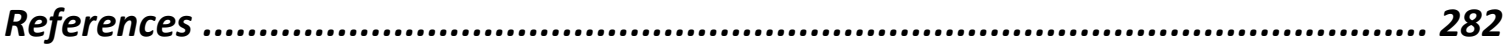

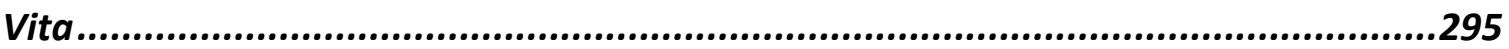




\section{LIST OF FIGURES}

Figure 1. Research design diagram (Crotty, 1998)..................................................... 23

Figure 2. Elements of the Theory of Diffusion of Innovations diagram ....................... 26

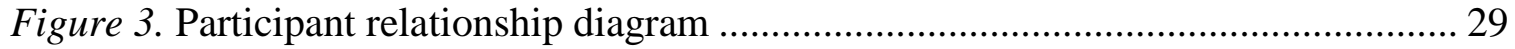

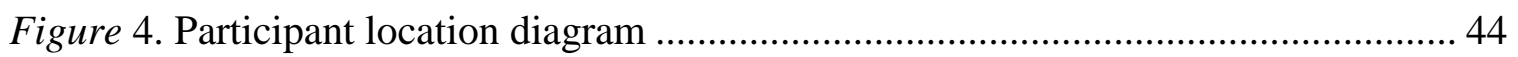

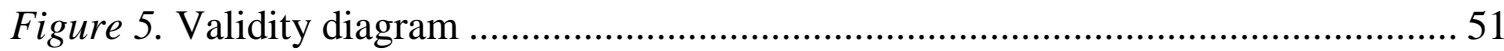

Figure 6. California Independent System Operator (CAISO) duck curve (Obi \& Bass,

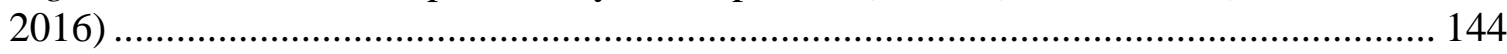




\section{LIST OF IMAGES}

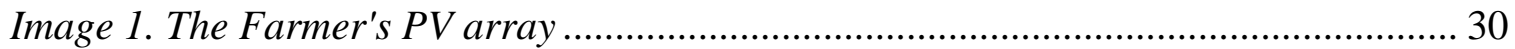

Image 2. Data collection from interview with the Farmer ........................................ 30

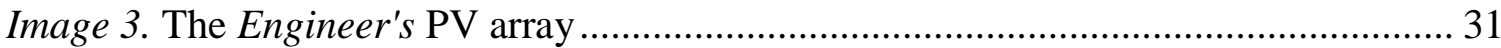

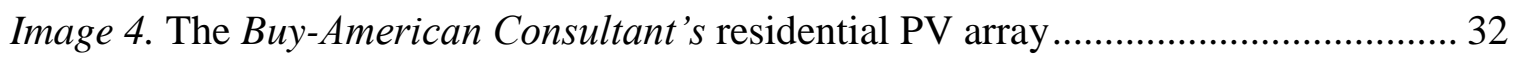

Image 5. The Firefighter's ground mounted PV array during installation ..................... 33

Image 6. The Surveyor's ground mounted PV array .................................................. 34

Image 7. The Surveyor's uncle's ground mounted PV array ..................................... 35

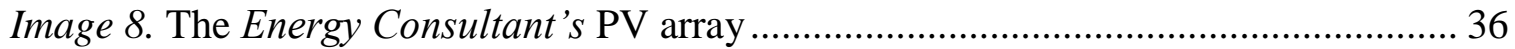

Image 9. An example of installation by the Energy Consultant .................................. 37

Image 10. The Farm Matriarch's ground mounted PV array ...................................... 40

Image 11. The Father-in-law/Farmer's machine shed with a roof mounted array ......... 40

Image 12. My Dad's Friend's ground mounted PV array ........................................... 41

Image 13. The Surveyor using an Enphase inverter smart phone app ............................ 60

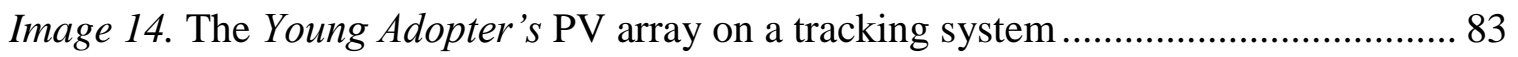

Image 15. The Engineer's PV array on an adjustable racking system .......................... 97

Image 16. The Cooperative Farmer operating the GPS in his combine ...................... 197

Image 17. The Engineer's charts and drawings used to design his PV array ................. 201

Image 18. Primary disconnect switch on breaker box, net meter, and micro inverters .. 209

Image 19. Missouri University of Science and Technology's Solar Village................. 214

Image 20. Missouri University of Science and Technology's Eco Village ................... 214

Image 21. Large ground mounted PV array at a grain elevator ................................ 218

Image 22. The Father-in-law/Farmer's farm equipment with high-tech features ......... 221 


\author{
SOLAR ADOPTION IN THE RURAL MIDWEST: \\ THE DIFFUSION OF SOLAR PHOTOVOLTAIC TECHNOLGY \\ IN TWO MIDWESTERN STATES \\ Heath Allen Pickerill \\ Benyamin Schwarz, PhD, Dissertation Supervisor
}

\begin{abstract}
In a nation of diverse geographies, many regions across the United States' vast rural landscapes have expressed support for the current administration's policies. At the same time, these rural areas have displayed a slow acceptance to renewable energy. In an effort to reduce government oversight and bring jobs back to rural communities struggling from high unemployment, the current administration has promised to lower environmental regulations and increase fossil fuel extraction with little regard to scientific research warning of the outcomes from climate change. Consequently, the U.S. finds itself immersed in a rhetoric promoting a revival of coal mining and other practices proven to negatively impact the environment. All the while, rural residents ignore job opportunities for skilled workers and increased revenues for their local communities, both of which could result from advancing solar photovoltaic (PV) technology in these areas.

Compounding the challenge of increased solar adoption in rural areas of the Midwest, existing research has predominantly focused on major urban areas or large scale RETs like wind power. Few studies have explored the barriers and motivations of adopting solar technology in rural areas of the U.S. The purpose of this study was to better understand the challenges and opportunities for rural solar adoption in the Midwest and explore the political and regulatory impacts. The qualitative study was conducted
\end{abstract}


using a grounded theory approach to theorize strategies in overcoming these barriers while promoting PV arrays as an energy source in rural areas where many residents are slow to embrace renewable energy. Twenty-four participants from Illinois and Missouri, representing various sectors of the solar industry, provided diverse perspectives on residential-scale rural solar adoption. Adopters, installers/consultants, advocates, government agencies, and utility companies were interviewed to collect data on the barriers and opportunities facing solar adopters in rural areas.

The data revealed several key themes related to the diffusion of solar technology in the rural Midwest. Not only did multiple factors and motivations that affect solar adoption arise as a theme, but also diverse barriers and challenges became an obvious second theme. Furthermore, multiple utility types emerged as a theme because they create inconsistent statutes and levels of support. Similarly, each state's policies and incentives for renewable energy surfaced as a theme. The final two themes centered on the perception of solar adoption in rural areas and the diffusion of solar technology through the adoption process.

The findings highlighted the effects of political environments on residential-scale PV installations in rural areas and the potential that energy storage advancements has to increase solar adoption. Additionally, growth for solar adoption in rural areas depends on a target audience willing to invest in PV arrays. This growth is possible by making solar technology assessable through firsthand experience. Accordingly, the findings support the promotion of solar technology through the development of a technical training center to educate and train potential adopters, installers/consultants, utility companies, and policy makers. 


\section{CHAPTER ONE: INTRODUCTION}

\section{Statement of the Problem}

The rural Midwest is a vast and diverse area populated by countless utility customers, the majority of whom are slow to embrace renewable energy advancements and even reluctant to acknowledge climate change. Most rural Americans continue to power their homes and farms with nonrenewable energy sources while ignoring renewable energy technologies (RETs) like solar power even though the sun represents an endless supply of energy. As solar panels become an even more promising energy source, they offer homeowners along with farmers an opportunity for less dependence on the energy from central power grids produced from fossil fuels (Zahran, Brody, Vedlitz, Lacy, \& Schelly, 2008).

However, a significant lack of research, especially about the barriers and motivations on the adoption of solar technology in rural environments, makes promoting solar energy to rural Americans difficult. Even for Germany, the leading country in solar adoption, a thorough literature review reveals little about the diffusion of solar technology in rural areas. Studies discuss the role of local communities in Germany's significant solar diffusion, a result of their feed-in tariff that stipulates utility customers must be paid for the power they supply to the grid (Sueyoshi \& Goto, 2014). Previous studies unfortunately do not explore the level of rural adoption or the barriers faced by those utility customers. Research in the United States has focused on urban areas known to embrace RETs or on large renewable energy sources like wind farms. With research focused primarily on urban areas, studies are needed to identify factors that can motivate rural utility customers to adopt solar technology. The key problem of this study was 
determining what challenges people face in the rural Midwest to install solar panels and what motivates those who do to embrace renewable energy.

Renewable energy technologies (RETs) make up a small percentage of the world's energy supply because most renewable energy markets rely heavily on direct subsidies, energy taxes, and feed-in tariffs (Masini \& Menichetti, 2013). The promotion of RETs relates to their economic potential and technological capabilities (Painuly, 2000). However, evidence shows that evaluations based solely on economics are not enough to explain how investors allocate capital or individuals choose from various RETs (Masini \& Menichetti). Therefore, the analysis of various renewable energy sources must include broader social and psychological considerations (Masini \& Menichetti). These considerations are gained through research for a better understanding of RET adoption.

A gap exists in the information available on the barriers preventing the rural population from embracing RETs, indicating focused research in this area is needed. Sovacool (2014) argued that little research has taken place in the "real world" in regards to energy technologies and human behavior related to energy consumption. He stated that most studies are done with computer models and experiments versus field observations, interviews, and surveys. He also argued for a broader understanding of how human behavior affects energy demand and the diffusion of technologies. The US Department of Energy (as cited in Sovacool, 2014) noted that individual choice, preference, and behavior impact supply and demand as much as technical performance. Sovacool (2014) added, "Social sciences, humanities, and the arts are marginalized in energy research, and major statistical agencies do not usually collect qualitative data about energy consumption” (p. 529). 
D’Agostino et al. (2011) further highlighted the need for this study by stating academic researchers too often focus on technical fixes rather than ways of altering lifestyles and social norms. Sovacool (2014) added that the problem-focused research of physical and social processes have a better chance of making a social impact; this research needs to include diverse participants and both qualitative and quantitative methods. I agree strongly with both researchers. Sovacool's article framed a strong argument for my research. I am interested in the social behaviors currently impeding the adoption of solar technology. I feel this research is critical in advocating widespread solar adoption in all areas of the U.S., especially the rural Midwest.

Additionally, limited original studies exploring rural adoption on any type of RET have been conducted. The majority of available literature includes reviews of studies or articles assimilating available information to identify key themes. Rural America has been excluded, for the most part, from studies on adopting renewable energy. Several literature searches on solar adoption failed to produce any matches when limited to solar PV technology in the rural United States. Therefore, my searches were modified to include the adoption of all RETs in the rural United States and solar PV technology in any rural locations. The results include articles on solar energy in the U.S. but not in a rural context (Bazen \& Brown, 2009; Denholm \& Margolis, 2008; Zahran et al., 2008). Other articles examine wind power in rural areas (Mulvaney, Woodson, \& Prokopy, 2013; Munday, Bristow, \& Cowell, 2011; Sovacool \& Ratan, 2012). Sustainable topics are addressed in studies located in the rural U.S. but do not focus on solar PV technology (Bowman \& Thompson, 2009; Brown, Weber, \& Wojan, 2013; Golding, 2012). Articles focusing on solar energy in rural locations are all cited outside of the U.S., many in 
developing countries (Baline, 2006; Chaurey \& Kandpal, 2010; Clifton \& Boruff, 2010; Duke, Jacobson, \& Kammen, 2002; Kamalapur \& Udaykumar, 2011; Pascale, Urmee, Whale, \& Kumar, 2016). This gap makes comparing the barriers and motivations of rural adoption very difficult because the literature often addresses specific issues within that country such as economic challenges not related to the U.S.

\section{Purpose of the Study}

The purpose of this study was to explore strategies in overcoming barriers for adopting solar technology and promote its acceptance as an energy source in rural areas outside of California and other Southwestern states known for solar energy production. More precisely, the goals of this study were to: 1) examine the most common barriers preventing individuals from adopting solar technology and 2) discover what motivates rural utility customers to install PV arrays. My intellectual goal was to theorize on the possibilities of widespread solar adoption in rural areas and understand how that adoption can transform our country's reliance on fossil fuels. My central question focused on identifying the barriers and motivations for individuals in rural areas to adopt solar technology. Homeowners living in a rural location who developed an understanding of the benefits associated with renewable energy by adopting solar technology were a key identifying characteristic. Anticipated relationships of this research included strong motivations of individuals to adopt solar technology driven by their understanding of such technologies and a willingness to promote their use. Understanding the barriers that prevent the adoption of solar technology will lead to determining the most influential motivations. Identifying ways to overcome the barriers is instrumental in developing a sound strategy of promoting the adoption of solar technology (McKenzie-Mohr, 2000). 
Changing the mindset in the rural Midwest is important because this vast area consumes energy and contributes to the environmental impacts of fossil fuels and other current energy sources. It is pivotal that the U.S. becomes more open to adopting RETs. Currently our society in general, especially rural areas, shows reluctance to move in this direction. Even though we continue moving toward a future more reliant on sustainable energy, we remain very slow to embrace and adopt it. Adoption implies an ongoing investment toward a more sustainable future and a behavioral change, both defining directives in my study.

\section{Research Questions}

My central question for this study asked: what complexities of solar adoption impact the adoption of residential-scale solar PV arrays in rural areas of the Midwest? Several related questions guided me. First, what personal priorities and experiences influence participants to install PV arrays? Second, what motivating factors in participants' surroundings direct their behavior to adopt solar technology? Third, how do utility and government imposed statutes and regulations affect the challenges and opportunities of solar adoption by participants? These are relevant since individuals' behaviors are influenced by the culture surrounding them (Crotty, 1998). Additionally, some sub-questions provided insight into the adoption of PV arrays and include: 1) What are the biggest barriers that discourage rural residents from installing PV arrays and 2) How can solar adoption be encouraged in rural areas?

\section{Design of the Study}

I chose the Midwestern countryside because of the significant lack of research on solar adoption outside of large metropolitan areas in states other than those with large 
concentrations of solar power like California and other Southwestern states. Based on research completed as part of a pilot study, it was apparent that focused data collection from utilities and government agencies was critical in linking the findings from these earlier studies that focused predominantly on data from adopters.

I conducted a qualitative study to better understand the impediments of solar adoption and discover how political and regulatory sanctions are impacting the factors involved with installing PV arrays. The majority of previous research has employed a quantitative approach. Some studies used a mixed methods design, but very few qualitative studies exist. To explore the challenges facing renewable energy, qualitative research is needed. Utilizing qualitative research methods in my study benefits the research of all RETs by providing insight into the barriers and motivations for solar adoption in rural areas of the U.S. Because I was interested in the social behaviors impeding the adoption of solar technologies in rural locations, qualitative research provided an interpretive, theoretical framework to inform my study on the meanings rural Americans ascribe to adopting solar technology (Creswell, 2013). I used methods that allow a holistic account of the participants' experiences, including their motivations to adopt solar technology and the challenges they faced. By utilizing grounded theory, I can theorize about increasing the rate of solar adoption throughout the rural U.S. with the implementation of a targeted promotion of solar PV technology to transform our country's dependence on fossil fuels.

While qualitative research is more labor intensive, expensive, and difficult in generalizing the findings, it allows for the inductive exploration of issues and revelation of how people articulate their values of adoption (Dietz, Fitzgerald, \& Shwom, 2005). 
Qualitative research also allows the direct observation of environmental behavior, which has often been missing in environmental behavior change studies, including adoption research. For this reason, Rogers (1995) proposed incorporating qualitative methods into research to overcome the difficulties of understanding adoption motivation through survey research data; surveys do not always reflect how or what people are thinking. Further, Rogers criticized the use of one-time surveys as the only means of gathering data in past adoption studies and proposed including qualitative methodologies in future studies. Rogers also added that cross-sectional survey data do not reveal the causes or time-order of adoption. Survey questions cannot uncover an adopter's impetus for using an innovation, so he encouraged researchers to ask more "why" questions about adoption to better understand the motivations of adoption, a difficult issue to investigate.

Additionally, he recommended field research, longitudinal panel studies, document reviews of archives, and case studies using data from multiple participants.

Clearly, a qualitative study expands the knowledge base on RET adoption beyond quantitative studies. Adopting the qualitative method of in-depth interviews provides more insight into not only the social but also individual behaviors impacting the adoption of solar technology. Qualitative research allows local knowledge to be incorporated. Parnell and Larsen (2005) argued that messages of RET adoption should be based on local knowledge with a strong local identity that allows homeowners to validate the usefulness and applicability of solar technology on their own. Finally, a qualitative study provides a broader understanding of how human behavior affects energy demand and the adoption of RETs, which is needed (Sovacool, 2014). Problem-focused research of 
physical and social processes of diverse participants will have a better chance of making a social impact (Sovacool, 2014).

\section{Organization of the Study}

Chapter One's introduction to the study focused on the problem statement and an explanation of the study's purpose. Chapter Two provides a technical description of solar technology and conceptual context, including how factors and beliefs influence the adoption of solar technology in rural areas. Theoretically, culture and social meaning affect the response to the usability of PVs and the behavior change necessary for adoption. Chapter Three details the research methods, including my theoretical paradigm and researcher position along with data collection and analysis. Chapter Four presents the findings of the data organized into the themes that emerged by interpreting the data. Chapter Five provides a discussion of the findings and their relation to existing research. The chapter also includes a reflection on what these findings reveal about the data in a broad context of renewable energy acceptance in rural America. Finally, chapter Six presents my conclusions on the significance of this study's contributions to the field of solar technology adoption and the recommendations to increase solar adoption in rural America. 


\section{CHAPTER TWO: BACKGROUND}

I provide a technical description of solar technology as well as an overview of the adoption of renewable energy technologies (RETs) as important background information for this study. Further, I construct a conceptual framework around this information as well as the concepts of sustainability and culture. My conceptual framework depends on research in the social sciences to reveal the rural cultural and social behaviors affecting the adoption of solar technology. The rationalization for the framework is that other researchers recognize the importance of behavior in the acceptance of alternative energy sources. Sovacool (2014) argued that utility companies should focus more on consumer behavior and energy demand rather than just generation, transmission, and distribution. D’Agostino et al. (2011) revealed that the most common research methods currently used come from an economics/engineering background. He argued for behavioral studies to enhance the energy studies field and increase the policy-relevance of contemporary research. Therefore, I framed my study around relevant background information, social science based concepts, and the Theory of Diffusion of Innovations, a theory useful in revealing cultural and social behaviors in rural settings. I began with a technical description of solar panels and followed with an explanation of the adoption of RETs. Next, I examined the concept of sustainability through social meanings, usability, and behavior change. Finally, I discussed the concept of culture and its importance to my study.

\section{Technical Description of Solar Panels}

With their ability to be applied to all sectors of the economy, including residential, commercial, industrial, and utility scale, solar panels represent an ideal source 
of electric power generation (Touryan, 1999). They can also generate energy more efficiently while creating significantly greater savings (Zahran et al., 2008). They have been shown to be especially cost-effective in remote applications because they can be grid-tied or completely disconnected from the utility grid (Zahran et al., 2008).

Known by the technical term photovoltaics (PV), solar panels are typically installed as a configuration of multiple panels called an array. The word photovoltaic describes the production of an electric current from exposure to radiant energy (Balfour, Shaw, \& Jarosek, 2013). PV arrays produce energy from the sun's solar radiation when electrons from a semiconductor are released and activated by exposure to light. An electrical current is then created when the electrons are collected by metal contacts on the front of solar cells. Because silicon atoms have four valence electrons that can be knocked into the conduction band easily, silicon acts as an excellent semiconductor in a solar cell, the basic building block of PV technology (2013).

Currently, the three basic types of solar cells include monocrystalline, polycrystalline, and thin-film silicon panels, each using different types of semiconductors (Kwok \& Grondzik, 2011). Monocrystalline and polycrystalline are both silicon-based technologies. Polycrystalline panels degrade in energy generation an estimated $0.7 \%$ each year, making monocrystalline panels more efficient, but they cost more to purchase. To date, monocrystalline and polycrystalline silicon cells are more efficient to produce and remain the most common and widely used (Balfour et al., 2013). Thin film panels use a metal base of copper, indium, allium, and selenium (CIGS). Silicon and metal-based technologies are becoming comparable in price, but silicon technology is still dominating the market. 
Frenchman Alexandre-Edmond Becquerel discovered the photovoltaic effect in 1839 when he placed metal electrodes in an electrolyte solution and shone light on it (Lynn, 2010). The first solar cell was constructed by Charles Fritts in 1883 (Balfour et al., 2013). However, it was over one hundred years after Becquerel's original discovery that a practical application was made to PV devices with the advent of semiconductor electronics in the 1950s (Lynn, 2010). PV power was used predominantly for electronics as well as satellites until the 1970s. In 1973, the oil embargo prompted dramatic increases in PV research and development in the United States under President Jimmy Carter, only to have government support drastically cut by the Reagan administration. Fortunately, Germany and Japan continued contributing to the efficiencies of solar cells and investigating new PV materials and cell structures. The stage was set for continued advancement of PV production, which increased greatly in the 1990s when developed countries began adopting grid-connected systems. The past 20 years have seen remarkable progress in research and development. Universities, government institutes, and PV companies continue improving existing cells in addition to inventing new ones, improving system reliability, and, very importantly, reducing the price (Lynn, 2010). High efficiency, low costs, high performance, and improved reliability stand out as key factors necessary in the continued advancement of PV technology (Balfour et al., 2013). PV arrays represent one of the largest and most widely researched RETs because they are one of the most promising energy sources and have several benefits. They can create more self-reliant and resilient communities less dependent on central power grids (Zahran et al., 2008). According to Stone (1994), "approximately two-thirds of the electricity generated in the United States is consumed in residential, commercial, and 
institutional buildings; major uses of electricity include lighting, air handling, air conditioning, pumping, and refrigeration" (p. 48). An ideal source for electric power generation, PV arrays can be applied to all sectors of the economy, including consumer/specialists, residential, industrial, rural locations, and the utility grid (Touryan, 1999). They have also been shown to be especially cost-effective in remote applications.

\section{Adoption of Renewable Energy Technologies}

RET adoption encompasses sustainable practices to achieve a renewable energy system in the United States (Reddy \& Painuly, 2004). Transitioning from non-renewable to renewable energy is dependent on the successful development, diffusion, and adoption of RETs, which include systems such as solar PVs, wind, biofuels, geothermal, and hydropower. This transition should rate as a top priority (Reddy \& Painuly, 2004). RETs reduce negative human impact on the natural environment by conserving resource consumption (Murarolli, 2014). RET adoption is a type of pro-environmental behavior. Defined as intentionally reducing the negative impact of an action on the everyday environment, pro-environmental behavior includes such areas as conservation behavior and household energy use (Dono, Webb, \& Richardson, 2010). Since conservation behavior is integral to sustainable practices and pro-environmental behaviors, RET adoption falls directly within the conservation landscape.

Beginning in the mid-1970's, the focus of energy and behavior research, including RET adoption, evolved from studies on voluntary conservation efforts (Lutzenhiser, 1990; Parnell \& Larsen, 2005). Energy and behavior research then began investigating the physical aspects of energy efficiency and technological advancements. The research also examined the economic impacts before finally incorporating 
psychology and the social sciences. Each of these areas, often represented by different disciplines, developed theoretical models of human energy-use behavior framed in "theories of value, identity, attitude-behavior, reasoned action, and learning" (Parnell \& Larsen, 2005, p. 791).

One of the challenges of promoting conservation behaviors is that many consumers believe they must sacrifice their quality of life and well-being to reduce their consumption (De Young, 2011). Promoting RET adoption faces these same challenges. A perceived need to maintain a certain quality of life based on culture and lifestyle exists and includes expected standards of comfort, cleanliness, and convenience (Parnell \& Larsen, 2005). The promotion of energy efficiency and RETs involves convincing homeowners that these standards will not be compromised. Making the content of messages motivating while framing them so they are perceived as relevant is viewed as a barrier (Parnell \& Larsen, 2005). This challenge grows more difficult because the energy expert and homeowner have different levels of knowledge for energy, energy use, and energy efficiency. Thus, the audience's level of understanding impacts the benefit of promotional materials on RETs.

\section{Concept of Sustainability}

The concept of sustainability focuses on a shared interest of developmental and environmental priorities, embracing objective science and ongoing development (Owen \& Dovey, 2008). Guy and Farmer (2001) stated that sustainable buildings are often assumed to be structures designed around technological innovations. They argued, however, that this definition ignores the social construct involved in building design. An understanding of how the concept of sustainability developed validates the social 
production of space, place, and environment. Marcuse (1998) argued the origins of sustainability that started in the environmental movement remain heavily focused on ecological concerns. Sustainability involves adjusting the actions of today to improve the environment for future generations. Marcuse defines sustainability as the current generation living within the limits of the natural systems for the sake of future generations. Campbell (1996) defined it as "the long-term ability of a system to reproduce" (p. 306).

According to Moore and Wilson (2009), sustainability was derived from two $19^{\text {th }}$ century social movements: the environmental movement promoted by John Muir with the Sierra Club and the Public Health Movement promoted by Colonel John Waring, the New York Street Cleaning Commissioner. They presented the classical definition as three competing frames of interpretation: economic development, environmental protection, and social equity. The 1987 Brundtland Commission Report, Our Common Future from the United Nations World Commission on Environment and Development (WCED) defined it as, "Sustainable development is development that meets the needs of the present generation without compromising the ability of future generations to meet their own needs" (p. 8). The WECD connected the environmental and public health movements in theory and defined the "three Es" of sustainable development as the societal values that assist in achieving this preservation of natural resources: environment, economy, and equity.

In recent years, sustainable development has evolved into the sustainable construction concept (Koranda, Chong, Kim, Chou, \& Kim, 2012), which encompasses the adoption of sustainable technologies into the built environment and creation of space. 
Sustainable technologies are used to solve problems with our natural resources (Tucker, 2008). Factors in how these technologies are adopted and beliefs in their positive impact on preserving natural resources influence sustainability's acceptance. These factors and beliefs provided conceptual context in this study on the impact of solar adoption to the social environment. Hoffman and Henn (2008) stated that organizational arrangements and cultural beliefs limit the adoption of sustainable building practices, including the adoption of RETs because of a perpetuated status quo.

Generally, Americans do not worry much about design as it relates to climate because of HVAC systems, insulation, thermopane windows, and other climate control technologies (Altman \& Chemers, 1980). Modern technology eliminates the need to focus on climatic or environmental conditions. Altman and Chemers (1980) asked whether the design of homes and the increased adoption of sustainable technologies will become more responsive to climate conditions if a shortage of oil and gas develops. They predicted that Americans will not be receptive to drastic and sudden cultural shifts to more renewable energy sources unless forced by shortages in other fuel sources.

Altman and Chemers (1980) also emphasized that Americans generally pay less attention to the availability of local materials and the use of natural resources. This lack of attention reflects an overall disregard by Americans for conserving natural resources in general and indicates a hesitancy to adopt sustainable technologies in U.S. homes. This reluctance calls into question whether the culture of a rural environment is a major barrier in the adoption of sustainable technologies; overcoming existing cultural influences within established social norms makes the acceptance of new technologies difficult. Policymakers and planners often make choices about sustainability that are contradictory 
to the everyday experience of human behavior (Cooper, 2006). Policymakers often blame technology when it is more about social, political, and cultural factors. Their policy objectives depend on various contextual factors, including cultural variations that may have as much influence as climatic conditions (Cooper, 2006).

Cultural variations rely upon the type of settings and the social groups found in urban versus rural locations. These social groups influence the conception, production, diffusion, and use of technologies (Farmer, 2013). Therefore, the urban or rural setting and the location of a project, because of differences in cultural factors and social meanings, influence factors and beliefs. A much greater concentration of sustainable practices exists in urban areas because of more access to technologies and social contacts with existing users. This availability provides a political and social framework to price sustainable energy more accurately. Additionally, urban areas have more politically liberal residents, a population more receptive to adopting sustainable technologies, according to most research.

Social meanings, usability, behavior change, and culture can influence the acceptance of sustainability differently in rural versus urban environments; these concepts were very relevant to discovering how rural Americans' behaviors affect their adoption of solar technology. The social meaning can have a strong influence on how rural Americans respond to the usability of PV arrays and the behavior change necessary to adopt solar technology. Therefore, the concepts of social meaning, usability, and behavior change are defined as they relate to solar technology and its adoption. The concept of culture is discussed in greater detail because of its importance to framing the data during analysis. 
Social meanings. The social meaning attached to sustainability can create barriers in the diffusion and adoption of RETs. These include such behaviors as a distrust of government agencies and a social failure to price electricity accurately (Cooper, 2006; Zahran et al., 2008). Efficiency is the key to a technology's use, not the social constructs surrounding the technology. To change these behaviors, strategies are needed. First, social structures must be redefined and social acceptance must be gained during the early stages of implementation (Hoffman \& Henn, 2008). Second, demand-sized management programs must be implemented and permitting must be streamlined (Sovacool \& Watts, 2009). Since meaning is impacted by various normative factors (Ozaki, 2009), strong social patterns are needed for innovation to become a norm and contribute to more sustainable local facilities.

Usability. The usability of solar technology is influenced by utility customers' perceptions of the quality and usefulness of PV arrays. Customers often think sustainability negatively impacts the built environment. They associate sustainability with smaller spaces, lower comfort, and problems with innovative technology installation. Other challenges stem from customers' perceptions of the quality and usefulness of technologies. Some acceptance strategies for promoting the usability of solar technology include demonstration projects, free energy audits, and smart meters. Connecting renewable energy producers to the grid can also create a more useable system in case of technology downtime. The usability concerns can be offset by the benefits. RETs can reduce operating expenses, improve the quality of buildings, and actually improve comfort (Ilyinichna \& Valeryevna, 2015). They also provide healthier indoor 
environments and improve building performance. Moreover, the more technologies are deployed, the more efficient they become.

Behavior change. The behavior changes associated with the adoption of solar technology result from an incorporation of new ideas and a departure from present fossil fuel technologies. For this change to occur, adopters must overcome the barriers. These include a fear of the unknown, a perception of risk, and a lack of knowledge and information. Diffusion is not a matter of substitution, making acceptance strategies necessary. Providing focused and useful information through technical-training workshops are effective strategies. A change in behavior toward sustainability depends on modifying regulatory and investment rules. Behavior changes concerning sustainability can create benefits for users and the environment. Users can then benefit from reduced energy costs and more stable and predictable fuel prices. The environment can benefit from reduced consumption of power and other material resources, minimized waste and impacts on ecosystems, and improved efficiency (Sovacool \& Watts, 2009).

Overall, these concepts -social meaning, usability, and behavior change - provide insight into rural Americans' prioritization of factors necessary to adopt solar technology. These behavior change factors are influenced by the culture and social meaning of rural settings necessary to install a PV array based on its usability in a certain location.

\section{Concept of Culture}

Culture also impacts the diffusion and adoption of RETs through certain cognitive factors such as local community characteristics (Zahran et al., 2008) and habitual routines of residents (Ozaki, 2009). Residents may doubt the value of unfamiliar technologies and building techniques because of a cultural influence on their values and priorities. 
Therefore, cultural beliefs join with individual biases as barriers for accepting sustainability (Sovacool \& Ratan, 2012). Additionally, organizational inertia and arrangements can slow the diffusion and adoption, so acceptance strategies are needed to offset cultural influences by addressing cognitive heuristics (Hoffman \& Henn, 2008). These strategies also include framing the issue in a manner most acceptable within a given cultural context, targeting the right demographic, and highlighting the benefits (Ozaki, 2009). Accepting and choosing a technology can be more about choosing a lifestyle than about that technology. For this reason, the perception of the environmental impact of sustainability may influence cultural behavior, making the adoption of sustainability a visual symbol of environmental awareness.

Since the focus of this study explores the social behavior of rural Americans' acceptance of solar technology, framing the process of adoption through culture provides insight into their decision patterns. Widespread solar adoption in rural areas of the United States depends upon a shift in the relationship between the culture of energy production in these rural environments and the behaviors of individuals. The interactions individuals have with other members of their communities and social groups can be meaningful in shifting the cultural values of rural Americans toward a willingness to adopt solar PV arrays and increase their acceptance. Farmer (2013) stressed that the more technologies are deployed, the more efficient they become. Therefore, increased adoption will continue to increase the efficiency of solar PV technology and its contribution to renewable energy production throughout the rural United States.

E. B. Tylor (1871) originally defined culture as, “...that complex whole which includes knowledge, belief, art, law, morals, customs, and any other capabilities and 
habits acquired by man as a member of society" (p. 1). Goodenough (1971) defined it as a collection of behavior patterns and beliefs that create standards for deciding what a situation both is and can be, as well as how an individual feels about the situation, what their decision is to act, and how to proceed taking the action. Goodenough added that culture is what individuals know or believe to function in an acceptable manner according to the members of a society. Geertz (1973) referenced Goodenough when he summarized culture as a collection of psychological structures that guides an individual's behavior or that of a group.

Rapoport (1980) acknowledged that while culture has been defined in many ways, it centers on defining humanity. Culture falls into three general complementary postures. According to Rapoport, "One defines it as a way of life typical of a group, the second as a system of symbols, meanings, and cognitive schemata transmitted through symbolic codes, the third as a set of adaptive strategies for survival related to ecology and resources" (p. 9). Based on these three complementary views, Rapoport defined culture as a set of values and beliefs which embody ideals that are "transmitted" to members within a group through such means as experience, observation, and instruction (p. 9). Since culture provides motivations for individuals' behaviors (Chase, 2006), culture was useful to explore the motivations for solar adoption by rural Americans. Culture and social meanings impact the acceptance of sustainability differently in a rural environment because of the difference in factors and beliefs between urban and rural settings. These differences are relevant in discovering how rural Americans' behaviors affect their adoption of sustainable technologies, including PV arrays. Lang (1987) argued, "Motivation is the guiding force behind behavior" (p. 85). With this definition in 
mind, understanding the motivations to adopt solar technology is critical to understanding the behavior of adopting PV arrays in a rural environment.

Additionally, organizational inertia and arrangements can slow the diffusion and adoption, so acceptance strategies are needed to offset cultural influences. These strategies include addressing cognitive heuristics (Hoffman \& Henn, 2008), framing the issue in a manner most acceptable within a given cultural context, targeting the right demographic, and highlighting the benefits (Ozaki, 2009). Adopting a technology can be more about choosing a lifestyle than a technology (Farmer, 2013). For this reason, the perception of the environmental impact of sustainability may influence cultural behavior, making the adoption of sustainability a visual symbol of environmental awareness. Symbols are used to transmit culture among individuals within a group and across generations, so their role is important to consider (Lang, 1987). Symbols can indicate status and be connected to environmental meaning as a way of establishing social identity (Rapoport, 1980). A symbolic meaning may be assigned to solar panels on a house and a certain lifestyle that they express.

Cultural, political, and economic factors impact the social acceptance of sustainable technologies, making it is critical to consider the social consequences of the implementation of technologies. Additionally, various groups impact the conception, creation, adoption, and application of technologies in a socially constructed manner (Farmer, 2013). Sociology is tied closely to understanding sustainability, its benefits and applications to society, the behavioral changes that must occur, and the challenges that must be faced to overcome the barriers that are preventing its widespread adoption (Guy \& Farmer, 2001). 
One sub-question of my research explores the barriers that discourage rural Americans from installing PV arrays. At a cultural level, barriers include the lack of knowledge and information available to potential adopters along with their fear of not understanding solar technology (Sovacool \& Ratan, 2012). In relation, potential adopters' underlying beliefs and individual biases influence their reluctance to install an array (2012). The sociological study of sustainability focuses predominantly on the barriers associated with the adoption of sustainable technologies while introducing strategies to remove these barriers. Hoffman and Henn (2008) proposed specific strategies for overcoming the barriers. These strategies include framing the issue, targeting the appropriate demographic, providing education, outlining structural and incentive change, and compensating the risks. Green building standard improvements and tax reform must also be addressed through education, cognitive heuristics, and social acceptance of the incorporation of a sustainable approach during the planning stage of a project (Hoffman \& Henn, 2008). Moreover, the perception of the environmental impact and financial benefits of adopting sustainable technologies are crucial. 


\section{CHAPTER THREE: RESEARCH METHODS}

\section{Research Design}

Grounded theory was employed in this study. In a grounded theory study, the research problem should shape the methods. Additionally, the methods should affect how the research questions are answered (Charmaz, 2006). Therefore, a grounded theory study allowed me to explore solar technology in rural areas and provide a method for developing theories to understand the barriers and motivations of adoption. I gathered data through interviews, wrote descriptive memos of observations, answered the central questions about what was happening in data collection and analysis, and developed theoretical categories to understand the phenomenon (Charmaz, 2006). Using Crotty's (1998) diagram for designing a qualitative study, I identified the key components of my research design (see Figure 1).

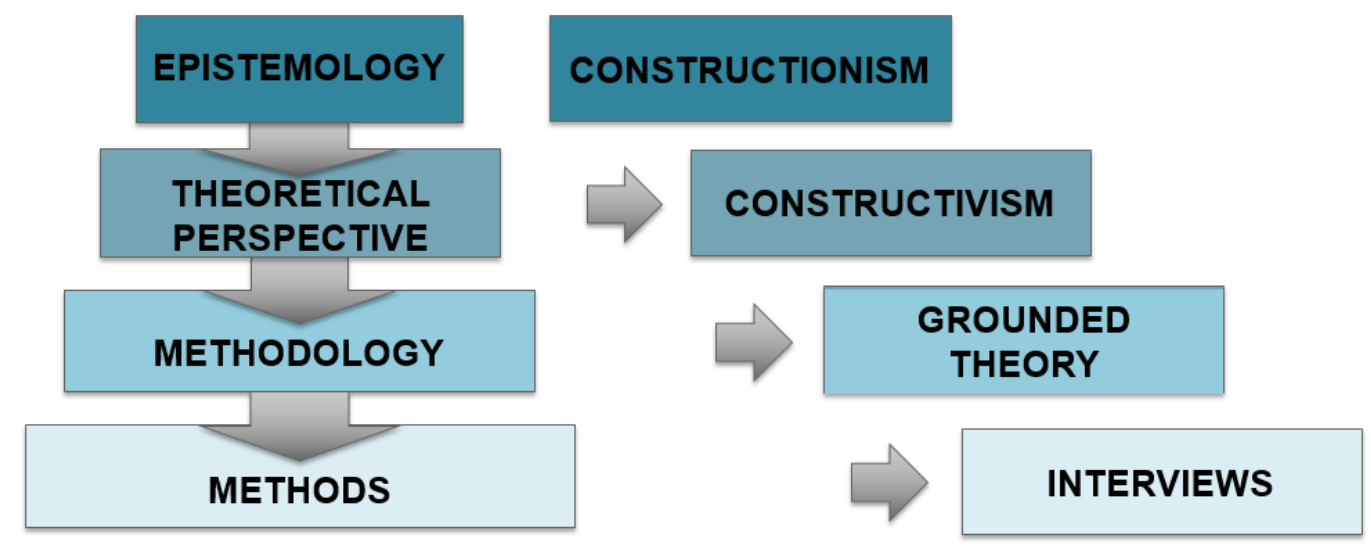

Figure 1. Research design diagram (Crotty, 1998)

\section{Theoretical Paradigm}

A constructivism paradigm helped me gain insights into the very slow adoption of solar technology with rural utility customers. Constructivism provided a schema for gathering, analyzing, and interpreting data while co-creating with the participants an 
understanding of the contextual impact of a study (Groat \& Wang, 2013). Since I was interested in constructing new information to incorporate into promotional materials and reference guides, rural utility customers' involvement provides insight in constructing the resources. Constructivism embraces how individuals differ in their interpretation and construction of an idea, and each homeowner's experience was worth considering when making sense of the phenomenon of solar adoption in a rural environment (Crotty, 1998). Additionally, I was interested in understanding how the participants differ in the construction of their personal norms and adoption behaviors by interpreting their challenges of and rewards for adoption. Interpretations of the given setting were important from the perspectives of the individuals as they experience their environment (Groat \& Wang, 2013).

\section{Theoretical Framework}

Theory of Diffusion of Innovations. The Theory of Diffusion of Innovations provides a useful theoretical framework for analyzing the data in this study since the theory outlines a process of diffusion and adoption for various innovations. Solar technology relies on diffusion among various groups. To reach the point of considering solar adoption in an innovation-decision process, an individual is influenced throughout various stages by "previous experiences, existing needs/problems, innovativeness, and social norms" (Ozaki, 2009, p. 2). Understanding the stages of the adoption process individuals move through and the rate at which the progression occurs can provide a better understanding for rural utility customers' apprehension to adopt solar technology.

The Theory of Diffusion of Innovations explains the social process of communicating a new idea about subjectively perceived information. Rogers (1995) 
defined diffusion as "the process by which an innovation is communicated through certain channels over time among the members of a social system" (p. 10). Diffusion represents the communication of new ideas through both planned and spontaneous methods and practices. Communication is viewed as a two-way process where participants within a defined social structure converge on the meaning of an idea and reach a mutual understanding by creating and sharing messages through converging channels.

Rogers (1995) outlined five sequential stages in innovation adoption: awareness, interest, evaluation, trial, and adoption. Further, he identified four main elements involved in the diffusion of innovations (see Figure 2). They include the innovation, communication channels, time, and social system. An innovation can be an idea, practice, or object perceived as new by the adopter. The attributes of innovations, important in explaining varying rates of adoption, include the relative advantage, compatibility, complexity, trialability, and observability. The second main element in the diffusion process, communication channels, is the means of transferring messages from one individual to another. The third element, time, is represented by five adopter categories: (1) innovators, (2) early adopters, (3) early majority, (4) late majority, and (5) laggards. The final element, a social system, represents an interrelated unit with a common goal of solving a problem. It defines a boundary for the diffusion of an innovation. Identifying the four elements in the diffusion of innovations frames the stages of the adoption process and defining the attributes explain the rate at which adoption occurs. 


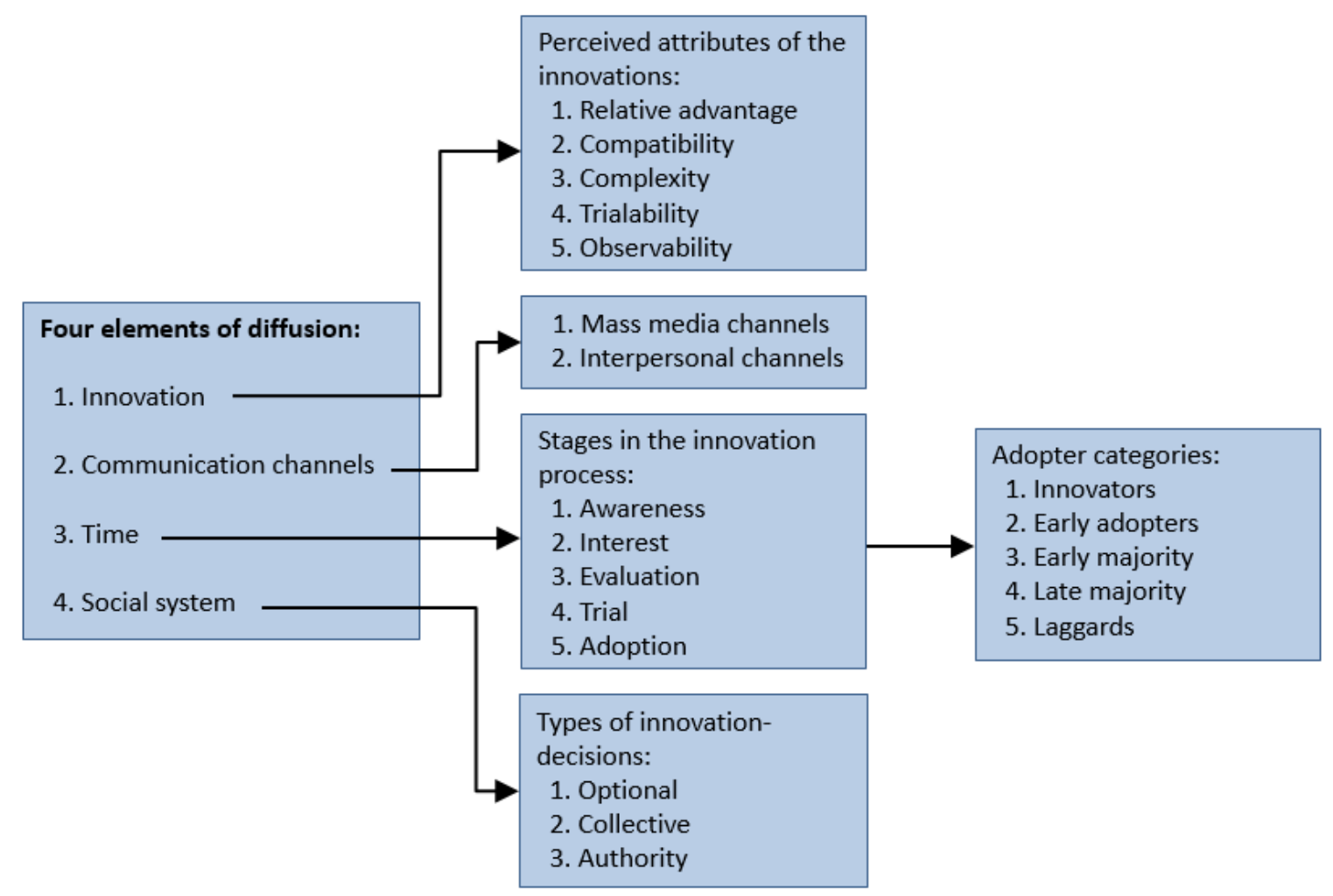

Figure 2. Elements of the Theory of Diffusion of Innovations diagram

Several studies have applied Rogers (1995) Theory of Diffusion of Innovations to examine the adoption of solar energy based on the attitudes of consumers toward residential PV arrays (Faiers \& Neame, 2006; Faiers, Neame, \& Cook, 2007; Islam, 2014; Labay \& Kinnear, 1981; Parnell \& Larsen, 2005). Analyzing the data using Rogers' Theory of Diffusion of Innovations provided a framework for developing an explanation of the stages and rates at which individuals advance through adoption. Understanding these stages of adoption clarifies why individuals may be apprehensive to adopt based on their motivations and priorities as well as the factors impacting solar adoption. 


\section{Researcher Position}

My positionality impacted how I interacted with participants, analyzed data, interpreted findings, and shared conclusions in a meaningful way for an audience who can benefit from the study (Berger, 2015). This study was influenced by my interest in solar technologies and experience with the Missouri University of Science and Technology (Missouri S\&T) Solar House Design Team during the US Department of Energy Solar Decathlons. I have served as the lead faculty advisor since 2010. This experience prompted this study. I focused on a rural setting because I grew up in a small farming community, and I appreciate the ingenuity of rural residents. I am confident that if existing barriers can be clearly outlined and motivations for adopting PV arrays explained, a strategy can be developed to promote their adoption.

\section{Participant and Site Selection}

Willing participants were selected to share their thoughts on adopting solar technology. I employed snowball sampling by identifying a few key participants, who referred me to other participants (Merriam, 2009). The sites were selected based on a rural context, which refers to the population density and socioeconomic characteristics of an area. By definition, ruralism often implies sparsely populated or agricultural in nature. A rural identity involves the relationship of individuals' identification with a rural environment and may be central to understanding the adoption of solar technologies in a rural setting (Golding, 2012). "Previous scholarship has asserted that rural self-identity is an anchor to place, a cultural expression or signifier, and a stance against urban, mainstream, or mass culture" (Golding, 2012, p. 1031). Golding summarized that rural communities continue to become more diverse as a crossroad with a variety of individual 
place identities. Consequently, how people think and act politically are influenced by their place identities (Stryker \& Burke, 2000). Moreover, people's rural self-identity may influence how willing they are to embrace solar technology if it is perceived to be outside the norm for rural areas.

\section{Data Collection}

Data was collected using in-depth interviews with participants associated with PV arrays in a rural setting as a homeowner, farmer, installer/consultant, utility company, or government agency. It is critical to acknowledge that the process of collection affected the data and the phenomenon of the study in terms of what I saw, how it was viewed, and what findings the data revealed (Charmaz, 2006). I avoided asking pointed questions about the motivations and challenges of adopting solar technology (See Appendix A for typical interview questions with solar adopters and Appendix B for typical interview questions with cooperative utilities). I asked open-ended questions to allow participants to better share their views to maintain a constructivist approach (Crotty, 1998). However, the external factors were minimized, and more consistent motivations for adoption were maintained by focusing the questions. I revisited earlier comments during interviews to unpack responses. I also restated the participant's key points to check for accuracy. I always expressed appreciation to each participant for his/her time and cooperation. Each face-to-face interview was audio-taped and transcribed by a third party source (Rev.com). I recorded any field notes immediately following interviews to capture my thoughts and the overall impression of the setting (Maxwell, 2005). I also recorded any subtleties not captured during the interviews (Maxwell, 2005). The field notes assisted in the development of thorough, descriptive memos. 
I conducted a total of twenty-four interviews in two stages of data collection.

Stage one was part of a pilot study. Because some of the interviews provided excellent data that guided further refining of the research question and methods, four of the six interviews were carried forward. Stage two included the remaining twenty interviews that broadened the type of participants and increased the depth of knowledge on the adoption of solar technology. The following summary describes each participant. I labeled each participant with a title meant to represent his/her connection to the findings in an effort to identify each more easily throughout the study. Additionally, the diagram illustrates the relationship between each of the participants in the two stages (see Figure 3).

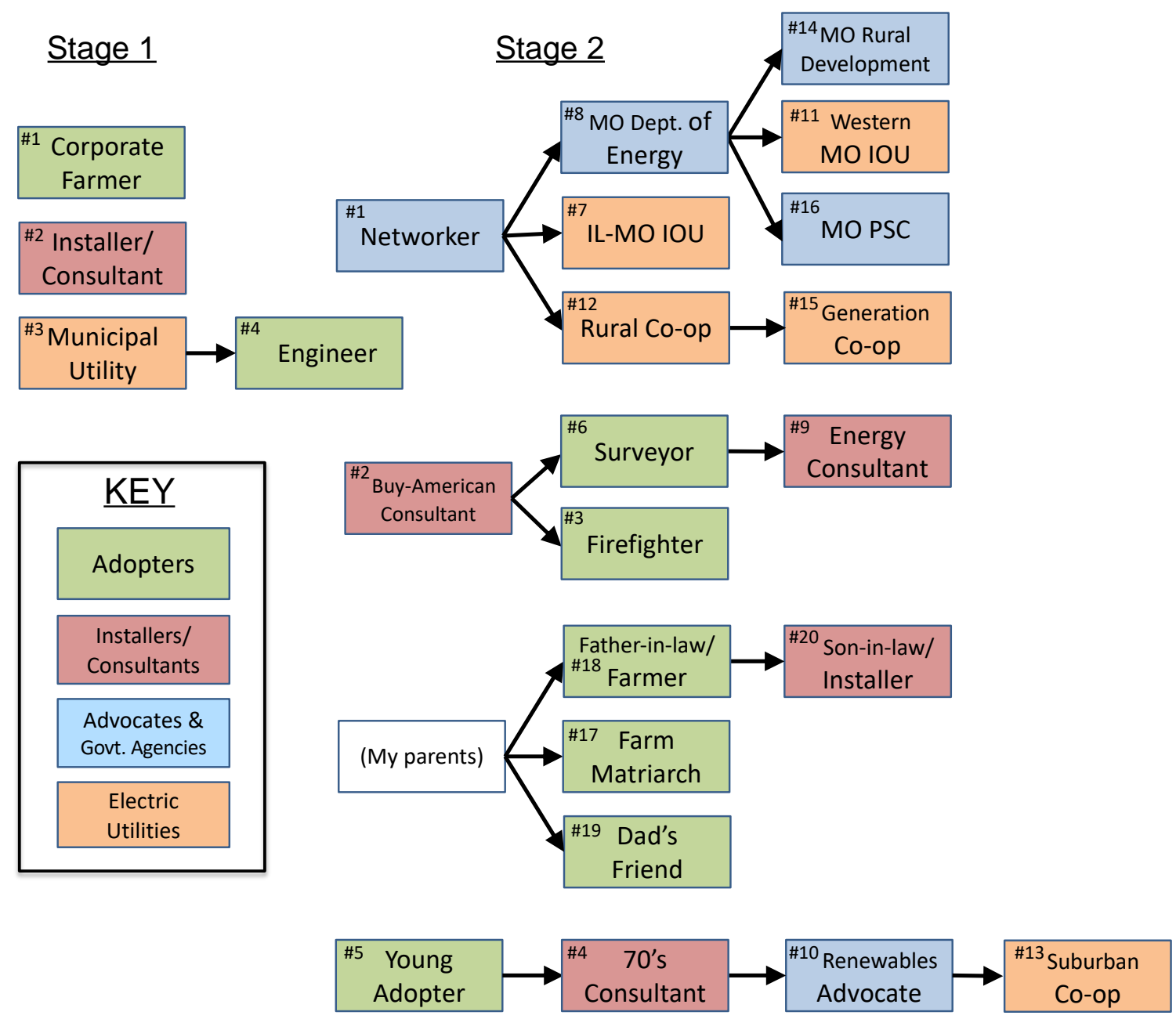

Figure 3. Participant relationship diagram 
Where and how the interviews were conducted differed from one to another based on the location and availability of the participants. During stage one, the first interview was conducted face-to-face with a farmer from my hometown in Central Illinois. The interview took place in a grain combine as he harvested soybeans (see Image 1). He installed a large free-standing array on the edge of town to power a small office building

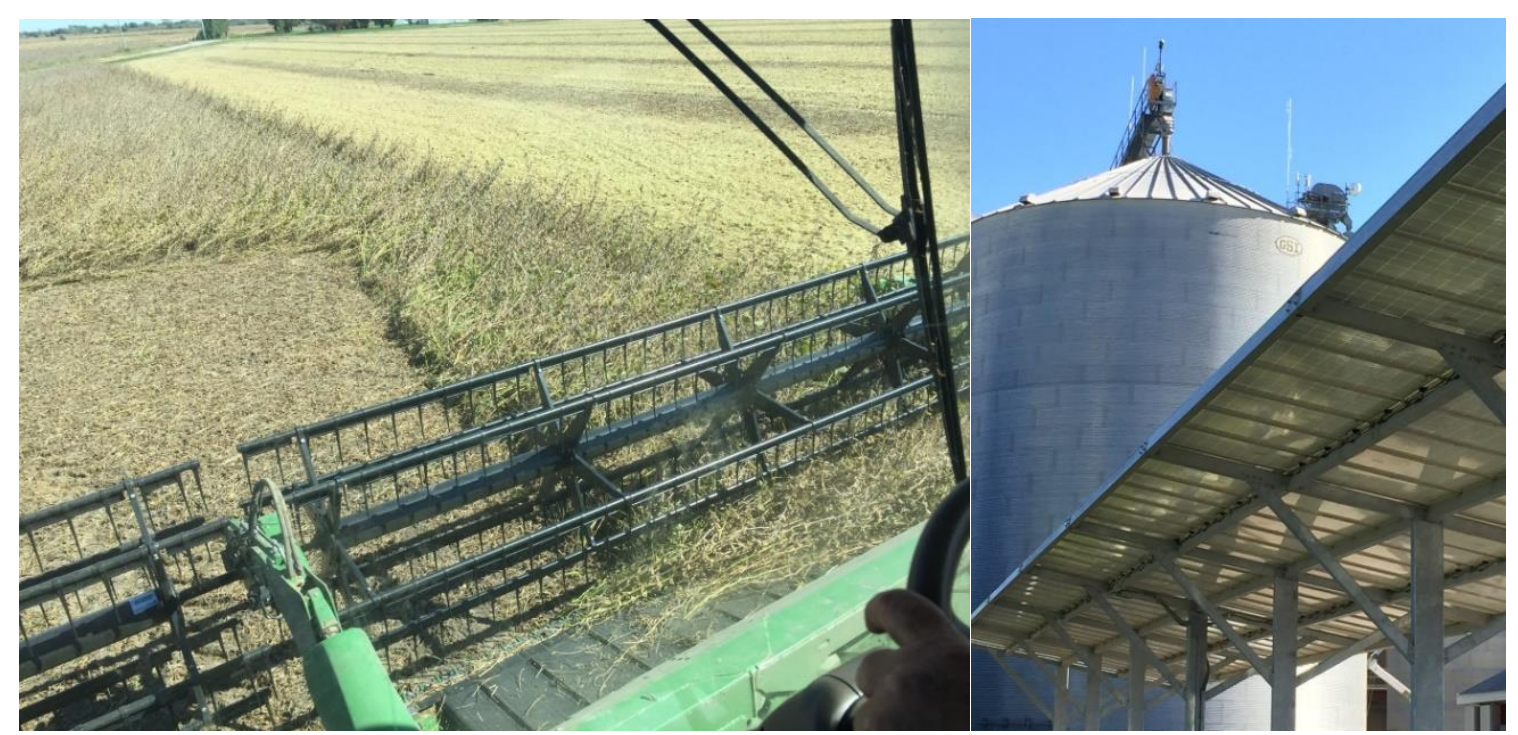

Image 2. Data collection from interview with the Farmer Image 1. The Farmer's PV array

and several large grain bins in 2014 (see Image 2). I refer to him as the Corporate

Farmer. The second interview was conducted by phone with a solar installer in a community ten miles south of my hometown. He and his business partner have installed over 100 PV arrays throughout Central Illinois. I refer to him as the Installer/Consultant. The third interview was face-to-face with the General Manager and Operations Manager from a local municipal utility at their office. Since both shared their responses during one interview, I count them as one participant referred to as the Municipal Utility. The fourth interview was face-to-face with a resident in the town served by this municipal utility. He and his wife are the only homeowners in the municipality who have installed a PV array. He attributed his ability to research and design the system himself to his engineering 
background, so I refer to him as the Engineer. The interview was conducted at his home, both outside by the array (see Image 3) and in his home office.

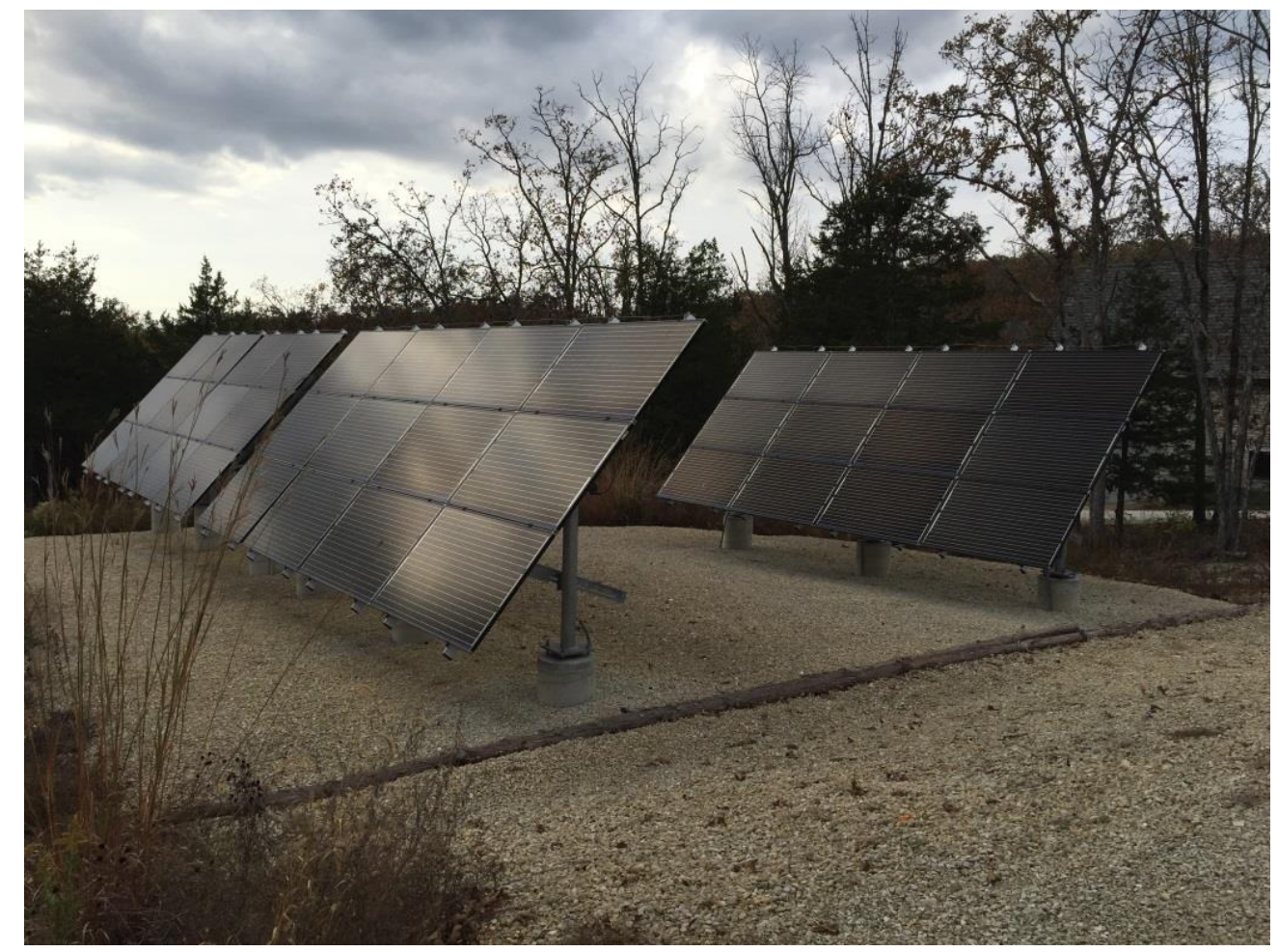

Image 3. The Engineer's PV array

The second stage of interviews started with a university sustainability director. I conducted the face-to-face interview at her home. She coordinated was a microgrid interconnection project, which brought together industry experts like electric utility leaders, renewable energy consultants, and solar product manufacturers. I conducted an observation of a meeting on the microgrid project and made contacts with a number of the energy professionals. I secured multiple interviews through follow-up emails. Because she provided me with access to her network of contacts, I refer to her as the Networker. She has since retired from the university but remains actively engaged in the solar industry as a consultant. 
I conducted the second interview of this stage with a renewable energy consultant in Central Illinois who installs PV arrays as well as wind energy systems. A close friend who taught her daughter gave me her name. As a solar consultant, she insists on using American made solar panels; therefore, I refer to her as the Buy-American Consultant. I conducted the face-to-face interview at her home (see Image 4). She proved to be a very valuable connection to other participants (see Figure 3 for a relationship diagram of the participants). My third interview was by phone with one of her clients from Central Illinois, a retired firefighter whose training in fire safety and understanding of electrical equipment gave him the knowledge and confidence to install his own PV array (see Image 5). I refer to him as the Firefighter.

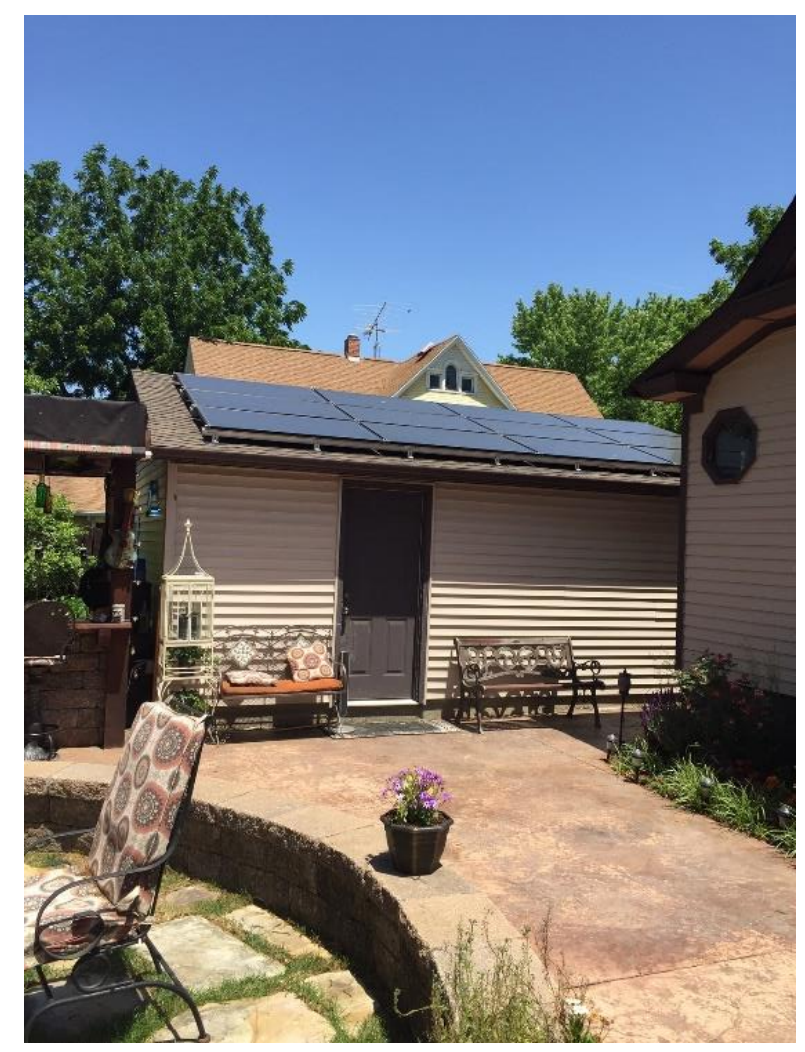

Image 4. The Buy-American Consultant's residential PV array 


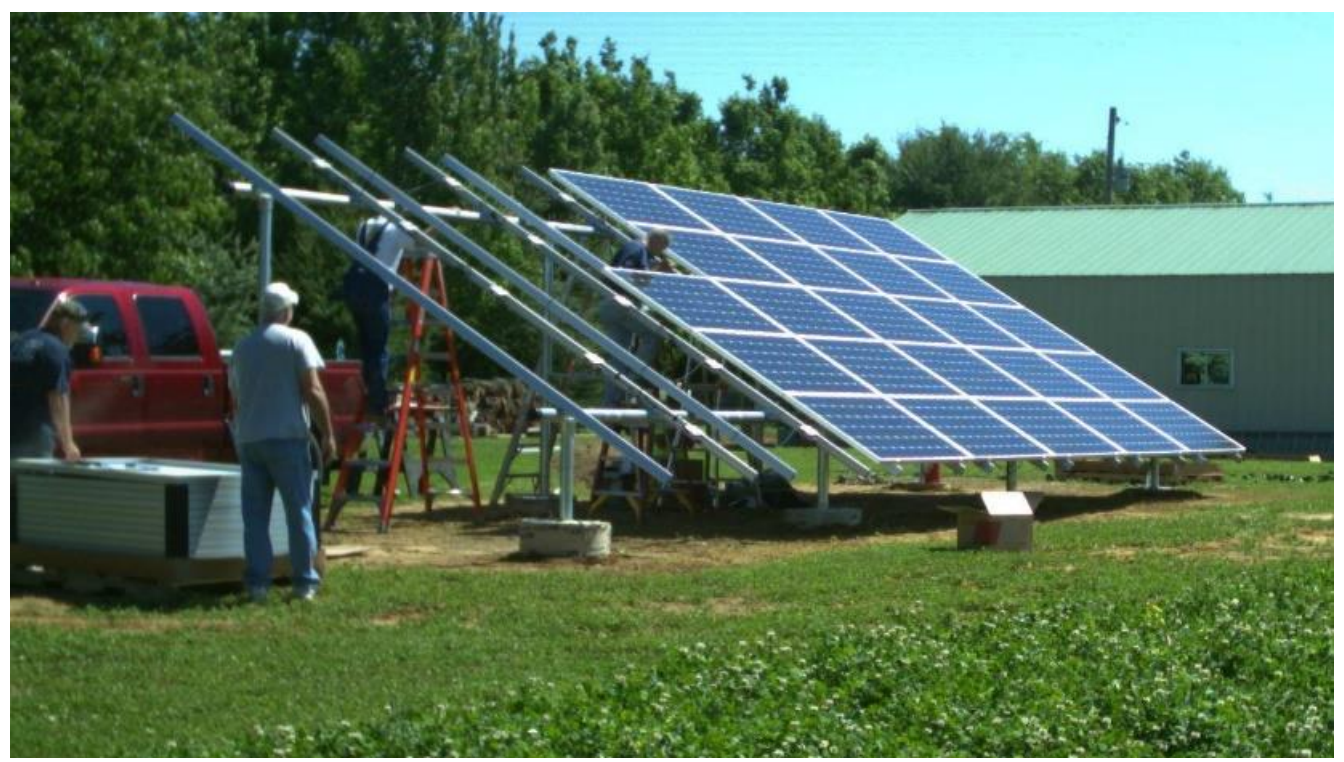

Image 5. The Firefighter's ground mounted PV array during installation

I conducted my fourth interview face-to-face with a solar consultant in Missouri who first explored solar technologies in California during the 1970's energy crisis under President Carter. He worked in research and development on a Department of Energy contract, estimating and designing portions of the Ivanpah Solar Electric Generating System project, a concentrated solar thermal plant in California. The project moved large amounts of high-pressure steam, generated by three separate 300-megawatt solar towers, long distances. He worked in California in the solar industry for six years before going to Saudi Arabia for nine years to work for oil producers in the 1980's to make as much money as he could. He returned to Missouri in 1990 and began working for his family's general contracting company. He did not get involved with solar technology again until 2008 when a close friend, the head of Dow Chemical's solar program in research and design, encouraged him to start installing PV arrays. Because of his decades of experience in solar technology, I refer to him as the 70's Solar Consultant. 
The 70's Solar Consultant was the solar installer for my fifth participant, a young man who does not fit the profile of other solar adopters whom I have interviewed for this research and previous projects. He is only 23 and had to finance the entire system cost, making him fall well outside the typical demographic for solar adopters. The Young Adopter, a participant from Missouri, lives just off a major two-lane highway but close enough that his 6.5 kilowatt PV array is quite visible to passing traffic. I had seen the array several times before deciding to stop and ask for an interview. The Young Adopter was gracious and agreed to an interview later that week at my office.

The Buy-American Consultant also connected me with another adopter from Southern Illinois who installed his own array based on his experience in the engineering profession as a land surveyor (see Image 6). The Surveyor was my sixth interview. I interviewed him face-to-face at his home and at his uncle's and friend's houses while looking at their PV arrays (see Image 7).

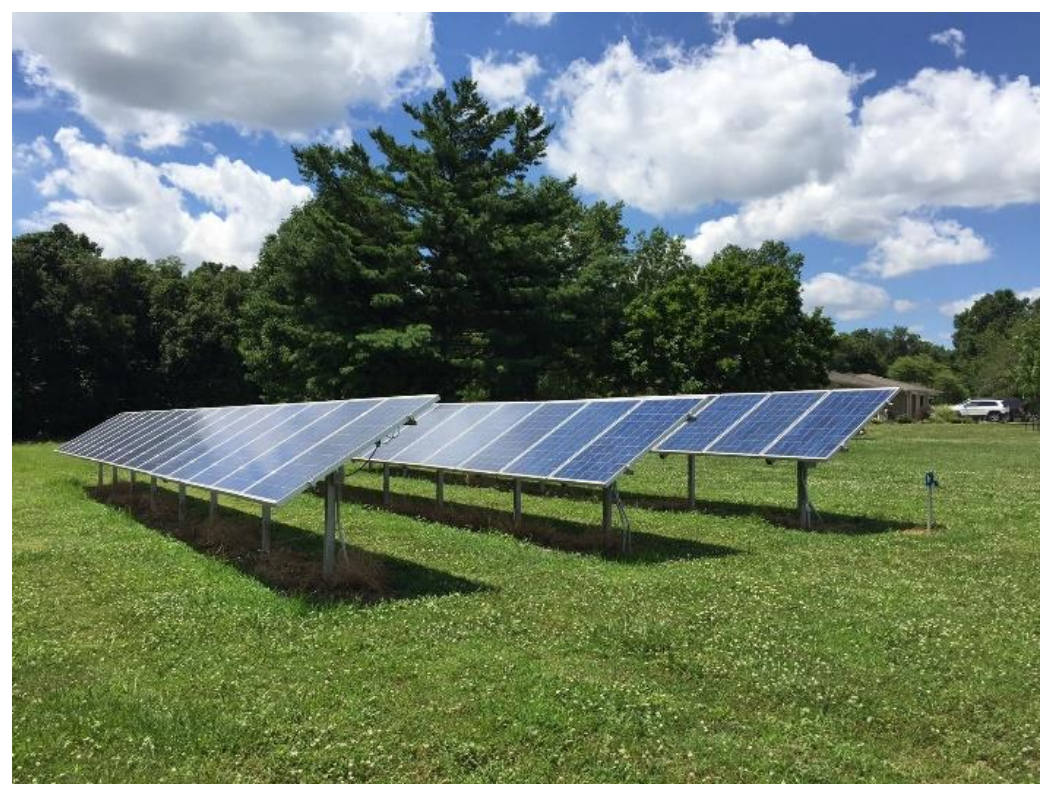

Image 6. The Surveyor's ground mounted PV array 


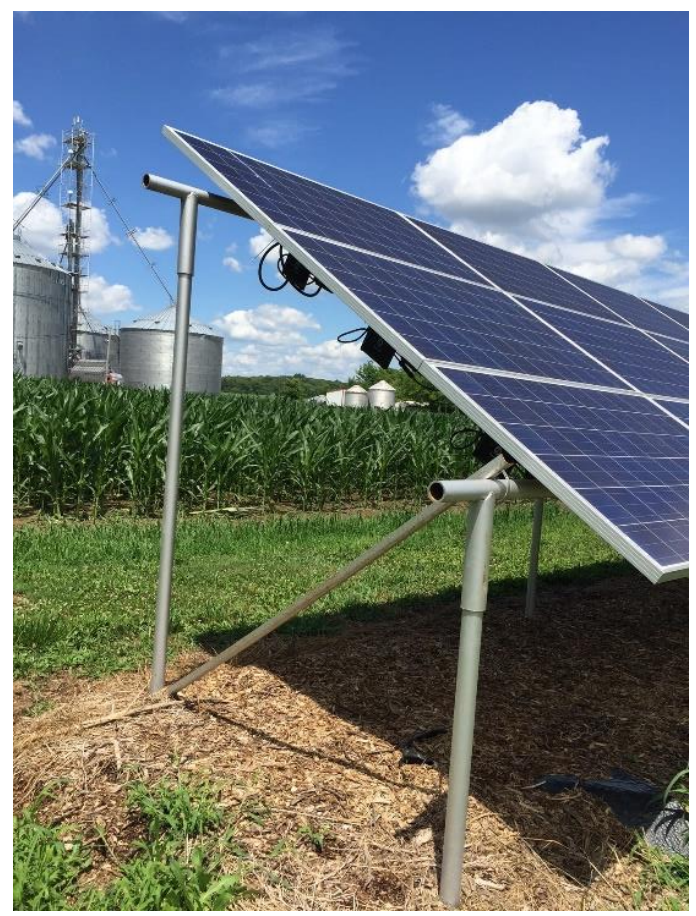

Image 7. The Surveyor's uncle's ground mounted PV array

My seventh interview was conducted with one of the three investor-owned utilities serving parts of Missouri and throughout Illinois. My contact, a technology and renewable business development manager with an electrical engineering degree, served as the project manager on the utility's community solar and solar partnership projects. $\mathrm{He}$ was also the electrical lead on the utility's microgrid facility in the St. Louis area. The project included a 125-kW PV array, a wind turbine, two natural gas generators, and a lithium-ion battery. Since the participant represented the views of the utility company, I refer to him as the IL-MOIOU.

I interviewed two individuals, an energy engineer and an energy policy analyst, with the Missouri Division of Energy for my eighth interview. Since both shared their responses during one face-to face interview, I count them as one participant referred to as the MO Division of Energy. They provided important insight on the statutes and regulations for renewable energy in Missouri. 
I traveled back to Southern Illinois and conducted my ninth interview with another solar consultant. Unique among the four solar consultants, his family business that he manages with his brother involves multiple segments of the energy field, including oil drilling, auto fuel and moto-marts, cathodic protection, and sustainability. He has two areas of focus in sustainability: energy assessments and solar technology. He even performs services in protective energy, which he described as being useful for people who are electrically sensitive. He started his training in solar PVs in 2008 and has several certifications, including one as a National American Board of Certified Energy Practitioners (NABCEP) professional to install solar PVs. I refer to him as the Energy Consultant. He was very enthusiastic to share his experience in solar technologies with me and spent an entire afternoon going through a presentation at his office, taking me to see the PV array on his home (see Image 8), and driving me to various PV arrays he has installed (see Image 9).

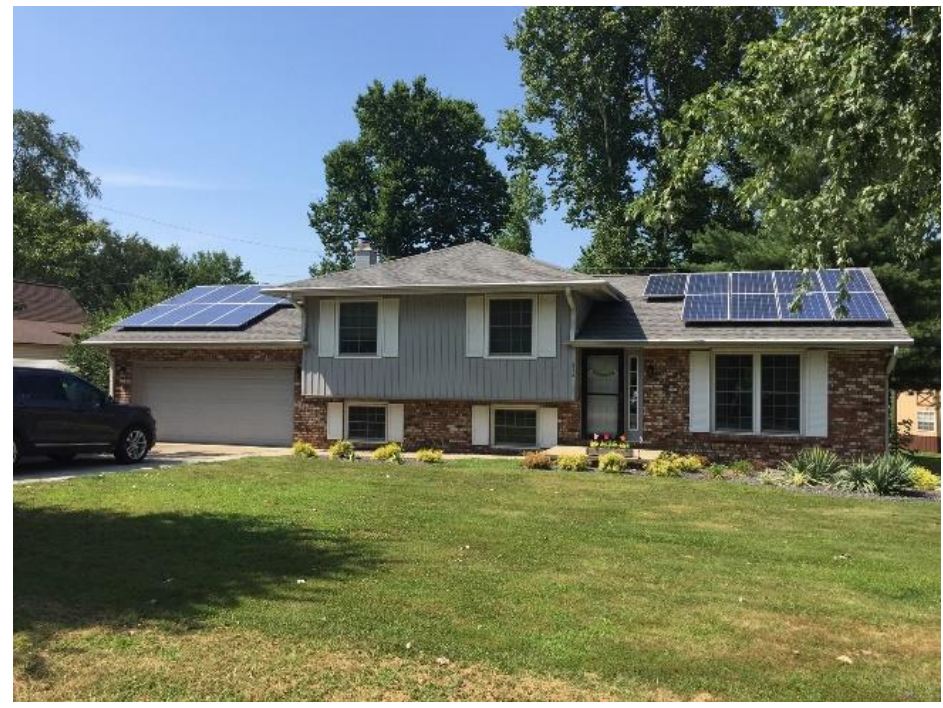

Image 8. The Energy Consultant's PV array 


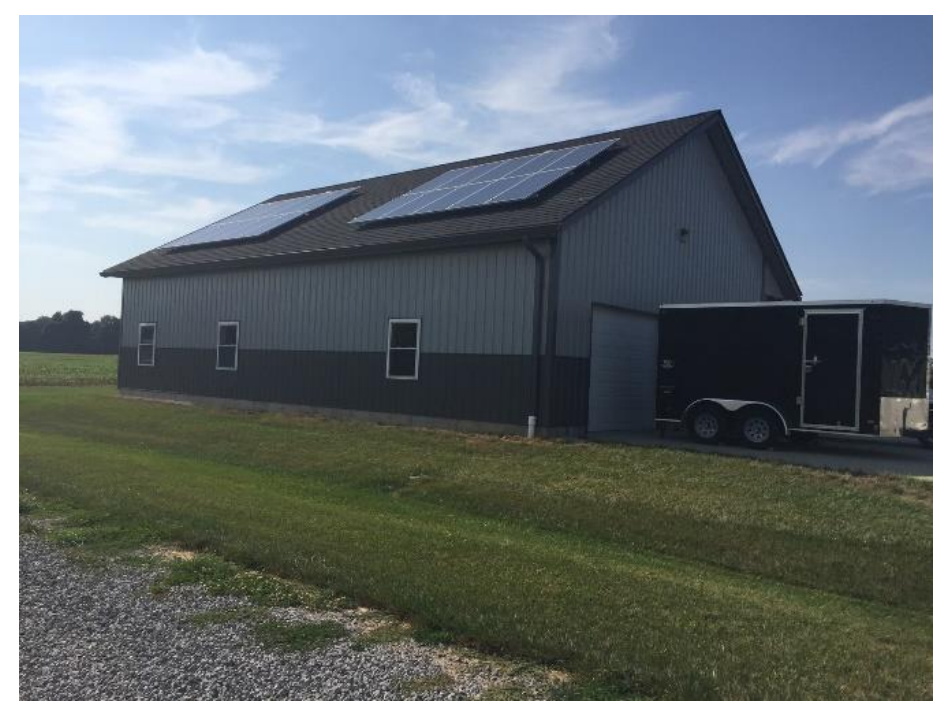

Image 9. An example of installation by the Energy Consultant

I was able to gain further information from a face-to-face interview conducted two weeks later with the executive director of a renewable energy advocacy group in Missouri, my tenth interview. The participant provided relevant updates on several ongoing challenges that the solar industry faces in Missouri. A goal of his group is to move Missouri into the top twenty states for renewable energy use. Much of what he does through the group is educating Missouri legislators on the benefits of renewable energy, so I refer to him as the Renewables Advocate.

Next, I interviewed multiple utility companies to gather diverse data on the issues utilities face in implementing solar power into their energy portfolios. My eleventh interview was face-to-face at the utility headquarters with another of the three investorowned utilities (IOU) serving parts of Missouri. My contact was a senior environmental coordinator. Since she met as a representative of the utility company, I refer to her as the Western MOIOU.

I also interviewed cooperative utilities to gain their perspective on solar adoption. The cooperative scale of power in Missouri is structured in three tiers. The first tier is the 
generation cooperative headquartered in Southwest Missouri. The second tier includes six transmission cooperatives that each provide power to multiple distribution cooperatives, 41 in all. My twelfth and thirteenth interviews were with two of the electric distribution cooperatives in Central Missouri. The first of the two, a very rural cooperative with a lower socioeconomic customer base, represents about 36,000 members. I met face-toface with an engineering manager but refer to him as the Rural Co-op. The second, a cooperative in the rural boundaries of an urban area, I refer to as the Suburban Co-op. While this cooperative has fewer members at 32,000 , its overall customer base is more affluent. I met face-to-face with a manager in their member services, who explained their community solar program and other solar initiatives driven by their members.

On the same day as my interview with the Suburban Co-op, I interviewed my fourteenth participant, a business program specialist with the Missouri Rural Development Office, an agency of the United States Department of Agriculture (USDA). I refer to this participant by the agency name MO Rural Development. He shared information on Rural Energy for America Program (REAP) grants in Missouri, which are managed by that agency.

Just a few days later thanks to an introduction from the Rural Co-op, I was able to interview the generation cooperative. I interviewed an executive involved with energy services for the cooperative's member organizations face-to-face at his office. I gathered follow-up data that the Rural Co-op had mentioned but recommended I obtain from the generation cooperative, the tier of cooperative utilities generating power for all 41 electric cooperatives in Missouri and the several surrounding states. I refer to him as the Generation Co-op, my fifteenth participant. 
The MO Division of Energy recommended that I interview a member of the Missouri Public Service Commission (PSC), my sixteenth interview. The Commission is responsible for regulating all investor-owned utilities for compliance with the statutes established by Missouri's Renewable Energy Standard. I interviewed one of the utility regulatory engineers face-to-face and refer to her as the MO PSC. She provided insight into the regulations for renewable energy that investor-owned utilities have to meet under Missouri’s Clean Energy Act.

My last four interviews were conducted near my hometown in Central Illinois. I asked my parents to contact my dad's friend, who has a $20 \mathrm{~kW}$ array. By the time I arrived to conduct the interview, my parents had coordinated interviews with two more adopters and one solar installer. The first of the final four was with the Farm Matriarch, as I refer to her because she had the final decision on her family's desire to adopt solar technology in an effort to offset high utility bills from drying grain each fall. After interviewing her face-to-face in her home, I viewed the panels up-close. These panels are very visible from the two-lane highway on their family-owned farm just outside the city limits of my hometown (see Image 10). 


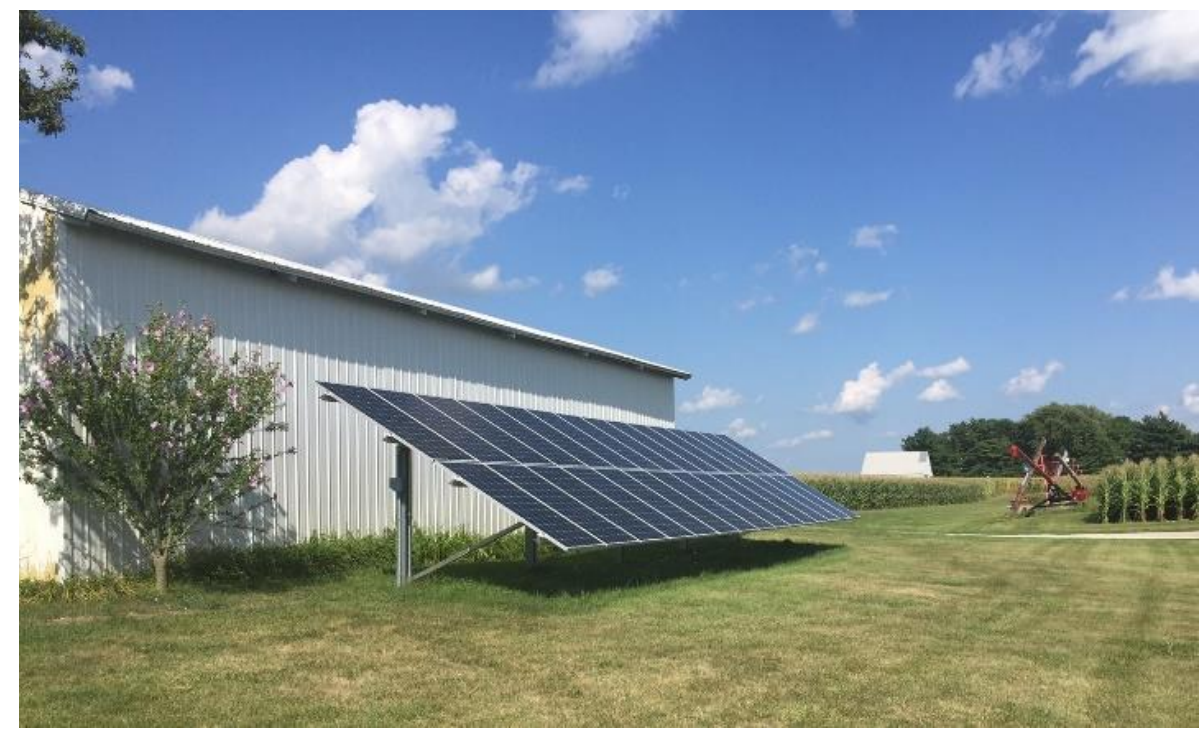

Image 10. The Farm Matriarch's ground mounted PV array

After leaving the Farm Matriarch's farm, I drove to another family farm and interviewed a farmer who convinced his son-in-law to pursue installing PV arrays. The Father-in-law/Farmer, as I refer to him, spoke to me outside near his 25-kilowatt PV array and inside the machine shed where the panels are mounted on the roof (see Image 11). He expressed his desire to get his son-in-law involved in the industry as one of his strongest motivations to adopt solar technology. I interviewed the son-in-law the

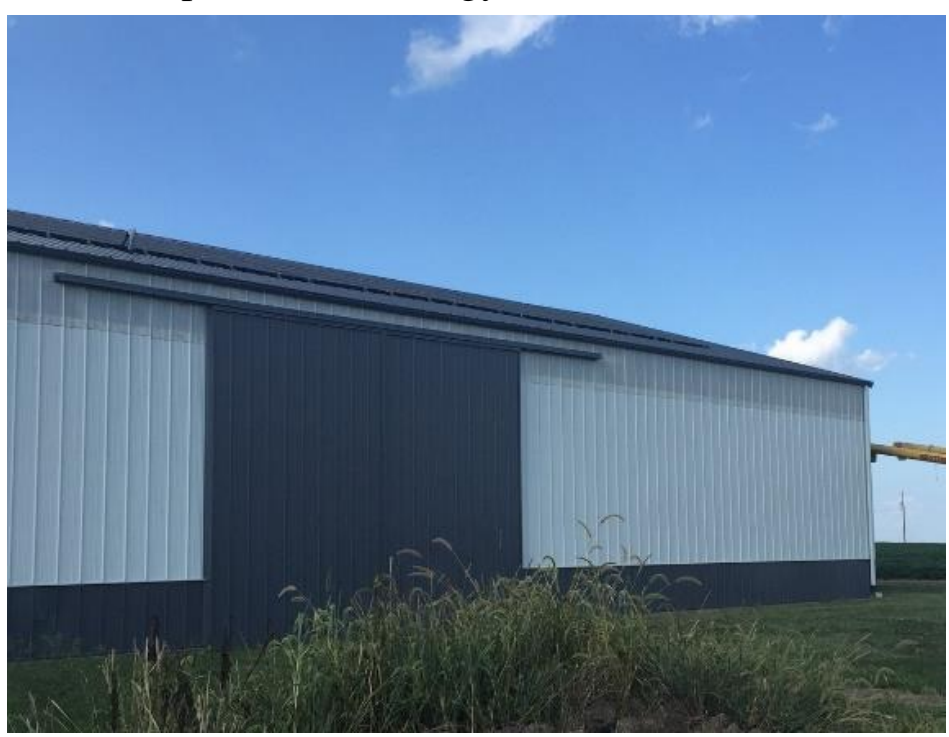

Image 11. The Father-in-law/Farmer's machine shed with a roof mounted array 
following day. I refer to him as the Son-in-law/Installer since he works solely as an installer and, in fact, works for the solar consultant that I interviewed in the first stage of my interviews, referred to as the Installer/Consultant. He provided in-depth knowledge of factors in deciding between ground mounts and installations on various roof types. The other interview on my final day of collecting data was with my dad's friend next to his 20-kW ground mount PV array (see Image 12). My Dad's Friend lives just outside a very small community neighboring where I grew up. He expressed strong satisfaction with the cost savings he is experiencing.

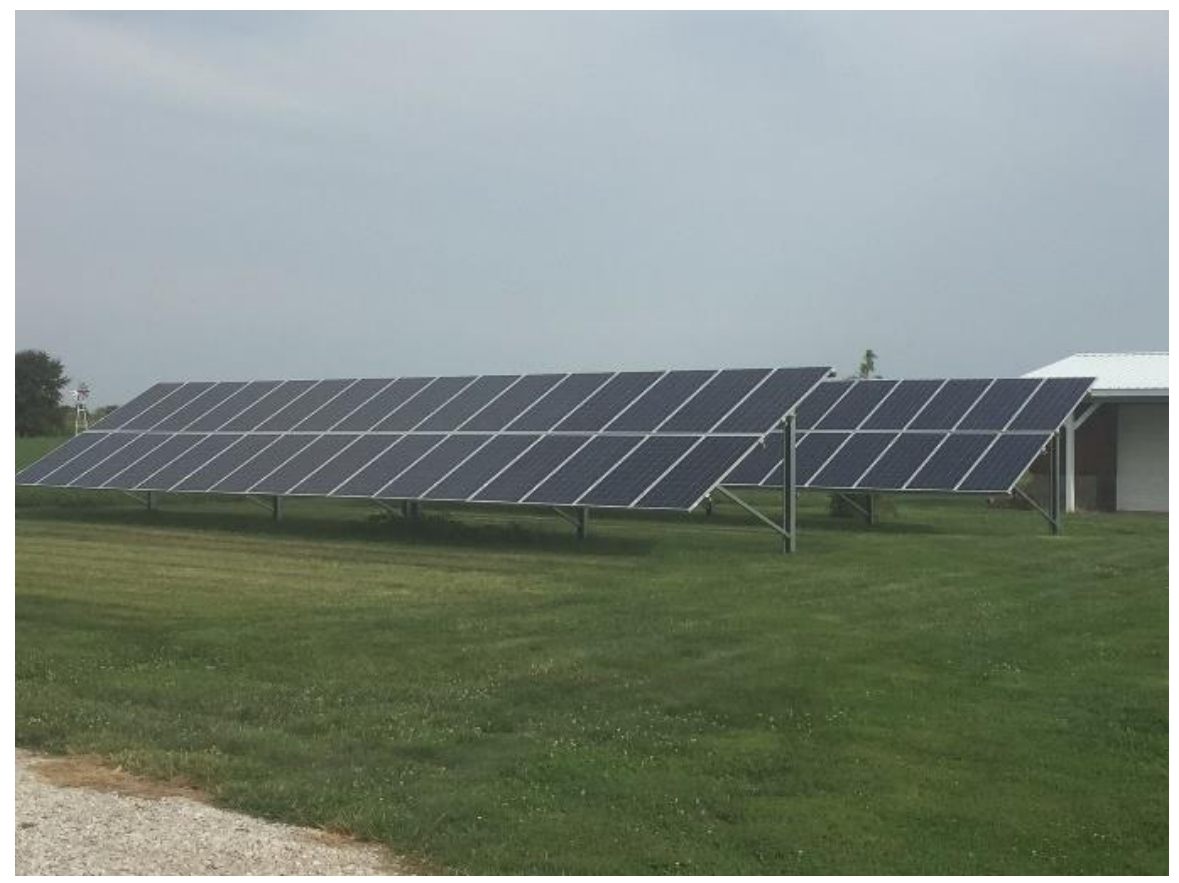

Image 12. My Dad's Friend's ground mounted PV array

The participants identified as the Corporate Farmer, Engineer, Firefighter, Surveyor, Young Adopter, Farm Matriarch, Father-in-law/Farmer, and My Dad's Friend installed PV arrays for their homes or farms. They focused on their motivations and the barriers they faced. The Installer/Consultant, Buy-American Consultant, 70's Consultant, Energy Consultant, and Son-in-law/Installer provided useful insight into the varying 
challenges of installing PV arrays in rural locations and the impact solar generation has when potential adopters experience it firsthand. The Municipal Utility, IL-MOIOU, Western MO IOU, Rural Co-op, Suburban Co-op, and Generation Co-op provided details on state statutes. These dictate the state and local policies that are enacted depending on the type of utility or the intended installation location. Interviewing various utility types provided more robust data on renewable energy portfolio diversification and the level of solar penetration within each utility's respective customer base. The Networker and Renewables Advocate discussed the importance of educating utility customers and utility companies as well as lawmakers about the environmental and economic benefits of solar power. The MO Division of Energy and MO PSC provided necessary information on the regulations of renewable energies while the MO Rural Development outlined available grants that promote the adoption of renewable energy in rural areas. The diversity of participants provided a broader depth of understanding to the barriers that are slowing the adoption of solar technology in rural areas. It also provided different views for understanding what factors motivate individuals to adopt solar technology.

Even though all of the participants are not associated with the solar industry in the same way, the knowledge and interest in solar technology were consistent and similar enough that the same coding protocol was employed. The similarities allowed for a consistent analysis. First, all of the participants were familiar with grid-tied systems, meaning the PV arrays are connected to the utility lines and send excess electricity to the grid or receive electricity from the grid when necessary. The utility grid acts as the energy storage, so battery backup was not a motivating factor. Second, all of the systems discussed are multiple panel arrays. It is important to differentiate between multiple panel 
arrays versus one or two-panel installations that an individual might have without the approval of their utility provider. Several of the participants referenced these do-ityourself type systems. I will discuss the concerns they create in the Findings Section. Third, all of the adopters I interviewed installed their array in cooperation with an installer/consultant and their local utility.

Some minor differences existed between the systems. First, some of the arrays are roof mounted while others are ground mounted. Second, one connects to utility grids controlled by a municipal utility while the others connect to grids controlled by cooperative or investor-owned utilities. This impacted the rebates available to the participants after their panels were installed. The impact of rebates warrants its own discussion as an adoption factor in the Findings Section. Third, the participants are from two different states. However, both states - Illinois and Missouri - have vast areas of rural populations. The following diagram illustrates the participants from each state and one investor-owned utility, IL-MO IOU, that services both states (see Figure 4). 


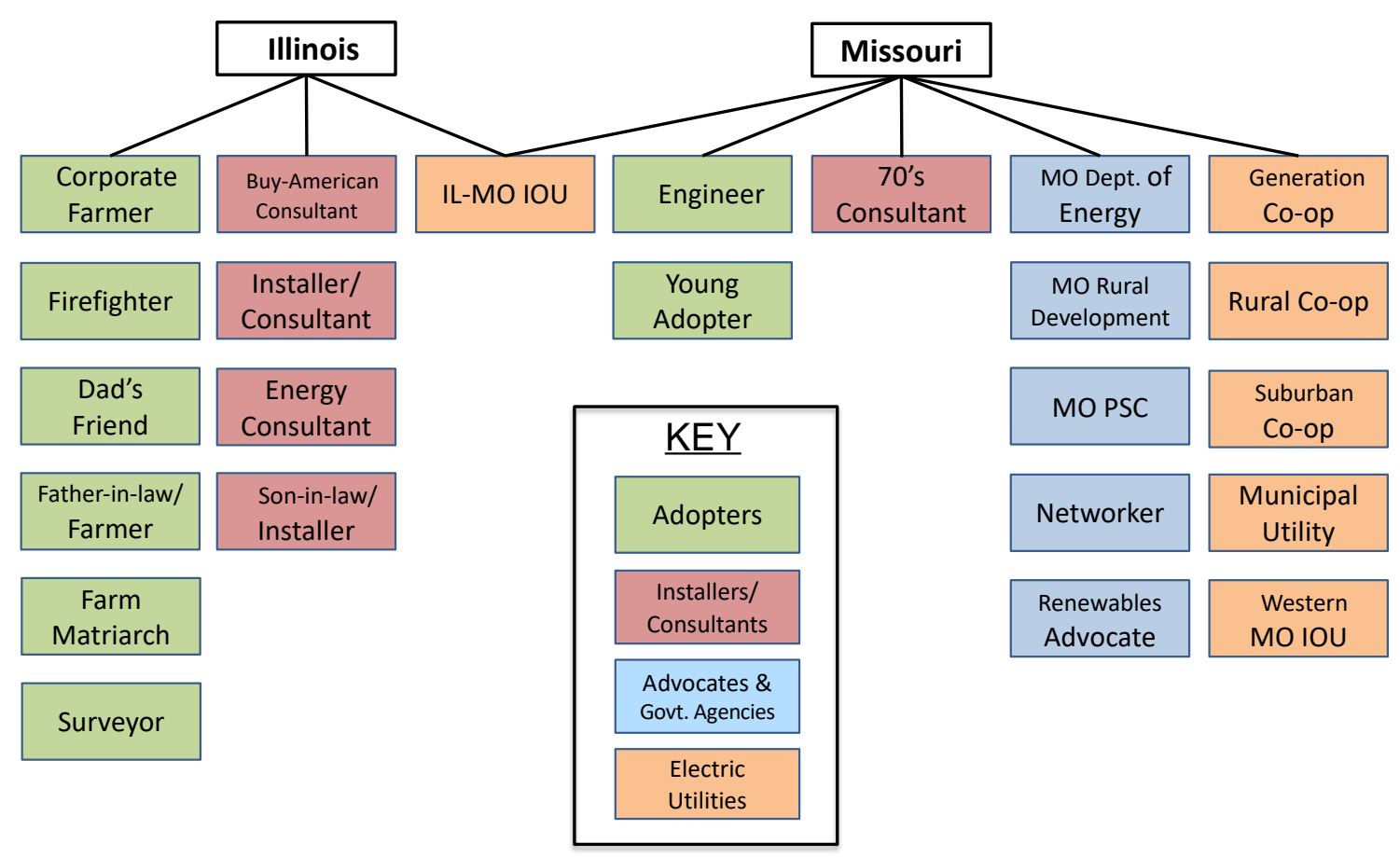

Figure 4. Participant location diagram

The data collection was shaped and reshaped throughout the study following the methods of grounded theory. A grounded theory approach dictated simultaneous data collection and analysis with a constant back and forth between data and analysis (Charmaz, 2006). Once I collected and analyzed a few pieces of data, I returned to the field and gathered additional data to answer questions and fill gaps that developed during the previous analysis.

\section{Data Analysis}

The data was analyzed with a constructivist framework using an inductive technique dependent on collecting and analyzing data that did not have prior themes and categories imposed on it (Patton, 1990). My constructivist research focused on the specific context of the participants' home and/or workplace (Creswell, 2014). I employed open-coding analysis using a constant-comparative technique. I used line-by-line coding 
during the initial coding process and then moved to axial coding, which allowed me to link categories with subcategories and explore how they are related.

I organized the interview transcripts into four groups: adopters; installers/consultants; advocates and government agencies; and utilities. I coded each interview in its respective group, which allowed me to maintain more consistency in my coding. I read the transcript the first time checking for typos and issues with sentence structure as well as filling in places marked as inaudible by the transcriber. When I listened to the audio recordings this time, I checked the accuracy of the transcripts. I was careful not to change the phrasing or intended meaning. After making the corrections, I read the transcript and wrote codes in the margins for each unit of data. This coding was sometimes a single line and other times multiple lines of data. I looked to find what was happening in the data and labeled it with short, active terms or phrases. I used gerunds whenever possible to maintain action and promote a perceived process. I tried to create clear connections between the data and my assigned codes. Effective coding relied on having good data. Coding allowed me to move from interviews and observations to theoretical insight and development (Charmaz, 2006). Though time consuming, the coding process made me very familiar with the data.

I then read the transcript a third time and assigned the codes to tentative categories represented by various colors. Highlighting helped me see important pieces of data that I had not coded. The categorizing served to build context, so I avoided using general or obvious categories (Charmaz, 2006). My intent was to construct open-codes that developed into categories to crystallize the participants' experiences so my study would fit into the empirical world. Individuals develop subjective meanings based on 
their experiences, so I refrained from narrowing meanings into a few categories when I began analyzing data because the goal was to rely on the participants' views (Creswell, 2014). Therefore, I kept categories as conceptual as possible. I tried to ensure the study's relevance by creating an analytic framework for what is happening in the day-to-day adoption of solar technology.

As my within-case analysis progressed, the codes were further organized into categories by analytical coding, a process I accomplished by refining conceptual categories after typing the categories into a table. I developed a table for each participant with the codes for the categories identified by the participant's initials for later reference. I also included quotes to be used in writing the findings to ensure the richness and validity of the data. See Appendix $C$ for an example of a participant-coding table. I then developed a separate table for all 22 categories where I combined each participant's codes related to the particular category (see Appendix D). I later worked from these tables to write the codes into my findings.

These conceptual categories were then elaborated and refined into my emerging theory through theoretical sampling. I examined how the codes fit together into categories and treated the categories more theoretically (Charmaz, 2006). Theoretical sampling focused further data collection to help me refine key categories and provide direction for the study. Additionally, memo writing guided further data collection by providing a means to compare data and explore ideas generated during the coding process (Charmaz, 2006). The memos included raw data, which provided evidence of what my ideas were generating during analysis (Maxwell, 2005). 
As I started my cross-case analysis, I developed subcategories using descriptive labels to better define the codes. I ensured that every subcategory fit under the major categorical headings. Some subcategories and corresponding codes were assigned to multiple categories. A continuous rearranging and even moving of some codes and categories to other themes grounded my approach in this data's analysis. I used axial coding to sort the large amounts of data. This coding allowed me to synthesize the codes, reorganize as necessary, and link categories and subcategories. By constantly refining my categories, I built the content and tried to foreshadow how I would write the Findings Section (Charmaz, 2006).

Once I organized all of the categories and subcategories, I refined them into thematic clusters. I then decided where the categories and codes fit best to eliminate redundancy. Finally, the categories were condensed and developed into holistic themes. I used categorical aggregation to establish the final themes. The aggregation involves mining issue-relevant meanings from a collection of instances. As I refined the themes, I prioritized them to develop a table for organizing the findings (see Appendix E). I was mindful of how the findings should unfold as I defined the themes and their corresponding categories, subcategories, and codes. Six themes emerged from the data. The first and second themes, factors and motivations and barriers and challenges, were clearly reflected in much of the literature I reviewed. The third and fourth themes, electric utilities and renewable portfolio/energy standards, emerged unexpectedly during the cross-case analysis. The fifth theme, growth of rural solar adoption, surfaced from the site selection of rural areas. The final theme, adoption and installation, was dependent on the consideration and influence of the previous five themes. All of the 
themes provided direction for the study both collectively and individually. Several subthemes added richness to each theme and reflected their categorical relationships. The subthemes also revealed more about the depth of the data as it related to each theme and the assertions that were made. The following themes emerged from the data:

Theme One - Factors and Motivations - Multiple factors, benefits, and familiarity with solar technology contribute to an individual's motivation to adopt solar panels:

- Inconsistent adoption rates in various locations due to multiple factors: impact of utilities and regulations, upfront capital necessary or willingness to finance, falling price of panels, improved technology, easy maintenance, and installation processes

- Personal motivations and accessing benefits that encourage solar adoption: saving money through lower utility bills, taking advantage of state and federal tax credits, receiving energy credits and rebates, having a strong return on investment, producing power for self-sufficiency, and contributing to environmental stewardship

- Solar adopters motivated by familiarity gained through: reading, researching and studying PV products, seeing systems firsthand, knowing about other renewables, and experimenting with solar technology

Theme Two - Barriers and Challenges - Diverse barriers present challenges for an individual to adopt solar panels:

- Upfront cost and various barriers make it challenging to consider solar technology: state, local and utility regulations; available rebates and incentives; 
insurance requirements; impact to energy industry; attitude toward and understanding of solar adoption; and installation constraints

- Lack of support in rural areas that were impacted by level of technical support, opportunities, availability of resources, and socioeconomic status of region

- Current political environment, threats of increased deregulation, and concerns of adverse effects of solar adoption on coal/fossil fuels impeding solar growth

Theme Three - Electric Utilities - Multiple utility types create inconsistent statutes and differing installation costs for an individual to adopt solar technology:

- Policy differences between municipal, cooperative, and investor-owned utilities are impacted by state statutes

- Cost of energy and economics of serving customers in determining percentage of renewables

- Utilities' energy portfolios impact on scheduling power usage and their willingness to promote solar adoption

Theme Four - Renewable Portfolio/Energy Standards - A renewable portfolio/energy standard dictates a state's statutes and regulations for including renewables:

- Incentives and rebates differ state to state

- Utility approaches to solar adoption include: net metering, cost recovery, and avoided costs

- Challenges of Renewable Energy Credits offset by benefits of the REC program Theme Five - Growth of Rural Solar Adoption - The growth of solar adoption in rural areas depends on increased visibility, finance and grant program availability, and improved technology: 
- Rural solar adoption increased by visibility of existing arrays, promotion and education, positive public reaction and perception, and interest in new technologies

- Solar technology available to more people through grants, loan programs, community solar, and solar farm developments

- Improvements in battery technology can greatly impact solar diffusion

Theme Six - Adoption and Installation - The adoption of solar technology often coincides with sizing and designing a PV array:

- Size of array based on utility size limits and energy use while design influenced by permit requirements, codes, regulations, and location determination

- Energy assessment is a critical step to determine optimal size of array and resulting utility savings

- Behavior change involved in adopting solar technology, which follows a fivestage process: 1) awareness, 2) interest, 3) evaluation, 4) trialability, 5) adoption I also analyzed documents that included local newspaper articles and promotional material to gather data. The document analysis was conducted by reviewing each article carefully to glean all relevant data that relate to the study. The supporting documents revealed local interest in solar energy, which I used to explore social norms influencing participants' willingness to adopt solar technology.

\section{Validity}

I initially checked the validity with the most common type of triangulation by collecting rich data from multiple sources employing two methods. First, data was gathered from interviews and observations as well as a document analysis. Second, data 
was gathered from participants with unique perspectives on solar adoption in rural areas.

I also incorporated another type of triangulation by using multiple theories to confirm emerging findings (Merriam, 2009). In addition to the Theory of the Diffusion of Innovations, I analyzed the data through a lens integrating the Concept of Innovativeness (Midgely \& Dowling, 1978). This theory did not have enough relevance on the findings to impact the conclusions drawn. However, both provided additional frameworks for considering other alternatives. These plausible alternatives were ruled out by presenting evidence that proved their implausibility (Merriam, 2009). Once my findings began emerging, I gathered feedback through member checks with some of the participants. I also performed a peer review with a colleague at Missouri S\&T, who is conducting research at the campus's Solar Village to explore the correlation between daylighting and HVAC energy requirements in a net-zero home powered with a PV array. He has provided validation on my findings for developing technical training. I developed the following diagram to outline the methods used to check the study's validity (see Figure $5)$.

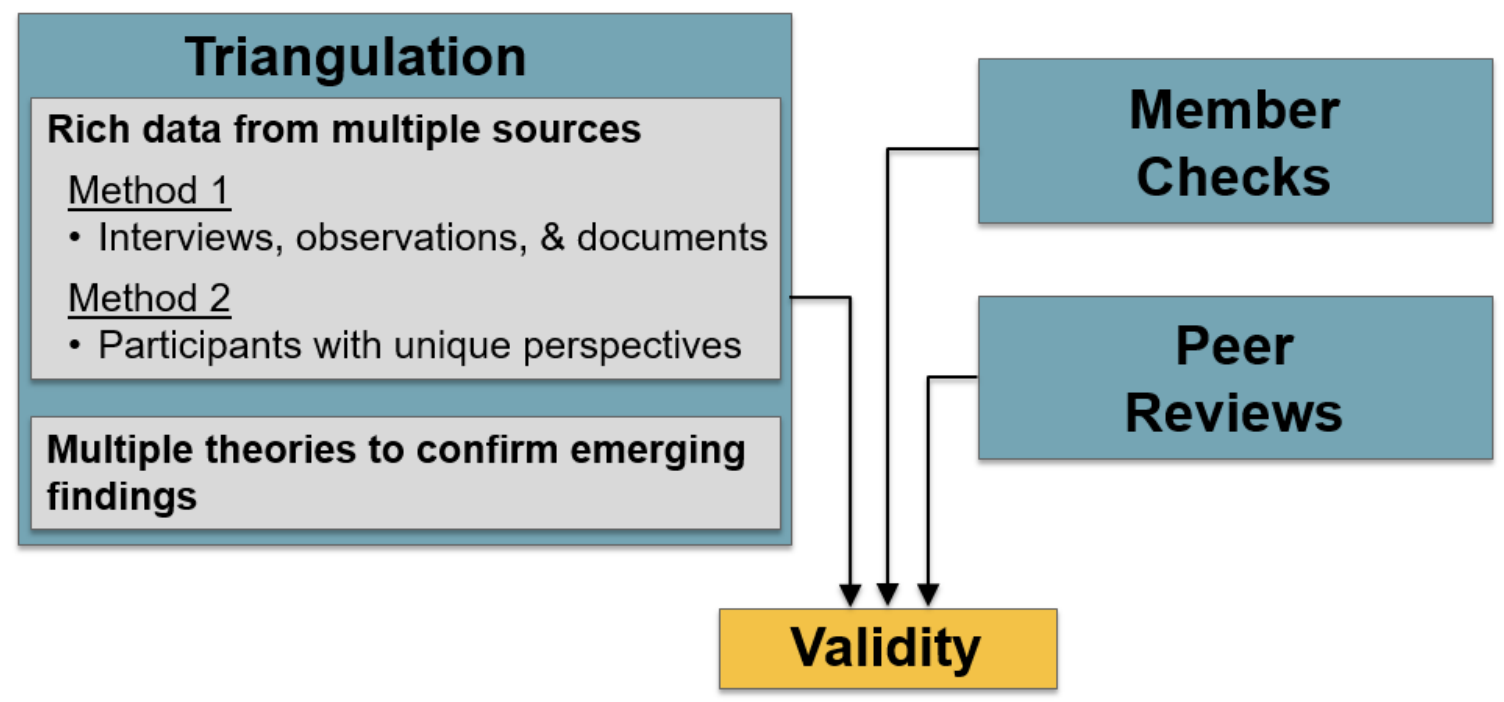

Figure 5. Validity diagram 
A possible threat to the external validity was not being able to transfer the results to other settings such as midsized Midwestern cities because the site selection is limited to rural areas. The unique perspective that rural residents have on solar adoption was consistent among the participants, but more extensive research would ensure that the themes developed in this study are consistent with a larger rural area in the Midwest. Another possible threat to the internal validity was my researcher bias. I minimized my bias through reflexivity, a continuous process of self-evaluating my positionality and acknowledging its impact on the research process and findings (Berger, 2015). The challenge was to use reflection and introspection as catalysts for gaining more insight into the participants' behaviors and interpreting the findings of my research (Findlay, 2002). I constantly repositioned myself in the research to maintain open dialogue for fostering collaboration between various methodologies and the participants (Bott, 2010). By incorporating a collaborative approach, I created a more insightful and meaningful study.

There were limitations of the study that emerged after completing the data analysis. First, conducting all of the interviews in only two states created a limited representation of the Midwest. While the investor-owned utilities provided some knowledge of adjacent states including Arkansas and Kansas to whom they provide utility service, the study may have benefitted from conducting interviews in other states. Second, not conducting interviews in Illinois with rural utilities limited a thorough comparison between rural utility companies outside of Missouri. Finding no contacts with Illinois municipal or cooperative utilities, I relied on the adopters from Illinois to provide valuable insight through their knowledge of and coordination with rural cooperatives in 
their area of the state. In relation, I was not able to conduct any interviews with Illinois government agencies. This lack of agency insight limited a comprehensive examination of renewable energy policy regulations outside of Missouri. Input from Illinois government agencies would have been helpful in comparing the two states' management of regulations and incentives driven by their renewable energy portfolios. Finally, interviewing elected officials at the state and local level from both political parties may have verified the partisan approach to solar adoption and support for renewable energy expressed by many of the participants. 


\section{CHAPTER FOUR: FINDINGS}

\section{Theme One - Factors and Motivations of Adoption}

Factors. The factors impacting solar adoption often determine how a potential adopter processes and reacts to his/her motivations to install a PV array. Factors and motivations can promote action separately but often relate and even rely on one another to tip an individual toward adoption. In those situations, a potential adopter's motivations must align with favorable factors for his adoption of solar technology. While some factors motivate him to consider solar technology more seriously as an option, others must be met before he will install panels. All of these factors determine the strength of an individual's motivation to pursue solar technology.

The data revealed a difference between factors that influence solar adoption versus those that predict it. Most literature has focused on the factors of prediction, including environmental, economic, social, political, and regulatory conditions. The distribution of renewable energy in the United States correlates with a number of these factors. Research indicated that homeowners using solar energy tend to live in urbanized areas because of increased marketing, access to solar technologies, and higher probabilities of social contact with existing solar users (Zahran et al., 2008). Additionally, the number of households using solar power is based on a combination of wealth, urbanization, and age. Social geography often indicates more renewable energy users at the peak of their lifecycle-consumption curve in communities with higher average household incomes (Zahran et al., 2008). As an example, the Suburban Co-op, in an affluent area, has 109 solar customers out of 28,000 total customers versus the Rural Coop, which has 27 solar customers out of 36,000 total customers in an economically 
depressed area of the Missouri. Therefore, research reveals that a local community's characteristics predict the likelihood of solar adoption (Zahran et al., 2008).

The data revealed factors that also influence solar adoption. These factors result from a changing solar market where prices for PV arrays have fallen and solar technology has improved. Solar technology also has fewer maintenance requirements compared to other renewable technologies. Additional factors are based on the geographic location of a PV array and include receiving state and federal incentives, taking advantage of available energy and tax credits, and having favorable state and local policies.

Lower costs. Falling prices on solar panels, components, and other products have reduced the costs of installing a PV array considerably. In some cases, participants indicated as much as a $50 \%$ reduction in price for an array from the time they first considered solar adoption to the time of their installations a few years later. The Suburban Co-op noted the price of solar panels continues to decrease. The Networker added, "And it really is in the last couple years though, where it has been cheap enough to say, 'You will save money.' But before now, it had to be people who were early adopters, wanted to save the planet... They weren't as motivated to save money on their utility bill."

Adopters like the Young Adopter have seen solar technology continue to drop in price. The Surveyor noted the falling prices of PV arrays factored into his adoption. He added that the lower purchase price of solar panels along with tax credits and a REAP grant motivated his uncle. The Firefighter agreed that the decreasing price of solar panels over the past few years coupled with the federal tax credit has made solar adoption more popular. He felt that making solar panels cheaper and easier to install should continue to 
increase its adoption rate. Additionally, the consultants such as the Buy-American Consultant and 70's Solar Consultant stressed that decreasing costs of solar equipment and products has advanced solar adoption. The 70 's Consultant stated that PV cells have become more cost effective at less than 50 cents per watt, which he argued is the most inexpensive way to produce energy.

Improved technology. These same participants also reported improved panel technology during this same period. In addition to increasing efficiency, panels now have an average life expectancy between 20 and 30 years. The Energy Consultant reported a 25 to 30-year warranty by most panel manufacturers with a projected lifetime of as much as 30 to 50 years. According to the Installer/Consultant, good reliability and longevity are benefits of installing panels from name brand companies like Trina Solar and Canadian Solar, who offer a 25-year warranty. The Son-in-law/Installer agreed with this view of the advancements by stating, “... solar panels are kind of like a big screen TV. The technology is just getting that much better every year. It is amazing how far technology's coming year by year. How it's changing." In fact, panels are producing about $1.3 \mathrm{~kW}$ hours a year with 1 watt of solar energy by the Energy Consultant's calculations. This increased production factored into the Young Adopter's decision to install a PV array.

As technology continues to improve, manufacturers continue to explore variations in products like solar shingles. Dow has been working on solar shingles since 2007, ten years before Elon Musk with Tessla began aggressively researching the product, according to the Energy Consultant. If the price can be comparable to panels, solar shingles could possibly advance solar adoption. They offer homeowners a consistent look 
and also reduce the concern of penetrating the roof with fasteners for traditional panels. The Engineer expressed his interest by stating, "If you could give me a shingle that wasn't very much more expensive that would produce electric, I would be all for it." The Rural Co-op admitted that he is monitoring the development of solar shingles and mentioned Tessla's purchase of the Zeptor technology, which creates a streamline look with interlocking master panels with less hardware showing. The Western MO IOU also see the promise of advancing solar roofing and monomolecular filament.

Less maintenance. Another supporting factor is that PV arrays have easy, straightforward installation and require very little maintenance. My Dad's Friend reported having no issues during or after the two-day installation. He, along with the Surveyor and the Energy Consultant, stated that PV arrays required little to no maintenance. They have no moving parts as explained by the Energy Consultant. Being maintenance free is a benefit of solar technology to the Father-in-law/Farmer. The Corporate Farmer summarized the lack of maintenance required, "Solar is simple. There's nothing to it. You put it up and watch it work!" Very little labor exists after the installation. He added, 'It's zero labor after it's up. There's nothing to do, so that's what makes it so unique." My Dad's Friend reported not checking his PV array often because of the infrequency of issues. The Surveyor also reported that he has not had any panels stop working. Even panels that cracked from a rock thrown by a mower still produce some energy, just at a lower rate. He orders one or two replacement panels easily. $M y$ Dad's Friend even boasted that his array has not been impacted by strong winds and has withstood a hailstorm. 
The Father-in-law/Farmer felt the low maintenance encourages solar adoption. In fact, solar technology is significantly easier to maintain than wind. The Young Adopter felt solar power had several benefits over wind energy due to PV arrays requiring so little maintenance. The Corporate Farmer expressed concern with maintaining a wind turbine because it has to be laid on its side or someone must climb the tower to make repairs. He reported very little maintenance for his large PV array even located next to several large grain bins producing dust.

Cleaning is recommended at least once a year under normal circumstances to increase the efficiency of the panels. Otherwise, no maintenance is required. The Corporate Farmer commented, "You know we have to wash them (solar panels) because of the grain dust, so we wash them once a year. And you can tell when they get real dirty. They don't produce as much.” Under normal circumstances, the panels are washed by rain except in very dry periods. The Father-in-law/Farmer speculated that his panels were being affected by dust from nearby grain bins, but his are difficult to clean because they are on the roof of a machine shed. The Engineer estimated that he has only washed his panels once in two years during a period of little rain.

In addition to recommended cleaning, most utility companies require that the automatic cutoff switch be tested regularly for all grid tied systems. Missouri requires solar customers to perform this check once a year. The cutoff switch ensures that the panels cannot back-feed power to the utility lines when the grid goes down and prevents possible electrocution of utility workers during a power outage.

Inverters present only a minor maintenance issue. An inverter converts the DC output from an array into AC power for use on the utility grid. An inverter also provides a 
safety component by allowing a predetermined number of kilowatts through to the grid based on the system's size. The Surveyor has only replaced a few Enphase inverters, a quick and easy process. The inverters have a status light that indicates if they are functioning properly. He has only replaced inverters on the first phase of his installation, so he speculated that it was a "bad batch". The Engineer acknowledged that inverters have been known to have technical issues. The Rural Co-op reported that an inverter may cost around \$4,000 to replace, but Enphase replaced the Surveyor's inverters at no cost.

The Surveyor monitors the panel production on his smart phone with an Enphase inverter phone app to see if the inverters are working properly or need replaced (see Image 13). Since he installed the system, he can see more with the phone app than homeowners can. The Corporate Farmer and the Installer/Consultant in Illinois as well as the Engineer in Missouri discussed the ease of monitoring energy production both online and through a phone app. The Son-in-law/Installer explained the Fronius Solar web app he uses on his smart phone to check the output of various systems he has installed. 


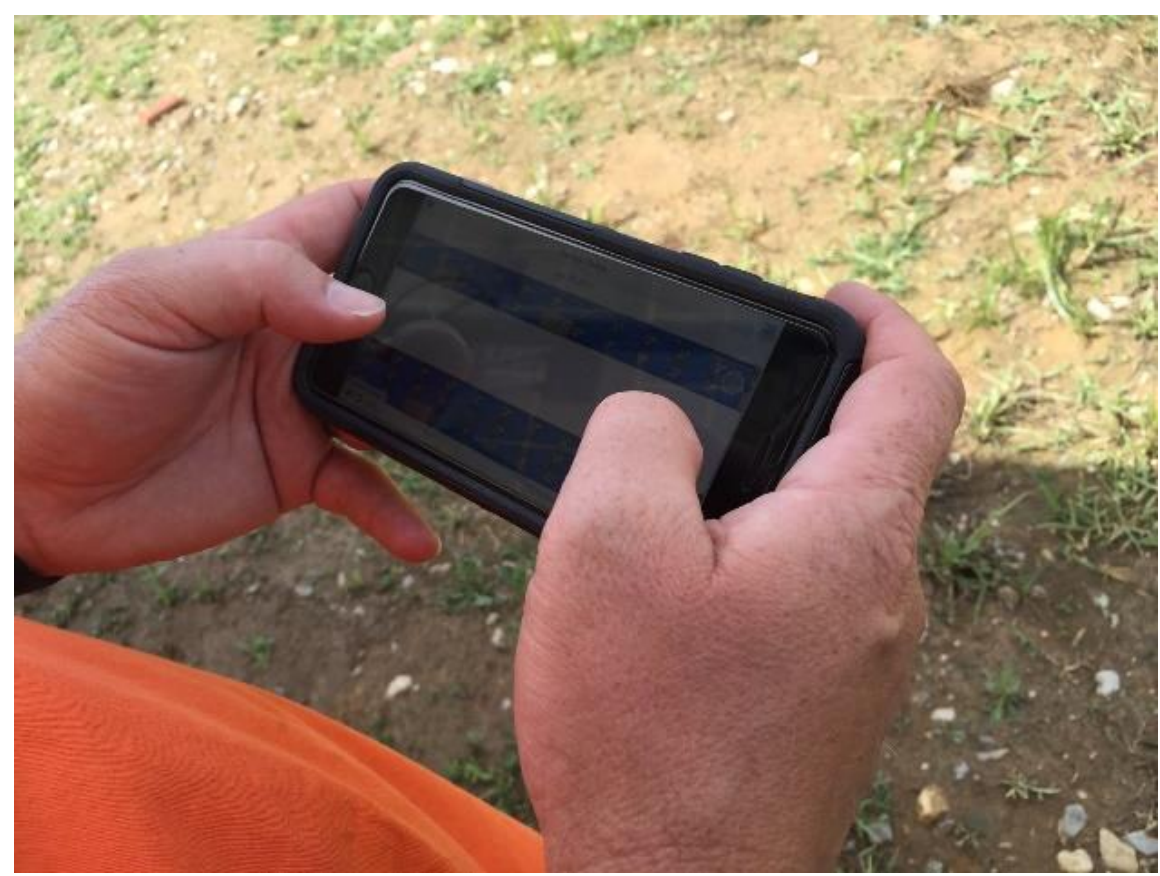

Image 13. The Surveyor using an Enphase inverter smart phone app

Geographic location. The geographic location of a PV array can have a significant impact on any number of factors, including the policies that govern solar adoption for the area, the incentives and tax credits that may be available, and the energy credits that may be offered. The state in which an array is installed as well as its location inside or outside the city limits of a municipality has to be considered. Differing statutes from state to state dictate the renewable energy policies and resulting structure of utility companies. A significant difference between Missouri and Illinois is the latter became a deregulated state in 2008 , meaning customers can choose their utility provider. Each state varies in the number of investor owned utility companies versus cooperative and municipal utilities. Each state also varies in how it handle the Renewable Portfolio Standard (RPS) mandated by the federal government. Missouri only requires investor owned utility companies to comply with the RPS. Illinois requires investor-owned 
utilities and alternative retail electric suppliers (ARES) to comply. Both States exempt electric cooperatives and municipal utilities.

Each state's statutes dictate how its utility rates are set. Statutes also outline the minimum requirements for net metering, cost recovery, and basic service fees. Missouri's statutes, for example, do not allow for full cost recovery because of net metering, a method of billing that credits customers for the excess electricity they produce and supply to the grid. The statutes do require that an array be sized for a homeowner's actual use without any excess generation. Missouri's statutes are part of the Easy Connect Act, which is the State's policy for a carbon neutral footprint required by the RPS. However, net metering varies greatly in different areas of the country depending on the state's legislation and implementation (net metering). Because a state's RPS dictates its statutes and regulations for RET adoption, the RPS plays a significant role in solar adoption within the state. The Buy-American Consultant stressed that passing legislation in Illinois has been critical. The State has seen monumental progress in solar adoption since the first RPS was passed in 2008. The role of a state's RPS emerged as a theme and is discussed in more detail later in this chapter under Theme Four-Renewable Portfolio Standards.

Each state varies greatly in the tax credits and direct cash incentives it offers. Federal renewable energy tax credits are available and help offset the cost of a PV array. Currently, the federal government offers a solar tax deduction of $30 \%$, but the rate is scheduled to start decreasing, giving adopters smaller deductions. Receiving the federal tax credit motivated both My Dad's Friend and the Fireman. These two participants stressed the importance of the $30 \%$ federal tax rebate because it significantly lowered the out-of-pocket cost of their PV arrays. The Suburban Utility stated that many of their 
customers were most interested in the $30 \%$ federal tax credit. My Dad's Friend noted, though, that the tax rebate is much lower than the cost of a $\mathrm{kW}$ of power, which gives adopters a greater savings.

Direct cash incentives include renewable energy credits, rebates, and grants that are issued once the array has been installed. The Municipal Utility noted that right now the government is pushing solar adoption by incentivizing grid tied systems. Incentives increase the likelihood that an individual will adopt solar technology. The Installer/Consultant added, "Now that's what drives solar is having some kind of rebate or incentive to put it up."

Another motivation for some adopters is using a PV array as a tax write-off. One customer of the Suburban Utility installed solar panels on a carport for two rental properties as a way to market the properties while getting $30 \%$ tax credit and being able to fully depreciate the arrays because they are installed on rental units. The Surveyor's uncle writes off the added insurance for the PV array as a farm expense. The Energy Consultant added that one of his customer's desire to adopt solar technology became feasible when he was able to reduce his income taxes. The Energy Consultant was motivated to install a PV array on his house by his own high taxes. He can also depreciate the value of the array. He insisted the higher the tax rate of a company or individual drives the incentive to adopt solar technology. Solar adoption becomes more attractive for the higher income rates because it becomes economically feasible, especially for businesses, which have sufficient income tax liability. Businesses with income profits can invest their income tax dollars in a PV array and save on future electricity bills. 
One challenge with tax credits is the exclusion of some possible solar installers such as retirees or non-profit companies (Noble, 2012). Additionally, a utility customer needs a tax income to take advantage of the investment tax credit as stated by the Generation Co-op. The variance in state tax credits produces another challenge; some states do not offer any while others offer small tax rebates. The Buy-American Consultant attested to the unpredictability of Illinois tax credits. The Surveyor was more motivated to adopt when it was rumored that Illinois's rebate might be ending. It was recently extended under the state's new energy bill that went into effect in June 2017. However, states like Missouri have phased out their state tax rebate. At one time, investor-owned utilities were required to offer rebates, and it made a big difference. Solar adoption in Missouri greatly increased five to six years ago for grid tied systems with investor-owned utilities. Missouri's program started to run out of funding around 2014 and was discontinued.

When discussing solar adoption in Missouri, the 70's Consultant reported, "It was huge and booming when we had rebates. We had rebates that dropped off tremendously probably as well as our employment too. The thing that has helped is that the cost of solar has dropped. That has helped, but it hasn't totally replaced the loss of the rebate." $M O$ PSC also reported a big spike in adoption when a rebate was available. Missouri has three investor-owned utilities regulated by the MO PSC. Proposition C required all investorowned utilities to meet a certain percentage of renewable energy. The Western MO IOU was already generating enough power through wind and hydro to meet the standards. However, the MO PSC later ruled that the Western MO IOU had to offer the tax rebate on solar energy starting in 2015. The Western MO IOU believes that their tax incentive has 
increased solar adoption in their area. The MO Rural Development added that getting a tax rebate from Western MO IOU has also motivated utility customers in that area to apply for REAP grants.

Having an electric utility that is accepting of solar technology is a factor dependent on the location of a PV installation. Much of the acceptance seems based on the adopter's type of utility service. The $I L-M O I O U$ said they, as a utility company, are very accepting and supportive of solar technology because they realize they cannot fight it. The Son-in-law/Installer attested to the IL-MO IOU's cooperation on projects and reported that they only take a couple days to process the paperwork required for PV arrays to be approved for operation. He also recognized that the utilities pushing or supporting renewable energy are doing so because of requirements from state legislation. He sees a willingness by the Illinois municipal utilities to cooperate. For this reason, the Installer/Consultant for whom he works has been doing the IL-MOIOU and municipal utility customers first because some of the cooperative utilities seem unsupportive of solar adoption and are slow in processing requests. The Father-in-law/Farmer stated, "(The IL-MO IOU) has been very friendly to these things. Our local electric co-ops have not been. It's been amazing. I mean, I understand it, but I figured there would be some resistance from (the $I L-M O I O U$ ), and there has not been." The Buy-Americann Consultant recognized that some municipal and cooperative utilities in Illinois are cooperative on installations and supportive of solar adoption.

Municipal utilities in Missouri, however, do not usually offer rebates because the money they would pay customers to install PV arrays would ultimately cost other customers more on their utility bills according to the Municipal Utility. They feel other 
customers who cannot afford the upfront cost of a PV array should not have to pay higher utility costs to offset the energy that an adopter produces. Adopters would be receiving the benefit of using the grid to store their excess energy without paying for it. Municipal utilities often base rebates on what the local community finds important. For example, the City of Columbia offers a rebate because their citizens felt strongly about solar adoption and passed a proposition to fund the incentive. In contrast, the City of Rolla offers no type of rebate or incentive.

Renewable energy credits (RECs) are another type of rebate dictated by state statutes. RECs are given to homeowners for producing excess power. One megawatt of excess energy produced equals one REC. Illinois currently offers the Solar Renewable Energy Credits (SREC) program available to residential solar installers while Missouri does not offer any to utility customers. Many states adjust their energy credit programs. Missouri offered energy credits at one time and defined a REC as being equal to one megawatt of power under Proposition $\mathrm{C}$ but discontinued them because of funding as previously mentioned. When a customer gets a rebate, the utility company gets the REC generated from that system due to a legislative change. Because the incentives with energy credits are no longer offered to individuals, customers cannot earn any payback for producing excess energy.

The MO PSC explained the management of RECs varies state to state. The act of customers retaining their RECs seems more prevalent according to the $M O P S C$. The agency explained that utility companies in Missouri can save their RECs up to three years if they generate more than needed in a year. The MOPSC used the $I L-M O I O U$ as an example of an investor owned utility that is purchasing RECs to meet their renewable 
portfolio standard's compliance requirements for renewable energy because it is likely cheaper than building solar farms. The $I L-M O I O U$ is trying to balance using RECs and building solar projects. Independent parties or municipal utilities can get certified through the MO PSC to sell their RECs to investor-owned utilities. Additionally, customers can combine RECs into bigger blocks through an aggregator for investor-owned utilities to purchase and use toward their compliance. The investor-owned utilities then demonstrate their compliance with the Renewable Energy Plan by retiring a required percentage of their RECs each year. The MO PSC conducts the review of the RECs being retired. The Renewables Advocate revealed that Missouri has raised the cap on how many RECs investor-owned utilities can use to meet their compliance.

In states like Illinois where energy credits are offered to customers, the credits can be used by farmers to offset higher than normal utility bills. For example, the Corporate Farmer saves his energy credits throughout the year and uses them at peak times of energy uses. Since credits must be used by November 1, he saves them until September and October when his farm's energy consumption reaches its highest usage. During harvest season, an average utility bill can be around $\$ 10,000$ due to the excessive energy used for grain dryers and other farm utilities. Illinois is currently issuing energy credits at a one-for-one rate. For every one megawatt of power produced, one energy credit is earned; however, they can no longer be sold back to the state for profit like a few years ago.

My Dad's Friend enjoys the rebates through the SREC program and sees them as a bonus over the savings on his monthly utility bills. He receives SREC rebate checks each quarter through the Installer/Consultant. He hopes the SRECs will be offered into 
the foreseeable future but expressed concern that SRECs for customer based solar installations may vanish because solar corporations are buying up large blocks of SRECs for profit. The Father-in-law/Farmer predicted that his PV array will pay for itself ahead of time because of both higher than anticipated SRECs and strong energy generation. However, he recognized that SRECs are limited. The Surveyor shared that his uncle has been getting money back through the SREC program by selling his excess generation to Illinois Power Company through the SREC program. The SREC payments furthered motivated the Firefighter to pursue solar adoption, and The Buy-American Consultant stressed that the SRECs have been a motivation for many adopters. She shared that strong SREC pricing has lowered the cost of a PV array significantly. For farmers, producing a megawatt of power becomes a commodity to sell. The Installer/Consultant stated, "So that megawatt of power, every time you produce one, it's like a tradable commodity for a farmer. It's like a bushel of grain."

The Installer/Consultant estimated that the monetary value of a certificate earned for generating one megawatt of energy is $\$ 160$ to $\$ 170$ per certificate. The Son-inlaw/Consultant reported that the Installer/Consultant was bidding \$160 for SRECs in 2017 and was paying \$167 to customers last year. The Buy-American Consultant explained that previously SRECs were awarded to the lowest bids first until the funds were exhausted. Lower SRECs benefited installers because they could secure SRECs more easily and pass a savings onto the adopters. In the beginning, not many people understood how the process worked, so it was easier for those few consultants who did to secure SRECs. However, that has begun to change. Additionally, Illinois started placing a capacity cap on the size of bids in 2016, which were met by the time only one-third of the 
funding was expended. Starting in 2017, the State allowed previously installed PV arrays to be bid along with new systems.

These changes have prompted the Buy-American Consultant to diversify her bids. She was not awarded any SRECs in 2016 because her bids were too high at $\$ 230$ per kilowatt. In 2017, she bid various prices with her lowest being \$200 per kilowatt. These bids were high compared to the average of $\$ 167$ quoted by the Installer/Consultant. The Buy-American Consultant ended up networking with another solar consultant to secure 100 kilowatts of SRECs. Therefore, the higher the price per kilowatt, the more rebate a solar adopter receives. The Buy-American Consultant explained:

So to give you an idea, this is a five year contract right, so the formula ends up being about 6.3 REC. A factor of 6.3 over the five years per REC. So now a 10 $\mathrm{kW}$ system, if we take 10 and we multiply times 6.3 , that's 63 RECs over the five years. We multiply that times $\$ 250$. That's $\$ 15,750$ that they would get quarterly over five years, divided. That's a lot of money.

The Installer/Consultant and the Buy-American Consultant asserted that Illinois' program has continued to change. The Surveyor, as an example, receives SRECs at a lower rate because his PV array was already installed when the program started. The BuyAmerican Consultant warned that frequent changes to the SREC program have created uncertainty. She stated, "What has stifled that (solar growth) a bit is the renewable energy credit program in Illinois...it's ever changing." The SREC program will be modified as part of the new Illinois renewable energy legislation, the Future Energy Jobs Act. The bidding will be levelized and SRECs will be awarded in blocks of set amounts of capacity. The Adjustable Block Program is still being developed. Previously, SREC 
pricing was locked in with five-year contracts. Under the new legislation, 15-year contract are available. The Firefighter locked in his SREC price for 15 years so he does not have to worry about changes affecting him. He insisted that even if the pricing increased, he preferred to just be finished with the process.

Some areas are currently only offering grant money as a type of cash incentive. The Corporate Farmer stated that he received a rural development grant to install his array for farm use. In other locations, the solar industry is doing other things like offering tariffs to maintain interest where the state statutes are not providing rebates. These incentives ensure a more fair market for solar power to compete with other energy options. Farmers and rural small businesses can secure loan financing and grant funding through the Rural Energy for America Program (REAP). The funding opportunities through the REAP program are described in detail under Theme Six - Growth of Rural Solar Adoption.

In summary, a number of factors influence potential adopters to consider solar technology. These factors include cheaper priced solar panels and components, improved solar technology, and fewer maintenance issues compared to other RETs along with available rebates and incentives. All of these factors were recognized to varying degrees by the interviewed adopters. Regardless of the priority placed on each factor, collectively they influenced the adopters to consider their motivations to install a PV array.

Motivations. The motivations for adopting solar technology could have easily been labeled benefits because they often provide a reward. However, many of the participants interviewed focused on why they were motivated to adopt versus how they benefited from adopting solar technology. They all demonstrated a strong motivation to 
pursue solar adoption based on personal priorities. To the participants, the most important motivations included saving money through lower utility costs and earning a strong return on the initial investment. Other motivations included producing their own power and making a positive environmental impact.

Previous research indicated that Americans are strongly motivated to adopt solar technology for the benefits that come from installing PV arrays. These include the environmental impact, technical efficiencies, and economic benefits. Lowering emissions and reducing pollution are key measures in the environmental impact. Brecha, Mitchell, Hallinan, and Kissock (2011) stressed the importance of lowering emissions of carbon dioxide and other greenhouse gasses through reduced home energy use and more renewable energy and carbon-free sources. They also pointed out that local and regional policies are important in reducing emissions and energy consumption in homes.

Dietz, Gardner, Gilligan, Stern, and Vendenbergh (2009) added that behavioral changes are necessary for reducing carbon emissions in the United States, thus increasing the environmental impact of solar adoption. Nevertheless, slow-acting policies fail to influence the behavioral changes necessary for reducing greenhouse gas emissions caused by current home energy sources (Dietz et al., 2009). Changes in behavior may have influenced how or to what degree an individual was motivated to adopt but did not emerge as a separate theme in this study. Of the adopters I interviewed, no common behavior characteristics stood out.

The technical efficiencies that act as motivations include saving energy, reducing the consumption of power and other material resources, and improving building efficiency (Sovacool \& Watts, 2009). The economic benefits include reduced energy 
costs, higher market returns, reduced operating expenses, and more stable and predictable fuel prices. Hoffman and Henn (2008) pointed out that the economic benefit associated with renewable energy and green building goes beyond capital costs to include reductions in operating costs for water, wastewater, and energy expenditures.

Utility savings. For many potential adopters, their key motivation involves saving money. Benefitting economically strongly motivated all of the interviewed adopters. The 70 's Solar Consultant stated, "What drives solar is economics. Most people do it because they want to save money on their electric (utility) bill." The majority of the adopters repeatedly mentioned that their main motivation was to save money. "You've got to look at the economics of it. It's a cost saver, and it's out there churning a little bit every day," added the Father-in-law/Farmer. Even the IL-MO IOU agreed that seeing a payback in the short term -5 to 10 years - is a strong motivation. The Son-in-law/Installer stated that many of the adopters he knows in Illinois have paid for their systems in four years or less with the $30 \%$ federal tax credit and SRECs. He said the biggest question from potential adopters is about the payback. The MO PSC stressed, "It really boils down to economics to me is what makes people decide to do it or not." The Rural Co-op said customers desire a payback in a reasonable timeframe. He saw the two main motivators for their customers as saving money and protecting the environment. The 70's Solar Consultant stated, "It's an economic decision for I'd say, pretty close to $95 \%$ of everyone that we sell it to. There's 5\% that just want to reduce their global footprint, and they're willing to pay for that. The payback is not really significant. They just want to do it." The Networker argued that saving people money will make it appeal to a larger part of the 
population. Showing them a serious savings could convince them, but otherwise they may not go to the effort of researching solar technology.

Some of the adopters attested to the economic benefit. The Firefighter boasted that with the federal tax credit and SREC rebates his system would pay for itself in less than four years while My Dad's Friend projected a payoff in seven to eight years. The Farm Matriarch is hoping their system pays for itself in six years. The Father-inlaw/Farmer predicted his array would pay for itself ahead of time because the SRECs have been higher than predicted. Since Missouri is not offering any state tax credits, the payoff is longer. The 70's Solar Consultant pointed out that in Missouri a 10 to 12 year payback is expected for residential systems but only about four years for commercial systems because they can be depreciated.

With the cost of energy projected to increase, these adopters prioritized reducing their utility bills. The Installer/Consultant, Buy-American Consultant, Generation Co-op, and the Farm Matriarch insisted that the increasing energy costs will drive the expansion. The Young Adopter specifically cited the increasing price of power as a motivation to adopt solar. The Energy Consultant stated that offsetting utility rates is critical in measuring the benefit of solar, but the Rural Co-op stressed that showing a strong payback from solar is easier if utility rates are 18 to 25 cents per kilowatt-hour. Utility rates then become a big motivator. In fact, energy prices in a state usually indicate the motivation to adopt solar. The Rural Co-op stressed that saving money is a bigger issue in western states because they have much higher utility rates but can benefit from an abundance of sunshine. The 70's Solar Consultant agreed that more solar adoption exists in states with higher utility rates, stating, "It's really an economic thing, which is driving 
(adoption). In California, where the electric rates are three times what they are here, you're a fool not to do it basically." He calculated that in states like California, solar equates to a $25 \%$ return on investment. Focused on the earning potential, he sees a $25 \%$ return as a great investment. However, he stated:

You still got to communicate that. They've got to come up with the money. You got to think with them, but really when you look at the investment, it's a great deal. That's why there's a lot more solar adoption in states where the utility rates are much higher. Like even in New York State, which is not nearly the solar power potential of Missouri, but the electric rates are so much higher. Where there's high electric rates you'll see the absorption of solar is much higher, and they're much more interested in it because the payback is more attractive. Like I said, they're not more green there, they're just more green in the pocketbook. That's all. That's all it comes down to.

According to the Municipal Utility, New Jersey, ranked second in grid tied arrays behind California (Krasko \& Doris, 2013), presents another good example where high energy prices have driven more solar penetration in a largely investor owned utility market and in a state that sees less sun than most in the Midwest. The Energy Consultant quoted increases in utility prices of $30 \%$ forecasted in the U.S. over the next 24 years due to environmental and safety related costs. This forecast uses past utility rate increases from 1970 to 2009 from 2 cents per kilowatt hour to 12 cents per kilowatt hour, a 4.14\% increase. At that projected rate, utility rates could reach 32 cents per kilowatt hour by 2034. A growing demand for electricity could drive this projection even higher according to the Rural Co-op. 
The Networker encouraged using the fact that electricity is only going to get more expensive as a means of promoting solar power. She stated, "Energy's never going to get cheaper. There will be a point where you get everybody switched over to natural gas, well then you've this captured market, and if they want to jack up the prices, they will." The Young Adopter also expressed his concern:

Well that's another reason why, is electric rates just keep rising. You don't know if they're going to double them in the next year cause the EPA is doing whatever they're doing. I don't know if Trump is going to shut them down and or if he's just gonna...it's like gas. You didn't know gas was going to triple in price. I mean it went back down obviously, but there's still that threat that it will go up or can. The likelihood of increasing utility rates motivates some Midwestern residents even when rates are low currently compared to states in the Northeast and Southwest. While Missouri has some of the lowest utility rates, customers pay some of the highest utility bills because of extreme temperatures.

The Young Adopter, My Dad's Friend, the Fireman, the Farm Matriarch, and the Surveyor all were motivated by saving money on their utility bill. They all reported the cost savings as the biggest benefit. For My Dad's Friend, saving money on his utility bill is more important than earning money through the SREC program; he reported paying the minimum amount now on his utility bill. The Installer/Consultant said the ultimate motivation for his customers is having the lowest utility bill possible, $\$ 17$ per month. That covers the connection fee with the utility company in Illinois. The Surveyor stated that his friend, for whom he installed an array, was motivated by having a high utility bill every month for his large house and is now paying the minimum for his utility bill. He 
also stated that his uncle pays the minimum charge on his utility bill for having a transformer. One of the Energy Consultant's customers was motivated by the idea of leaving his house to one of his children who would not have much of a utility bill.

Even the $I L-M O I O U$ spokesperson admitted he is strongly considering adopting solar technology because of high utility bills for a large house. He sees higher utility bills as a big motivation for many customers. The Western MO IOU felt that the idea of not having a utility bill more than caring about the environmental hooks people to adopt solar technology. The IL-MO IOU warned of a snowballing effect, though, as more people install PV arrays. He stated:

I can see this almost snowball effect where you have more and more people saying, "Well my rate keeps going up, I'd like to put solar on my house." And they put it on their house. The guy next to him says, "Well my rate's even higher now because of the model, and so I'm going to put solar on.” It just keeps happening and happening.

Farm benefits. The Installer/Consultant also explained that farmers in rural Illinois are further motivated by even higher utility bills caused by grain dryers. Grains like corn, soybeans, and wheat frequently have to be dried before being stored to prevent spoilage. The extent of the drying depends on the moisture content of the grains during harvest. Large fans push air up through the grain as it is stored in bins, requiring large amounts of electricity to dry the grains layer by layer. By installing PV arrays, farmers are able to reduce their operating costs for grain dryers significantly. While solar power can help greatly lower utility costs, it most likely will not eliminate a farmer's utility bill entirely. Several of the participants acknowledged the common misconception of 
producing free electricity. A more realistic objective is to use solar technology to offset the electricity purchased from the utility company. The Farmer Matriarch stressed that having high utility bills from the grain dryers was her family's main motivation and that they probably would not have installed a PV array otherwise.

In addition to using excessive electricity for drying grain, the Father-inlaw/Farmer also uses even more for his hog buildings, which require ventilation fans to be run at all times to keep the hogs cool and remove the methane gas. In addition to raising hogs for meat production, he produces organic fertilizer with the hog manure. He explained that energy usage for hog operations is steadier throughout the year unlike with crop production where energy usage increase dramatically every fall because of drying grains. The Son-in-law/Installer asserted that hog farmers are a good target market for solar technology because they have consistently high-energy loads every month from the exhaust fans.

The Father-in-law/Farmer has not seen any negative response to solar technology and elaborated on several other factors that make it appealing to the agricultural sector. Farmers are willing to invest money today to save money in a few years. Since farming is unpredictable due to a host of elements like the weather and fluctuating grain prices, farmers are accustomed to risk and uncertainty, making them more willing to adopt innovations like solar technology. He stated, "Farmers love this kind of concept." Also, farmers like the efficiency of solar technology, which makes the concept of solar adoption appealing to them. Farmers can increase the efficiency of their farming operations by adopting solar technology. He stated: 
If it goes to this efficiency thing and cost of production, it really helps lower your cost of production. It's all about cost of production. It just seems like farmers like this kind of thing. I think they're solar panel friendly. I think... one of the buzzwords in agriculture the last few years, as margins have gotten tight and they really have, is just efficiency. I think it just makes it a little more efficient. Maximizing production, whether in bushels per acre or pounds of pork produced, while lowering costs drives farming. Because productivity has been increased with less waste through advanced technology, the Father-in-law/Farmer feels technology has immensely improved agriculture. He stressed, "Farmers like technology too. Farmers love technology. They really do. They just love it. It's just amazing." Farming operations are going to continue expanding in his opinion. Increasing productivity is critical because farming now competes in a world market and not just in the U.S. For example, the Father-in-law/Farmer owns farm machinery in partnership with two other farmers. He also revealed that farmers like getting tax breaks. Based on these factors, he encouraged promoting solar adoption with farmers more than with other utility customers who live in town and face a number of barriers such as shading from trees and nearby structures, lack of land for ground mount systems, and steep roof pitches on older homes.

The Son-in-law/Installer has seen more willingness from farmers who are more business minded or just open minded to invest about $\$ 20,000$ in a PV array. He sees farming as a diverse group where some farmers are trying to save their way to prosperity while others are willing to invest in technology to increase their profits. Those willing to invest in technology see a PV array as cash back after it has paid for itself in about four years. The Suburban Co-op said farmers are thinking about solar power as a cheaper 
alternative to buying large quantities of propane or natural gas. He added agricultural areas are especially focused on the return on investment with PV arrays.

The Installer/Consultant boasted that he could fill a legal sheet with the installations they have scheduled to complete. "So what the underlying market for us in this rural area is the farming community" he proclaimed. "It's (the array) a depreciable asset because a lot of it is used on the farm for grain drying and other pieces like that. So the array helps take some of those peak charges off," he stated. The other advantage for farmers is that utility rates tend to be higher. Rural utility providers often offer rates around 16 cents per kilowatt versus about 11 cents with municipal utilities. Farmers are able to offset the higher per kilowatt price with an array.

The Buy-American Consultant recognized that farmers know a little bit about everything from working on their farm and regularly maintaining and fixing equipment. Farmers even upgrade facilities and operate excavation equipment for placing new drain tiles in fields or installing electric and water lines. Because of this diverse skill set, she argued farmers are capable of installing a ground mounted PV array if they can read an electrical diagram. In fact, she has consulted with a number of farmers who completed their own installations, including the Firefighter and the Surveyor. Being able to do it himself was a big motivation and advantage for the Surveyor. He saved about \$2 per watt doing the installation himself, which included fabricating the racking system and brackets. The $I L-M O I O U$ reported a similar savings of $\$ 2$ per watt for two friends he described as handy and able to do much of the installation themselves. The Energy Consultant clarified that while structural and electrical engineering is not required for 
residential or farm installations, codes do require commercial installations be designed by an engineer.

Investment potential. Many adopters see a PV array as a good investment because of the savings potential due to projected energy price increases. They have to be realistic about how much money they can save on utility bills, but when compared to the very low interest rates on most savings options, many of the participants viewed a PV array as a good investment. The Installer/Consultant stated, "The best line I got probably was a guy told me, you know, last year I made $\$ 87$ in interest on my savings account, so what I decided to do is that I decided to put an array in.” The Engineer added, when comparing his return on investment in terms of monthly utility savings, his array gives him a better return than a certificate of deposit (CD). On average, CD's are earning about $1 \%$, and he calculates that he is earning about 4 to $4.5 \%$ with his array. He stated, "Bottom line is $4 \%$ versus $1 \%$. I mean that's the real bottom line."

Since the Engineer is earning approximately $3 \%$ more each month by installing an array versus investing in a $\mathrm{CD}$, he emphasized the investment potential as a way to market solar adoption to homeowners. The Engineer suggested solar installers are not doing an effective job of promoting solar technology as an investment opportunity when arrays have a much greater potential than most savings accounts. The Installer/Consultant reinforced this point, "If you can make it as an investment, you know, it opens up the door for bringing more solar here (to rural areas)." The Engineer concluded, "If somebody was out there hustling a little bit, they could sell him (a retired guy with 40 acres and CDs in the bank) one (PV array) and say 'hey you' re going to make $4 \%$ and be happy."' 
If a homeowner has the upfront capital necessary or is willing to borrow money and plans to live in a house for many years, he/she may recognize the investment potential. The Young Adopter saw adopting solar technology as an investment as he looks to the future even though his utility bill was not too high. The Surveyor also saw adopting solar technology as an investment in his house since he plans to live in it for many years. The Father-in-law/Farmer installed his PV array as a way to plan for the future of his farming operation.

The Energy Consultant declared that solar technology is a good economic investment and acts as an economic stimulus by preserving and increasing adopters' disposable income and spending power. He stated, "Now you've got money. Instead of burning it up on energy, you've got money for housing, durable goods, vacation and leisure activities, and shoppers' goods, securities in investments in education and the IRS.” In the short term, business will increase for manufacturers, contractors, retailers, and service technicians. Even trade workers like electricians, pipe fitters, carpenters, and installers benefit according to the Energy Consultant. In the long term, consumer spending will increase in the private and public sector. Additionally, saving money on energy allows people to invest and spend what they save on other things.

The Buy-American Consultant stated that creating solar manufacturing jobs increases economic development. The Father-in-law/Farmer explained that installing PV arrays has provided a good side business around farming for the Son-in-law/Installer, a union electrician. The Son-in-law/Installer agreed that installers like him are making a good income in the solar industry. He argued that the solar industry will provide more jobs than power plants and coal mines in the next few years. He compared the coal 
industry to the automotive retail business, which is struggling because people can now buy cars online. Additionally, coal plants have significant overhead, making the solar industry more efficient. He stated, 'I guess I would say I think it's just like everything. Times are changing, and it's going to happen. Whether it's a car business, a farming business, whatever it is, I think it's just a different world today, and you've just got to kind of adapt."

The Buy-American Consultant encouraged replacing jobs in the coal industry with jobs in the solar industry. She stated:

Okay, so jobs may go away in the coal industry. That's okay because guess what? We have something that can replace it. We can replace it with jobs in a different way. And are you scared because you don't know about that? And are you scared that there's going to have to be education? Sure. But it's okay. We can do it. So I think getting rid of fear, and I think that that's going to be what's going to continue to push this movement forward.

According to the Renewables Advocate, the solar industry added about 51,000 jobs in 2016, a number equal to the jobs in the coal industry right now. Both the 70 's Solar Consultant and the Suburban Co-op pointed out that solar technology is creating many jobs and boosting the economy because the installation is fairly labor intensive. On the contrary, the coal industry has been around a long time, so the Suburban Co-op said it should only take a few people to operate coal fired power plants as well as mining operations because of automation. Due to job creation, the Buy-American Consultant sees solar adoption as an opportunity to boost the U.S. economy and thinks that developing American solar manufacturing opportunities should be a priority for the government. The 
70 's Solar Consultant shared, "Solar is truly the cheapest way to go if you do it via a rebate. You do it through the private sector. That creates a lot of jobs, a lot of economic activity because it's very labor intensive to build all these fabulous solar systems."

Many of the participants stressed the importance of solar adoption on the future. The Father-in-law/Farmer commented, “I think that solar's got a lot of potential yet. It's not a mature market. There's a market that's just starting to come on. I don't see it as a fad." The Farm Matriarch predicted that solar adoption will continue to increase and stated, "I think it's the thing of the future." The Father-in-law/Farmer added, "I think the future's golden. I really do. I intend to do more.” The Energy Consultant emphasized that everyone has a responsibility to save the planet with the population projected to grow by roughly $30 \%$ by 2040 . He summed up solar technology's impact on the future by quoting Thomas Edison who in 1931 stated, "I put my money on the sun and solar energy. What a source of power. I hope we don't have to wait until oil and coal run out before we tackle that."

Self-sustainability. In addition to saving money and capitalizing on the investment potential of solar technology, many of the adopters conveyed a desire to be self-sustainable in generating their own electricity. They all expressed enjoyment in producing their own power. The Young Adopter focused on being self-sustainable after experiencing a power-outage for a few weeks due to an ice storm. Even the Farm Matriarch sees the benefit in being self-sustainable. Even in applications where energy use can only be supplemented by the array and not completely offset, the participants reported a sense of satisfaction in producing their own power. Both My Dad's Friend and 
the Firefighter have a strong curiosity in the electricity they are generating. My Dad's Friend checks his utility meter periodically and monitors his production online.

In some cases adopters incorporated features to increase their production. The Engineer estimated a 20 to $25 \%$ gain in production by adjusting the angle of the array each month. He boasted that he produces more power under ideal circumstances (cool, sunny temperatures) than what the array was designed to produce. My Dad's Friend also reported excess generation during cool, sunny weather. The Young Adopter installed solar panels on a tracking system (see Image 14). Even though it doubled the cost of his array, he felt it was worth the expense because of the significant increase in energy production. Installing solar panels on a tracking system maximizes generation by adjusting the position and angle of the panels to follow the sun as it moves across the sky.

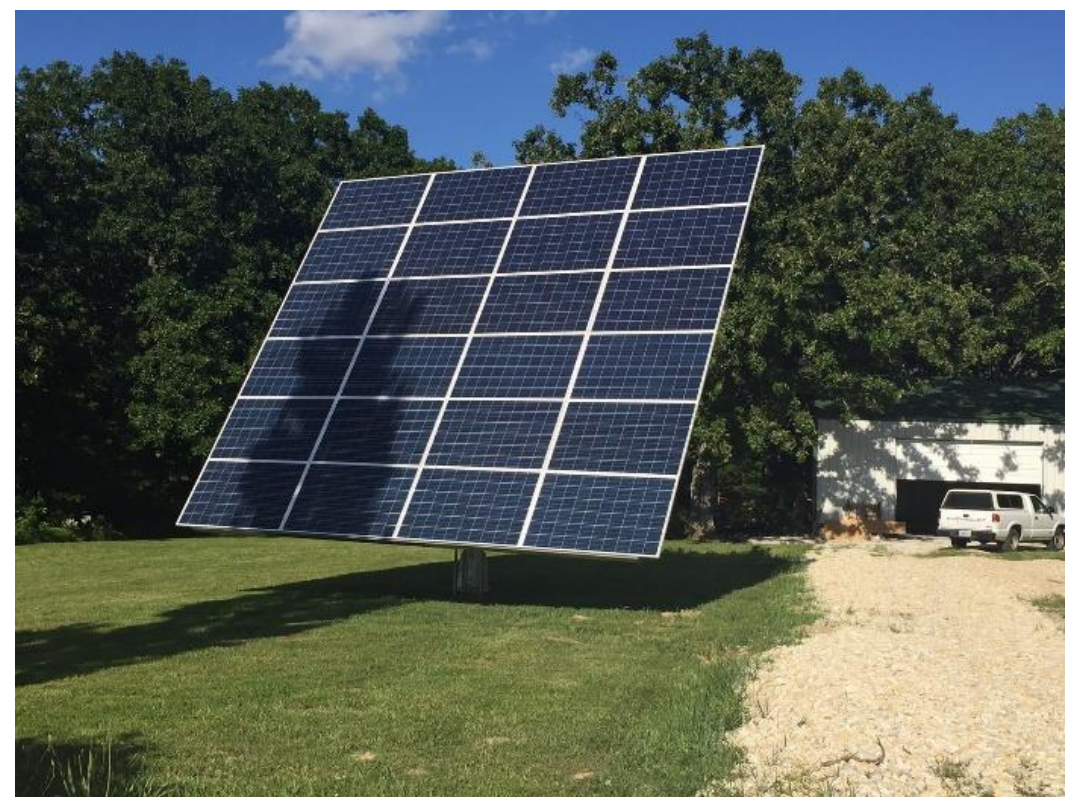

Image 14. The Young Adopter's PV array on a tracking system

Regardless of whether the participants aimed to optimize their production or just offset large energy usages common with farmers, an eagerness to save money motivated them to adopt. They simultaneously aimed to improve their savings opportunities and 
reduce their environmental impact by producing their own energy from the sun. Part of this desire to produce their own power comes from an independent spirit. The Young Adopter discussed the importance of following one's own vision and having an entrepreneurial spirit. He also insisted on not listening to naysayers or being influenced by negative feedback. He encouraged being open-minded and demonstrated a willingness to start exploring solar technology and learn throughout the process. The Farm Matriarch echoed the motivation to be independent. She said her family adopted solar technology for themselves not for what others would think.

Beyond the sense of independence, the Energy Consultant argued that higherorder needs also drive solar adoption; these needs are often rooted in success and higher education. A number of concepts like environmental stewardship and global climate change are introduced in a higher education setting. Additionally, one often gains a willingness to invest in the future and accept regulations and public initiatives. One also develops an appreciation for what benefits society beyond one's self-interest. According to the Energy Consultant, this appreciation reflects a willingness to benefit others.

Investing in solar adoption as a cost-savings technology motivated the interviewed adopters. While several of them recognized the potential to be more selfsustainable through solar energy generation, many also cited the environmental impact of a PV array as a motivation for considering solar technology. Regardless of how they phrased their motivation - supporting environmental stewardship, trying to do the right thing by positively impacting the environment, embracing the green aspect of adopting solar technology, reducing their carbon footprint, or believing in the reality of climate change - they stressed a desire to help the environment by doing their part. The 
Installer/Consultant shared a story from a customer, "He (the customer) said it's not the money that I'm doing it for. I'm doing it for my grandkids. I could care less about the money. It's not a big deal to me, but I just want to do something that impacts the next generation." The Farm Matriarch expressed satisfaction that solar technology helps the environment. The Father-in-law/Farmer acknowledged supporting sustainability and green practices and thus indicated his mindfulness of the environmental stewardship of adopting solar technology.

Both of the electric cooperatives attributed environmental stewardship as motivating the majority of their customers to adopt solar technology. According to the Rural Co-op, environmental responsibility seems to be the main motivation for their customers. Since they have relatively low priced energy in their area, environmental stewardship emerges as the primary motivator. Their solar customers are slightly older and have lived in their houses longer. While they want to supplement the power they buy from the utility, they also feel it benefits the environment. The Suburban Co-op echoed these same thoughts. He has spoken to many customers who adopted solar technology because of their passion for passionate about doing the right thing environmentally and thinking it will help combat climate change. He added that he sees environmental stewardship as a bigger motivation in urban areas.

The Energy Consultant spent significant time discussing the negative impacts of current energy production on our environment and, subsequently, promoting solar adoption for its positive effects. He argued that the U.S. is using non-renewable resources, like coal, to generate the majority of our energy. Burning coal, a major source of electricity generation, is a dominant source of carbon dioxide and a major factor in 
climate change. He cited numerous effects of climate change that include an increasing number of severe storms, changing weather patterns, and rising ocean levels. Moreover, increasing ocean acidification could begin destroying coral reefs. He also discussed the food web and explained how polar bears could become extinct due to the Artic Ripple Effect caused by climate change. Additionally, he named a number of adverse health effects from climate change and related them to increased health care spending in the U.S. He further argued that reducing the use of coal lowers levels of carbon dioxide, sulfur dioxide, nitrogen oxide, airborne particles, carbon oxide, mercury, and disabling neuro-toxins, all benefits to humans, wildlife, and aquatic creatures.

Additionally, the Energy Consultant warned of the harm associated with nuclear power, natural gas, and other methods of energy generation. He questioned the safety of nuclear power and the shift from coal to natural gas, a methane-producing, nonrenewable resource. Methane is playing as much of a role in climate change as carbon dioxide. Moreover, fracking, the process of injecting high pressure liquid into rock layers to extract natural gas from deep underground, is increasing the risks of manmade earthquakes.

The alternative to continued use of non-renewable resources is harnessing free fuel from the sun to generate solar power. Solar generation eliminates the harmful effects on the environment caused by burning fossil fuels and provides an infinite source of power generation. The Energy Consultant, the electric cooperatives, and many of the adopters stressed environmental stewardship as a motivation for solar adoption and the positive impact of solar technology on future generations. In fact, the desire to improve their families' futures became a priority for the adopters. The Surveyor wished to set a 
good example for his children. Being a positive role model was more important than supporting his land surveying business, which serves natural gas and mining companies throughout Southern Illinois. The Father-in-law/Farmer was also motivated by a desire to influence his family. He saw it as a way to get the Son-in-law/Installer interested in the solar industry. He also wanted to be progressive so his children would not think he was stuck in his ways and unwilling to consider new technologies. Being an avid reader exposed him to such technologies, including solar PVs. He was persuaded that the diffusion of solar technology is exciting and worth the barriers and challenges he faced.

\section{Theme Two - Barriers and Challenges}

The barriers for adopting solar technology must be identified to promote PV arrays as an energy source throughout rural America. If overcoming the barriers is too difficult, an individual is not likely to adopt solar technology regardless of his motivation. For this reason, understanding the challenges allows solar advocates to outline strategies for removing the barriers and increasing adoption in rural areas. A thorough review of research indicated that barriers preventing solar technology from being adopted are varied and complex, including everything from technology-based challenges to social and behavioral impacts. Sovacool (2009) referenced historian Thomas P. Hughes (1983), who argued "the generation, transmission, and distribution of electricity occur within a sociotechnical system that extends beyond the engineering realm" (Sovacool, 2009, p. 4503). Sovacool added, that according to Hughes, "large technological systems are simultaneously social and technical or socio-technical” (p. 4503). This type of sociotechnical system includes economic, educational, legal, administrative, and technical considerations. Sovacool further stated that by identifying the socio-technical barriers for 
renewable energy, the system will be visible again and help to understand and implement more sustainable forms of electricity.

Sovacool (2009) explained that socio-technical barriers for the supply and use of renewable energy range from social and cultural influences to political and regulatory factors. A variety of interconnected barriers and challenges lead to the rejection of renewable energy. According to Sovacool, three distinct sets of barriers - economic, political, and behavioral - all interconnect. The economic barriers include financial barriers and market uncertainties. The cost of technologies is often cited as the most common barrier (Sovacool \& Watts, 2009). The political barriers include challenges related to regulation changes, including inconsistent rebates, incentives, and standards. Additional political barriers include underfunded research and development along with varying utility support (Sovacool \& Watts, 2009). Political party affiliation can also be a barrier for embracing renewable technologies; homeowners using solar energy are more likely to vote Democrat (Zahran et al., 2008). Democratic voters are significantly more likely to adopt behaviors that conserve resources and support government policies that protect the environment (Zahran et al., 2008).

Behavioral impediments result from not understanding the fundamentals of electricity. According to Sovacool (2009), barriers originate from a feeling of entitlement to cheap and abundant sources of electricity. Social and cultural factors impact these barriers, often affecting how consumers of electricity react toward changes in utility rates and alternative energy options. Factors can include attitudes toward RETs in an area or utility practices that safeguard fossil fuel use for power generation. Sovacool added that utility customers can more easily ignore renewable energy systems if suppliers do not 
give accurate electricity pricing when comparing standard rates to the costs of solar generated power. He also argued that policymakers should focus their attention on helping the general population better understand energy systems. Instead, policymakers often focus on increasing utility system efficiency and capacity when they should be challenging set utility practices. Requiring utility companies to address renewable energy options in a standardized approach would provide customers with a clearer understanding of their utility company's renewable energy policies and incentives.

Similar to the literature, the data also revealed a variety of barriers, some obvious and straightforward, others more complex in nature. The MO Division of Energy pointed out that not much has changed in the past six to seven years in residential barriers for solar adoption. Potential adopters have to consider the upfront costs of installing a PV array and determine if the physical location and weather conditions are conducive to maximizing electricity generation. These decisions often determine if a potential adopter further investigates installing an array.

Upfront costs. Unfortunately, installing a PV array remains too expensive for the average homeowner even though the cost is roughly half what it was five years ago. At the time, the cost made solar technology unappealing to even the adopters, who indicated they started considering solar adoption several years before finally installing a system. Multiple utilities confirmed that cost remains a barrier for many potential adopters in spite of an expressed an interest in RETs by a large number of utility customers. Both the Generation Co-op and the Suburban Co-op reported their customers' willingness to support renewable energy and solar adoption based on survey results of all utility customers in their respective cooperatives. 
The Generation Co-op reported that they have surveyed their utility customers every three years since around 1988 . He stated:

... and the cost is number one. And reliability is number two, and way down on the list or way down percentage wise below that is clean, cause that's a question we ask, “Are you concerned with clean power?” (Many) claim yes. "Will you pay more?" No! I want clean air, but I don't want to pay anymore. I can't afford it. He said having clean energy does not matter if the customers can neither afford it nor perceive it as reliable. They have customers who are struggling to pay their bills and worrying about their next meal, so for these people, clean energy is not important.

The Suburban Co-op shared similar thoughts. He said they had most recently surveyed their customers in 2012 and 2014 and found that $69.9 \%$ of those surveyed only care about a utility bill that is as affordable as possible. They are not willing to pay another penny towards clean energy. He reported $22 \%$ said they would be willing to pay \$15 more per month to support solar generation, but they currently only have 55 customers who have installed their own PV array and 59 customers who have signed up for their community solar program. He stated that many customers ask about their community solar option but are not willing to spend the money each month to be enrolled.

When first researching the costs of solar systems, many of the adopters discovered that the upfront costs would exceed what they were willing to invest. Unfortunately, financing a system does not always make economic sense because the return-on-investment can be too long. Most of the participants agreed that the application of solar technology is limited because the average homeowner does not have the funds 
available without financing. Most homeowners are reluctant to finance a system when the payoff can vary. The Farm Matriarch stressed, "The important job is having the money to do it." The Firefighter revealed that needing to borrow money to install his system would have been a barrier. The Engineer felt that the potential adopter has to be able to afford the upfront cost out-of-pocket for the installation. He stated:

You've got a couple with a mortgage, two kids, getting by, saving a little bit for college, whatever. You tell them they're going to have to go borrow the money...the commercial rate is...I don't imagine...less than 5 or $6 \%$. That's the end of the story. It's just ain't going to work.

However, this demographic is slowly changing to some degree.

The Buy-American Consultant argued that adopters are no longer just affluent homeowners. This shift resulted from the cost PV installations falling by half and funding opportunities increasing in recent years. Banks and realtors are recognizing that PV arrays are adding value to homes. The Young Adopter financed his system through the GreenSky Program and the Surveyor borrowed at a low interest rate on a home equity line of credit. However, the Young Adopter admitted that the cost of a PV array presented a barrier when he first started considering adoption. He, as well as the Farm Matriarch, recognized that the upfront cost remains the biggest barrier for many people. The Fatherin-law/Farmer revealed that borrowing the money to install his array on a line of farm credit was not an issue because he borrows heavily to operate his farm. However, he has not added more panels to his array because the profits from farming have been low for a few years. He explained that while he was willing to finance his system, many people living paycheck to paycheck cannot even consider adopting solar technology. 
The Rural Co-op confirmed the Father-in-law/Farmer's observation; many of their utility customers live paycheck to paycheck and lack the necessary upfront capital. The Generation Co-op described these same customers as a lower income population, making under $\$ 70,000$ or even $\$ 50,000$ annually per household. He said the demographic of their customers, in addition to the price of PV arrays, created barriers for adoption in their energy market. He stated, "I think it's price and then demographics." The Rural Coop added:

This is a lower income area, and I think that's a contributing factor. One of the bigger contributing factors more than likely is that a lot of our members (customers) can just get by month to month and don't have the capital necessary to even invest in the small system.

Regardless of whether an adopter has the full amount available or finances the system through various means, many of the participants recognized a common demographic among adopters. The Son-in-law/Installer noticed that most of his customers are middle aged or older, and the 70's Solar Consultant said, "Almost everyone is over 40 because they've built up a little equity in their home. They got a little bit of money." The Suburban Co-op acknowledged that their solar customers are upper income with no financial issues. The Generation Co-op shared the sentiment in saying adopters have the financial ability or the credit rating required to borrow to install a PV array.

The Rural Co-op has seen utility customers willing to spend their retirement on a system. He stated that the adopters he has visited tend to be older with a tax liability large enough to see the benefit from an investment tax credit. The Generation Co-op and the 
Suburban Co-op stressed that potential adopters need a tax appetite beyond just receiving a federal rebate, meaning adopters have enough taxable income to benefit from the depreciation on their investment.

The Rural Co-op noted that solar installations increased for a period when federal government threatened to phase out the investment tax credit. The Suburban Co-op saw that solar adopters benefit the most financially by taking advantage of the federal tax credits and accelerated depreciation. He clarified that only farms or businesses can use the accelerated option to fully depreciate their solar investment for the full advantage. Residential adopters still earn $30 \%$ federal tax credit but cannot deduct the depreciation cost. The Suburban Co-op reported having one solar customer who installed a PV array on a carport for two rental properties. The property owner can fully depreciate the array since it powers rental units in addition to earning the tax credit. Moreover, he markets the properties to environmentally conscious renters by highlighting the solar panels.

The Surveyor boasted about taking advantage of the federal and Illinois state tax credits but complained the IRS taxes him on both rebates. He filled out a tax form for the State of Illinois to ensure his real estate taxes did not increase. The Suburban Co-op contended that many customers are most interested in the $30 \%$ federal tax credit; these tax credits have been a motivation for many solar adopters according to the BuyAmerican Consultant. In addition to the Surveyor, the Firefighter, the Farm Matriarch, and My Dad's Friend stressed the importance of the $30 \%$ tax rebate, which lowered the cost and the out-of-pocket expense. Understandably, the Generation Co-op warned that the declining federal tax credit in 2019 might have a negative impact on solar adoption. 
The Energy Consultant reported seeing some consistency in the demographic older individuals with money wanting a tax break. The Young Adopter is the exception from more than a dozen adopters I interviewed for this study and earlier projects who does not meet the demographic described. He is only 23 and lacked the upfront capital, but his strong desire to save money through energy savings motivated him to finance the system.

If homeowners do have the upfront capital available or are willing to finance the installation, they have to evaluate their return-on-investment by considering the projected payback period. Spending money to make money on a solar investment of $\$ 20,000$ or more can be difficult for most people according to the Son-in-law/Installer. The Rural Co-op estimated that a potential adopter may need closer to $\$ 30,000$ or even $\$ 40,000$ to install a system. In considering their return-on-investment, the participants had to accept that a PV array may not increase the value of their home or property, making the approximately $\$ 200$ per month savings unappealing to some homeowners according to the Son-in-law/Installer. The Installer/Consultant recognized that many homeowners do not live in a house over eight years. If the projected payback for an array is ten years, those homeowners never see the true financial benefit of producing electricity. Thus, marketing a strong return-on-investment is difficult knowing the payback period can be longer than some homeowners reside in one location.

The Son-in-law/Installer pointed out that explaining the payback remains the hardest part of selling solar systems. Many of the potential customers are not sophisticated enough to compare anything but the initial costs according to the 70 's Solar Consultant. The Surveyor admitted that even his uncle worried about the length of the 
payback at first. Additionally, the Rural Co-op warned that the maintenance of an array or the replacement of any components that may fail in the first 15 to 20 years is not always included by installers in the payback estimate.

Physical location. As previously noted, the geographic location of a potential installation results in vastly different state regulations, statutes, and incentives. Additionally, the physical location for an array determines its optimal generation capacity. Unfortunately, a roof mounted array does not work well on every house or building. An adopter must consider the orientation of the house, slope of the roof, and possible shading on the panels according to the IL-MO IOU. The Son-in-law/Installer stressed that having no obstructions and shading are major challenges to overcome. Installing panels on roofs in neighborhoods can be a challenge because of shading issues from surrounding houses. Additionally, putting panels on an existing roof can be problematic if the slope is not ideal. The Energy Consultant summarized many of the challenges in locating panels. He stated:

So the hurdles to overcome: unshaded structure, which we have a lot of in rural communities; ample structure size, which you don't have a lot in rural communities; structural integrity, which we don't have a lot; surface readiness of structure - well better be ready to replace that roof!

As the Installer/Consultant noted, the easy installs without obstacles are completed first. Many of the participants described their own concerns for installing solar panels on a roof. The Networker stated that many homeowners might not want something else on their roof to worry about. The Energy Consultant added that homeowners should have a very recently installed roof or be willing to invest in a new roof, an increase to the cost 
of their solar system. He needed a new roof, so it made sense to install his PV array at a time when state rebates were available in Illinois. The Young Adopter recognized that replacing a roof to install solar panels could be a barrier for many people. Both the Sonin-law/Installer and the Rural Co-op warned that re-shingling becomes more expensive when panels are installed on an existing roof because the entire PV array has to be removed and reinstalled.

Adopters frequently decide on metal roofs because panels can be fastened without the penetrations necessary for shingled roofs. The Father-in-law/Farmer shuttered at the idea of screwing panels into a shingle roof. The Engineer expressed emphatically a similar concern, “You ain’t puttin' holes in my roof. You ain’t going to cover up my shingles. I ain't going to take it all down and re-shingle. It ain't happenin'!" The Western MO IOU also cautioned that many people do not want more roof penetrations because of the threat from tornadoes, hail, and high winds.

Other challenges with installing solar panels for a roof mounted array are having the correct slope and not having too many obstructions on the roof. The Energy Consultant highlighted the fact that many older homes in rural areas have steep roofs. The MO PSC expressed her desire to adopt solar technology but revealed that her house's steep roof is not conducive to solar panels. Additionally, many roofs do not have enough surface area because they have obstructions like valleys, hips, and dormers according to the Son-in-law/Installer.

The Engineer did not want the holes necessary to mount panels in his roof, so he decided on a ground mounted system. That meant clearing a one-acre site, a decision that added significant costs. He faced clearing and grading the hillside as well as adding more 
base rock to level the site. The slope of the hill still impacts the array as it casts a shadow on the panels in the morning. He estimated that it limits his solar production by one hour each day (see Image 15). While a ground mount system can be a good option for utility customers who live outside of town, the Father-in-law/Farmer recognized that most other homeowners do not have enough room around their house without putting the PV array on their roof.

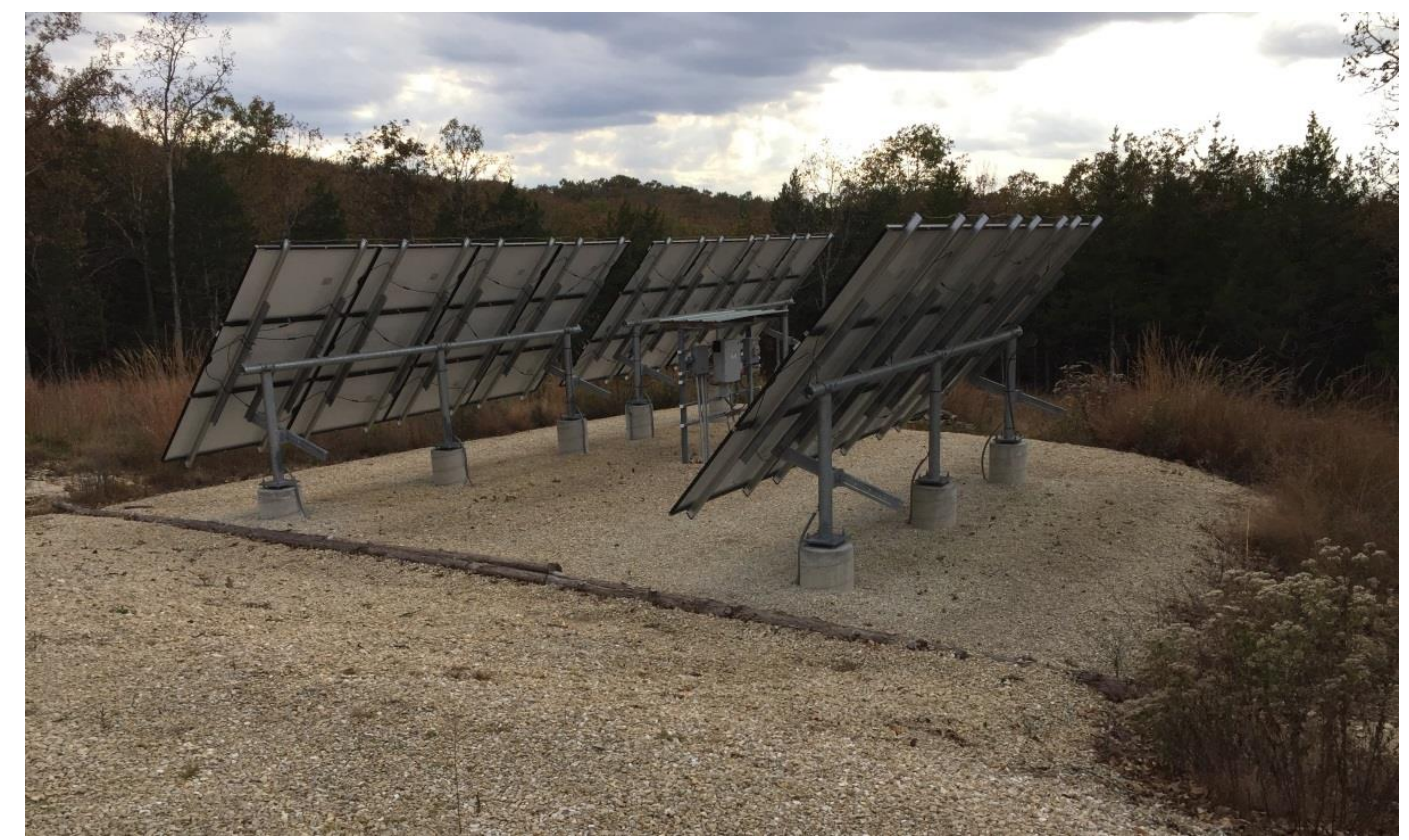

Image 15. The Engineer's PV array on an adjustable racking system

Another option, in addition to a ground mount, for farmers and rural homeowners, is installing the PV array on a garage or agricultural building such as machine shed. However, these installations are not without challenges. The Son-in-law/Installer talked one potential adopter out of placing panels on an old garage. He also said some machineshed manufacturers do not want solar panels placed on the roof. The Son-in-law/Installer knew of one farmer who hired an engineer to approve placing the panels on the roof to ensure the truss manufacturer would not void the warranty. The Father-in-law/Farmer 
added that some truss manufacturers do not recommend placing solar panels on the roof even though panels only weigh approximately 50 to 60 pounds each. He checked the loading limits for the trusses with the manufacturer who had constructed his machine shed a few years earlier, but he never got an answer. He was left to assume the manufacturer was not worried about the extra weight.

If an array is being designed for an existing house, not only do the direction and slope of the roof have to be considered, but the energy efficiency of the home must be considered as well. Having an old home can be a barrier because of its lack of energy efficiency according to the MO Division of Energy. Most energy experts recommend that homeowners conduct an energy assessment before installing a PV array. The $M O$ Division of Energy insisted that inefficiencies should be addressed first through an energy assessment. If the house is too inefficient, generating solar energy does little to offset the energy being wasted. The MO Division of Energy recommends making upgrades first. However, improving the energy efficiency of a home could reduce the size of an array or increase the payback period for a solar customer according to the MOPSC. She warned that some solar consultants might not promote energy assessments for that reason. The Suburban Co-op admitted they encourage customers to make their home more energy efficient versus adopting solar technology. In fact, the $I L-M O I O U$ cited increased energy efficiency as a reason for less solar growth.

The weather conditions and other challenges from nature also vary depending on location, thus impeding installation. Natural conditions such as hailstorms, lighting, heavy snow, or excessive dust all present barriers. The weather causes big changes in the energy production from an array. They perform at optimal levels in cold, sunny 
conditions. As the Municipal Utility indicated, renewable energy technologies often perform best in geographic locations with fewer people. While this holds true for wind power, it is not always the case for solar power.

Inconsistent regulations and incentives. If costs are affordable and conditions are favorable, the barriers become more complex. Potential adopters must address inconsistencies in policies and regulations at the state and local level along with fluctuations in available incentives. While incentives help offset costs and initiate interest, state statutes often directly impact them. For this reason, inconsistent rebates and tax credits can cause frustration in pursuing solar adoption. Additionally, local regulations vary greatly between utilities providing service to a location. Depending on the remoteness of a location, limited resources and knowledge may slow solar penetration. Rural areas also often take a wait-and-see approach to advances in technology. However, as the technology and the industry have evolved, more requirements and changes have added to the complexity of interfacing with utilities. Sometimes overlooked requirements like additional insurance coverage further complicate the challenges facing potential adopters and increase the costs.

Differing regulations from state to state impact varying installation and permitting requirements in addition to inconsistent energy credits and incentives. The MO Division of Energy acknowledged meeting the State's regulations can be a challenge. An installer not familiar with the regulations in an area can cause significant delays. Coping with changing regulations creates more difficulties according to the Energy Consultant. The Installer/Consultant acknowledged the lack of consistency from state to state, between utilities, and even among municipalities. For example, some states require a person to 
own his property. Since renters cannot install PV arrays in these states, it excludes many possible installations. The Buy-American Consultant explained that often inconsistencies within a state from one area to another depending on the utility type introduces a challenge. She has been talking to her Illinois state senator about the issue of inequality of access to solar power in the State.

Navigating the building permit process and certifying PV arrays with the utility company create another hurdle, especially if the utility or municipality is not very familiar with solar technology. The building permit requirements often differ greatly, although they are a bigger issue in large urban areas. Sovacool and Watts (2009) advocated streamlining the permitting process for all locations to integrate the planning requirements and speed up the construction of renewable energy technologies. The Father-in-law/Farmer warned that increasing permit requirements would create more of a hassle and slow down adoption. The Surveyor also cautioned that certifying a PV array with a utility company before they allow it to be energized can be a lengthy and frustrating process. It is important to recognize that inconsistent regulations and cumbersome requirements can quickly turn burdensome in offsetting the incentives for solar adoption.

While incentives and energy credits usually act as positive factors for solar adoption, they too can cause frustration by acting as a barrier. Incentives do offset the cost of installing an array and make it affordable to more people, so when the incentives are limited or phased out entirely, the expense challenges potential adopters. In fact, most incentives face uncertainty in the future. The Energy Consultant expressed frustration in 
coping with changing incentives. The federal government, in general, has been unpredictable in tax credit promotion for renewable energy resources (Sovacool, 2009).

Since Missouri already phased out its rebates, the Installer/Consultant divulged the lack of incentives greatly reduced the interest there. The 70's Solar Consultant also attested to the decline of solar adoption in Missouri when state rebates ended. The $M O$ PSC explained that the State's rebate decreased the value of a PV array from $\$ 2$ per watt to 25 cent per watt until it expired completely. Missouri is just one example of a state already feeling the effect of lost incentives.

Many other states are also trying to pull back incentives to control the amount of solar adoption. Utilities in these states are finding it challenging to keep energy rates at current pricing because solar adopters are benefiting from grid connection without paying higher service fees. For this reason, utility pools such as the one to which the Municipal Utility belongs often do not offer energy credits, incentives, or rebates. The Municipal Utility's pool does offer credits for producing excess energy, an incentive not offered by many utilities.

Incentives maintain interest in states such as Illinois where the Installer/Consultant reported installing the majority of their systems. However, the Energy Consultant warned that Illinois's rebate program is running out too quickly. Their initial rebate's expiration in 2013 kept him from doing more solar installations. The rebates went to a lottery system in 2014; he did not have any projects selected. The Surveyor also bemoaned Illinois's reduction in solar rebates. He expressed concern too that solar adopters are taxed on the state and federal rebates. Being taxed on the rebates means adopters need a taxable income to take full advantage of incentives according to 
the Energy Consultant. Retirees and not-for-profit entities in addition to many small businesses not making a profit do not benefit from income tax credits. He stated, “...you got a lot of lower income people here (Southern Illinois). You have a lot of retirees here. You got a lot of small businesses that aren't making a profit - cannot benefit from that $30 \%$ federal tax income credit." Additionally, he revealed that taxes have to be paid on any power generated by individuals and solar installers.

Utility differences. In relation, conflicting factors for various utility types investor owned, cooperative, and municipal - are creating challenges for solar adoption. Each type of utility has differing regulations, rate structures, and priorities, which create a complex situation in the promotion and regulation of solar adoption. Differences between utility types are discussed in detail under Theme Three - Electric Utilities. Differences include the utilities' structure, operation, and economics. Variances also occur in how the individual utility diversifies its energy portfolio and schedules customers' power usage. Each one of these factors influences the utility's support for solar adoption. However, a number of challenges that solar adopters face result from utility companies' approach to and management of solar power. These challenges need to be viewed in their relation to other barriers for adoption.

At the same time, some resistance by utility companies exists because they worry about more penetration on the grid from solar power. The Municipal Utility expressed concern about increased solar penetration to non-adopters. The Western MO IOU declared that a small segment of their customers benefit from solar adoption, but everyone pays for the added expense of billing and other operations necessary to integrate solar power into their electrical load profile. The Western MO IOU reported 
doing their solar customer billing manually, which is adding additional work. They bill customers based on PV Watts and have used the expertise of other investor-owned utilities to set up their databases for solar customers. She said the organization is still struggling to do it by hand, and this chore impacts a large number of personnel. They need an electronic system of billing to support solar customers, but even their new parent company does not have an automated process in place. She admitted that initiating their solar rebate program quickly has caused some growing pains for their billing and maintenance operations. She also expressed concern that not all solar customers are always metered in the same manner. This topic is further discussed as it relates to cost recovery for utilities under Theme Three - Electric Utilities.

Since utilities are maintaining the grid for every user, they want to manage the amount of solar power produced. Some lower what they pay for excess electricity generated with solar technology. Several states, like Missouri for example, no longer pay for excess electricity. In many cases, utilities are limiting the size of an array that customers can install. If a customer chooses to install a larger array, the utility company does not purchase any excess electricity generated. The MO Division of Energy stressed that determining the value of excess solar generation is an issue that needs attention.

Utility companies also face the challenge of differences between the peak production of solar power and their load profile according to the Generation Co-op. For example, the low solar production at 7:00 AM. does not correspond with the peak demand at the same time when people get ready for work. Solar power peaks from about 2:00 PM until people come home from work, so it does not match the load profile when people are using the most electricity. He stated, "Everyone assumes that solar is 
advantageous to me from a peaking capacity standpoint, and that couldn't be further from the truth."

All interviewed adopters expressed similar thoughts on what they perceived as a resistance to solar adoption by utility companies. My Dad's Friend, the Father-inlaw/Farmer, and the Surveyor all reported knowing of utility cooperatives that were limiting the size of PV arrays. My Dad's Friend suggested cooperatives are limiting the size as more people adopt solar technology, but he reported having no issues working with his cooperative. However, the Farm Matriarch expressed immense frustration with the same cooperative and said they were the most difficult to work with in the area and provided little help or instruction on the installation process. The cooperative would not provide the necessary information when they were ready to turn on the system.

Cooperatives are against solar adoption, in her opinion, because they lose money by customers generating their own power. The Son-in-law/Installer agreed, saying that since PV arrays are reducing the revenue, many utilities are "dragging their feet." The Farm Matriarch also expressed frustration that the cooperative does not pay for the excess electricity her farm generates. My Dad's Friend shared a similar concern; he is losing energy due to the cooperative only allowing customers to carry over excess power for up to three months. In addition to size limits, cooperatives may be discouraging larger arrays by not paying the full value for the excess energy produced over 10 kilowatts according to the Firefighter. The Son-in-law/Installer expressed concern that cooperatives are greatly impeding farmers' motivation to adopt solar technology by limiting the size of arrays to 10 kilowatts. 
Cooperatives are seen as less friendly to solar adoption than investor-owned utilities or even municipal utilities. The Networker attributed this reputation to investorowned utilities often exhibit more forward thinking. She also recognized that municipal utilities usually have less expertise in solar technology. As a result, municipal utilities may give city councils unfavorable information on solar adoption according to the 70 's Solar Consultant. The MO Division of Energy has noticed that many cooperatives not only lack expertise but also have little experience in designing solar programs for their customers. Furthermore, if customers do not ask the right questions to cooperatives lacking experience with solar technology, these potential adopters are faced with yet another challenge. The MO PSC added that further confusion results when solar vendors or installers do not understand the utility rates and do not communicate well with the utility companies. As a result, customers do not understand what is involved in the process. The MO Division of Energy noted, however, that having a big solar customer like an agricultural producer makes a cooperative consider solar adoption more seriously. The 70 's Solar Consultant sees cooperatives as more difficult. They process paperwork much slower, perhaps as a means of discouraging PV installations according to the Son-in-law/Installer. The Installer/Consultant has started installing the system first before contacting the cooperative because it takes, on average, two weeks for the paperwork to be processed. The Son-in-law/Installer reads this delay as a reluctance by those cooperatives to have individuals generate power independent of utilities. He also shared that the Installer/Consultant strives to maintain a good working relationship with the utilities in the area to expedite the approval process as much as possible. However, he shared an example where they had a contentious start with one cooperative because they 
went slightly over on the kilowatt amount the array generated. The solar panel company ran out of one type of panel used on the project. They were forced to finish using a few panels that generated more electricity. The cooperative was upset because the array produced slightly more than the limit.

The Son-in-law/Installer also raised other concerns. He warned that rural utilities might resist solar adoption more if too many farms generate power and push their excess to the utility grid. He described a second hidden issue for customers with geothermal systems that have a much lower utility rate because of the energy savings. However, solar adopters can be charged at a higher, standard rate for any energy they use above what is generated by their PV array. He stressed the importance of explaining this disparity to potential solar adopters with geothermal systems.

Inconsistent policies between investor-owned utilities and cooperatives creates an issue in many areas, like Central Illinois where the Father-in-law/Farmer lives and farms. The Firefighter even attested to inconsistencies among different cooperatives' policies. The Buy-American Consultant shared that only investor-owned utilities are regulated, which is exacerbating the issue. No means of publicly regulating municipal and cooperative utilities exist. The Surveyor agreed, saying that deregulating utilities gives them the ability to resist solar adoption. Additionally, the Buy-American Consultant feels the power providers, the Generation Co-op would be an example, have negatively influenced the municipal and cooperative utilities because they just provide power distribution to customers.

The Surveyor reinforced this concern, stating the utilities' control of energy generation remains one of the biggest barriers for solar adoption. This control of power 
generation and distribution allows them to maintain their control of the energy market. The 70's Solar Consultant stated:

The utilities do not want solar. They have a monopoly of power. They're happy to do solar if they produce it and sell it to you, and they continue to make their profit. Distributing solar is what they're dead set against because that puts power in the hands of the customer, or in the hands if you have your own power plant (a PV array). You don't need them for energy because you have your own power plant. They're very against net metering. They're only happy with solar if they control it. They don't want to lose control. They like their monopoly.

The Surveyor agreed, “The utility companies don't want to lose the grip they have on that energy. I mean they have a monopoly..." The Renewables Advocate recognized that monopolies for utilities in the state sanctioned by the Missouri government have been established for 105 years. In 1913, it was not practical for everyone to install their utility lines, so the government authorized utilities companies to control the utility grid. As the Networker sees the situation, most utility customers want to stay connected to the utility grid for security, so the utilities have the control.

The MO Division of Energy attributed the cause for some of the inconsistencies in policies and regulations to a disparity in the value of solar energy between the various utility types. The solar value appears different for investor-owned utilities versus cooperatives because the investor owned have generation facilities. The cooperatives just buy and distribute the power, reducing their value of solar energy. The Buy-American Consultant reiterated that determining the value of solar energy is much different for investor-owned utilities who generate power. The 70's Solar Consultant stressed that 
investor-owned utilities do not want to lose their ability to generate power and cooperatives do not want to increase the amount of distributed solar energy. As utilities maneuver to keep from losing profit, rifts between the solar industry and utilities are surfacing. He stated:

That's what all the fights are in a lot of areas between solar and utilities. These utilities feel like they're losing customers. They're losing the ability to generate energy. They don't like that. They're for profit. The co-ops are even the worst because...they don't want to empower distributed solar.

He clarified that he thinks cooperatives are the worst about fighting customer PV installations.

Miscellaneous requirements. Potential adopters may overlook other unexpected requirements. The Engineer highlighted the requirement of carrying liability insurance per the utility interconnect agreement. Because of the risk of a PV array back-feeding power to the grid during an outage if the emergency cutoff switch fails, utilities require solar customers to carry liability insurance. The Engineer was faced with a \$1 million general policy in addition to a $\$ 3$ million liability policy. Since his system produces less than 10 kilowatts, he was only required to have liability coverage on his standard homeowner's policy. My Dad's Friend reported that he added liability insurance because his electric cooperative required it even though his insurance company was not familiar with the requirement. Luckily, his rates did not increase significantly. Similarly, the Surveyor only had to increase his homeowner's policy by $\$ 300$ each year. His uncle’s insurance increased $\$ 1,100$ per year in proportion to the larger array for his farm. However, the insurance company did not limit the size of an array they would insure. The 
Father-in-law/Farmer was only required to increase his insurance on the machine shed where he mounted the PV array.

The Energy Consultant was familiar with some electric cooperatives requiring over one million dollars in liability insurance. The higher rates are especially true for larger arrays producing over 10 kilowatts. The Western MO IOU sees some insurance concerns with the larger systems selling power back to the grid. Understandably, this added insurance is creating confusion for some potential adopters in the Western MO $I O U$ 's territory. These insurance requirements for larger systems, therefore, can limit the extent of solar production by an individual according to the Engineer.

In addition to insurance coverage, increasing safety requirements must be addressed during research, design, and installation. The Municipal Utility explained that fire departments are reporting safety issues during fires. Often firefighters must go into a building through a roof, so panels may get damaged. The question of whether the panels are still generating power and feeding it back to the system during a fire also concerns building code officials. Another concern focuses on the possible contamination to the environment if the panels' enclosure is damaged. Even single panel installations can create safety hazards. The Municipal Utility expressed concern about homeowners who buy a single panel to experiment with solar power. Not only does plugging a panel into the wall create a safety hazard if it back-feeds power when the grid goes down, but it is also illegal because net metering laws prohibit plugging in a solar panel without approval by a licensed engineer or electrician. Customers, especially in rural locations, often buy one panel to generate a small amount of power. Along with the issue of legality, one panel does not provide a good return-on-investment because the amount of energy 
produced does not save enough each month to offset the cost of the panel over a short enough period.

Since one cannot just purchase panels and plug them into the utility grid, individuals have no easy opportunity to adopt solar technology without finding a consultant or installer. However, working with a trustworthy installer can also be a barrier to overcome. None of the adopters reported any issues with the installers they used, but the Suburban Co-op said solar technology is misrepresented in some situations. The Engineer warned of some installers, stating, "...the shyster could be a problem, but as long as you had this local guy that was doing and selling it to him, you cut down on a lot of that." The Western MO IOU mentioned hearing of a few instances where installers did not deliver on their promises. The Municipal Utility even questioned the ethics and trustworthiness of some installers. They stated that dishonest consultants and installers cause problems by sharing inaccurate information. They added, "They might make claims that might inflate the value that a homeowner's going to get. Are they giving you the right rates? Are they giving you the right production curves? We're not the experts in them, but we can see some that are flat out liars."

The Western MO IOU agreed that solar installers are pushing solar adoption in many areas and seem to be creating much of the momentum. Nevertheless, the importance lies in finding a reputable company; sometimes just finding a solar consultant or installer presents a difficulty. The Surveyor voiced concern that finding a registered solar installer in Southern Illinois is difficult. The lack of installers has caused a lack of promotion for solar technology in the area. The 70's Consultant admitted that improving the sales process will increase adoption. The Networker said just being able to 
recommend good installers to potential adopters while outlining the benefits and financing options will help promote solar technology. She also acknowledged the lack of easy access to solar installers or vendors in rural areas, "I think for rural areas, it's just not having people handy who could help you understand it and help you understand the value of it." She further explained that not having someone local to consult about adopting solar technology slows the dissemination of information. A knowledgeable consultant can help a homeowner more easily understand solar technology and assess whether the homeowner's house has the optimal roof slope and orientation.

Consultants can also help potential adopters understand the value of solar technology and the impact on their utility bills according to the Networker. However, caution should be employed when working with a consultant or installer to assess the value of a PV array. For example, installers sometimes figure 7 to $8 \%$ inflation when calculating the payback period. The Generation Co-op admitted the importance of considering the inflation in energy rates but insisted that many assumptions are made in calculating paybacks. Therefore, the potential adopter must ask what rates were used to calculate the payback amount. The Suburban Co-op argued that utility rates have only increased 2 to $3 \%$ each year over the last 40 versus 7 to $8 \%$ quoted by some installers.

The Western MO IOU added that access to solar support after installation is critical, but sometimes difficult to find in rural areas. She sees the proximity to solar support and repair services in rural areas as a barrier in need of improvement. She admitted, however, that with programs like the Alternative Energy Program at Crowder College in Southwest Missouri, support should continue to improve in rural areas. She 
stated, “As more people have good experiences, I think it will help as they see that support structure or if they have an issue."

Consultants and installers face several challenges of their own that add to the slow adoption rate of solar technology. The Energy Consultant shared several concerns he has with installing PV arrays. First, designing a solar system can be time consuming and complex. Deciding where to locate solar panels involves everything from assessing a site and determining the solar potential to evaluating a customer's preferences and budget. Every job is unique and requires extra work with hurdles to overcome and unforeseen problems to solve. Second, he finds it difficult to make a profit on solar installs because of the many factors to consider. Additionally, several trades and trained professionals are involved, including designers, structural engineers, electricians, and excavators, most of whom must have a good understanding of the National Electric Code. Third, installing PV arrays can be both physically demanding and dangerous when completing tasks like trenching electrical lines, digging holes for footers on ground mounted arrays, mounting panels on roofs, and working around high voltage electric. A thorough energy assessment, which often involves crawling under a house or climbing in an attic, is also demanding work. Finally, the liability concerns some consultants. The Energy Consultant carries a million dollars in professional liability insurance for just his solar projects to protect his business. The Buy-American Consultant expressed nervousness about labiality concerns, especially for the projects where the homeowners completed their own installations. Luckily, no issues have ever arisen.

Consultants and installers are also facing other challenges as the solar industry evolves. These challenges include increased installation requirements and prolonged 
delays during the procurement process. Because of added requirements, installers sometimes need more time to design and install solar systems. Additionally, as PV arrays become more widespread, solar technology has advanced, but components are taking longer to procure according to the Energy Consultant. The Engineer warned that panels and sometimes other elements often have long lead times. Usually, extra time is needed to procure and install components if an array has to be customized, especially with ground mounted systems.

Even though solar technology is advancing and components are improving, these changes do not always increase adoption. Many of the participants waited beyond their initial interest to see how the industry and the technology would advance. An increasing number of components included in a system has also added to the complexity of the technical connections between arrays and utility grids for installers. Furthermore, the cost of these additional components can discourage potential adopters as installation prices increase.

Solar products. In an effort to reduce cost, many solar installers are importing panels and components from China and other foreign manufacturers for cheaper priced solar products. The Buy-American Consultant explained that importing solar products allows installers to buy at a lower price but sends most of the solar manufacturing jobs overseas. She lamented, "It's all because of developers choosing not to do the right thing." She compared it to the electronics industry in the 1980's. She admitted that many American solar companies have been driven out of business trying to compete with Chinese companies. She stated: 
They (Solar World AG) went bankrupt trying to compete against the Chinese, trying to keep their pricing down at a level they could compete. Solar World Americas, which is the Oregon factory, is still operating; still producing modules; say they will continue to do so. They're looking at possibly having to do layoffs though just to be able to be competitive.

The Networker added, “... when you see what China did, they undercut everybody. They lost money so that they would have the market."

The IL-MO IOU acknowledged that most installers buy the least expensive panels to keep costs down. As an example, the Surveyor admitted using foreign made solar panels on his own array because he wanted the cheapest available while ensuring the manufacturer was stable enough to provide a reliable warranty. He used three different brands for each of the arrays that he installed. He did use American made panels on his uncle's array because the Buy-American Consultant was involved. The Buy-American Consultant has always specified American solar products and feels it is the right thing to do. She stated, "I was offering...American made products, which I always have. So being able to keep my overhead low allows me to be able to do that and still remain competitively priced.” She has never considered switching to foreign products. She added, "It was about doing the right thing, for the right reasons, for the right people." The Buy-American Consultant argued that placing tariffs on foreign solar products does not have to be devastating to the U.S. solar market if installers are willing to use American products at a slightly higher price. She debated with one of her competitors that a Buy-American initiative does not have to be devastating to the solar 
industry. She admitted that increased project costs might have a negative impact unless consultants explain the difference in quality. She stated:

But it's not devastating to the industry. People might have to pay a little more.

But I think that when you take the time to sit down and talk to people about what that means and to educate them again, that they get it. Yeah, I'd rather support American companies and American manufacturing.

American solar modules average 62-72 cents versus just 42 centers for foreign manufactured modules according to the Buy-American Consultant. However, Solar World, the oldest American solar panel manufacturer, has been in business since 1975 . The longevity of the company makes their 25-year warranty mean something in her opinion. She stated, "So what I say to consumers is when you're getting a product that has a 25-year warranty, don't you think that you want to have a company that has some longevity to stand behind that?" American solar companies use 80 to $85 \%$ component parts made in the U.S. These factors contribute to a superior quality of American made panels.

At the time of the interviews, Suniva, an American solar panel manufacturer, had already filed a complaint with the U.S. Attorney's office asking that tariffs be placed on Chinese panels. Since that time, the current administration imposed a 30\% tariff on solar panel components; the rate will decline over four years (Gonzales, 2018). Solar manufacturers are applauding the move while installers worry it will eliminate jobs. The Installer/Consultant has been specifying Trina Solar, a Chinese company, and Canadian Solar; however, the owners have expressed strong concern about tariffs according to the Son-in-law/Installer. How these tariffs will impact the solar industry is not yet evident. 
Energy storage. While many solar products continue to advance, energy storage technology has not been addressed. The Networker and the Suburban Co-op both expressed concern with lead acid batteries' short life span of only 5 to 10 years along with the large amount of space they require. The expense of replacing batteries every 10 years on average roughly doubles the cost of a solar system. The Suburban Co-op agreed that the technical challenges with solar energy storage prohibits deeper solar penetration in some areas. The Engineer discussed the possibility of increasing solar adoption if the power could more easily be stored. He mentioned substation sized battery banks being developed in the future.

The Suburban Co-op outlined other challenges with using battery backup storage versus being grid-tied. During a power outage, any power being generated goes to the batteries first as well as any critical loads like a refrigerator or water pump. If the panels do not generate enough power, the batteries must supplement the remainder. It takes up to one-third of the power generated just to keep the batteries charged. He argued that it is cheaper to use a generator because of the power lost keeping the batteries charged. He stated, "You're far cheaper to put a generator there and use a generator than you are to try to rely on batteries simply because of all the power that you're losing that it takes to keep the batteries charged." The Rural Co-op also raised the concern of being disconnected from the utility grid. He asked, "I think it's challenging because what do you do if you have a week of no sun, right? Once your batteries are dead, then you're dead."

The Networker noted that having standby power is expensive, but the solar industry is working through technical issues like energy storage. Another reason for the 
importance beyond developing affordable, reliable solar storage is a concern over the condition of the current utility grid. She stated:

So there are the technical issues that they (solar industry) are working through, and energy storage is still a big piece of that. And it's also just the health of the grid, being able to send that stuff (electricity produced by PV arrays) over the current grid for long distances.

Storage capabilities are also needed because of the intermittence of renewable energy. According to the Western MO IOU, this intermittency poses a challenge for utility companies since they must have a companion generation source like a natural gas or a coal-fired power plant that can ramp up quickly. She referenced the high cost of current renewable energy storage. She sees solar energy as a nice addition until storage capabilities improve. Until then, in her opinion, utility companies must have another source for generating power. She stated:

...solar is an adjunct...We aren't a third-world country. We do have hospitals and schools that need power all the time. And I really do see the merit of solar, but I think that we have to get the understanding that it is an intermittent power source, so you have to have the backup, the base load, the capabilities at all times to provide power to everyone. And we all love our power, more and more. Even though many of the challenges for adopting solar technology can be avoided going off-grid, none of the adopters did so. Most indicated an unwillingness to give up the conveniences of being grid-tied. The Rural Co-op stressed the importance of convenience to most people and the grid connection allows solar adopters to still live as they want to live. The Young Adopter expressed an interest in battery backup and a strong 
desire to be self-sustainable but is unwilling to sacrifice comfort and convenience.

Wanting very inexpensive electricity, he has set a goal to be off the grid in five years.

The Son-in-law/Installer recognized that battery technology is still not reliable or cost effective, but he feels it eventually will evolve to that point. He has not installed a battery backup system yet, but he potential adopters frequently ask about the advantages of gridtied versus off-the-grid systems. According to him, many potential adopters are interested in solar energy with thoughts of not relying on the utility grid.

Most solar adopters share the desire to use PV arrays during power outages. The Engineer wants to develop technology that allows panels to be utilized when the grid is down. He wants to design a device that would detect the load being generated continuously and allow emergency backup power without the grid. Unfortunately, solar panels require a power supply to operate and generate power. The $I L-M O I O U$ revealed this common misunderstanding among solar adopters who want to generate power when the utility grid is down. This use cannot work because of Underwriters Laboratory standards, which protect against anti-islanding on the grid from residential generation. Anti-islanding protection on inverters prevents any voltage from being stored on the system. The $I L-M O I O U$ reported homeowners calling their customer service group to ask why their PV array was not working when the grid was down. Many solar adopters have installed a back-up generator for times when the utility grid is not in service. $M y$ Dad's Friend installed a backup generator when his house was hit by a tornado several years ago and now uses it when his panels cannot produce power because of power outages in the utility grid. Other than purchasing a generator, installing a battery backup system is the only option. 
Fossil fuels. The price of power currently being generated compared to the price of solar energy and its return is much lower according to the MO Division of Energy. The MO PSC feels the current prices create a financial barrier for adopting solar technology in the Midwest. While energy prices are projected to continue increasing, they currently remain at a reasonable rate in the Midwest. Purchasing fossil fuels at low prices in the current market prevents utilities from being more willing to incorporate RETs into their energy portfolios. The Western MO IOU explained that utilities are resisting solar power as an option because the cost per megawatt consistently stays higher than that of fossil fuels. Those costs prohibit solar power's inclusion in their energy mix. Right now, utility companies are buying coal in Missouri for 4 cents a kilowatt-hour compared to other states outside the Midwest where they sometimes pay anywhere between 8 to 15 cents per kilowatt-hour. The importance of economics in power production factors into the barriers for solar adoption.

The perception that renewable energy will negatively affect American workers and local economies has produced a significant barrier related to fossil fuels. According to the Networker, many rural residents are dismissing solar technology as against the American worker and believe it puts coal miners out of work. The Renewables Advocate views all of the rhetoric in support of the coal industry by the current U.S. President as reinforcement of that attitude. The Networker summarized:

I think there are some who could dismiss it (solar) because, "My brother's in the coal mine. I would be putting him out of work," without realizing that it has nothing to do with solar. But the way you see it on TV, and the way Trump puts it out there, these solar, these renewable energy projects are putting the coal miners 
out of work, which is not what's putting coal miners out of work. But yeah, I think people who have limited news sources, who watch Fox News, who don't get exposed to much, yeah, I think it's easy to say, "Whoa, of course, I would never consider that. That's against the working man!" So yeah.

The Surveyor considered installing a PV array on his office building but faced resistance from his municipal utility because drilling for natural gas and building the infrastructure to support it has boosted the local economy. He confirmed resistance to renewable energy in Southern Illinois where the economy depends on fossil fuels. While he wanted to set a good example for his children by adopting solar technology at home, he realizes that much of his livelihood comes from fossil fuels. He also admitted to worrying about the perception that solar technology is displacing coal mining jobs even though he thinks natural gas will more likely replace coal. He stated:

I mean the sheer number of people that coalmines employ in Southern Illinois; you can't just get rid of them. The number of mines that shut down over the past three or four years around here, if it wasn't for what little oil and gas we still have going on with the low prices, there's nothing in Southern Illinois other than that. The Energy Consultant also recognized that because of an abundance of fossil fuels in the region, coal played a vital role in Southern Illinois's economy until recently. He claimed Southern Illinois has more BTU's of coal than Saudi Arabia has BUT's of oil. However, he voiced concern that the US is going through millions of years of coal and other fossil fuels in roughly 200 years with no means of replacing them.

Similarly, the Son-in-law/Installer shared that many people in his rural community are opposed to solar technology because a coal-fired power plant creates 
good paying jobs and provides a significant tax base for his town. The people against solar adoption think it is hurting the coal industry. He carefully chooses what he says in his community about solar power because of the importance coal plays in the economy of the area. He stated, “In this area, you've gotta be kind of careful. There's people against it (solar). Number one, we have a coal mine. Then we've got the power plant." He added that often, when he goes to the local lumberyard, one of the employees always asks, "You still trying to put my wife out of business?" The man's wife works at the local coal-fired power plant. The Son-in-law/Installer clarified, “He's just joking, yet I know people are thinking that in the back of their minds that solar industry is going to hurt the coal industry and some of the power plants." While he does not want to see the power plant shut down - he did reveal that the utility company has threatened to close it for the last decade because of competition from renewable energy and increased energy efficiency he compared coal-fired power plants to farming 20 years ago. Farmers unwilling to change with improved farming practices and technology have had a harder time competing in a more commercialized market. He predicted that the energy market would evolve in a similar manner. The Farm matriarch noticed an increasing unhappiness with coal. While talk focuses on bringing coal mining jobs back, she recognized the expense involved to reopen coal mines. The Father-in-law/Farmer agreed, going so far as to say the energy market could become saturated with solar power in several years as dissatisfaction with the coal industry increases.

Further opposition to renewable energy is bolstered by the current administration; the administration is advancing an argument against solar adoption, claiming it negatively impacts the coal industry. President Trump has promised to increase coal mining jobs and 
made countless attacks on the solar industry. Additionally, he has discounted climate change as a hoax and withdrawn from the Paris Climate Agreement, a move seen by many as symbolic according to the Renewables Advocate. The Renewables Advocate argued that the decision to not make renewable energy a priority had largely been decided prior to withdrawing from the Paris Agreement. The Networker said the U.S.'s withdrawal horrified many in the solar and renewable energy industries. However, the Buy-American Consultant is not worried about the growth of solar adoption being affected negatively by the U.S. withdrawing from the Paris Agreement. A new U.S. coalition is forming to continue honoring the agreement and contributing to America's part. The Renewables Advocate felt the decision to repeal the clean power plant requirement is more problematic to the environment. The Buy-American Consultant expressed similar concern with EPA clean air and water regulations reversals.

Claims made by the current administration to discount the negative impacts of fossil fuels have affected the advancement of clean energy in countless ways. Renewable energy topics currently face more contention among lawmakers and are becoming more politicized. This trend is even influencing the approach to research. In response to renewables' threats to fossil fuels, government agencies are rejecting grant applications for research funding if they reference climate change and global warming or cite the effects of fossil fuels such as the increased likelihood of earthquakes due to natural gas fracking. Electric cooperatives are also adjusting their energy mix based on the administration's support of fossil fuels. The Generation Co-op remarked that they certainly feel comfortable using coal during the remainder of the current administration. 
Political impediments. Because renewable energy has become politicized, party affiliation has become a barrier for solar adoption. The Energy Consultant argued that political party preference often affects potential adopters' motivations to embrace solar technology. He also added that conservative politicians who do not understand the value of renewable energy tend to represent rural areas. The Networker has observed that legislators usually tow the party lines. The Energy Consultant stated, "Motivation is also affected by political preference. Rural areas tend to be more politically conservative. Going green has been perceived as being in alignment with the Democratic Party and is part of big government programs."

Responses to increased solar adoption are not just happening with the Federal Government. Missouri recently tried passing legislation that would have affected solar adoption significantly. Missouri House Bill 340 would have allowed utility companies to charge adopters additional fees above the minimum monthly amount most solar customers pay by creating a tax increase rate of $75 \%$ for the fixed utility charges. The bill passed the House but failed in committee before it reached the Senate floor. The Networker voiced concern that it would have hurt the solar industry, particularly consultants and installers. Electric cooperatives supported the bill as a way of eliminating what they see as subsidies to solar customers. The Generation Co-op argued that currently only solar customers benefit while other customers ultimately end up paying more. The Suburban Co-op also defended the bill as a means of making solar customers at least pay fixed costs for utility services so non-adopters are not subsidizing their solar adoption. 
The 70's Solar Consultant saw it as a bill sponsored by the cooperative utilities.

He stated:

The co-ops...that's why they wanted a tax - increase the rate by $75 \%$ of your fixed charge for bogus reason basically. They say, 'Well, solar hurts. It doesn't help the grid.' That's just not true. There's been a lot of studies showing the value of solar.

The IL-MO IOU supported the bill too, as revealed by the Renewables Advocate. They, like the electric cooperatives, have the money to lobby against solar adoption. As an example given by the Networker, utilities have lobbied against net metering. The electric cooperatives have also been good at crafting a message against solar adoption that appeals to rural conservatives. The 70's Solar Consultant agreed that utilities have a surplus of money for lobbyists, making utility pushback one of the biggest barriers in his mind.

Encouragingly, many of the participants expressed optimism that solar adoption, while it may slow under the current administration, will continue to advance. The Renewables Advocate concurred:

I don't think that even a Republican President for very long is gonna be able to say, "Renewable energy is just something we're gonna ignore." Right now I think you've got that because you've got a President who has a lot of rhetoric about the coal industry. I don't think it will pass back up that rhetoric very well. Democratic or Republican, you're gonna have to see that change. I think Missouri is gonna have to make a very conscious decision. Are we gonna be someone who embraces 
this as an idea and put energy into it, change our policies to deal with it, changes our laws to deal with it, or are we not?

The Father-in-law/Farmer felt the current administration is not endangering solar technology, and the Farm Matriarch agreed that the administration will not slow down solar adoption for very long. The Networker even declared that the current political environment could be a motivator for people to do something positive and help move solar adoption along more quickly.

Rural resistance. The last major barrier identified in the data was the resistance to solar technology in rural areas. The MO Rural Development defined rural areas as towns or communities of 50,000 people or less. Even though a perceived interest and expressed knowledge of solar technology exists in the rural areas where I conducted the interviews, all of the participants acknowledged differing views. The Installer/Consultant stated that many people just do not believe in solar technology, including some contractors who bid solar projects high just to avoid installing them. These contractors and potential adopters chose to ignore the benefits. However, the factors are more involved than just a dismissive attitude by rural residents. According to the Energy Consultant, rural communities are usually older with larger trees that create shading issues. Also, rural homes are often older and smaller with less roof area and may lack structural soundness. These homes often require the replacement of electrical panels and other components to accommodate PV arrays in accordance with building codes.

Other factors are based on the socioeconomic and cultural indicators of rural communities. The Energy Consultant referenced the income inequality and disparity common in rural areas. The Rural Co-op said in his experience household incomes are 
lower in rural versus urban areas, which is a contributing factor in solar adoption. As an example, the Suburban Co-op stated that most of their solar customers live close to Columbia and have good paying jobs. The Energy Consultant further argued that while more residents in rural areas are lower income, fewer have pursued higher education. However, the Networker stated, “I don't think people are dumb just because they're rural. I think it is more the information and the opportunity aren't being provided where it's an easy thing to do." The Western MO IOU continued by saying, "I do think there's somewhat of a misconception that rural means uneducated, and in our area rural does not mean uneducated. It means well educated, often some of the most. The farmers and the people in our area are some of the wealthier people."

While being less educated may be a factor, the Networker also recognized that being less informed or choosing not to be informed at all about solar technology can make rural resident less likely to adopt. However, she admitted that researching solar adoption - discovering how solar technology works, understanding the installation process, knowing the benefits and challenges along with finding the local contractors often requires great effort in rural areas. The challenge, as she noted, is potential adopters often lack enough easily available information in rural areas, a much different situation than in urban areas where multiple contractors provide resources. Potential adopters in rural areas often need to be strongly motivated to find the resources necessary to pursue solar adoption. The Networker summarized her thoughts:

That is a lot of effort. It's like in a city where multiple contractors are doing this all over the place, and you see it, and you have people you can talk to and people you can ask. For you to be the first rural customer would take a lot of effort, and 
you would have to be very motivated. I honestly just don't think the information is there in front of them to excite them about doing it.

As the participants indicated, vast differences separate varying rural locations. According to the MO Division of Energy, one of the most important differences between rural locations is whether areas have significant amounts of agribusiness. Large farming operations and related retail stores such as farm equipment dealers bring more revenue to communities. The Energy Consultant stated, “There's a lot of prosperity in agribusiness because not only are they (farmers) growing the world's food, but they're also growing energy." Rural areas that lack profitable businesses and other revenue sources become economically depressed and are often more focused on immediate results instead of investing in their future.

The Renewables Advocate compared many rural areas of the country with parts of Missouri where residents do not focus on the future because they are consumed by dayto-day economic survival. They worry about not having good jobs, the opioid and heroin epidemic, and countless other problems facing rural America. He shared his opinion that rural locations in Missouri are suffering because the federal government has eliminated protections and regulations that assisted manufacturing companies. He summarized by stating:

There's a lot of parts of the country like parts of Missouri that don't care about the future because they're not sure we're gonna survive and make it. I mean, like when I was in Marshfield, I look at all the businesses that left and all the empty places. They don't care about the future. They want to know, "What's gonna help us right now?" 
Much of that stems from the socioeconomic group of rural residents living from paycheck to paycheck. The Suburban Co-op pointed out that part of the utility market customers struggle to pay their bills and cannot afford to adopt solar technology. This fact means that having affordable utility rates in rural areas is the biggest issue.

Unfortunately, rural geography often impacts the affordability of utility rates based on the cost density of customers and varying topography. Because utility customers live further apart, utility lines and services cost more per customer. The Generation Coop explained that low customer density per line affects the affordability. Six customers live in the same sized rural areas on average versus 30 to 50 in urban areas. Further, the rural terrain can make it more costly to maintain utility transmission lines. Rougher terrain and more vegetation make servicing and maintaining lines expensive and increase these costs. Additionally, a difference divides the customer density for cooperatives and investor-owned utilities according to the Buy-American Consultant. Because cooperatives have fewer customers than investor-owned utilities, they are more spread out, creating higher costs per customer for each mile of transmission line.

The attitude of rural residents toward new ideas and technologies can also be a barrier. The Renewables Advocate explained that many people in rural areas do not like change and are suspicious of new things. He added that rural residents might love solar technology if they understood it and if the laws allowed them to take advantage of it. He feels many rural lawmakers worry more about what benefits the utility companies and thinks the investor-owned utilities and electric cooperatives like coal better than renewables. He stated: 
Here's the thing about rural lawmakers...they opportunely, more likely than not, have areas that the rural electric cooperative has provided power there. Plus, they also don't really have to worry about any blow back from the Public Service Commission allowing investor-owned utilities to increase rates because they see that as a Kansas City or St. Louis deal.

The ideology of a group influences its acceptance of new ideas and practices. Zia and Todd (2010) claimed that ideology also affects a group's scientific understanding, specifically referring to climate change science. The Western MO IOU questioned whether Missouri represents the best location for solar generation because of attitudes toward solar product manufacturing and weather related issues. Southwest Missouri supports American manufacturing; they prefer to purchase products made in the U.S. In recent years, China has been manufacturing the majority of solar panels and components, which she feels is an issue with many rural residents in that area. She thinks many people in that area view solar technology as a Chinese industry, so they do not want to support it. She stated, "This is an ultra-conservative part of the country. The dollar means a lot to people, and they're not going to go with something that's not proven yet, which I don't believe solar has been in the minds of people in this area. We're really cautious about our roofs in this area because of the tornadoes and the hail, and people don't want another penetration in their roof." The Renewables Advocate shared similar views and added, "They (residents) live there (rural area) because it is a conservative, traditional community." Moreover, he stressed the importance of recognizing that rural residents often live in the country because of their desire for independence; hence, they are not always receptive to new laws and regulations. 
Solar adoption in rural areas also faces competing priorities, especially from agribusiness. Even though farmers often have the wealth and tax income to benefit from solar technology, the Energy Consultant said farmers often lack the motivation because of other priorities. Farmers typically pay high taxes, but they would rather prioritize their investments in the latest farming equipment and technologies. He stated, "Agribusinesses have been more interested in reinvesting in the latest technologies associated with their business in new tractors, combines, etc. than to invest in a solar power system." He told stories of farmers he had consulted on adopting solar technology and shared:

But they wanted a new combine. It was only two years old, and they wanted a new one. They wanted the latest in whatever. I mean it was almost like I want to show the next guy down the path what I got. Solar wasn't something they were wanting to show the rest of the world they had, their fellow farmers.

Sadly, he does not know many farmers in his rural community who have adopted solar technology.

In summary, exploring the challenges facing potential adopters confirmed obvious barriers like affording the upfront cost and maximizing electricity generation through favorable locations and weather conditions. Additionally, the research revealed more complex barriers that help clarify how policies from the state to the local level impact solar adoption. While state statutes affect incentives, rebates, and tax credits, local regulations influence the interaction between adopters and their energy providers. This interaction is dependent on the utility type, which warrants a more detailed explanation. Because utility types play a critical role in how solar power is managed in rural areas 
through their approach to renewable energy generation and solar adoption, they emerged as a separate theme.

\section{Theme Three - Electric Utilities}

Various types of utilities operate under separate regulations, creating inconsistent policies and additional barriers for adopting solar technology. Regulatory and political factors, often closely related, help explain why the U.S. has been slow to adopt renewable energy due to inconsistent political regulations and a bias toward fossil fuels and nuclear energy (Sovacool \& Ratan, 2012). As pointed out by the Son-in-law/Installer, the federal government heavily subsidizes other energy sources like nuclear power and coal. This inconsistency causes isolated decision-making, unexpected regulatory changes, and significant barriers for grid access and interconnection (Sovacool \& Ratan, 2012). Hence, the utilities and the regulations they operate under impact a multitude of factors, influencing many of the challenges that adopters face. Considering these factors necessitated an exploration of utility types in depth as an independent theme.

State statutes impact municipal, investor owned, and cooperative utilities differently and subsequently affect local policies and regulations on electricity generation and solar power. The Municipal Utility represents a municipal utility, the IL-MO IOU and Western MO IOU are investor-owned utilities, and the Rural Co-op, Suburban Co-op, and Generation Co-op all represent cooperatives. Each utility provided insight on the challenges it faces incorporating solar power into a more diversified energy portfolio.

The other participants, both solar consultants and adopters, shared their unique perspectives on utility companies along with varying opinions on how utilities both support and impede solar adoption in rural areas. The Networker asserted that the 
leadership in a utility has a big influence on that utility's position on solar adoption and its willingness to embrace new ideas. She referenced the book The Grid by Gretchen Bakke, who claimed that utilities have always been a conservative, white man's business. The Networker expressed optimism in young leadership's ability to stimulate change in methods of operation that have been in place for decades. She stated, "New technology is good. You've got to embrace it, and if you're smart, you figure out how to make money from it as a company. Not say, 'I can't let this happen because this is how we've always done it."

Overall, the solar consultants and adopters expressed concern with the challenges utilities create through individualized approaches to solar adoption. Even the utility companies admitted to no single best-approach for incentivizing and regulating the installation of PV arrays. While some displayed a greater willingness to embrace solar energy, most expressed reluctance. These diverse perspectives highlighted key challenges utilities face and their various approaches to solar adoption. Utilities must address these challenges in net metering, cost recovery, power scheduling, and power purchase agreements to ensure a fair and appealing solar market for their customers.

Net metering. Net metering allows utilities to credit solar adopters for any excess power they supply to the grid. Customers are only charged for the energy they do not produce or their "net" energy (SEIA, 2011). Net metering provides solar customers a mechanism to sell a portion of the energy they produce back to the utility company. State statutes set the minimum requirements for net metering, but it varies greatly state to state. The MO PSC revealed that other states handle net metering differently. Missouri, like many states, has statutes that mandate net metering for every utility and homeowner. 
Large-scale solar farms, however, are exempt. The Installer/Consultant discussed the policies in Illinois and stated that cooperative utilities like the Rural Electric Convenience Cooperative use net metering.

The Networker mentioned that some states are eliminating net metering. According to the Energy Consultant, California is pushing back against net metering, and San Diego has already discontinued it. The Networker warned against policymakers negatively affecting net metering if solar adoption is going to continue growing. She sees no reason why utilities should want to discontinue net metering. Unfortunately, the 70's Solar Consultant insisted that many utilities, especially municipals and cooperatives do not support net metering, but the $M O P S C$ is not seeing pushback from the investorowned utilities in Missouri because they are required to offer it. The IL-MOIOU explained, "Missouri's a net metering state, and I think that it can be supportive for resident putting solar on their house. There's a mechanism for them to sell a portion back into the market." However, the $I L-M O I O U$ criticized net metering since it supports individual customers. He argues that everyone who does not have a PV array, in effect, is subsidizing those who have adopted solar. The MO Division of Energy explained, “...if you're net metered in Missouri, you're not charged anything different than anyone else. You might have to pay for some interconnection costs, and other than the net metering credit, you basically have the same bill."

The MO PSC asserted that utilities have to offer net metering to their customers based on interconnection standards. Krasko and Doris (2013) explained that interconnection standards outline the procedures and regulations of connecting a PV array to the utility grid and outline such items as fees, inspection and certification 
requirements, standard agreements forms, and system capacity. The $M O P S C$ then enforces the net metering in the interconnection agreements to ensure their rules are followed. These net metering and interconnection rules, according to the MO Division of Energy, represent one of the most obvious barriers for adoption because of the inconsistencies between utilities. They explained that solar adopters are allowed to connect to the utility grid and receive energy credits under net metering laws even with municipal and cooperative utilities. However, these utilities have varying size limits for arrays and different rates for crediting excess generation. The Buy-American Consultant expressed her passion to standardize net metering and system size limits for all types of utilities in Illinois. The Energy Consultant also stressed the importance of states instituting public policies toward levelized net metering.

The IL-MO IOU maintained that considerations for net metering regulation have to be explored further as solar power continues filling up the utility grid. He also warned that installing too much solar generation will require infrastructure upgrades, a part of interconnection agreements. The 70 's Solar Consultant revealed that some utilities cap solar generation at $5 \%$ of a solar customer's peak energy use because they maintain that it starts affecting grid stabilization. The MO Division of Energy reported that the Missouri Public Service Commission is reexamining net metering and co-generation rules. Further, the $M O P S C$ is now willing to evaluate the value of residential scale distributed energy generation based on examining avoided costs more. Traditionally, avoided costs have been based on conservative figures of just fossil fuel costs. The MO PSC has started considering the cost of energy capacity at a generating plant while factoring in the line 
capacity, an amount for line loss, the environmental compliance cost, and any health benefits as avoided costs.

The interviewed adopters shared various experiences with net metering, which reinforces the concern of little consistency among utilities. The Farm Matriarch complained that their net metering restarts every three months, so they are willing to waste electricity to prevent the cooperative utility from receiving their excess generation. The Surveyor revealed that his net metering resets once each year and estimated that he still loses one thousand kilowatts yearly through net metering. He explained that his local cooperative currently allows solar customers to roll over excess generation annually, even though by contract the utility could enforce a quarterly rollover. He emphasized the adverse effect of restarting his net metering every three months. The Father-inlaw/Farmer expressed appreciation for the IL-MO IOU's net metering policy of paying the same rate as traditional energy generation, or the full retail rate, for any excess solar energy generation.

The Suburban Co-op reported the City of Columbia, Missouri gives a full retail rate for excess generation, but the MO Division of Energy asserted that many solar adopters are not getting much money back for their excess generation. Most Missouri utilities are compensating solar customers under the $M O P S C$ 's rule for compensation at an avoided cost versus a retail rate. The Missouri statute states that any net excess is paid at the utility's avoided cost. The MO Division of Energy defined avoided cost as the amount a solar customer would incur for using another type of fuel for energy generation, such as natural gas. For instance, the Generation Co-op buys net excess energy at their avoided cost and then becomes a party in an agreement with their cooperative member 
who is generating solar energy. They are using an avoided cost of 2.5 to 3 cents for fuel costs for all banked excess kilowatt-hours. Utilities use fuel costs as the avoided rate, which is low now because of cheap natural gas and coal prices.

Nationally, questions have arisen on the avoided cost value and distributed resources. In Missouri, state law only requires cooperatives to give avoided costs. They can elect, however, to pay more than avoided costs, but no cooperatives are, at this time, according to the Suburban Co-op. The MO Division of Energy added that figuring out what an avoided cost means, how much the rate is, and when it is used continues to be contentious in Missouri because many smaller utilities do not understand the concept. Many cooperatives in Illinois are also displaying a lack of understanding in applying avoided costs.

An inconsistency also exists between cooperative utilities on their net metering polices. The Buy-American Consultant cited one cooperative that was following the same net metering and array size limit as one of the state's investor-owned utilities until their power provider forced all of their cooperatives to lower their size limit to 10 kilowatts and use an hourly cost value on a monthly period. Customers can no longer carry over any excess generation from month to month. The investor-owned utilities in Illinois use annual reconciliation periods to bank excess generation for an entire year. The power provider started requiring the cooperatives to credit excess generation at an avoided cost. They refer to it as an hourly marginal electricity value, equaling about 3 cents per kilowatt-hour versus the retail rate of 12 to 15 cents. The Buy-American Consultant also denounced some cooperatives in Illinois for charging solar adopters a special meter fee of 
approximately $\$ 2,000$ plus $\$ 5,000$ for a feasibility study. She also revealed that one of her customers had to petition her utility board to get net metering adopted.

The Rural Co-op explained that solar customers are net zero when they generate as much energy as they use. In which case, they use the utility grid like a battery. They store the energy they produce during the day on the grid and use it in the mornings and evenings. The Rural Co-op expressed their position that solar customers should pay their share of distribution costs if they are net zero for the use of the utility grid as a battery.

The Suburban Co-op explained that under net metering, a customer uses any power generated by a PV array at the home first. Then the excess electrons flow through the net meter to the utility grid. Measuring this flow of energy requires switching to a net meter system with two separate meters - one that records the power delivered and one that records the power generated. The generated power goes to a disconnect switch and a sub meter before going into a breaker panel connected to the array. A bidirectional meter then records how much power the PV array delivers to the home or how much it pushes to the utility grid. The Municipal Utility requires a separate dual meter for an array as part of their net metering requirements as a utility.

The solar customer pays for the net difference between the two meters if he uses more power than he generates. According to the Rural Co-op, a net meter aggregates this difference. The utility often must install the net metering as was the case reported by $M y$ Dad's Friend. His net meter was installed by the cooperative utility. The Young Adopter also reported completing a net agreement with his cooperative but was relieved that the consultant oversaw the process. The Son-in-law/Installer reported working with one cooperative who requires two solar meters to transmit exactly how much solar energy an 
array produces. One meter is for the installer's solar-log, and the other is for the cooperative's solar-log.

The inconsistency in net metering regulations creates uncertainty in the amount solar adopters are compensated for their excess generation and dictates, to some degree, how utility companies recover costs lost to increased solar energy generation. The interviewed utility companies argued that, while the state statutes determine cost recovery, the process of recovery becomes more difficult with net metering. Missouri state statutes require a utility to charge the same basic service fee to all customers regardless of whether they generate the majority of their power or receive it from the grid. Therefore, solar adopters pay the same service fee even though they are generating their own power. According to the Municipal Utility, customers who cannot afford to install a PV array are subsidizing those who can because solar adopters still use the grid but pay little to the utility company. Those who cannot afford solar power pay higher bills to offset the money utility companies lose from selling less electricity. The Municipal Utility summarized that the other customers help pay for the benefit of individual PV arrays. The Municipal Utility stated, "So Granny Smith who’s living on, I call it fixed income - low income social security, whatever it happens to be, she can't afford to put solar cells up and so ultimately her utility bills are incrementally higher because of what's going on here (on the graph)." He referred to a graph of a residential PV array not producing any electricity while using it from the grid.

The Energy Advocate stressed the importance of ending American's dependence on natural gas and coal, but he acknowledged that many utility companies believe 
renewable energy adversely affects lower income customers. The Energy Advocate stated:

I know one of the problems is when you're trying to promote renewable energy, there's always this belief that it affects people who are a lower income as far as users. Because the reality is, when you're trying to make a shift like this, there are gonna be people who suffer financially. I think being able to get us off our dependency on gas, on coal is really important. But we don't want to have people who are going to have to make a choice between buying their medicine and paying their utility bills.

The Energy Advocate also admitted that some environmental groups do not seem as concerned and think high utility rates will be advantageous for the increase in RETs. He feels no one should suffer from the promise of solar energy. This situation necessitates minimizing negative financial impacts on people who cannot adopt solar technology by helping them with their utility bills if necessary or possibly subsidizing solar energy. The Suburban Co-op references one group in particular, the Worldwatch Institute, a thinktank in Washington, D.C., that believes utilities should charge a premium on all people's utility bills and redistribute the excess revenue to those in need to assist in paying their utility bills. He countered, however, that helping lower income have access to solar technology on the East and West coasts makes sense because electricity is cheaper to produce from the sun than conventionally with fossil fuels. However, in Missouri and other Midwestern states, conventional energy is cheaper than renewable energy.

Cost recovery. The utility companies expressed concern over recovering losses to the fixed costs of their utility grid operation. Increases in solar adoption reduce the 
demand for electricity sold, but their costs of operation remain the same. Because less revenue is generated, the fixed costs are covered with higher monthly service fees to all utility customers. The Suburban Co-op reported that service fees continue to go up even though the kilowatt-hour charge stays the same. They are currently charging a $\$ 27.95$ per month service fee but spending $\$ 44$ per meter in fixed costs. They use a declining block for monthly charges; the first 600 kilowatt-hours are more expensive because the charges help recapture the fixed costs.

The utility rates that customers pay bundle the cost of electrical lines, utility poles, transformers utilities, and other services as well as the variable costs of generation, transmission, and distribution in the case of electric cooperatives. The bundle rate costs about eight or nine cents per kilowatt-hour for most rural Missouri cooperatives. The Rural Co-op shared insight that some utilities are trying to unbundle the variable cost by increasing the monthly flat, fixed rate. Referred to as embedded costs by the Generation Co-op, the bundled cost includes those charges above the fuel needed to create a kilowatt-hour of energy that exist even if fuel is not burned.

The Generation Co-op felt that neighbors have to make up those embedded and bundled costs for solar adopters. The Rural Co-op wants to treat all customers fairly by having solar adopters pay their share of the utility grid fixed costs. Keeping their fixed costs low allows them to increase the variable charges slowly. The Rural Co-op has also increased its service availability over the last few years. This service increase includes a cost to connect to the utility grid regardless of the amount of use, which has increased revenue and allowed them to keep the kilowatt charge lower. According to the Rural Co$o p$, cooperatives can better adjust to increased solar adoption by managing their rate 
structure appropriately. Building rates around classes of customers like residential, commercial, and large industrial sectors allows utilities to subsidize increased solar adoption in one class with revenues from another class that consumes more energy.

To understand cost recovery fully, one needs to compare the cost of solar power to conventional power and examine how utilities calculate the cost of solar power. The Suburban Co-op quoted the cost of conventional coal power generation to be 2.5 to 3 cents a kilowatt-hour versus 15.95 cents for solar power, using NREL data. NREL's calculator pricing is typically between 14 to 15 cents for solar power. The Generation Co-op said their final rate for conventional power ends up being 10 cents a kilowatt-hour. He added that over the course of 30 years their rate has only increased from .07 to 10 cents. He clarified that the cost for residential solar power often ends up between 16 to 18 cents a kilowatt-hour when professionally installed. Installers usually get $\$ 4$ per watt. Some of the adopters who installed their own systems saved significantly. They installed at $\$ 3$ per watt, which brings the cost down to 14 cents a kilowatt-hour. Both the Suburban Co-op and Generation Co-op said that the cost of solar power per kilowatt-hour has to become considerably less than other power for solar adoption to be a reasonable option for a large sector of the rural population. The Generation Co-op summarized his thoughts by saying:

I think that the per watt install price at some point, it gets driven down to a level that it can include a much larger group of people that have access to that. When it was $\$ 4$ to $\$ 5$ per watt-installed price that excluded a large chunk of people who just didn't have access to that. 
Many states are recognizing the issues with cost recovery and net metering. States with dense solar penetration are amending their laws to allow for full cost recovery. Nevada, for example, has modified its laws to allow utilities to recover more costs. Missouri statutes, however, do not allow for full cost recovery because of net metering, which requires a nonstandard contractual agreement with the utility. The Municipal Utility pointed out that net metering for individuals is not favorable for cost recovery and added that most software does not factor net metering into the billing.

Because of significant differences state to state, vendors find difficulty in modifying their billing software. As a result, utilities must bill solar customers by hand, but they are not able to collect additional fees to cover the extra time and effort for processing more billing information and managing different rates. Vendors can only recapture the costs by raising rates for all customers. Consequently, the Municipal Utility urged, "I think there needs to be... work needs to be done on the statutes so it's easier. Not easier, that's the wrong word. It allows us to recover our costs, and the customer still gets want they want."

Power scheduling. In addition to net metering and cost recovery issues, solar energy generation can create scheduling challenges for utilities because it does not produce power at a constant, predictable rate. Either a PV array produces power or it does not with no accessory loads. However, homeowners have accessory loads; they are consuming power even when an array is not producing. Solar energy generation only peaks at its maximum generation for three to four hours each day. Unfortunately, the peak generation does not match the peak consumption, which makes it difficult for utilities to schedule power. The gaps have to be filled in with other power sources. 
Additionally, large spikes in production like the one residential PV arrays can produce are difficult to schedule. The Municipal Utility stated that managing and scheduling power is easier for large-scale solar systems, like solar farms, because of a more consistent load curve.

Utility companies consider several factors when integrating solar energy into their energy portfolio and scheduling power to customers throughout the day. The Generation Co-op explained that utilities schedule their power distribution using a chart called the duck curve, so called because of its shape (see Figure 6). The chart shows the output of utilities to meet customers' energy demands while accounting for the decrease in output from RETs. This decrease is most evident around 7:30 p.m., a time when demand peaks but when solar energy production starts to drop off noticeably. This disconnect between when energy use peaks and the actual solar production significantly decreases presents one of the biggest challenges for utilities to ensure consistent energy availability to customers. 


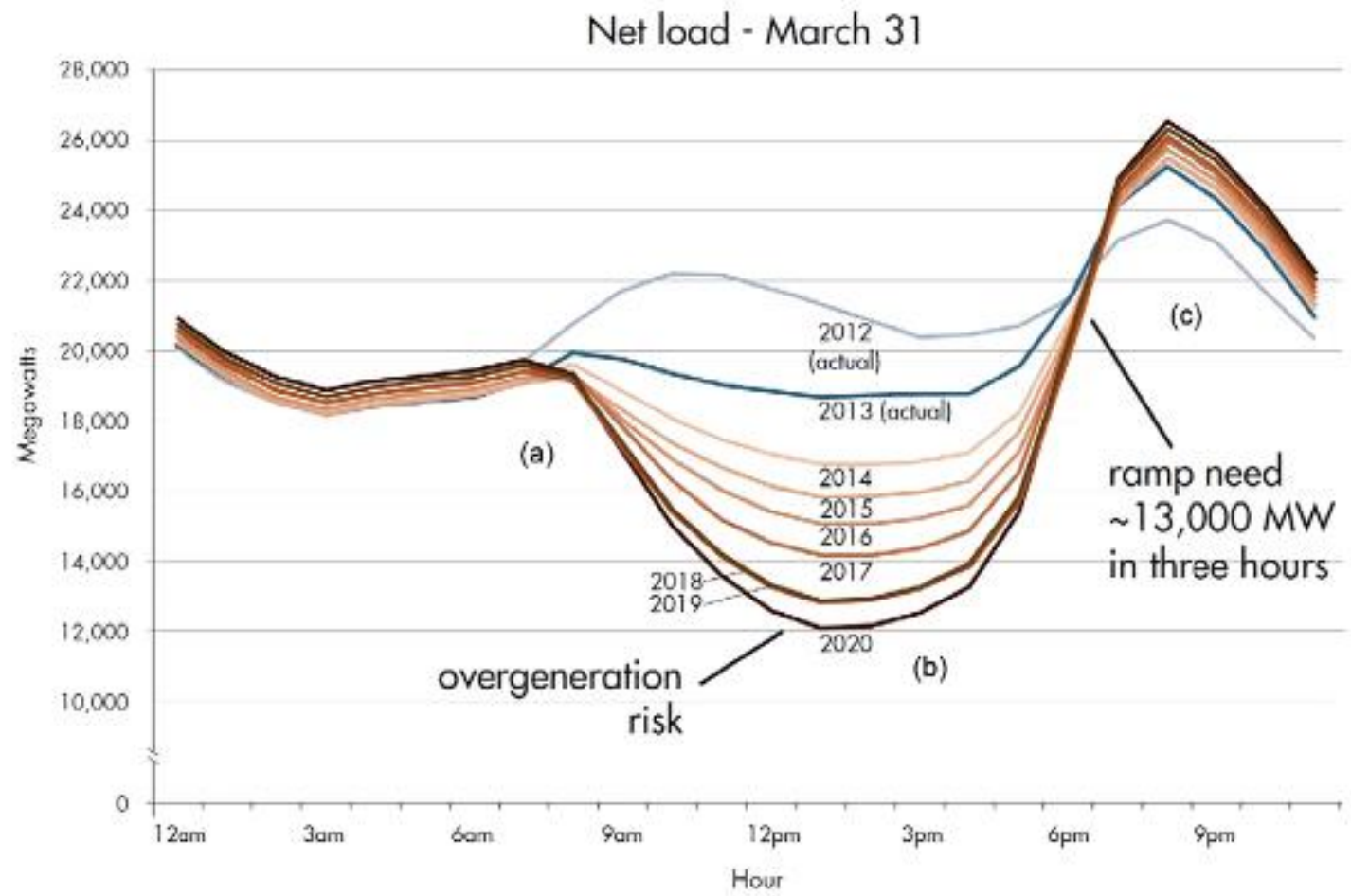

Figure 6. California Independent System Operator (CAISO) duck curve (Obi \& Bass, 2016)

To offset the decrease in production by renewables during peak demands early in the morning and late in the evening, non-renewable energy must ramp up quickly because renewable energy cannot be stored easily. The Western MO IOU stressed the importance of recognizing that the sun does not shine all of the time. The Suburban Co-op stated:

So you can see there (by looking at the duck curve) how quick we have to (make up for a drop in production from renewables) because we've gotta have all these coal and natural gas plants sitting in an idle and ramp them up super quick to meet the demand. Otherwise lights dim, bad things happen and not a good situation.

The Western MO IOU warned of challenges that states like California and Hawaii face from generating too much solar power during times when too few people are using it. The utility grid can become unstable from too much electricity traveling over the lines, 
so these states are dispatching residential solar power. They are either shutting off the supply from residential arrays or giving the electricity to surrounding states during windows of excess generation. The Rural Co-op revealed that California is already mandating renewable energy storage while Hawaii is starting to address their issue of energy storage produced by residential arrays during times of low use.

The Suburban Co-op encouraged implementing time-of-use utility rates by using more advanced metering. He again referenced the duck curve graph to point out times of excess generation during the day when cheaper rates could be charged. The Networker suggested making smart grid technologies a tool for utilities to cope with peak demand. Smart grid technologies, such as smart meters, allow utilities to track and record energy use in a home. They also give utilities the ability to manage residential solar customers' power supplied to the grid, to assist with concerns of excess generation.

Utilities must also contend with decreasing electricity use when deciding how to integrate solar power into their energy mix. This decrease is due to milder winters, more energy efficient lights and appliances, and advancements in green construction. The Suburban Co-op cited a 3\% decline in U.S. annual residential electric sales and a 7\% per capita drop from 2010 to 2016 . A decline in energy use has postponed the Generation Co-op's need to add more generation capacity until 2032 or 2033. Adding more capacity before that time would only increase customers' costs. According to both cooperatives, good public relations are the only benefits of adding capacity now from solar power or other RETs.

The difference in energy density per customer factors into integrating solar power and scheduling power. Energy density is the amount of energy stored in a given system or 
mass. The Midwest shows a greater difference than that found in western states. The Suburban Co-op explained that a greater energy density results from a larger difference in temperature and more humidity. He reasoned that since the Midwest gets far greater temperature fluctuations, it takes more energy to maintain the temperature and comfort level of an interior space. Pushing the thermostat up only one degree actually takes $3.1 \%$ more energy. He summarized, "What you have to realize is that anytime there is a greater difference in temperature, the need for energy to maintain air conditioner or heating goes up exponentially." Cooling a space with air conditioning requires more energy because the system must also remove humidity. He concluded that $100 \%$ renewability is more easily attained in California, Hawaii, and other states with moderate climates. Increased heating and cooling are required to maintain indoor comfort in states throughout the Midwest where temperatures can reach well over 100 degrees and plummet to below zero.

Finally, utilities like to diversify their energy portfolios to schedule power more easily. A diversification of energy sources also allows utilities to keep energy prices low. Some of the participants understood that solar energy only represents part of utilities' solution for affordable energy. The Farm Matriarch, for example, maintained that solar energy is not the only answer. Other participants advocated incorporating a greater percentage of solar power and other renewable energy. The Renewables Advocate questioned why utility customers cannot have as much renewable energy as possible and felt utilities should try harder to make renewables part of their energy mix. These differing positions illustrate utilities' various approaches in response to increased solar adoption. Depending on a utility company's structure, methods of operation, and 
mandated regulations, the three utilities - municipal, investor owned, and cooperative utilities - each approach energy diversification and the inclusion of solar generated power differently.

Municipal utilities report to their city governments, which influence their methods of operation and willingness to embrace solar energy according to the Buy-American Consultant. Additionally, the Suburban Co-op revealed that municipal utilities set their rates for solar customers' over-generation through their city council. However, varying priorities between city councils produce different approaches to solar adoption and net metering rates for over-generation. In the Networker's opinion, these varying approaches create the need for municipal utilities to have solar standards along with agreed upon methods and processes.

Power purchasing. Since municipal utilities usually buy all of their power, they often belong to a public energy pool that shares the needed energy load in an area for collectively buying energy. The Municipal Utility belongs to a pool that includes other municipal utilities throughout Missouri along with ones in surrounding states. This energy pool provides resources at a utility scale, meeting regularly to decide on plans for purchasing energy while discussing the economics of any planned projects. In addition to six current solar farms throughout Missouri, they plan to build seven more. However, the Municipal Utility admitted that the plans are not without controversy because the energy pool has to consider the cost effectiveness of renewable energy projects.

According to the Municipal Utility, the energy pool can choose from other cost effective ways to generate renewable energy other than solar power. Hence, the energy pool relies on wind farms and biogas facilities along with solar technology to produce the 
renewable energy they purchase. In addition to the renewable sources, the energy pool purchases power from several coal fired power plants throughout Missouri. The solar power they do purchase comes from large-scale PV arrays because of the cost effectiveness based on the economy of scale versus residential arrays. Additionally, it allows the energy pool to share the benefits of solar power with all the customers and not just the homeowners who can afford to install an array. The energy pool maintains a power purchasing agreement with the developer of each solar farm to buy power only when the arrays generate power.

The Municipal Utility also discussed that the energy pool serves as a sounding board and a networking platform with other municipal utilities. They belong to a statewide organization, Missouri Joint Municipal Electric Utility Commission (MJMEUC), and a national organization, the American Public Power Association. Both give municipal utilities further opportunities to network and share ideas. They often discuss varying electric issues they are experiencing and incentives they provide. "You talk about solar. You'll talk about whatever incentives because there are cities that do incentives for heat pumps and all kinds of different things. It just depends what that local community finds important," the Municipal Utility stated. This organization provides an opportunity for municipal utilities of various sizes to collaborate. The Municipal Utility added that the municipal utilities vary greatly in size across the country, from very small like Newburg, Missouri, to extremely large like Los Angeles, California. The cooperative utilities have their own organization, the Association of Missouri Electric Cooperatives (AMEC) that allows them to discuss challenges faced by other cooperatives exclusively. 
Utility structure. The Municipal Utility stressed that municipal utilities are not against renewable energy. In fact, they have more solar energy than investor owned and cooperative utilities combined. The Municipal Utility expressed the desire to maintain a good relationship with any customer regardless of whether he decides to adopt solar technology or not. They will have a potential adopter as a customer after he installs an array, so they want to support the customer regardless. If a customer does decide to adopt, the Municipal Utility along with most municipal utilities in Missouri uses the same agreement as the state template. However, municipal utilities are not required to follow all state regulations for renewables like investor-owned utilities. In Missouri, investorowned utilities are heavily regulated by the Missouri Public Service Commission.

A state's Renewable Portfolio Standard regulates investor-owned utilities not municipal and cooperative utilities, except in a few states. Both Illinois and Missouri regulate only investor-owned utilities under their respective RPS. However, how investor-owned utilities operate from state to state differs significantly depending on the amount of regulation. For instance, the ownership of generation facilities in Illinois versus Missouri falls under differing laws between these states. The IL-MO IOU cannot own any generation in Illinois. On the other hand in Missouri, they own coal, hydro, and solar generation facilities. The $I L-M O I O U$ also services all of the utility lines throughout Illinois but not in Missouri where municipal and cooperative utilities service their own lines. However, as pointed out by the Son-in-law/Installer, the IL-MO IOU owns all of the utility lines in Illinois.

The MO Division of Energy explained that investor-owned utilities operate quite differently than municipal and cooperative utilities. Investor-owned utilities are managed 
by shareholders and operated as for-profit businesses. Consequently, investor-owned utilities have more revenue and resources, which allows them to assume greater risks. Investor-owned utilities have a reduced risk in diversifying their energy portfolio by incorporating renewable energies like large solar farms. For example, under a power purchase agreement the $I L-M O I O U$ developed and sold a 5.7-megawatt DC solar farm in O'Fallon, Missouri in 2014. The Networker mentioned that investor-owned utilities also have a large number of employees coupled with several engineers to incorporate solar adoption more easily.

The MO Division of Energy also noted that differing philosophies and methods of operation create unique cultures from one utility type to the next. They have noticed cultural differences between investor-owned utilities' focus on shareholders, and cooperatives that operate more independently. They stated, "The co-ops are a lot more independent. And they don't necessarily want to jump on board with the newest trend. My assumption would be that the cultures are just different between co-ops and muni's (municipals) and IOUs." The MO PSC suggested that differing cultures within different utilities might influence their motivations to include renewables in their energy portfolio.

Unlike investor-owned utilities, cooperative utilities are not regulated under a state's renewable portfolio standard. In fact, they are largely deregulated according the Renewables Advocate. The Surveyor feels that deregulating utilities gives them the ability to resist solar adoption. However, cooperatives only provide about $15 \%$ of the energy produced in Missouri. The Renewables Advocate stated:

They're not really reaching that many customers, but they're still very powerful. I think ultimately, when I look at the Paris Power Agreement, you're talking about 
that's a kind of form of deregulation. But I think that a little bit of deregulation wouldn't hurt. But I think it's really a matter of changing the way they look at it (solar).

He added that deregulation leads to more diversification in cooperatives and municipal utilities. The deregulation allows them to do some innovative programs.

As described by the MO Division of Energy, cooperative utilities operate under a board of directors elected by the cooperative customers, giving them a voice in the policies. Board decisions usually reflect the feelings and priorities of the customers. The Rural Co-op argued that if solar adoption is important to their customers, it should be important to the cooperative. He added:

They're (cooperatives) governed by their members (customers), so basically if you're a co-op member and you take electricity from them, you get a say in what their policies are going to be, which, of course, is very different than the investorowned utilities where it's the shareholders and management.

The Suburban Co-op echoed the same sentiment. They are adapting to whatever their membership wants. The MO Division of Energy said, unfortunately, most cooperative customers and their board members do not know the right questions to ask about solar adoption. The Rural Co-op noted that cooperative boards have to establish whether residential scale solar generation provides more benefits than a larger renewable asset like a 10-megawatt solar farm.

Moreover, most cooperatives have very small staffs, who lack experience dealing with solar adoption and distributing power generation from residential PV arrays. The MO Division of Energy has seen that the lack of experience causes some of the smaller 
cooperatives to feel threatened by solar penetration on the utility grid. The Rural Co-op added that resources usually limit some of the smaller cooperatives. Cooperatives belong to both regional and national organizations. Unfortunately, these organizations often do not know the right questions to ask about solar adoption either according to the $M O$ Division of Energy.

The lack of state funding and public benefit funds create another challenge facing solar adoption in rural areas with cooperative service. These funding sources can help cooperatives develop their solar programming. The MO Energy Department highlighted that leading states in renewable energy have public benefit funds. Illinois is such an example. The funding shows as a small charge on each customer's utility bill for funding an organization, such as the state's energy office, to implement energy efficiency programs. Developing these types of programs for rural areas provides incentives and technical assistance to solar adopters. Unlike Illinois, all of Missouri's funding has traditionally come from the U.S. Department of Energy to the State Energy Program. Cooperatives operate as non-profit entities. They pass any profit back to their customers. For example, the Generation Co-op passes any profit to the transmission cooperatives and the distribution cooperatives. Even though the Generation Co-op operates as a nonprofit and has no tax appetite, it has for-profit subsidiaries and partner with tax equity investors to build and own PV arrays. These moves allows them to take advantage of tax credits and accelerated depreciation.

The Rural Co-op explained their willingness to help their customers connect a PV array to the utility grid, but they cannot give any rebates or incentives because they would be doing so with other customers' money. The Rural Co-op emphasizes treating 
customers fairly. They want equitable treatment for those customers who adopt solar technology as well as those who do not. He clarified:

Our board has taken a position; we can't use our members' (customers') money to just give it to the few that have access to do this. If they want to do it, that's fine.

We'll help them get connected, but we can't give them money. You can't incentivize them to build the solar with other member's money.

The MO Energy Department also noted that cooperatives often operate in groups. The leadership of these cooperative alliances can influence decisions in the direction for individual cooperatives. In Missouri, for example, the 41 cooperatives operate in six different groups to purchase the power they distribute from various transmission cooperatives. These six all purchase their power from the Generation Co-op. The transmission cooperatives transmit the energy from the various generating facilities operated by the Generation Co-op to the various distribution substations. The transmission cooperatives then transmit the energy to their customers.

The Rural Co-op indicated that their cooperative has a 100\% power purchase agreement with a transmission cooperative that prevents them from generating power or purchasing it from anyone else. He stated, "The best place to do generation is not all 41 of us trying to do generation. Let's pool our resources and the Generation Co-op can more effectively and efficiently do generation assets." The Buy-American Consultant reported that many of the cooperatives in Illinois have similar agreements. Ten cooperatives in Central Illinois have long-term power purchase agreements with a power provider; they have invested in a new coal-fired power plant that the power provider developed. The Municipal Utility explained that this arrangement differs from that of 
most Missouri municipal utilities belonging to the Missouri Joint Municipal Utility Commission power pool. The power pool trades and buys power through a balancing authority, the Midcontinent Independent System Operator. They operate a large portion of the generation and transmission assets and decide what power to include and eliminate in the energy mix. This type of independent operator also decides operational protocols like when to use generators and what levels to load transmission lines. The Western MO IOU belongs to the Southwest Power Pool, an organization dictating how much power can be brought into the area and what is sold to outside utilities. In contrast, the Generation Co-op has resisted joining a power pool, a move that would require board approval, and still balances its own energy mix.

The cooperatives have a full-requirement contract requiring them to buy all of their energy through the Generation Co-op. The Rural Co-op explained that all of the distribution cooperatives, including them, are somewhat limited in developing solar generation. They would have to negotiate an agreement for the Generation Co-op to buy the solar energy generated and sell it back to the distribution cooperatives through the wholesale chain. The Generation Co-op noted that they are somewhat unique in the U.S. since they generate energy for customers throughout the State in all 41 cooperatives. Currently, its renewables include hydro and wind but no large-scale solar energy generation.

The Suburban Co-op noted that the cooperatives, through the Generation Co-op, are utilizing more wind power than solar generation because the Generation Co-op benefits more in this overall energy mix. The Generation Co-op's entire solar generation includes two community solar projects plus the individual residential PV arrays. It totals 
about 10 megawatts of power but still does not show up as part of their energy mix. Coal plus some natural gas forms most of their energy portfolio. It varies every year based on the lowest dispatchable generation at the time. The Generation Co-op has a new CEO, so the board seems to be considering all options for energy generation. The Rural Co-op sees solar power as a good fit in the Generation Co-op's energy mix because of the economy of scale for residential PV arrays. He also thinks all of the cooperatives in the State, including those in very rural areas with a small number of customers, can benefit when the Generation Co-op incorporates solar power into its energy mix.

The Rural Co-op acknowledged that as a cooperative, their board monitors solar adoption. He stated, "I think all of the co-ops have an eye on it, especially as the boards are considering the right way to manage their utility. The co-ops' boards are also considering is this something that the co-op should do, whether it's community (solar) or otherwise?" However, he admitted that they are usually not early adopters on the leading edge of innovations. They wait for other utilities to work through the challenges. Serving 36,000 customers in rural Missouri, they rank in the lower half of the 41 cooperatives in the number of solar adopters even though their solar adoption rate has been steady in recent years. The Rural Co-op had four installations in the first half of 2017.

The cooperatives near larger metro areas with more affluent customers rank much higher on the list. The Suburban Co-op recognized that cooperatives exist to provide customers with the cheapest electricity. However, the MO Division of Energy noted several differing philosophies toward solar adoption in various cooperatives and stated, "I think based on how much they're regulated and they're different organizational 
structures, I think they do have somewhat different philosophies and methods of operating. And it also probably depends on who's in charge at a given moment in time."

Solar integration. Several challenges face all three types of utilities as they integrate more solar generation into their energy portfolios. First, they are considering the impact of solar technology on their workforces since it requires little maintenance as noted by the IL-MOIOU. They are trying to avoid alienating their own workforces. He reported no internal conflicts of interest exist to this point between supporting solar adoption versus reducing the amount of maintenance required. Second, utilities must consider the impact that grid parity could have when solar energy reaches the same price or less per kilowatt-hour to install as current utility rates. When grid parity starts occurring, a greater incentive will develop for customers to adopt solar technology. The $I L-M O I O U$ has groups within the company examining the locations of low growth areas for utility customers. These areas can result from solar power and other renewable energy use or increased energy efficiency in homes. The $I L-M O I O U$ tries to manage these areas since they see them as a risk in controlling their costs to keep utility rates low for their customers.

Another challenge many utilities face is being long on capacity according to the MO Division of Energy. They are overcapacity, meaning utilities have the ability to produce more energy than is currently used. The Renewables Advocate noted that both the Il-MOIOU and the cooperatives throughout Missouri are currently overcapacity with the exception of the Western MOIOU. As an under-capacity utility, they are offering an incentive for solar adoption and investing in wind energy through purchased power agreements with two Kansas wind farms to meet their Renewable Portfolio Standards 
requirements as regulated by the MOPSC. Utilities in Western Missouri can access wind power much easier than other areas of the State.

The MO PSC noted no limits in Missouri for geographic sourcing, so utilities can purchase renewable energy outside of their own regions. The Western MO IOU confirmed that they have close proximity to wind farms throughout Kansas. Even with their current incentive offered, their use of solar energy remains insignificant. They are utilizing customer generated solar power toward their renewable portfolio standard, but it is roughly 11 to 13 megawatts, a relatively small amount. They continue to foster customer generated solar power, but the number of installations has decreased since the incentives were first offered in 2015 and have now leveled off.

Several of the utilities interviewed offered various solar programs. The Suburban Co-op exhibits a progressive attitude toward clean energy by already meeting the clean power plan standards that current administration has since rolled back. The Suburban Coop is supporting solar adoption through net metering and their community solar program. As the first cooperative in Missouri to offer wind in energy in 2003, they purchased the entire renewable source the Generation Co-op had under contract from wind farms. Since that same time, they have offered their Renewable Choice program. This program started in August 2016 with clean air cards and now includes the community solar option. They reported that their board is listening to the customers who have expressed an interest in having more renewable options. Therefore, they are promoting solar technology to their customers in their monthly magazine. They have 109 members who currently support solar energy generation out of 28,000. 
The Rural Co-op had approximately 27 grid-tied solar customers as of July 2017, who produced about 162 kilowatts of power by the end of 2016 . They require customers to complete a net metering application if they plan to connect a PV array to the utility grid according to Missouri's net metering statutes. The statutes also require them, as a cooperative, to brief their board once a year on net metering. The Rural Co-op stressed the importance of solar customers informing them of their intent to install an array and completing the application so the net metering works correctly. The IL-MO IOU also mentioned their requirement for potential solar adopters to complete a simple application for installation of a new bi-directional meter necessary for net metering.

The Western MO IOU touted their foresight in renewable energy through hydropower in the early 1900's and wind power in 2008. They began as a utility to provide electricity to the mining industry in the area. Their first power plant was a hydro dam in Riverton, Kansas. However, they admitted they have resisted solar energy generation based on its expense as an energy option for their customers. They were limiting how much renewable energy they could incorporate into their energy mix because solar power is higher per megawatt than their base load from coal or natural gas generation. They have incorporated emission controls in their coal-fired power plants to help with the carbon emissions. Unfortunately, the MO PSC determined they were not meeting their renewable energy requirements under Proposition $\mathrm{C}$, so they initiated a rebate program for residential solar adoption. They have not developed any solar farms and use only the customer generated solar power to meet the requirements. They also expressed concern over the solar energy's ability to meet peak demands and reported having one quick-start power plant that has experienced an exponential increase in the 
number of starts to provide power when solar generation decreases early in the morning and late in the evening. To ensure a diverse energy portfolio, they periodically go through an integrated resources process to determine the best energy mix for their portfolio. It is worth noting that the Western MOIOU was recently purchased by a Canadian company with a renewable energy focus.

The Generation Co-op provides electricity to parts of Missouri, Oklahoma, and Kansas. They currently have 750 megawatts of wind scattered in all three states - a wind farm in Northwest Missouri as well as long-term power purchase agreements between 20 to 25 years with a windfarm in Northeast Oklahoma and one in Southeast Kansas. They transmit wind power and resell it to other utility companies with a wheeling charge, the cost of transmitting the power over utility lines. Wind makes up $14 \%$ of the renewable energy included in their energy portfolio with hydropower forming the remainder. The Generation Co-op is also not opposed to solar adoption. They currently have about 1,050 residential PV arrays, which amount to 9.5 megawatts of energy. The have seen 30 to $50 \%$ growth over the last three-plus years in smaller arrays. They are willing to help their customers make an informed decision on solar adoption because they focus on what is best for their customers. Because they serve a lower income population, they are trying to keep their rates affordable. The Generation Co-op stated:

Our mission statement says it pretty simply, and it just basically says we exist to provide our co-op members (customers) with the lowest possible cost of electricity that we can provide. That's not verbatim, but that's what it says. That's why we exist and why the cooperatives are there, and I think they all follow that same philosophy. 
They would consider solar generation at the right price point that matched their needs. For now, they continue monitoring it but are not concerned with incorporating it into their energy mix. Annually, they conduct resource planning based on where they project needing resources in the future. Since 2008, they have had stagnant load growth, so they are not currently building any additional generation facilities. Having diversity in their power supply keeps it affordable and reliable. They are using coal, natural gas, and nuclear power for the remainder of their baseline generation when renewables are not producing any energy.

Each cooperative utility interviewed has a unique program depending on its customers' interest level in solar adoption and other renewable energy options. These individualized approaches among cooperative and municipal utilities create challenges for solar adopters. The utility companies admit they have different approaches to net metering, cost recovery, power scheduling, and power purchase agreements. While the majority of utility companies want to provide a fair solar market to potential adopters, they remain focused on ensuring the lowest energy prices possible to all customers. Even investor-owned utilities, the only type regulated by renewable portfolio standards in most states, prioritize and incentivize the inclusion of solar energy uniquely based on their leadership and culture. Because a state's renewable portfolio standard dictates the renewable energy policies to such a large degree, I develop it as the following theme.

\section{Theme Four - Renewable Portfolio/Energy Standards}

Each state provides individualized oversight of its public utilities, regulating rates, and services under a public utilities commission. For example, the Illinois Commerce Commission governors Illinois's utility regulation. However, Missouri operates under a 
Public Service Commission to provide oversight for public utilities. Adding to the complexity, some states', like Missouri's, utility or service commission only provides oversight for investor-owned utilities while elected bodies regulate the municipal and cooperative utilities. Other states, like Arkansas and Iowa, as reported by the Municipal Utility, include cooperatives under the oversight of their service commission.

Furthermore, each state has uniquely integrated the requirement of renewable energy into its renewable portfolio standard. This requirement is often determined by the priorities of the citizens. The differences, state to state, in oversight and regulations coupled with priorities create a unique set of challenges and add to the complexity of adopting solar technology depending on the type of utility involved.

The Missouri Public Service Commission, referred to throughout this study as the MO PSC, regulates investor-owned utilities, focusing on equity returns and utility rates. Customer input is integrated into the Integrated Resources Process through the MO PSC to ensure that processes are equitable for customers. Additionally, they review and approve applications and certify renewable resources awarded by the Missouri Division of Energy for investor-owned utilities. Not a regulatory agency, the MO Division of Energy focuses on promoting renewable energy.

The MO PSC does not review any of the municipals or cooperatives because they are not regulated under Missouri's renewable portfolio standard. They are only regulated for safety compliance. The MO Division of Energy reported that municipals and cooperatives do not often share much information about their energy plans. For example, they revealed that some cooperative utilities are incorporating some renewables into their energy portfolios for power generation, but they do not always share many details since 
they are not regulated. The $M O P S C$ also assists in the planning process for investorowned utilities to develop 20-year plans using a standardized template. The MO Division of Energy revealed that only the $I L-M O I O U$ is not meeting its 20-year goal for renewable energy, but the Division's calculations show the IL-MO IOU would reach a retail-rate level of impact first. This outcome would result from the statute limiting compliance to no more than $1 \%$ of base rates. Finally, the MO PSC handles customer complaints on issues like solar rebate applications, net metering, and expiring energy credits.

Every state differs in handling its renewable portfolio standard (RPS) and setting utility rates for customers. Most states have adopted an RPS that requires a portion of their energy be generated from renewable sources by a given date. The MO PSC highlighted a useful website, www.dsireusa.org, which maps the states with an RPS and the states' regulations, net metering policies, and rebate programs. Missouri passed an RPS, referred to as the Renewable Energy Standards (RES), by the vote of the people under Proposition C in 2008. It requires Missouri's investor-owned utility companies to use at least $15 \%$ renewable energy by 2021 (Miller, 2010). According to the MO Division of Energy, that percentage is lower than many states. The Renewables Advocate insisted that Proposition C passed unexpectedly but was a big break for the State as well as his renewable advocacy group because it put renewable standards in place for Missouri. He stated, "It's (Proposition C) a little outdated, but it's still doing what it needs to do. Being able to offer rebates and that sort of thing and really help get the solar industry off the ground." His group remains focused on keeping it in place. 
Proposition $\mathrm{C}$ also put renewable energy statutes in place and outlined rules by which the Public Service Commission enforces these statutes. In Missouri, the RES only applies to regulated utilities which fall under the jurisdiction and oversight of the Public Service Commission. In fact, an RES is heavily dependent on the Public Service Commission, who sets the rates. All investor-owned utilities in Missouri are required to have an RES, which applies to all types of renewable energy, not just solar power. The RES includes solar power along with hydropower, wind energy, and landfill gas. The $I L$ MO IOU, one of the three investor-owned utilities in Missouri, has built two large solar farms near St. Louis to help meet their RES requirement. The Public Service Commission reviews the investor-owned utilities' compliance with RES standards. Even though they are much bigger, the Municipal Utility indicated that investor-owned utilities still sometimes have difficulty meeting the RES policies. The MO PSC recognized that some of the utilities have pushed renewables into their energy portfolio mix more than others.

The RES does have a specific percentage required for solar energy according to the MO Division of Energy. The IL-MO IOU discussed meeting the continuing requirements under Proposition $\mathrm{C}$ that will actually increase over the next three years, starting in 2018. They are trying to meet their RES with community solar projects and partnership programs through rebates offered to customers. They are supporting residential solar generation to meet their requirement under the RES. Offering a solar rebate to customers has allowed the $I L-M O I O U$ to own the rights to the residential PV arrays and include it as part of their renewable portfolio requirements. However, they cannot use that energy production forever under the guidelines of the RES. The $I L-M O$ 
$I O U$ emphasized they are trying to meet the RES along with environmental standards while keeping utility rates as low as possible.

Originally, the RES included rebates for investor owned utility customers to adopt solar technology. The MO Division of Energy explained that eventually some modifications decreased the amount of rebates. Various regulatory cases led to the capping of rebate amounts that could be paid to solar adopters. These rebates have already been expended except for the Western $M O I O U$ because they were originally exempt from offering a solar rebate under the RES for the first five years; they were already exceeding the $15 \%$ requirement for renewable energy with wind and hydropower. However, in 2015 the MO PSC determined the Western MO IOU needed a small percentage of their renewable energy to be generated solely from solar power. A court ruling then determined that they did have to offer solar rebates. Therefore, the Western MO IOU began offering rebates to their customers in 2015 . They asserted that buying renewable energy credits (RECs) would give them the cheapest lease cost but recognized the requirement to offer customer rebates in the RES. Utilities can purchase RECs to comply with the standard as a portion of their $15 \%$ renewable energy requirement according to the MO PSC. The MO Division of Energy also discussed solar rebates being offered under the RES to meet part of the solar energy requirement. This adjustment reflects modifications made in response to the required amount for rebates continuing to decrease under Proposition C.

Municipal and cooperative utilities in Missouri do not fall under the Public Service Commission and are not required to have an RES. While the State has fewer investor-owned utilities than municipal and cooperatives, no requirements for either of 
these utility types encourage development of renewable energy or offer any type of incentives to customers for solar adoption. The Municipal Utility stated, "The renewable portfolio (energy) standards only apply to investor-owned utilities. Cooperatives and municipals do not have a renewable portfolio standard. We're not required by any state law to have any percentage of our power come from renewable sources." However, some municipalities, like Columbia, have passed a self-imposed vote of their citizens.

The municipal and cooperative utilities are locally governed and controlled, so they do not fall under the Public Service Commission. Municipal utilities have a city council or board of public works comprised of citizens, who are the owners of the system while cooperatives have an elected board representing their membership to provide oversight. For example, cooperative boards have been promoting more rules and regulations as well as limiting how much solar generation can be installed by their respective cooperative utility. Some states, unlike Missouri, do require their municipal and cooperative utilities to fall under a public service commission. The Rural Co-op revealed that some states have cooperatives offering rebates because their RPSs require it. However, it often happens at the generation and transmission level because they need the RECs. These variations in oversight of utilities do create differing utility company regulations. The Installer/Consultant shared his thoughts, "So you know, that's the tough part is that there needs to be more rules and regulations on the co-ops to really get power started out there (in rural areas)."

The MO Division of Energy reported that the State Energy Plan, based on recommendations from stakeholder discussions, was developed in 2014 and has been well received. The municipal and cooperative utilities were involved in this 
comprehensive State Energy Plan and the clean power plant proceedings. The MO PSC noted that significant planning was happening to meet the EPA's clean power plan, but that has since changed because of the current administration's repeal of the regulations. The MO PSC also noted that many of the utilities involved in the discussions exhibit selfmotivation to exceed compliance regulations. The Generation Co-op revealed that they meet Missouri's standards with their wind energy and hydropower, even though as a member-owned cooperative, the MO PSC does not regulate them under the State's RES. Their hydropower currently contributes $7 \%$ to their energy portfolio, and they have continued to develop wind farms.

Statutes and regulations. A state's statutes outline the management of its RPS and the regulation for all renewable energy requirements. The RPS then set limits on solar installations and provides incentives to promote their adoption. The manner in which regulations and other policies are applied holds some flexibility according to the MO PSC. The Municipal Utility stated that right now the government is encouraging solar adoption by incentivizing it and not amending statutes to limit or better regulate it. In Missouri, customers are currently allowed to install up to a 100 kilowatt array for commercial use and only a 10 kilowatt array for residential use under the net metering limit. Depending on their rate structure, some utilities increase the size limit. Others also increase the limit if they need extra solar energy to offset a deficit in their energy mix to meet the RES. The MO Division of Energy argued that the limit for commercial arrays should be 500 instead of just 100 kilowatts. They pointed out that standards are usually streamlined for arrays of 10 kilowatts and less. If customers install an oversized array, they cannot install a state net meter and would not receive credit for any excess 
generation. Installers and manufacturers lobbying for looser statutes, requirements, and restrictions have initiated flexibility with some utilities.

However, utilities are pushing back against state governments by discussing changes in state statutes with legislators. The Installer/Consultant warned of possible impending regulation changes. Some states like Nevada, ones with largely investorowned utilities, have already begun modifying their state laws to allow more cost recovery by utilities through stricter net metering policies. This trend has motivated the Renewables Advocate to lobby the Missouri legislature through the Public Service Commission to protect Proposition $\mathrm{C}$ and the renewable regulations already in place. According to the MO Division of Energy, the MO PSC sometimes influences changes to state statutes, so lobbying through this agency can be effective to institute solar friendly regulations. The Renewables Advocate stressed that ballot initiatives remain difficult and expensive to pass. He also warned that lawmakers meddle with them easily once they are passed, thus making the education of legislators as a means of safeguarding regulations critical. The Buy-American Consultant feels like Illinois, on the other hand, is currently headed in a positive direction with levelized solar policies and funding mechanisms.

The Generation Co-op maintained that, since state regulations have more of an impact than those at the federal level, each state decides on its priorities for renewable energy and solar programs. Rebates and incentives vary state to state. The Renewables Advocate reported that Missouri is not investing much state funding into its energy policy. He added that so far the federal budget is still providing the funds. He stated, "We don't really put a lot of state money into energy policy here. It's all...federal funds." The funds are then administered in the state by the Division of Energy. However, he warned 
that the future of federally funded energy programs is uncertain. He added, "Obviously the federal government is not interested in spending any money on that stuff. I think it's just them that leaves it up to the state to decide. Each state's got to decide what priorities is it gonna be." He continued to encourage Missouri to make renewable energy a priority and embrace policy changes to address solar adoption.

The Networker agreed that policy has to play a role, and solar adoption needs to be made easier through improved policies. She stated, "So there's a policy piece of making it easier...so there is a definite benefit and the utility is on board and all of those things." While many states are modifying their renewable energy policies along with solar incentives and rebates, they are making policies more restrictive and reducing subsidies. The Generation Co-op cited Greentech Media research that published an executive report from the U.S. Solar Market Insight showing only five or six states that are not discussing a change or elimination of subsidies at the legislative or public utility commission level.

Rebates and incentives. Offering rebates genuinely helped solar adoption get started in Missouri according to the Renewables Advocate. The MO PSC reported seeing a big spike in solar adoption anytime a rebate is available. They are hearing less about solar adoption now that the IL-MO IOU's rebate has expired. The IL-MO IOU actually expended the rebate funding quickly because of its popularity. However, the popularity has declined significantly after the rebate stopped in 2013. All of the rebates in Missouri are finished except with the Western $M O I O U$ because a judge struck down the provision of the law under Proposition C exempting them. They must generate $1 \%$ of their energy mix with solar energy, and the MO PSC must agree with their calculation of the 
percentage of solar energy generation. The Western MO IOU started its rebate program in 2015 and will continue until the rebate phases out by 2020 unless the $1 \%$ solar energy cap set by the voters is reached before that time.

The Western MO IOU reported enticing people into their program with early signon incentives they offered briefly. The program gained momentum on its own and grew tremendously even after the first year. The MO Rural Development attested to increased interest in solar adoption where rebates are still offered. They are seeing the most activity in renewable grant applications where the utility provides an incentive. The MO Western IOU confirmed a similar observation; $99 \%$ of their solar customers reside in Missouri due to the rebate even though they also serve Arkansas, Kansas, and Oklahoma. She concluded that the rebate makes installing a PV array affordable for those customers who show interest in adopting solar technology.

Missouri was originally giving a \$2 per watt rebate for residential solar installations under Proposition C. Installing PV arrays without rebates costs about $\$ 4$ per watt. This rebate equaled $50 \%$ per watt rebate, which the 70 's Solar Consultant argued made solar power the cheapest form of energy. Unfortunately, the utility companies lobbied the Missouri legislature to stop the $\$ 2$ per watt rebate, and it was phased out. He claimed the utilities wanted to stop the rebate because too many people were starting to adopt solar technology. He shared:

It was a great story! Then the legislature started to get lobbied by all the utilities basically to put a kibosh on solar. That's what they did. They got to the legislature, and they cut off the two dollar per watt. They said, "No, we're not 
going to do that anymore. You're going to have to phase it out, or I'm going to stop the program.”

It is worth noting that specific goals under the 2009 SunShot Solar Program aimed to get the price of installed PV arrays down to about \$1 per watt.

Currently, the City of Columbia passed its own renewable energy policy for a $50 \%$ rebate, which equals 50 cents per watt. The 70's Solar Consultant explained that 50 cents per watt over 30 years totals about 3 cents per kilowatt discount. He stated, "If they (State of Missouri) did a 50\% a watt rebate, it is the cheapest form of energy out there. It beats anything - natural gas, coal, anything." He proclaimed a 50-cent rebate for the State would have to come from the legislature, but too much pushback at the utility level will stop the proposed rebate. He stated, “The utilities aren't going to volunteer that. It's got to come from the legislative level. But there's so much pushback at the legislative level, at least here in Missouri. It's going to be very difficult.” He asserted that giving a \$1 per watt rebate or a 6-cents per kilowatt-hour discount would greatly strengthen solar adoption.

Only investor-owned utilities in Missouri were required to offer rebates to homeowners under the State's RES. Cooperative utilities do not offer rebates for residential PV arrays. The Rural Co-op insisted they are not willing to give rebates because they would collect money from all 36,000 customers but only give it to a small number who could afford solar adoption. He elaborated that any rebates they offered would have to come from the Generation Co-op. The Generation Co-op would receive the RECs and pass the incentives through the distribution cooperatives like the Rural Coop and Suburban Co-op. 
The generation and transmission cooperatives that are giving rebates in Missouri are accomplishing it by building community solar projects. All customers who want to purchase solar energy can then opt into the community solar program on a monthly basis. The Rural Co-op insisted on their interest in a community solar program but want to see how other cooperatives do with it. He stated, “Our board is interested. Right now, they've taken a position of, 'Let's see how the few co-ops that have ventured into that, how well it's accepted in their areas."' They are trying to determine if it is worth spending customers' money on development.

The 70's Solar Consultant argued for giving rebates as the cheapest way to generate energy and that getting solar technology past the tipping point in Missouri would require rebates. As an example, giving a rebate of $\$ 1$ per watt of energy produced would make electricity cost only 6 cents per kilowatt-hour. This level of rebate would really make solar adoption take off. The Energy Consultant proposed extending the federal tax credits as an option to people without a taxable income, such as retirees, who could benefit by taking credit against their federal payroll withholding taxes. This extension of tax credits would greatly increase the number of eligible homeowners who could adopt solar technology. He also proposed including broader adjustment tariffs.

Illinois has also seen inconsistencies in their solar policies and incentives. The Surveyor explained that the State froze their funds for a period and has since reduced rebates. Vast differences separate the incentives offered by the various types of utilities. The Son-in-law/Installer shared an example of the municipal utility in Springfield, Illinois offering a \$5,000 renewable energy rebate as part of a power plant expansion and upgrade. 
Inconsistencies in policies and frequent changes in rebates and incentives are not unique to any one state. Each state decides on its priorities for renewable energy and solar programs through the regulations set forth in its RPS. Moreover, a state's RPS dictates its renewable energy policies while determining the amount of renewable energy it must generate by a given date. Since state statutes influence regulations and incentives for renewable energy more than federal guidelines, having an RPS is critical to advance solar adoption. However, every state differs in how it handle its RPS and sets utility rates for customers. Each state regulates rates and provides oversight of its public utilities individually under a public utilities commission. Some only provide oversight for investor-owned utilities, leaving elected bodies to regulate municipal and cooperative utilities. The difference in oversight ultimately affects a utility company's approach for incentivizing solar adoption and managing solar installations, which in turn influences potential adopters' willingness to install PV arrays. Thus, a state's oversight of utilities and its regulation of renewable energy guidelines impact the future growth of solar technology.

\section{Theme Five - Growth of Rural Solar Adoption}

As previously examined, solar adoption depends on several diverse factors. To increase the rate of adoption in states where renewable energy has experienced slower growth, solar advocates must address these factors along with unique considerations for rural locations. The participants discussed various programs and approaches for advancing solar adoption in rural areas. Solar adopters have several financing programs available specific to rural communities that include the Property Assessed Clean Energy (PACE) programs and Rural Energy for America Program (REAP), along with financing 
options through lending institutions like the Green Sky Program and Green Banks. Additionally, rural utility companies are exploring solar farms and community solar projects as options to increase the amount of solar power in their energy mix and bring solar technology to more homeowners.

The participants also highlighted ideas for increasing solar adoption in rural areas. More financing options would add appeal to solar technology for a broader group of prospective adopters. Many agreed that advances in energy storage could drastically increase adoption if the technology becomes more reliable and affordable. They also advocated more education for rural utility customers and increased training opportunities on residential scale solar generation for cooperative and municipal utilities. Finally, even though some of the participants claimed the solar energy market is slowly maturing, they encouraged heavier promotion of solar adoption in rural areas to increase growth in the rural energy market.

Financing options. One of the more popular financing options available to rural solar adopters, the Property Assessed Clean Energy (PACE) programs, provides a financing mechanism for renewable energy improvements on residential properties. A homeowner obtains the loan through his/her local municipality and repays through a property tax assessment (Kirkpatrick \& Bennear, 2014). The municipal lender creates an assessment district to serve as a primary lien on the property for securing the loan. The PACE assessment then becomes attached to the property and transfers with other traditional property tax assessments if the property is sold, meaning the debt is attached to the property and not the property owner (Kirkpatrick \& Bennear, 2014). The $M O$ Division of Energy explained that the loan payment occurs through the assessment of an 
individual's property tax. Additionally, the interest on the payments can be deducted as home mortgage interest.

The 70's Solar Consultant described PACE as a "game changer" for solar adoption because a utility customer will no longer have to spend money out-of-pocket for the installation of a PV array; it will pay up to $100 \%$ of these costs. He explained this payment helps solar adoption since people who cannot borrow money through a typical lending agency can qualify under PACE. He stated, "It's (PACE) more lenient than maybe a bank might require." He did clarify these loans require an individual to have adequate credit.

The 70's Solar Consultant also shared some insight into the history of the PACE programs. It started in Berkeley, California in 2008. As one of the earliest states to adopt the program, Missouri residents have enjoyed its continued popularity. He stressed that the county or municipality has to adopt for it to be a financing option in that location. The Kansas City and St. Louis areas are seeing an increased use. While availability has stretched to Jefferson City, the program was not offered in the area when the Young Adopter installed his PV array about two years ago. The Generation Co-op reported having no relationship with PACE in Southwest Missouri. Unfortunately, the future of PACE programs are unclear, as the current administration has reversed guidelines adopted under the Obama administration. The reversal means the Federal Housing Administration will no longer insure home mortgages financed under the PACE programs (Gerdes, 2017).

The Rural Energy for America Program (REAP), another financing option for rural residents who operate any agricultural related business, offers grants as well as loan 
assistance to rural small businesses and agricultural producers. Operating under the USDA Rural Development offices in each state, the REAP program awards grants up to $25 \%$ of the total project cost, from $\$ 1500$ to $\$ 500,000$. Project types can include energy efficient improvements or renewable energy installations. The MO Rural Development reported that solar installations are the most popular projects right now. REAP is the main method that the USDA and the states' Rural Development offices used to support energy efficiency and renewable technologies. The USDA allocates the funds for each state based on a budget passed by the United States Congress. The MO Rural Development summarized the intent of the REAP program by stating:

If you take a look at our mission at Rural Development, it's to improve the quality of life for rural Americans. By having this program, how do we do that? Well, we offer financial incentives either through grants or loans for a business or a farm. To qualify, a rural business just needs an agricultural related component and a location defined as a rural area, having less than 50,000 people, according the MO Rural Development. Personal residences are not eligible for farmers under the agricultural producers' option. The MO Rural Development indicated that many poultry farms have been applying for grants to fund both energy efficiency improvements and renewable energy installations. He stressed that saving $25 \%$ on the cost of a PV array is significant and makes a project more palatable. On average, about half of the grants have been awarded to farmers and the other half to rural business owners.

The MO Rural Development explained that loans are reviewed and awarded on a monthly basis while grants are based on two funding deadlines, March 31 and October 31. According to the MO Rural Development, the number of applications for grants 
varies each year. They had about 90 in 2016 and between 60 and 70 in 2017. They market the program through news releases and email notices for funding through a federal government delivery system. The applications are scored on a number of elements. For example, solar systems need to offset $50 \%$ of an existing electricity load to score well. The Rural Development office looks at a system's possible energy production and compares it to information on the National Renewable Energy Lab's website. They are also looking at the payback based on the eligible cost of a system and the proposed savings per year. These paybacks cannot include other incentives and rebates. An application must show a commitment of funds for the remaining amount. Rural Development provides an online tool for applicants to calculate their eligible project cost. Additionally, full points are awarded to a new grant recipient; someone wanting to add additional solar panels to an existing array will not score as high. Finally, more points are awarded to applicants with a smaller gross annual income as well as agricultural producers and smaller businesses.

Most grant applicants submit their applications through a grant writer or solar consultant even though the process only requires four or five forms, equaling about eight or nine pages. The Son-in-law/Installer claimed, based on his experience, the application involves answering a lengthy questionnaire. For the average person not familiar with grants, the application appears somewhat complicated. Therefore, many individuals he knows in Illinois have worked with a grant writer. The Father-in-law/Farmer worked with a grant writer but applied too late in the solar adoption process, so he was denied eligibility. Now, he recognizes the application must be submitted before making the final decision to install an array. The application is submitted during the initial planning 
stages. He plans to apply if he installs another array because of the financial benefit and cost savings in receiving a REAP grant.

The Father-in-law/Farmer and the Son-in-law/Installer discussed a grain elevator owner who installed a large PV array and two neighboring farmers who installed arrays to provide power to hog confinement buildings. All three worked with solar consultants to navigate the application process. Similarly, the Surveyor's uncle worked with the BuyAmerican Consultant and received a REAP grant for the second phase of the array on his farm. The Rural Co-op reported that two of the adopters in his Missouri cooperative were farmers. He knew that one had been awarded a REAP grant.

Various participants discussed the accessibility of other loan programs for rural residents. Having the opportunity to finance solar adoption is critical in rural areas for those who cannot pay anything upfront. The Buy-American Consultant asserted financing options are evolving:

Lending institutions are willing to lend money. That's key to finance systems. So that creates an opportunity for those that have good credit. Now we're into the middle class being able to afford to do solar because they have the means to be able to get the money to do so.

The Young Adopter financed his PV array with a home equity loan through a credit union under the Green Sky Program. Green Sky, LLC, a private financial company, provides technology to financial institutions for lending on solar installations and other home improvement projects. The MO Division of Energy also mentioned the Pay as You Save (PAYS) on-bill financing option that allows a solar adopter to pay back any financing through his utility bill. The Networker promoted having property assessed clean energy 
for residential solar sytems. Not yet a reality, this financing method would allow a low interest loan for a PV array to be paid back with property taxes. Another program the $M O$ Division of Energy mentioned, Energy Investment Partnerships, is also called Green Banks. These public-private partnerships leverage private capital with renewable energy initiatives to maximize public funds. The MO Division of Energy explained that currently they are partnering with Colorado to use public funds to enhance private capital for energy efficiency. Hopefully, this method will expand into solar adoption.

Even though funding opportunities have grown, solar adopters still face challenges in securing available grants and financing options. Difficulty in receiving grants is increasing as solar adoption increases according to the Son-in-law/Installer. Even though more people are applying, the amount of funding has not increased. In fact, the MO Division of Energy is trying to leverage more public funds since some grants are being eliminated.

In relation, even if rural residents can identify financing options, many are apprehensive to finance a solar installation. As the Surveyor insisted, financing solar adoption is just hard for many people to embrace and accept. Additionally, financing does not always reach widespread outside of urban areas. The Networker added that financing packages are sometimes available through solar companies, but she has not found many in rural areas. To broaden rural financing, the MO Division of Energy suggested, "It might be a good idea to propose a financing model for rural areas in project development since that's a key piece of the whole picture." Furthermore, financing models lack consistency from state to state. In fact, the MO Division of Energy revealed 
that some states, including Missouri, are questioning the legality of third party financing and leasing options.

While increased financing options hint at making solar technology more accessible to rural homeowners, utility companies are exploring other options to incorporate solar power into their energy mix. By developing solar farms and community solar projects, utilities are both reacting to their customers' desire to have increased clean energy and meeting the requirements to incorporate renewables into their energy portfolio.

Solar farms. Some utility companies are exploring solar farms or fields as an option for adding renewables to their energy mix. Additionally, solar companies outside of the Midwest are offering lease options for farmland in Illinois, Missouri, and surrounding states to develop large solar fields. My Dad's Friend received a letter from an out-of-state solar company expressing interest in leasing farmland for a very large PV array to sell electricity on the utility grid. The Son-in-law/Installer shared that his wife had been contacted by a solar company in Arizona offering a 20-year lease on at least 200 acres and up to 400 acres. He knew of several other farmers and landowners who had been receiving letters from the same company. He expressed skepticism on the farmers' willingness to lease valuable farmland, but he acknowledged that supplementing burning coal with a solar field may turn into a necessity in the near future. The Father-inlaw/Farmer maintained that farmland is too valuable around him in Central Illinois for growing crops versus leasing it for a solar farm. However, he predicted that some solar farms will likely be developed. 
The Western MO IOU reported considering other options like solar farms instead of using residential scale PV arrays to meet their requirements but decided against developing any solar farms based on the cost. The 70's Solar Consultant explained, "What does it cost for a utility to build a solar field? It works out to 12 cents a kilowatthour. Well, 12 cents a kilowatt-hour is higher than the IL-MO IOU charges now. They can't build a solar field for cheaper than two dollars a watt." According to him, utility companies may want to build large solar farms, but it is no more cost competitive than coal or natural gas. However, he insisted that by using land around Missouri, utilities can avoid shipping coal from places as far away as Wyoming and allow utility companies to offer a clean energy option to their customers.

Community solar. Community solar projects are gaining popularity in rural communities as a means of bringing solar energy to homeowners. Community solar, sometimes referred to as subscriber solar, gives utility customers the option to subscribe on a monthly basis. Enrolling in the community solar option allows utility customers to purchase blocks of solar power. The Suburban Co-op explained that they are trying to be customer friendly and support solar energy by offering a community solar program. That focuses on making solar adoption affordable and reliable. Customers can enroll for one month under no obligation and then opt out if they choose. They pay an additional $\$ 2.50$ per solar panel each month and can purchase as many panels as they want.

The Suburban Co-op built a 100-kilowatt array in 2016 with Shelter Insurance, a tax equity investor. Shelter Insurance owns $99 \%$ of the solar farm until the end of seven years at which time the Suburban Co-op will buy it for $\$ 1$. Shelter Insurance can utilize the tax credit and accelerated depreciation, something the Suburban Co-op cannot do 
since they are not-for-profit. They stressed that having a good relationship with various renewable energy groups has helped them considerably with the project.

The Suburban Co-op's community PV array has 400 320-watt panels that produce 41 kilowatt-hours each month. At the time of the interview in the summer of 2017, they only had 59 customers using 201 panels even though they promote it each month in the Rural Missouri magazine. Of those, nine are board members and a handful are cooperative employees. The Suburban Co-op stressed they must examine the financial considerations - insurance, taxes, cost of renting the land, maintenance in cleaning the panels annually, and a reserve fund for replacing the inverters in five to ten years - before offering community solar to their customers.

The Generation Co-op is buying power from both the Suburban Co-op's community PV array and another 100-kilowatt array installed by a cooperative north of Kansas City. The Generation Co-op said that even with these two community PV arrays and the entire customer generation from residential arrays, which equal about 10 megawatts, solar power does not show up in their energy mix. On the other hand, supporters of community solar argue that it allows customers who cannot afford to install a PV array access to solar energy. Some municipal utilities, in addition to cooperatives, have developed community solar projects as an option for their customers. One example, a solar field for the City of Nixa, was partially funded with a REAP grant according to the MO Rural Development. The array provides renewable energy to municipal utility customers who may otherwise not have access to solar technology.

The IL-MO IOU has also developed two community solar projects targeting residential customers under two rate classes and a solar partnership project with 
commercial and industrial customers. They calculated the monthly cost and then gave subscribers a chance to enroll for blocks of 100 kilowatt-hours of solar energy. Subscribers were limited on the number of blocks based on their energy usage. Initially, they waited to start the installation until they had subscriptions for a portion of the blocks. The IL-MO IOU's solar partnership program targets larger commercial and industrial customers. These customers use a portion of their land or roofs to install PV arrays and then provide the energy generated to the utility grid. The $I L-M O I O U$ is trying to meet its RES while also offering customers other services with its community solar and partnership programs as pilots to see gauge customers' levels of interest.

Utility companies' development and control of community solar projects as an opportunity to generate additional revenue caused concern among some participants. The MO Division of Energy questioned if community solar projects have to be developed by utility companies or whether third party solar developers can legally sell power to individuals. The Buy-American Consultant also raised the concern of utility companies charging customers an extra fee to subscribe. She argued that the utility companies, who claim to be not-for-profits, generate revenue by setting up limited liability companies. She cited a rural cooperative in Illinois who now operates an LLC. The Generation Coop discussed doing a similar thing in creating LLCs. The Buy-American Consultant insisted that the utility companies should lower customers' rate once they have paid for the system, but she doubted they actually would.

Regardless, many of the participants promoted the benefits of community solar projects. The Renewables Advocate maintained that having more community solar programs in Missouri would benefit a larger number of utility customers. He stated, "I 
think having community solar in the state would be a big thing." Illinois is also offering community solar and incentivizing solar generation for low-income communities through the "Solar for All" component of the "Future Energy Jobs Act". The Father-inlaw/Farmer said he might support community solar if he lived in town since the Son-inlaw/Installer calls it a good option for adopting solar technology for individuals who do not have the space to install a PV array with a community solar project. The Energy Consultant urged utility companies to make solar energy an option for someone with a roof that is shaded or may not be oriented the correct direction. He also added:

The other thing about community solar that's nice is if they (the homeowner) move somewhere else in the community, they don't have to worry about losing their solar benefit. How many people have you heard, 'I would do it, but I'm probably not gonna live in this house ten years from now?' Community solar fixes, addresses their concern.

He also proposed using brownfields for community solar projects as a means of saving valuable ground used for growing crops and significantly reducing real estate taxes on land formally declared as brownfields.

Through these various approaches to developing community solar projects, utility companies can provide numerous benefits to their customers. Community solar lets utility customers purchase blocks of solar power, giving homeowners who cannot afford a residential PV array the opportunity to use solar generated power. However, while community solar programs provide a means for utility companies to offer their customers an affordable and reliable solar option, some utilities have been reluctant to develop a project because of the expense and marginal responses from customers. 
Solar farms can increase the percentage of solar power in an energy mix, but the expense of developing the large arrays along with the cost per kilowatt of generated power can deter some utilities. Regardless of the challenges, the development of community solar and solar farm projects indicates that utilities are exploring various options for increasing the amount of solar generation in rural areas. These projects may simply be an effort for utilities to maintain more control over power generation. If community solar and solar farms continue expanding, they may well slow the adoption of residential scale PV arrays. Therefore, developing affordable and reliable battery backup systems could fuel the adoption of residential scale PV arrays.

Battery backup. Energy storage systems are currently not an option for most solar adopters because of reliability and cost. Off-grid systems that use batteries require significantly more maintenance then grid tied systems. The batteries require regular maintenance and are quite costly to replace. Additionally, the lifespan of most batteries is around ten years, which is less than half that of most panels. The cost prevented $M y$ Dad's Friend from considering installing batteries, but he recognized how better battery backup systems will change the solar market. He frequently looks online for improvements in battery options. The Networker agreed that batteries must decrease in cost. As the Western MO IOU highlighted, available ones remain too costly, and utility companies would need to find a viable option for renewable energy storage to compensate for the intermittent generation of renewable energy. In fact, the Networker believes utility companies worry about better batteries. She argued that they should instead change their focus. She suggested, “And I think that's one of the things that 
utilities fear, but then the forward-thinking utilities think, 'Well how do we use this to our benefit?’ Not, 'Oh my God, we can't let this happen!'”

The MO Division of Energy stressed the necessity of energy storage in rural areas as a key variable to increase solar adoption. The Generation Co-op added that energy storage comprises part of the solution, insisting that energy storage makes sense with or without solar adoption. The Western MO IOU stressed the importance of PV arrays with storage capacity so the electricity is available when needed. The MO Division of Energy predicted utilities will be forced to examine storage options as battery technology decreases in price; one of the IOUs in Missouri is currently working on energy storage, which could be valuable to rural cooperatives.

If energy storage does advance to the point where utility customers start disconnecting from the grid, the Suburban Co-op emphasized that it will drastically impact the role of utilities. He proclaimed, "The game changer is batteries. And if anybody ever comes up with a battery that can truly generate the power and have enough in quantity, look out. It's a game changer for everything." He acknowledged that they may become just a grid company in 15 to 20 years. In fact, the Rural Co-op foresees energy storage upending the business model for all types of utilities across the country if it becomes cost effective and customers no longer need the utility grid. He often reads various electrical engineering journals to stay updated on energy storage. He wondered if at some point the utility grid will become obsolete. He compared people disconnecting from the utility grid in the future to people disconnecting their landline telephones. Traditional telephone cables are vanishing quickly, leading him to ponder whether the utility grid will be the same. He stated, "I think a more interesting take on that is there at 
some point where disconnection becomes the preferred method of supplying." All of the utility companies agreed that energy storage will likely impact energy generation, transmission, and distribution significantly in rural areas. Therefore, as the Generation Co-op affirmed, the importance lies in utilities staying informed about battery technology. He used Elon Musk's power wall as an example because it, along with other advances in energy storage, could be a "game changer". The utility companies, thereby, acknowledged they cannot be complacent and assume the energy industry will continue operating under protocols of the last century.

Training. Furthermore, the recognition of training and education along with promotion drive adoption forward in rural areas, making each an integral part of advancing solar technology. Providing training opportunities on the latest technical advances coupled with policy and regulation changes will increase the likelihood that utility companies will support solar adoption. Moreover, utility support is imperative to boost the number of PV arrays installed by rural residents. However, disparity between the level of knowledge and available training with investor-owned utilities compared to that of cooperative and municipal utilities is especially apparent in rural areas. Additionally, the MO Division of Energy reported more marketing, customer outreach, and training are happening by investor-owned utilities because they have greater resources. As an example, the $I L-M O I O U$ has built a new training facility in St. Louis and is developing training programs for their personnel who manage services for residential solar equipment.

This level of commitment to training does not always exist for smaller, rural utility providers. The Networker shared: 
But then you've got the rural electric cooperatives and municipal utilities who don't have that same breadth of expertise. This is how it could be benefiting you. Stop putting your head in the sand. Start educating at that level. But that rural utility has to be part of that group, listening to that, being educated and in some towns, they just don't.

Additionally, small, rural cooperative and municipal utilities often lack resources to provide in-house training. The MO Division of Energy proposed training these types of utilities on PV installations through their associations or the resources available from NREL or USDA.

Multiple participants acknowledged the need to train rural utility providers. For example, the Renewables Advocate stressed the importance of training cooperatives throughout the state on the latest industry standards and pricing for residential-scale distributed solar generation. While many participants focused on cooperative utilities often associated with rural utility service, this training need also exists for non-urban municipal utilities with limited resources. The three IOUs in Missouri all have both urban and rural areas of service according to the MO PSC. Furthermore, the MO Division of Energy noted that the Western MO IOU services many rural areas. Solar adoption would benefit in each of these areas through additional training for providers.

The Networker also maintained the importance of raising utilities' awareness with workshops and training opportunities through additional organizations including the American Public Works Association (APWA), who could start promoting solar adoption to the municipal utilities they represent. She advocated educating utilities and mentioned that the Department of Energy has awarded grants to help educate utility workforces. 
Additionally, she advocated sharing success stories at state and city government gatherings about solar projects in California and other more progressive states in the U.S. Regardless of the type of utility, rural providers have to be included in plans to provide a more widespread training. The Buy-American Consultant serves on the Illinois Solar Energy Association (ISEA) board and participates in training projects as part of the organization. She chairs a committee in ISEA to help standardize policies for municipal and cooperative utilities to make solar adoption more consistent and predictable for all utility customers. Her committee works with the Illinois Municipal Electric Agency (IMEA) to train safety personnel, including municipal electricians, firefighters, and first responders on understanding and working with solar technology.

The Buy-American Consultant also wrote grants to fund electrical training and install one-kilowatt solar awnings at three rural schools in Southern Illinois. The solar awnings were then part of the training program for electrical contractors. She used classes that other ISEA board members teach around Chicago to develop her training for these rural areas of the State. Previously, very few solar installers worked in Southern Illinois; however, through the training program, seven installers will become certified. She insisted that the installers need hands-on training to sell solar technology effectively. She continues working through her committee to help standardize renewable energy policies for municipal and cooperative utilities.

Looking forward, the Rural Co-op mentioned that training has been improving for cooperatives through continuing education courses to meet recertification requirements for maintenance technicians. This training provides optimism that utilities, both urban and rural, are recognizing the growth potential of solar PVs. Ideally, utilities will 
cultivate a culture of support as increased education and promotion prompts more customer interest in adoption.

Education. Solar growth in rural areas also depends upon educating the residents about solar technology. The Buy-American Consultant insisted that education of the general public will eliminate the fear people have about solar technology and push solar adoption forward. Other participants agreed, citing a variety of educational opportunities occurring throughout the solar industry that can increase solar adoption. According to the MO Division of Energy, homeowners are being educated through utility bill inserts, home shows, and other events. The Energy Consultant, on the other hand, tries to educate rural residents through lectures. Recently, he gave a presentation to an economic development group in Southern Illinois on solar adoption's potential boost to local economies.

As another example, the Buy-American Consultant teaches classes on the introduction to photovoltaics and site assessment as a certified renewable energy trainer. These classes cover the general knowledge of solar technology such as understanding how a PV array generates power, tracking the path of the sun, and recognizing the basics of shading. She is also beginning to teach about solar technical sales, a program that outlines how to develop a cost model to demonstrate the financial performance of an array over time. Her diverse audiences range from young people interested in a career related to solar technology to homeowners who want to educate themselves on solar adoption. She speaks with potential customers about how PV arrays works, what incentives are available, and how to complete a system sizing analysis. While none of the classes offer college credit, she does work with an area community college who used State of Illinois funding to complete a PV installation for educational purposes. The PV 
array provides a variety of events from solar tours to legislative mixers. She has used her connections from these events to educate state legislators along with other levels of government, including mayors and municipal boards. Topics often include the basics of net metering and the reconciliation process for billing.

Still more participants echoed many of these same ideas on solar education. The MO Division of Energy insisted that educating homeowners will help them understand potential issues and the realistic payoff for a solar system by using sources like PV Watts. The Networker and the Renewables Advocate repeated the benefit of educating state legislators, arguing for job creation and economic development versus just environmental protection. The Networker stated, "I think even the legislators in Missouri have a true lack of knowledge about this topic. They're going to tow the party line." She added:

We have to put it all around economic development because of their mindset. We can't say, 'Save the planet - renewable energy!' But when you realize what an impact on economic development it is for our state, it's crazy, and that's how we have to couch it.

The Renewables Advocate insisted that solar adoption needs to be talked about in a different way. People need to be educated about it differently, so they look at it from every perspective and understand the real world application. He stated, "Just because we're talking about it in a different way, and we're trying to educate people about it in a different way, it doesn't mean we don't care. It just means that we're trying to make people look at every side of it." He insisted that rural residents might love solar power if the laws allowed them to take advantage of it and they understood and heard more about the opportunities for solar adoption. 
Promotion. Additionally, promoting solar technology in rural areas must continue expanding to increase the number of adopters. Familiarizing the public with PV arrays remains critical to increase the adoption rate of solar technology in rural areas. The Father-in-law/Farmer insisted that exposing people to solar technology helps it continue to grow. Increased exposure also increases people's awareness of its benefits according to the Buy-American Consultant. The Networker explained that more awareness allows people to see how adopting solar technology benefits them and helps alleviate their fears, such as potential damage to their roofs. She proclaimed, "I do think we've made some amazing progress with the investments that were made in the SunShot Solar Program. I think the awareness, getting the price down..." However, she maintained that the information on solar technology has to be easier to understand and access.

The Buy-American Consultant advocated promoting solar adoption by publishing articles and creating connections between adopters and others in a community with an interest in solar technology. She contributed to an article in Successful Farming about an Illinois farmer who installed his own PV array. She has also created a "solar family" of adopters to promote connectivity between the individuals. She sends a "solar welcome" on Facebook when an installation is finished and is currently working on a promotional video series. She wants to encourage adopters to tell people about solar adoption and have those individuals tell more people. She stated:

And so that's another thing that I think is important, is creating connectivity. Then the people in the family go out and tell other people. So it reminds me of that commercial. I don't know if you remember, what was it, Alberto VO5? She washed her hair and then she told her friend about it and so on and so on. I think 
of that, so I'm like that's what it is. That's how it is. That's the way I want to be with solar is I want it to be the so on and so on and so on.

The Networker asserted that consultants and installers should be talking to individuals about residential-scale PV arrays. She claimed it may even take them knocking on doors in neighborhoods of houses with roofs oriented correctly. The Energy Consultant, for example, promotes it at trade shows and other events. The Generation Co-op reported that installers are certainly advertising solar adoption in his area. He sees installers promoting the Western MO IOU's rebate around the larger urban areas, which then spills over to areas that are more rural. The Generation Co-op remarked that rebates along with advertising can be effective in promoting solar adoption. He stated, "There are pockets...generally around where there is a dealer that is aggressively marketing. I was at the farmers market in Springfield; there was a solar dealer there trying to sell his panels."

A concerted effort beyond the promotion by consultants and installers is needed to move rural adoption forward. Promoting solar technology in rural areas should center on the unique considerations for rural solar adopters. These considerations include financing options only available to rural residents along with programs like solar farms and community solar projects that bring solar power to a broader audience. As utility companies explore these programs, financing options like PACE, REAP, Green Sky, and Green Banks give rural homeowners more opportunities to install their own residential scale PV arrays. Meanwhile, education and training provide a means for informing utilities, legislators, policy makers, and the public about solar technology and changes in regulations to ensure increased rural adoption. 
The idea of growth in rural solar adoption elicits an image of the wide-open landscape throughout the Midwest and numerous PV arrays converting the sun's rays into electricity. As the $I L-M O I O U$ noted, having more land in rural areas is a positive factor for installing PV arrays, and the ideals of rural living encompass an independent lifestyle where residents have the freedom to generate their own electricity. In addressing the need for independence, the Renewables Advocate pondered, "I think it plays into why people want to live in rural areas." Even with increased promotion, the successful implementation of solar energy in rural settings depends on potential adopters' willingness to explore the adoption and installation process.

\section{Theme Six - Adoption and Installation}

The participants displayed several consistent behaviors during the adoption process. The solar adopters, utilities, and installers/consultants all discussed the process of adopting solar technology by highlighting similar behaviors in solar adopters. These behaviors include adopters developing their knowledge on prior and related experience while showing an interest in solar technology or other renewable energy options. Behaviors also center on demonstrating an interest in new technologies in addition to researching and experimenting with solar technology. Considering various types of installation and promoting solar adoption positively combine with these previous behaviors to provide a better understanding of the 5-stage decision process of adopting a technology. The stages of adoption include awareness, interest, evaluation, trialability, and adoption as part of Rogers' (1995) Theory of Diffusion of Innovations. Not all individuals adopt solar technology in the same amount of time. Rogers' five attributes: 
compatibility, trialability, observability, complexity, and relative advantage can explain the varying rates of adoption.

The adopters and installers/consultants described diverse experiences that led to adopters' awareness of solar technology. Seeing PV arrays firsthand is one of the most obvious and meaningful ways. For example, My Dad's Friend saw PV arrays around his area, representing his initial awareness, and the Firefighter knew someone who had already adopted solar technology. The Firefighter said he found solar technology interesting long before he adopted. He waited until he experienced it firsthand, seeing other homeowners' arrays and different types of systems on a solar tour. Similarly, the Father-in-law/Farmer remembered first seeing solar panels in urban areas, like St. Louis and Kansas. He then learned about solar technology in rural applications at a farm exposition before discussing solar adoption with the Installer/Consultant. He was aware of the Corporate Farmer's large array, which the Corporate Farmer installed a few years earlier after seeing PV arrays and other renewable energy forms. The Corporate Farmer discussed seeing other PV arrays and one neighboring farmer's wind turbine. The Surveyor, on the other hand, only knew of one other array in his area before he adopted. The Engineer uniquely attributed his knowledge to being an engineer involved in the construction industry. He attends professional engineering seminars once a year where he first heard about solar technology.

Other solar industry professionals influenced the installers/consultants in various ways. The Buy-American Consultant learned from other renewable business owners who provided advice, yet the 70 's Solar Consultant received encouragement to become involved in the solar consulting business from a friend tracking solar technology in 
California. The Energy Consultant, however, traveled thousands of miles attending workshops and presentations on solar technology to learn more. He insisted that the most important workshop was given by John Wiles, a foremost expert on solar technology, who discussed code compliant issues for PV installations.

During the second stage, the participants developed an interest in adoption based on their awareness of renewable energy and a general curiosity in technology. The Corporate Farmer expressed an enthusiasm for renewable energy in general and acknowledged considering other possible renewable energy technologies (RETs). He first considered wind power and compared it to the cost and maintenance of solar power before ultimately deciding solar technology was the better option. He preferred solar technology because it requires little maintenance after installation. Moreover, tax incentives, energy credits, and available rural development grants often apply to solar adoption easily. The Father-in-law/Farmer also considered wind, but the salesperson for small wind turbines actually recommended solar technology as a better option. For the Engineer, geothermal systems in California many years ago while he served in the Navy were the only RET with which he was familiar. My Dad's Friend installed a geothermal system 15 years ago, giving him an appreciation for saving money through renewable energy adoption. The Energy Consultant even researched and dabbled in solar thermal for hot water heaters and tested a trial on his father's house for HVAC in the 1980's.

All of the adopters revealed a willingness to research solar technology through a variety of sources to increase their interest before deciding to adopt. The Father-inlaw/Farmer reads extensively about new farming practices and started reading about solar technology, which prompted him to adopt after becoming aware of solar energy 
generation. My Dad's Friend also read about solar technology before deciding to adopt and still looks online periodically for improvements in battery backup options. The Firefighter and Young Adopter researched online to learn about solar technology; the Young Adopter admitted that the internet and Google made researching on his own easy. However, he admittedly possesses a strong self-initiative to learn about solar technology and a willingness to educate himself through research. The Surveyor used online resources and tools too, in sizing his array and researching the optimum angle of 32 degrees for his panels. Even the $I L-M O I O U$ spokesperson warmed up to the idea of solar adoption after looking at it online and now uses internet resources like the solar calculator on Google. The IL-MO IOU eventually added their own online resources for answering questions for potential adopters. Nevertheless, the MO Division of Energy uses the technical assistance team for solar technology from NREL and gets data from the Energy Information Administration (EIA). Additionally, they read trade press articles in journals like Utility Dive and ENE News to stay updated on advances in solar technology. An interest in and a willingness to embrace new technologies formed a common characteristics among the adopters. The Corporate Farmer expressed his interest in trying new things with technology. He stated that he is always willing to try new things in both farming and technology. I saw this firsthand riding with him in the combine as I conducted the interview. A sensor would beep, indicating that he had reached the end of a row of crops. I was struck by how advanced the technology of farm equipment has become (see Image 16). This realization was further reinforced when I rode with my dad as he plowed a field in one the Corporate Farmer's tractors that almost drove itself with the use of GPS. The Engineer also expressed an interest in new technology and was 


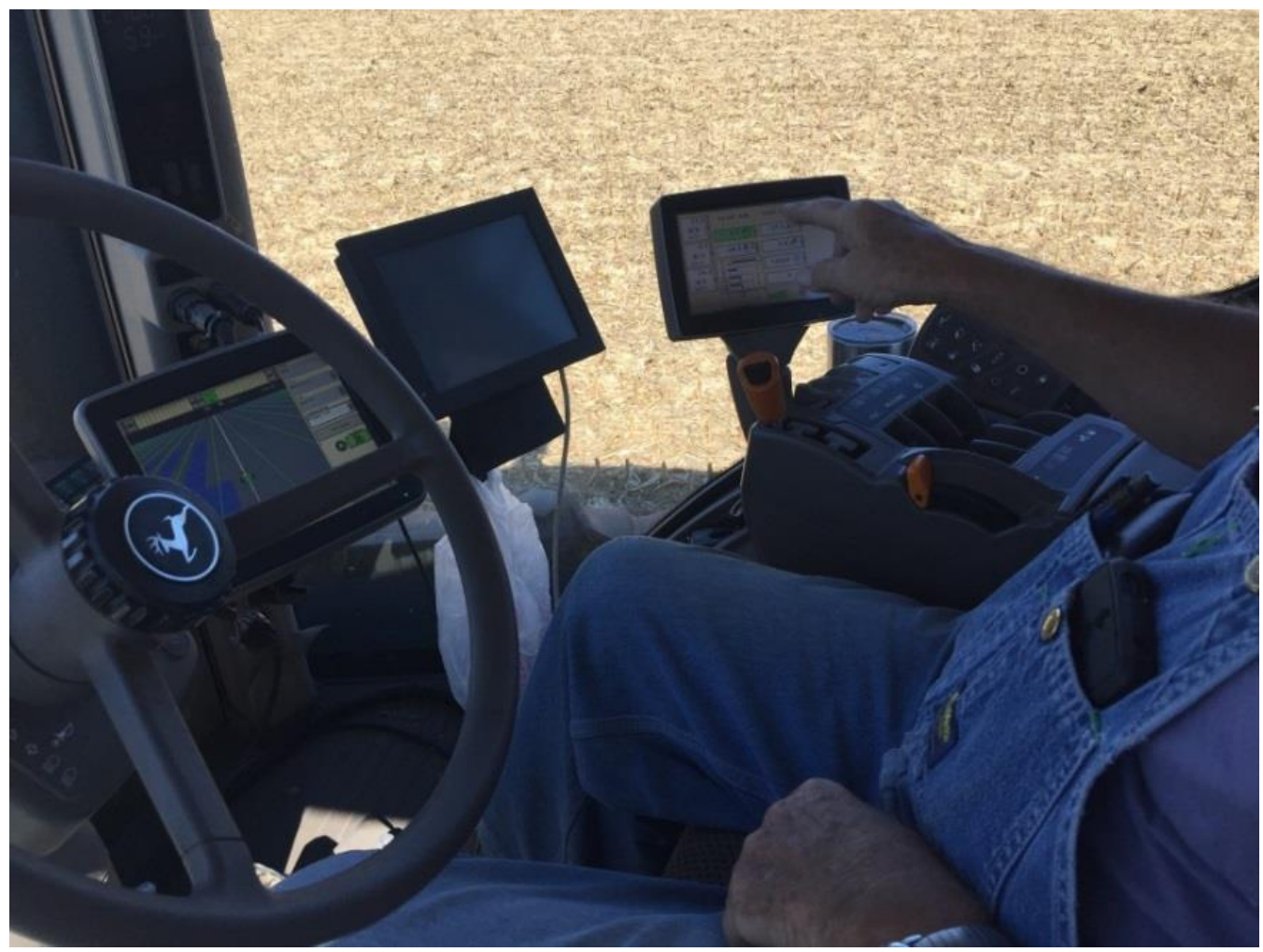

Image 16. The Cooperative Farmer operating the GPS in his combine

partially motivated by this interest to adopt solar technology. He experienced technology early in his Navy career and first used a computer in a construction battalion to complete construction project schedules.

The participants' evaluation - the third stage - determines how to install the panels, where to locate them, and what size of array produces the required power. The Engineer, for example, carefully evaluated how and where to place the array on his property to take full advantage of the sun without drawing attention to it. He ultimately decided on a ground mounted system to avoid putting holes in his slate roof. $\mathrm{He}$ mentioned that installing a ground mounted system has appealed to many homeowners.

Evaluating the location of the panels often requires a thorough site assessment. Someone knowledgeable in determining optimal solar generation from a PV array should conduct the site assessment. This individual is often a solar consultant or installer but can 
be a potential adopter trained on site assessment. The Buy-American Consultant teaches classes throughout Illinois on the steps involved in determining the usability of a site. Trained as an independent site assessor, she provides reports to homeowners for use by a solar contractor.

A solar adopter must also decide if he/she prefers a roof or ground mounted system. Deciding where to place panels is usually based on a personal preference unless the adopter has a roof not conducive to solar panels because of its orientation or pitch. The Father-in-law/Farmer wanted his array on the roof of a machine shed so it is out of his way. However, some of the participants, including My Dad's Friend, the Firefighter, the Young Adopter, and the Surveyor never considered a roof mounted system. For My Dad's Friend, he had heard panels mounted on a roof produced less power. Both he and the Firefighter worried about the panels causing leaks in their roofs. My Dad's Friend chose a prefabricated aluminum frame for his ground mounted system, typical of many ground mounted systems described by the Energy Consultant. Aluminum rails hold the brackets for the panels that are supported by a two-inch diameter pipe structure set in 12inch diameter footings set six-feet deep to withstand the wind uplift.

The Son-in-law/Installer stressed that panels on a ground mounted array can be installed more easily at the correct orientation of straight south and adjusted to the correct angle. Regardless, if a customer prefers a roof mount, he recommended placing panels after first installing a new roof. He suggested that shingles may even last longer when covered by a PV array. However, the freezing and thawing on the roof has to be considered. Shingle roofs have to be properly flashed, and the panels have to be installed in a portrait orientation. More labor is involved with shingled roofs because of flashing 
the roof properly, installing aluminum rails, and connecting the supports into the rafters with lag screws. The appearance of a roof mounted array is a consideration of some adopters, as well. The Installer/Consultant indicated designing arrays on roofs to blend in with the aesthetics of buildings as one of their goal.

Installing PV arrays on metal roofs presents fewer challenges. Installers can easily clip the panels to the ridges of the corrugated metal in a landscape orientation. Regardless of the roofing material, the Son-in-law/Installer cautioned that panels cannot be tilted to the correct angle if the pitch of the roof is too low because of uplift from wind. The Energy Consultant said the mounting systems for solar panels are so strong that he has seen panels remain attached to a roof that was blown off. The Son-in-law/Installer estimated that he installs an equal number of roof mounted arrays versus ground mounts.

Sizing the array correctly using past energy usage was another important step in the participants' evaluation. The Municipal Utility advised sizing an array to be net zero if the state or municipality does not buy excess power. The Engineer faced this limitation, so he designed his system to produce just less than his monthly average energy consumption over a three to four year period. He had documented his power usage since 2007. My Dad's Friend installed a 20-kilowatt array because he had already signed an agreement with his electric cooperative before they started limiting the size to 10 kilowatts. He sized his array based on his energy usage. He suggested the cooperatives are limiting the size as more people start to adopt solar technology. The Farm Matriarch has service with the same cooperative, but her family was limited to a 10-kilowatt system since they installed their array after the limit was set. 
Consultants also provided vast knowledge on sizing arrays. The 70's Solar Consultant stressed the necessity to factor in production loss over a 20-year period, and the Energy Consultant noted the importance of considering the amount of space required in sizing an array. He estimated that 72 square feet are needed for every kilowatt. As an example, the 5.8-kilowatt array on his roof required 880 square feet to meet code. As another example, the Suburban Co-op's 100-kilowatt array for their community solar program sits on slightly more than one-half acre and generates what it was sized to produce. The Son-in-law/Installer shared that the largest array he has installed is a 225kilowatt solar field for a hog confinement building to house 8,000 animals.

To assist customers with assessing solar adoption, the Rural Co-op gives potential adopters their energy information for the last 12 to 36 months. However, he warns people not to oversize their arrays since they will not be paid for any excess generation. He noted that the early arrays installed by their customers were three to five kilowatts but are now anywhere from three to fourteen kilowatts. He claimed that if an array is sized correctly, it should create a surplus in March through May and September to November and then use these RECs the customer earns to supplement June through August and December to February, respectively.

Trialability - the fourth stage - refers to the degree to which participants were able to experiment with the technology on a limited basis (Rogers, 1995). The Engineer started searching for information online five years prior to installing. He did an experimental analysis using two years of data based on previous energy use. He also researched the best adjustable racking systems and drew up initial designs. He shared his charts of information and drawings that helped him determine whether to install an array 
(see Image 17). He stated that anyone can calculate the economic feasibility to adopt solar technology. Through his research and experiments, the Engineer reviewed solar energy generation extensively before adopting. The Municipal Utility noted the likelihood of considerable "tinkering" or experimenting with solar technology in rural areas because rural homeowners pride themselves in being able to do things themselves and the panels can be easily ordered from a catalog.

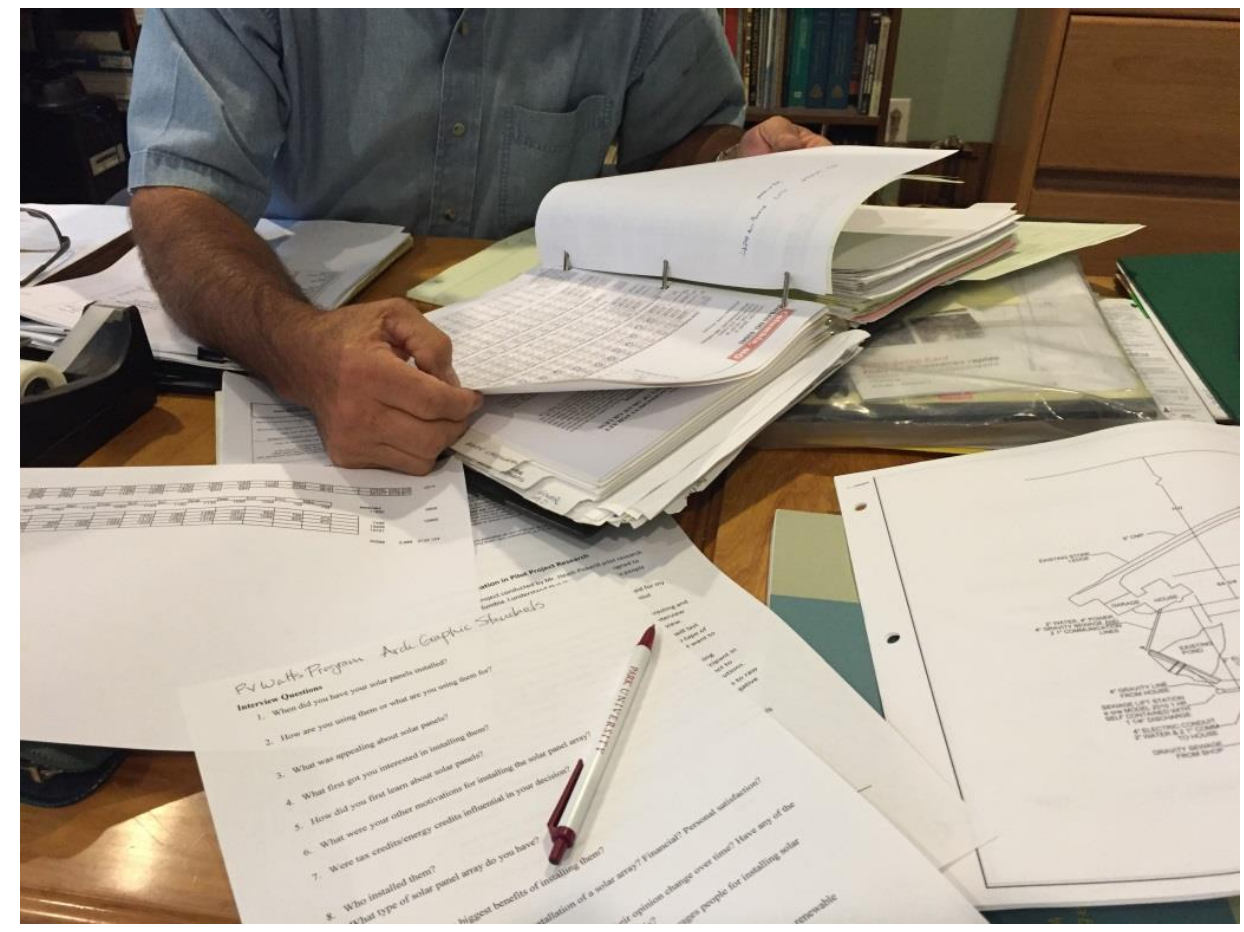

Image 17. The Engineer's charts and drawings used to design his PV array

The Energy Consultant even recognized the importance of trialability through a willingness to make changes during the design process to please customers. He also stressed documenting the costs and scope of work during construction for each installation to learn and make improvements for the next solar project. He uses his own home as a test bed and practices what he promotes to potential adopters. He stated, "I use my home as a playground because I didn't want to go out and preach something that I 
didn't also practice." He started by making his own home energy efficient and then implementing energy savings methods at four of his family's retail stores and their office building before installing a PV array on his house. The Installer/Consultant shared a similar experience, which prompted his business interest in solar technology. After installing a PV array on his house, the Installer/Consultant started installing residentialscale PV arrays.

Gaining a comprehensive understanding of solar technology through awareness, interest, evaluation, and trialability led to the participants' adoption, the final stage in the process. The Buy-American Consultant estimated that anywhere from 50 to $75 \%$ of the people who inquire about solar technology install a PV array. Once they reach the final stage, adopters work through the necessary actions differently. Most of the adopters expressed excitement in involvement with the process. The Firefighter wanted to start sooner than he did but waited until the Buy-Americann Consultant knew the exact amount of eligible rebates. While all of the adopters indicated some level of involvement in designing their system, the Engineer designed his system almost entirely on his own. Having a bachelor of science in mechanical engineering and master of science in civil engineering contributed to his ability to design his own system. Regardless of the extent to which adopters participated in the design process, all had to collaborate with various entities, including their utility, the installer, and the city or other local government agency where they were installing their systems. This collaboration created overlap between actions as the participants navigated through adoption.

Only the Engineer was able to design his own system. Most installers/consultants are directly involved in the design. The adopters, other than the Engineer, worked closely 
with their installers and reported no major obstacles. Typical tasks in the process include requesting a Google Earth aerial view, analyzing the array size, projecting the energy generation, and completing a cost modeling for a system. The final task, conducting a site visit after the installation, ensures everything works. Two of the participants, the Firefighter and Surveyor, installed their own arrays. The Buy-American Consultant witnessed the excitement of these adopters who completed their own installs and did not have any questions or concerns from them.

Installers represent just one of the many entities that adopters collaborate with during the adoption stage. The utilities play a key role because they must know who will design and test the system. The Municipal Utility explained that their involvement starts by meeting with the individual to discuss the entire system. They want to review the design and ensure the array is sized appropriately. The Municipal Utility considers the production curves in the design of the array to avoid excess energy production. By reviewing the plans, they make an assessment of whether the customer understands what they would be getting. Their goal is to help the customer make an informed decision.

Permits and inspections must be coordinated through the city for any installations within city limits. Permitting requirements present more of an issue in bigger cities. The Western MO IOU explained that needing a building permit depends on the location. The Corporate Farmer and Surveyor stated that installing in a very small town had the advantage of having no building codes or permits and made the approval process very easy. The MO Division of Energy added that the State of Missouri does not have many specific permitting requirements for solar installations. The Municipal Utility indicated that the permitting process in their city of about 20,000 is standard from utility to utility 
and not overly complex. For an installer who knows what he is doing, the process is relatively easy.

Proper installation is critical because, as the Municipal Utility stressed, installing panels correctly protects linemen from being injured or killed. As the Energy Consultant revealed, solar panels produce enough DC electricity to kill a person. They convert DC power to AC at a very high voltage and amperage. For this reason, training for electricians and installers ensures PV arrays are safe. PV arrays must be installed to meet the National Electric Code as well as the International Building Code, which dictates requirements such as the amount of space surrounding panels on a roof. The National Electric Code requires a disconnect switch at the meter. Unfortunately, most people lack any knowledge and understanding of these codes according to the MO Division of Energy. Additionally, many states, including Missouri, are home rule states, so the state cannot require local municipalities to adopt certain building codes.

A varying degree of experience and qualifications for installing PV arrays existed among the consultants, installers, and adopters. The 70's Solar Consultant is one of only a few licensed solar installers in Missouri outside of Kansas City and St. Louis. He knows many of the other installers through his membership in the Missouri Solar Energy Industries Association (MOSEIA). The Son-in-law/Installer was previously a union electrician without a license. He installs PV arrays under the Installer/Consultant's license in cities with building code enforcement. Licensure is usually a non-issue since the majority of his installations are for farms and rural businesses.

The Energy Consultant, who passed the difficult North American Board of Certified Energy Practitioners (NABCEP) test to become certified, has witnessed some 
electricians installing solar systems incorrectly because they were not properly trained on PV arrays. He also expressed concern that some adopters install their own arrays. However, the Buy-American Consultant, one of only a few NABCEP certified consultants in Illinois outside of Chicago, has worked with three adopters who completed their own installation. She admitted nervousness at first about the liability of do-ityourself installations, but it was never an issue. As a consultant, she provided the engineering documents and access to the panel manufacturers' technical support team. She had an electrical team complete the wiring. Her confidence in rural adopters installing their own arrays is based on farmers' general knowledge. She stated: Because I came up with this idea that ag producers in many cases are very well versed in running excavation equipment, know a little bit about everything. Well some of them have been out on the farm working since they were little kids, right? She found no reason they cannot install a ground mounted system if they can read a wiring diagram.

The IL-MO IOU acknowledged that having a consultant install an array adds about $\$ 1$ per watt, which brings the install cost to about $\$ 4$ per watt. The 70 's Solar Consultant admitted that the sales process adds significantly to solar adoption. The ability to install much of their own system to save money certainly motivated the Firefighter and the Surveyor. They were confident in their ability to install PV arrays because of related experiences. The Firefighter had training on backup generators, which gave him experience working with electrical systems. The Surveyor grew up on a farm, welding and working with metal, so he was capable of erecting the racking system. He installed his own system, one for a friend, and a large array in two phases for his uncle. He 
encountered some resistance from the utility company on his own system, but he reassured them that it would operate safely. He purchased his panels and inverters online. He learned how to install the systems more easily after the first one and modified the racking system for the other two. While the Young Adopter had the 70's Solar Consultant complete everything on his installation, including calculating the size, he is willing to install a larger array himself if he moves.

Although some adopters feel comfortable installing their own PV arrays, most adopters the MO PSC knows have worked with installers. The Rural Co-op also reported that their primary contact on new PV arrays is with the installers, who sometimes send the solar applications for approval. He tells a potential adopter that he should have a civil or structural engineer check the structural loading on the roof, check for relevant building codes, and inform the homeowner's insurance provider. The Western MO IOU has had over one thousand PV arrays installed since its rebates started in 2015 and has seen several solar installers from states like California come to Southwest Missouri because of increased solar adoption due to the rebates. The Western MO IOU and the Suburban Co$o p$ warned that potential adopters have to be cautious of some installers. For example, the Suburban Co-op stated that solar energy is being misrepresented by many of the vendors who claim it is cheaper than power from utility companies. Local installers can be more reliable.

Several of the participants attested to the ease of installing solar panels. While the Energy Consultant claimed installing a PV array requires a diverse skill set with the right training and tools, the Surveyor, who completed his own installation, and the Son-inlaw/Installer insisted the process is not complicated. The Firefighter, who also installed 
his own array, prepared all of the materials for the installation and erected the racking system with the help of a few friends. He only had to ask the panel manufacturer one question when installing the panels. A licensed electrician connected the wiring once he installed the panels.

Additionally, an installation does not take long. My Dad's Friend and the Fatherin-law/Farmer boasted that their arrays only took two days to install. The Son-inlaw/Installer agreed that typical installations only take two days, and the longest has taken four days. In Illinois, he uses a post pounder to drive 13-1/2 foot support posts six to seven feet in the ground, eliminating the need for concrete. It also eliminates the concern of open footing-excavations filling with water like the Firefighter experienced. The equipment, a $\$ 100,000$ investment, works well in Illinois, but the Son-inlaw/Installer recognized it may not work in Missouri's rocky soil. He has also considered purchasing a utility locator because he frequently encounters buried utility lines on farms.

Having a system inspected and tested, the last step in the installation process, requires a licensed electrician or engineer. The Son-in-law/Installer explained that installers turn an array on and test it before the utility company conducts an inspection. They use a knife-disconnect switch on the meter to prevent the array from sending power to the utility grid until it passes inspection and approval. The utility company normally replaces an existing meter with a net meter when they test the system. The $I L-M O I O U$ simply reprograms their meters. For this reason, the Father-in-law/Farmer, who has electrical service with the $I L-M O I O U$, did not have to install a second meter. The Son-inlaw/Installer reported that once the meter has been replaced or reprogrammed and the system is tested, the utility turns on the system and leaves it. 
When inspecting and approving a system, the $I L-M O I O U$ places a sticker on the system showing the installer's name and takes photographs for their records, a requirement of the MOPSC. They also require installers to follow proper guidelines and safety measures before a licensed electrician or other authorized professional inspects each array. Similarly, the Western MO IOU requires PV arrays be installed to its specifications as part of its rebate program. The utility then verifies the installation before approving the final connection to the utility grid. A city code official completes a code review during the approval process for the Municipal Utility, inspecting items like the construction of ground mounted systems, site setbacks, and roof supports for roof mounted systems.

The $I L-M O I O U$ also ensures the safety of its maintenance personnel through training so they approach solar equipment, such as the panels and smart inverters, safely from an operational and maintenance standpoint. For the safety of maintenance crews, it also require primary disconnect switches on breaker boxes for micro inverters (see Image 18). Easy-to-install micro inverters provide power production even when shading may be an issue. The Rural Co-op and Suburban Co-op also require a primary disconnect switch along with surge protection on the panels in case of a lightning strike. The Rural Co-op noted that they inspected the first few installations but now just require the installer to send photographs showing the disconnect switch properly labeled as "PV disconnect". Then, they also require the material specifications and cut-sheets from the installer. They add the PV array to their GIS database to alert their field crews as a safety precaution. The $I L-M O I O U$ is focusing on standardizing smart inverters in Illinois. They want to 
communicate with smart inverters in case of voltage issues that are either over or under production.

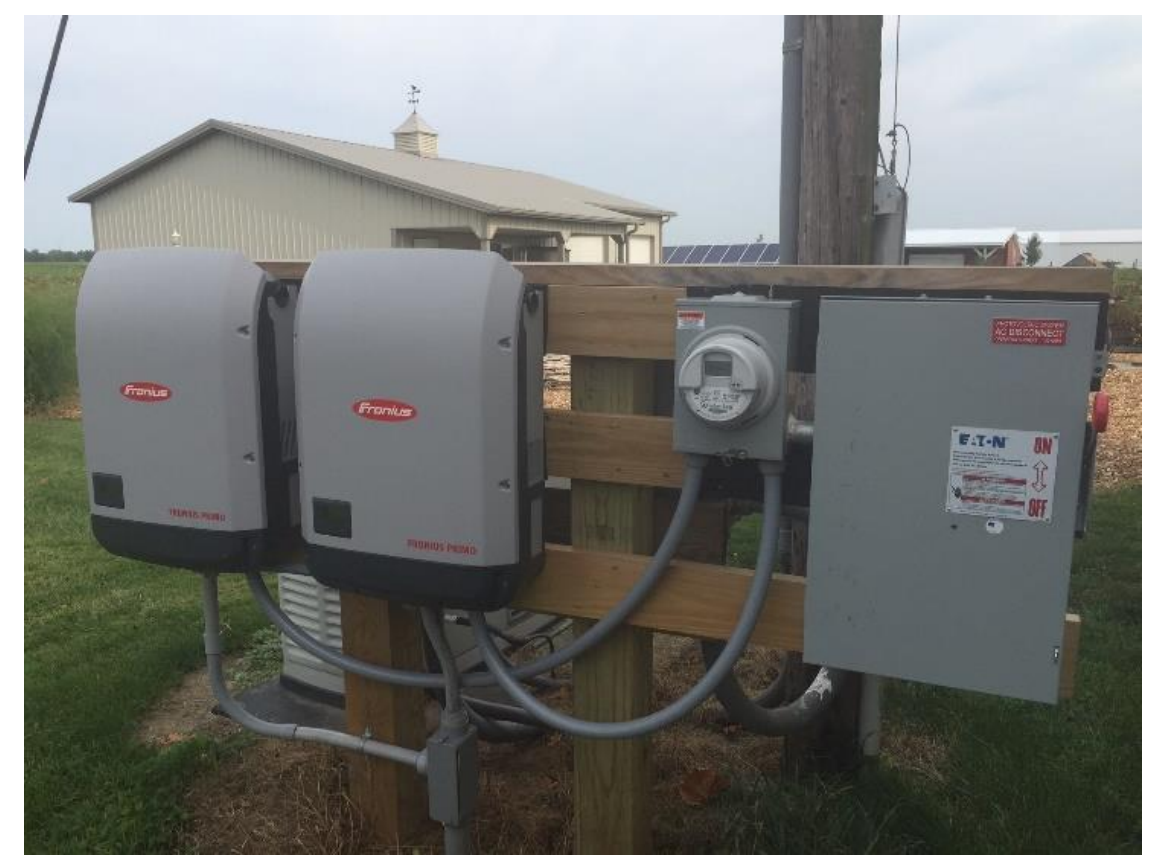

Image 18. Primary disconnect switch on breaker box, net meter, and micro inverters

Ensuring the safety of maintenance personnel and adopters is paramount to providing usable and beneficial PV arrays that generate the estimated production needed to offset an adopter's monthly energy usage. Evaluating what size array meets a potential adopter's energy needs while staying within the limits set by the utility company was just part of the evaluation stage of adopting solar technology. Adopters also evaluated how and where to install solar panels to maximize energy production and address their own concerns of maintenance and aesthetics. After an evaluation, adopters usually experimented with solar technology in some manner during a trialability stage.

Adopters only performed a thorough evaluation and experimentation after first cultivating a strong interest in solar adoption from an initial awareness of solar technology. Becoming aware of solar energy production and seeing its benefits and 
challenges firsthand or hearing about it from other adopters started the progression towards solar adoption in the initial stage. All of the stages - awareness, interest, evaluation, and trialability - gave adopters a comprehensive understanding of solar technology, leading the participants to adopt solar technology, the final stage in the adoption process. As outlined by Rogers (1995), the five stages explain how an adopter progresses through the process. Rogers' Theory of Diffusion of Innovations provides a framework for understanding the stages of adoption, and his five attributes help explain the varying rates of adoption.

Adoption attributes. Rogers' five attributes include compatibility, trialability, observability, complexity, and relative advantage. The compatibility of solar adoption refers to how consistent it is with an individual's existing values, past experiences with solar technology or even other renewables, and their needs (Rogers, 1995). Compatibility was reflected in the participants expressing their desire to reduce their carbon footprints and improve the environment, discussing their prior knowledge of solar technology or other renewable energy options, and researching solar technology to see how it can meet their needs. These compatible qualities were discussed in depth under the adoption stages. The trialability was also explained as a stage in the adoption process and was described as the degree to which an individual can experiment with solar technology. It reduces the uncertainty of adopting (Rogers, 1995).

Observability, the third adoption attribute, refers to how easy it is for individuals to see the results of adopting solar technology to stimulate a behavior change in friends and neighbors (Rogers, 1995). One of the means of observability that participants described for their PV arrays was monitoring the production of power through direct 
experience. Getting to watch an array generate electricity every day is exciting according to the Installer/Consultant. The Corporate Farmer described monitoring the production and efficiency of his panels through his smart phone, which allows individuals to observe the results of their array.

The demonstration of solar technology represents another means of observability. The Installer/Consultant described the excitement of turning on a PV array. He stressed the impact of seeing firsthand an array produce power. "Every time you turn one on and you talk to a customer, you've never seen anything like it," he shared and cited an example of an 82 year old man who adopted solar technology because he saw an array work in person. "The smile on that guy's face is just...it's amazing," he gushed. The Installer/Consultant explained that installing arrays in very visible locations helps promote their adoption, "You know it's head turning to watch it work." Influencing other people has been limited for some of the participants, but the observability still enables others to see the results of adopting solar technology through direct experience.

Literature supports this idea; according to De Young and Monroe (1996), most environmental education occurs through direct experience. People acquire knowledge in a selective manner biased strongly toward certain types of information found mostly from direct experience (De Young \& Monroe, 1996). Humans have selective memory; therefore, merely relaying information through the printed texts of pamphlets, instructions, and typical newspaper articles is usually ineffective at initiating behavior change (Kearney, 1994). Kearney (1994) stated, "Information that is uninteresting, confusing, or seemingly-irrelevant will tend to be ignored altogether" (p. 421). De Young and Monroe (1996) acknowledged the findings of Fazio and Zanna (1981) who indicated, 
"that attitudes and knowledge developed through direct experience are better predictors of future behavior than are attitudes formed without behavioral experience (e.g., gained through reading a brochure filled with factual information)" (p. 172).

The Young Adopter acknowledged that visibility plays a role in his experience of people stopping to ask questions about his PV array. It benefits those who look at his array because of his willingness to answer questions and share information with others. My Dad's Friend also has an array very visible from the road. He has not had a strong reaction from his neighbors since he lives on a road without much traffic. However, the Firefighter and the Father-in-law/Farmer both have had several questions from neighbors even though their arrays are not visible from the road. The Firefighter does enjoy posting photos of his array on Facebook and answering questions about things like the expected lifespan and warranty period. He took photographs throughout his installation to post on his Facebook page. The Father-in-law/Farmer even shared one of his utility bills with a friend and fellow farmer who shared interest in adopting solar technology. The Surveyor and the Farm Matriarch each had comments and questions from neighbors about their arrays when they were first installed. The Farm Matriarch joked that her array was the talk of her small town after its completion.

Many of the participants attested to the impact of observing solar technology. The Father-in-law/Farmer claimed that seeing solar technology firsthand or hearing about it from an adopter has the biggest influence. He related it to seeing agricultural equipment and new technologies on farms. He insisted that exposing people to solar technology helps with expansion. The firefighter stressed that going on a solar tour provides a good opportunity to see several types of systems and expressed his interest in participating in a 
future tour. The Energy Consultant proclaimed the importance of observing solar technology, stating, "Consumers need a role model. They need role model installations to imitate. Monkey see, monkey do! Studying an example is not the main means of influencing others; it's the only means, according to Albert Einstein." The IL-MOIOU also recognized that seeing solar projects has an impact, so they are providing a visual example by installing solar panels on their general office building in downtown St. Louis.

Allowing people to see solar technology in person, according to the Networker, has a strong influence. She proposed holding events at Missouri S\&T's two solar villages as demonstrations, showing the public how to operate a house powered by solar technology while increasing their understanding of solar adoption. The Solar Village and Eco Village (see Images 19 and 20) are a collection of six solar-powered homes designed by students for past U.S. Department of Energy Solar Decathlon competitions. She stated, "Having people be able to come in there and see that and understand that, I think could make it take off here. It's just we're so close to being able to, but we're not there yet." Such events would also allow contractors to observe solar technology's potential and become informers as well as educators. She also suggested having local solar installers available for visitors to contact to inquire further about solar adoption. Additionally, the Solar Village provides a location with years of data to reinforce the benefits of solar adoption without invading homeowners' privacy. She summarized by stating, "I think Solar Village is a start, and then having neighbors who have done it. And then I think it could just go, go, go, go, go as long as the policy makers don't mess up the net metering." 


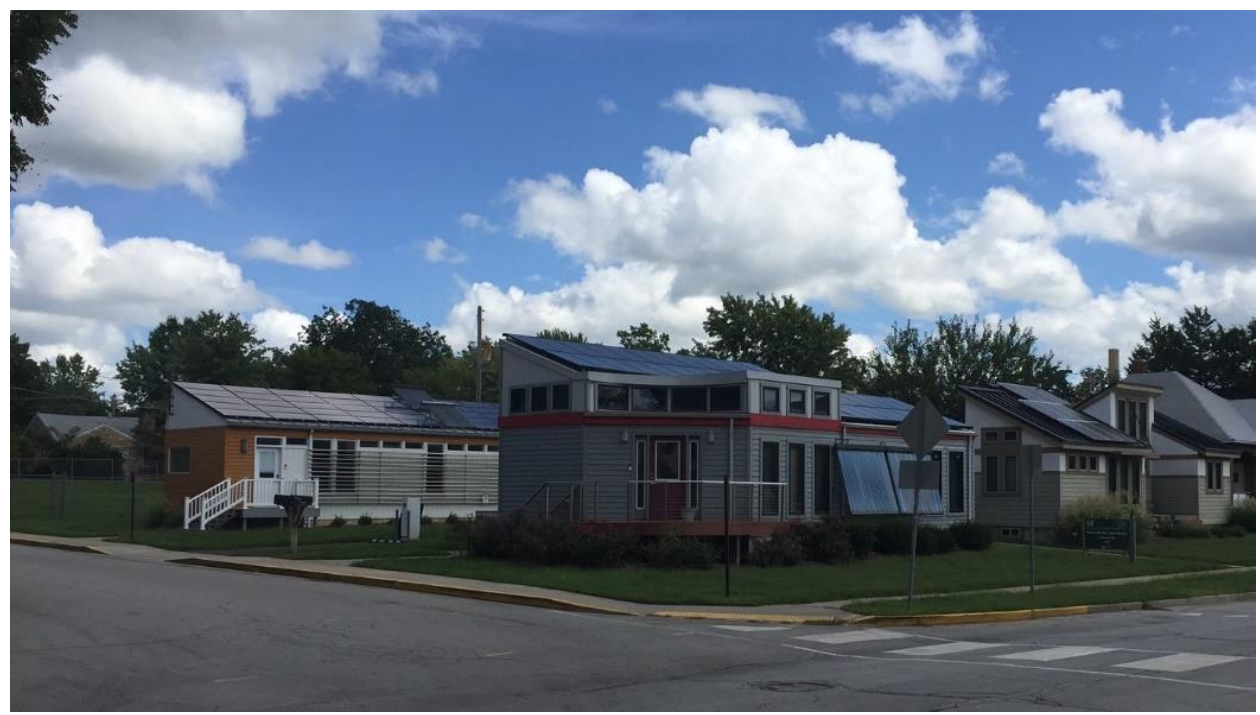

Image 19. Missouri University of Science and Technology's Solar Village

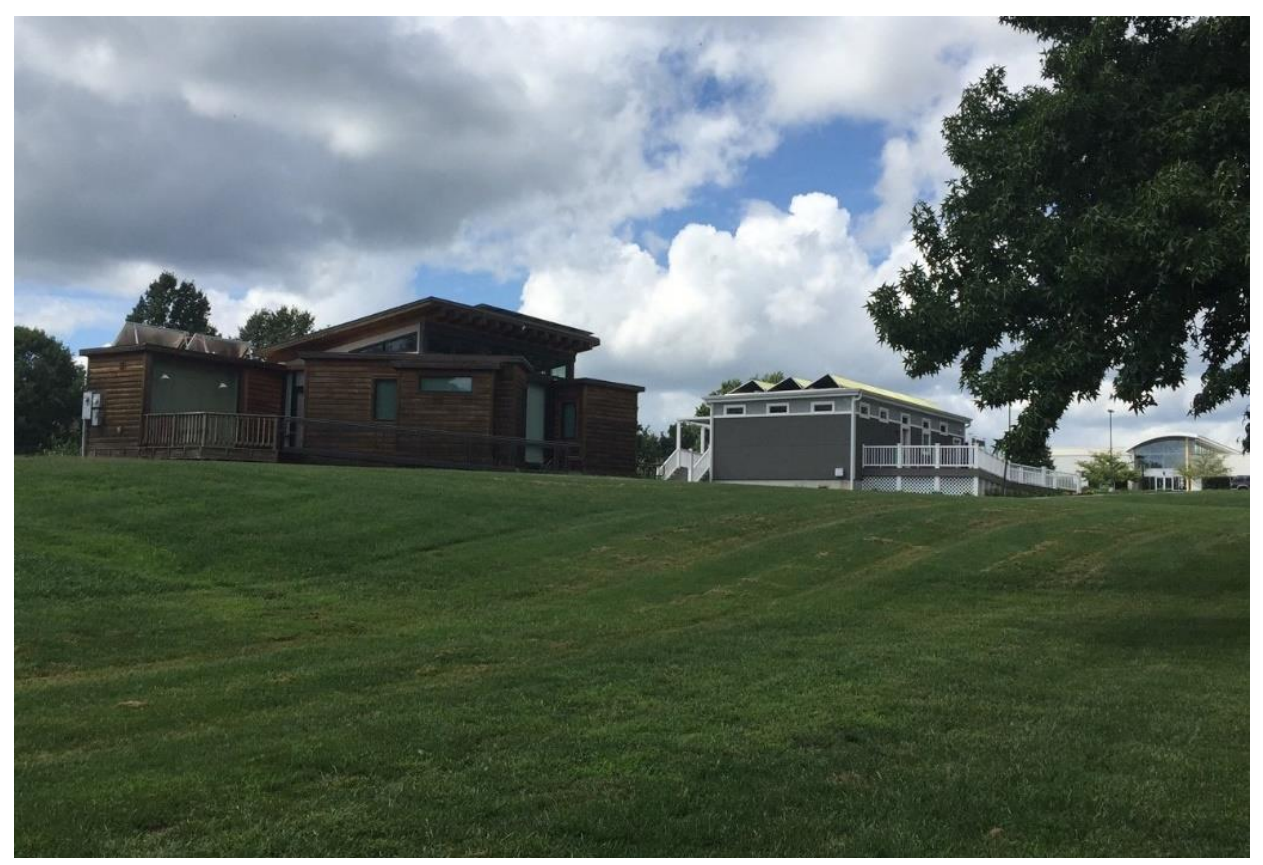

Image 20. Missouri University of Science and Technology's Eco Village

The Networker also insisted that neighbors who adopted have a strong effect on potential adopters. She insisted, "You need those first couple people!" The Son-inlaw/Installer said trusting a friend or neighbor who has adopted is very meaningful. He added that talking to friends and asking questions then doing research increase potential adopters' comfort levels with solar technology, and stated, "Now it's getting to the point 
where people are talking to friends and doing the research and saying, 'Hey, this is working!" Word of mouth has strongly impacted an increase in solar adoption for many areas. He further stated, "Word of mouth is good. Word of mouth has been really good, especially in a smaller town." The Father-in-law/Farmer echoed the same thought, "I think a lot of it's word of mouth. You can read about it, but it doesn't have the effect on it until you see it or you hear somebody tell about it."

The IL-MO IOU feels so strongly that people are influenced by their neighbors they have an analytics and customer segmentation group to track the demographics of their adopters and the impact of homeowners adopting solar technology in their neighborhood. They are seeing a definite trend where neighbors influence solar adoption. He stated, "I think there's something with seeing solar going in..." It allows potential adopters to talk to a neighbor who has adopted about the cost and even the difficulties or challenges.

Seeing solar technology in person lets potential adopters experience the reality of generating electricity from the sun according to the Son-in-law/Installer. The Energy Consultant insisted that people want to do what they can see. Sometimes the experience replaces something that might benefit them more such as an energy assessment. Seeing solar panels often makes people want to install them before doing an energy assessment to determine the energy efficiency of their homes. He stated, "But everybody wants to go for what they see rather than what actually might do them the most good. You can't see a lot of magic that you bring to energy savings. You can see solar.” This visibility becomes an important piece for promoting environmental stewardship through reduced energy consumption and increased renewable energy generation. The MO Division of Energy 
acknowledged the dilemma of promoting solar adoption while also encouraging energy efficiency. They stated, "It's kind of a tricky message because the solar panel is visible. It's shiny. It's a cool piece of technology. Efficiency stuff, not necessarily as obvious." He added, “So it's public messaging, I think. How do we make energy efficiency glitzy? And what leaps to people's mind first?"

Seeing other systems seems to be tipping more utility customers past just considering solar and toward installing an array. The Buy-American Consultant felt residential solar adoption sits at the tipping point in Illinois, and the Generation Cooperative proclaimed Missouri is really close as well. Gladwell (2002) defined the tipping point as the threshold where the unexpected becomes expected. The 70 's Solar Consultant insisted, "We're at the tipping point. We already passed the tipping point in California where electric rates are high. Tipping right here in Missouri, it's going to take a rebate in the low cost areas to make that economic case more attractive."

Complexity, the fourth attribute, refers to the ease with which solar technology can be understood and adopted (Rogers, 1995). People's perception of PV arrays reveals the complexity surrounding the adoption of solar technology. The Installer/Consultant explained the public's perception that he has observed. First, the public has the misconception that solar panels do not really work. Second, many people have the misunderstanding that it is all "smoke and mirrors". Therefore, one of the challenges of promoting solar adoption is fighting the misconception that it does not work. He stated that the community's response to his company was that of confusion; he joked it was were making the locals' heads spin. "You can tell in the Midwest people just didn't believe it. They just don't believe that you can power a house with panels setting on it." 
The Corporate Farmer also joked about his town's reaction when he started constructing the frame for the array. He was often asked if he was building a Sonic Drive-In. Confusion surrounded the structure in the small town because of the novelty involved. "It got a lot of people talking when I started building it," he stated. The Municipal Utility summarized the adoption of solar technology as a complex issue because of the lack of knowledge about the technology and the mistrust of the entities involved. While community members see utilities as the bad guys and not in favor of solar adoption, installers are perceived to take advantage of potential adopters.

The relative advantage, the final attribute, represents the degree to which an adopter perceives solar energy as better than what he had previously, such as power supplied entirely from fossil fuels (Rogers, 1995). Adopters may consider factors including the economic value, convenience, personal satisfaction, and social status when measuring the relative advantage of solar adoption. In discussing the benefits of adopting solar technology, the participants highlighted these factors. The Installer/Consultant and the Corporate Farmer concurred that installing an array provides positive public relations. According to the Installer/Consultant, going green has been a positive promotion for a grain elevator in Central Illinois. For the grain elevator owner, his PV array has become a conversation piece among farmers; it provides good publicity for the elevator business (see Image 21). It has also been effective in promoting solar adoption in rural areas, especially farming communities and in helping to educate people in telling the story of solar power. 


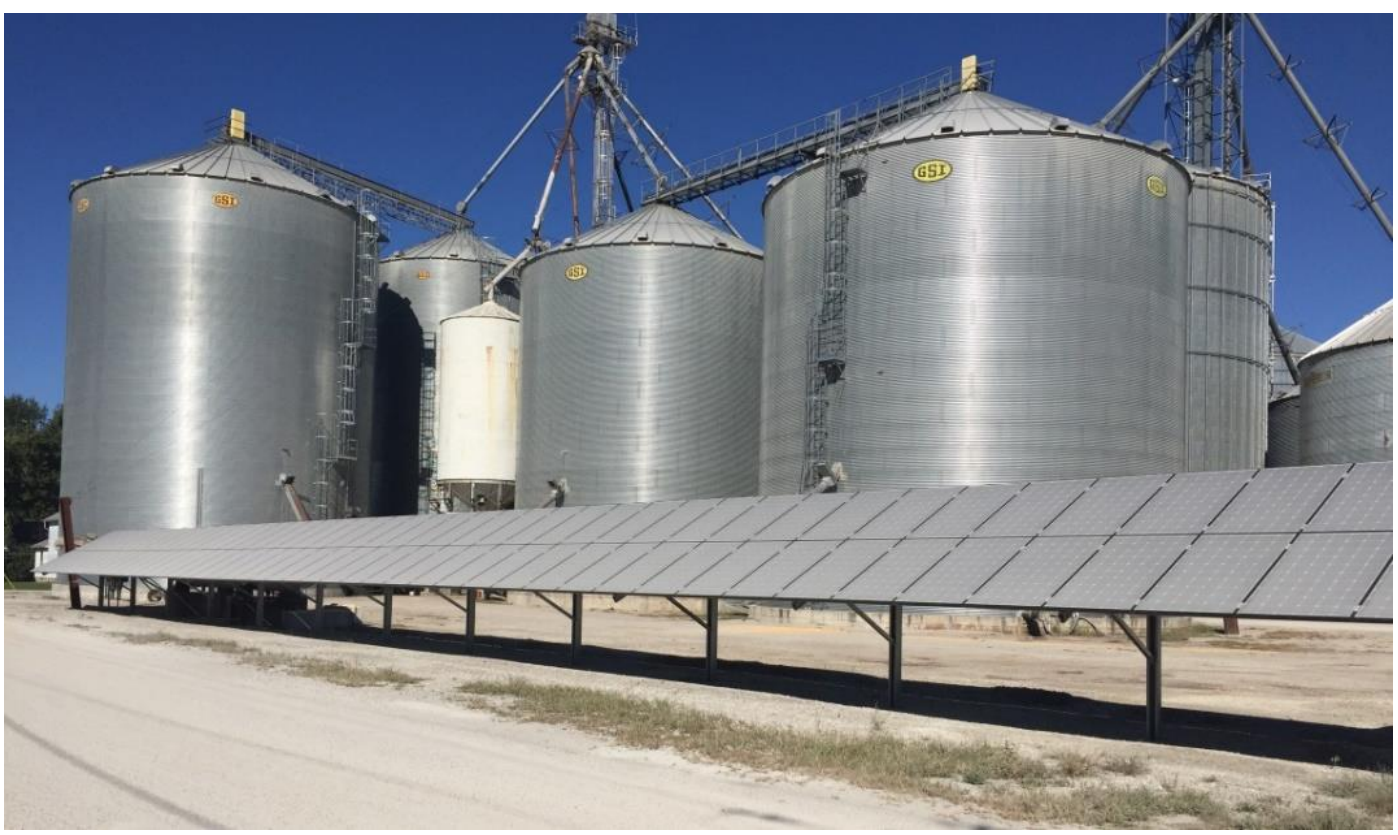

Image 21. Large ground mounted PV array at a grain elevator

Word of mouth influences many potential adopters, making advertising for the Installer/Consultant's business unnecessary. "It just takes one guy that put it (solar) in and then he tells four or five people, and they watch it work," he stated. The Installer/Consultant has also disseminated information by speaking at meetings hosted by the farm bureau and other organizations. This exchange of information positively promotes solar adoption as shown by their increase in PV installations during the past few years and a long waiting list at the time of the interview.

The Corporate Farmer expressed satisfaction with solar adopiton; no drawbacks have arisen from installing a PV array, and, in fact, he wishes he had done it earlier. Many of the other adopters expressed similar satisfaction. Only the Farm Matriarch was still deciding on how she felt about having the PV array. While she likes not seeing it from her house because a machine shed hides it from view, she does not mind its physical appearance next to the road. My Dad's Friend reiterated several times that he and his wife have been very happy with their array so far. The Firefighter also reported that his 
wife appreciates their array now even though she was skeptical at first. The Surveyor's uncle expressed satisfaction in adopting solar technology too, and the Father-inlaw/Farmer stated he has absolutely no regrets.

The adopters in this study all expressed satisfaction with the relative advantage of solar power. The adopters also exhibited the other attributes outlined by Rogers (1995), which include compatibility, trialability, observability, and complexity. These attributes appeared throughout the five stages of the diffusion process. Additionally, Rogers used five adopter categories to explain the varying rate of the diffusion of innovations. While each adopter in this study displayed personal motivations and challenges, all of them most closely fit into the profile of one of the five categories of adoption.

Adopter categories. The five adopter categories described by Rogers (1995) in the diffusion process include innovators, early adopters, early majority, late majority, and laggards. The interviewed adopters all clearly demonstrated the characteristics and values of innovators. Innovators possess an independent spirit and sense of uniqueness that differentiates them from society (Woodruff, Hasbrouck, \& Augustin, 2008). The prerequisites for an innovator include the means to absorb a possible financial loss, the ability to understand and apply complex technical knowledge, and the willingness to accept an occasional setback. All of the adopters discussed the importance of having the upfront capital to fund an array or the willingness to apply for grants and financing. This ability demonstrated their means to absorb the financial risk involved.

Additionally, the interviewed adopters all had strong technical knowledge based on degrees or relevant experience. The Engineer has degrees in both mechanical and civil engineering, and the Surveyor is a Professional Licensed Surveyor. The Corporate 
Farmer and the Father-in-law/Farmer have years of experience working on mechanical and farm equipment while the Firefighter has worked for years in the construction industry. The Young Adopter made up for his lack of experience with extensive research, and the Farm Matriarch relied on her son's and nephews' research and knowledge.

Many of the adopters demonstrated other characteristics and values typical of innovators. The Corporate Farmer, as an example, stated that he likes to be the first to do something new and does not worry about what others think. He responded to the town's reaction by stating, "Oh just the same thing, wondering what had I done stupid now. How nuts I was. It seemed like the thing to do. It made sense to me, so I did it." He embraced his independent spirit and willingness to differentiate himself from the society around him through his uniqueness.

The Father-in-law/Farmer asserted that farmers often epitomize the characteristics of an innovator. He stressed that farmers routinely apply technical knowledge, making them innovators of adoption in various farming practices and technological advancements. He also described the technology on some of his farm equipment and explained how technology has improved agriculture immensely (see Image 22). He cited the use of improved herbicide application. Additionally, he discussed how many farmers adopt various types of seed corn by listening to dealers and not by what farmers around them are planting. He then explained that some agricultural innovations, which includes many technological innovations, spread by word of mouth. He stated:

Solar is going to be lumped in with the technology and not with the seed corn, and it's going to go quick. Real quick! Most farmers will refrain from being an early 
adopter of new technology. Then once the thing comes out, and it seems like it's got its bugs out, they jump on it.

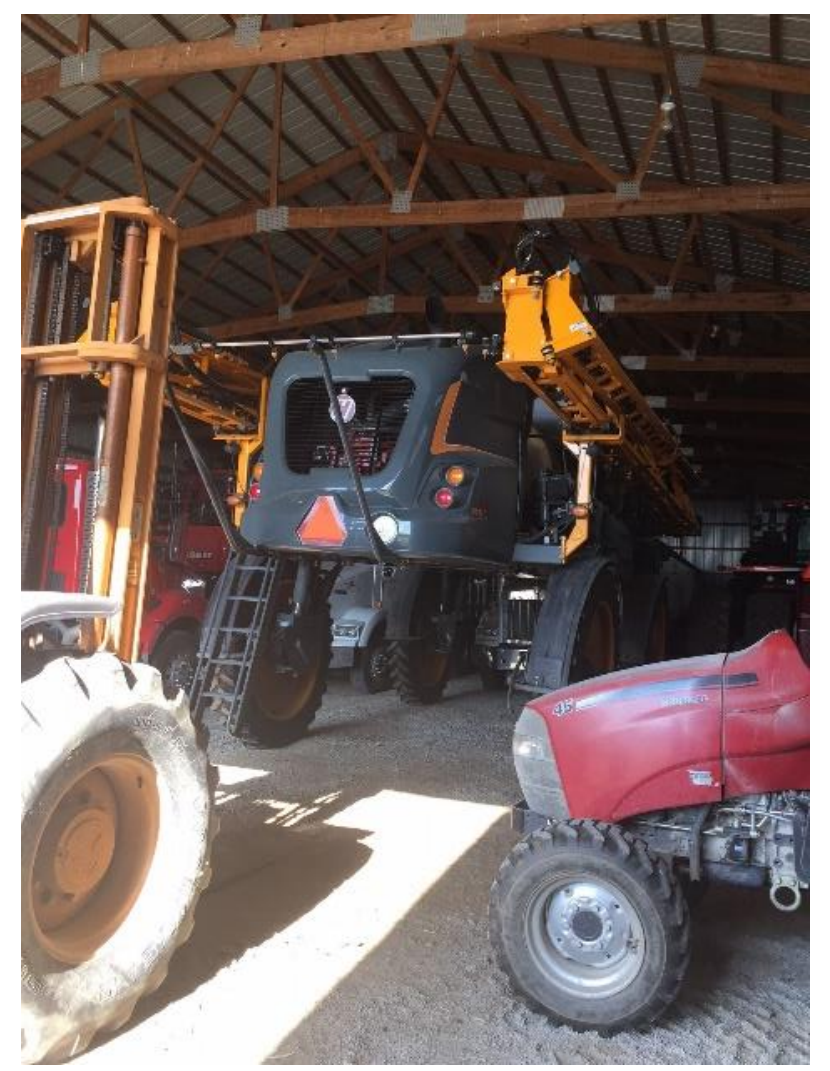

Image 22. The Father-in-law/Farmer's farm equipment with high-tech features

The Networker insisted that some of the first solar adopters were those who wanted to save the planet and were not as concerned with saving money. As the cost has decreased, she has seen that shift. She feels that the solar industry should target the early adopters now because of the influence they can have on the diffusion of solar technology. Early adopters are role models, integrated into local social systems, and have the most influence over potential adopters (Rogers, 1995). The Networker stressed that sometimes it is getting the first person to take the leap and then starting to tell others about the benefits. She acknowledged the impact behavior change plays as more people adopt solar technology and influence their neighbors. She emphasized: 
But it's the same thing, if you get a few people to do it and they live in a neighborhood and they start telling their friends... and then the next guy does and the next guy does it. I think that's what it's going to take. It's getting that first person to take a leap and see the benefits.

The Buy-American Consultant argued that solar adoption has moved further on the diffusion curve, even further than LED lights. She claimed most adopters now fall in the early majority category, the largest adopter category. The early majority often contemplate adoption for some time while interacting frequently with their peers before adopting; consequently, they are also influential in social systems (Rogers, 1995).

From exploring solar technology as a renewable option to installing a PV array, the adopters as innovators successfully navigated the various stages of solar adoption. Understanding the adopter categories as part of the diffusion of innovations provided greater insight into these adopters' attributes. Moreover, examining the characteristics of the adopters as innovators provided more context in outlining the stages and varying rates of solar adoption. Finally, summarizing the adoption process in accordance with Rogers' Theory of Diffusion of Innovations provided a more thorough understanding of the challenges potential adopters face, the various stages involved, and the expected rates of adoption.

A better understanding of the adoption process explains the possibility of expanding solar technology in a maturing market throughout areas of the United States experiencing less solar energy generation. Compared to an industry like trucking, the market for solar technology is just beginning to mature according to the Father-inlaw/Farmer. He warned of the countless regulations with trucking that make it 
cumbersome. In his opinion, easing regulations in the solar industry will maintain and likely increase the adoption rate.

Adopting solar technology needs to become easier to appeal to a broader audience, one who has likely experienced power outages. The Western MO IOU stated, “And I think there'll be a time where it will be very important because if it's easy to do and just makes some sense because rural areas are sometimes without power." The majority of participants expressed interest in making adoption easier and shared ideas to increase adoption to a more diverse demographic. As the Buy-Americann Consultant explained, she wants solar technology to be available to everyone and not just affluent retirees.

The Energy Consultant shared numerous ideas for increasing PV arrays in Midwestern states, thus reflecting his great thought and insight along with his passion to increase adoption in rural areas. First, solar technology needs governmental support for research and design. Funding is also needed to document and promote best practices through various media platforms. Second, he recommended instituting public policies that mandate a minimum percentage of power sold by public utilities be generated using solar technology and other renewable sources. Additionally, utilities should allocate rebates, bypassing the typical legislative process for appropriations, to prevent states from spending the money appropriated for solar energy generation on other programs. In most states, these rebates are administered through renewable energy credits (RECs).

The Energy Consultant continued, explaining his third suggestion that utility providers should collect a greenhouse gas fee and require utilities to replace or offset nonrenewable energy with a renewable source. As an example, a gas company would 
have to offset any natural gas extracted with a usable renewable energy source or pay a severance charge into a fund to develop a renewable source. Fourth, customers should earn more credit for investing in renewable energy and not be taxed on solar power equipment or energy improvements. Finally, he supports enabling solar installers to generate residual income from PV arrays like in other industries such as satellite TV, telecommunications, and oil. Solar installers would earn a small percentage of state and local incentives paid toward a PV array.

The Renewables Advocate declared that it will take some government assistance because government regulations currently make it impossible for a customer to buy renewable energy from an independent power provider. He asserted, "It's gonna take a little bit of government assistance on that because right now...you can't buy your renewable energy from an independent provider." He also stressed:

We don't have a power purchase agreement in the state. The utility companies need to have green tariffs where they sell renewable energy on to a company. Right now the laws in Missouri won't let them do that. They can't be $100 \%$ because they can't buy renewable energy from $I L-M O I O U$ and then they can't buy around the $I L-M O I O U$.

The Buy-American Consultant also stressed the importance of implementing power purchase agreements. The Energy Consultant insisted that the solar contractor in a power purchase agreement should be entitled to a tax credit against federal payroll withholdings. He further argued the government should not charge sales taxes and fees on the energy sold through power purchase agreements. 
The findings of my study support these ideas for advancing solar adoption - ideas formulated through the participants' understanding of the challenges facing solar adoption and the motivations encouraging rural residents to embrace money-saving, clean energy. While the participants voiced concern that changing regulations and uncertain incentives, may slow adoption, they expressed optimism that the solar industry will maintain its momentum. They recognized the impact that utilities have on renewable energy and the close connection with factors impacting the growth of solar technology in rural areas.

The participants' expressed enthusiasm for the future of solar adoption and provided insight to advance solar technology in rural areas. They provided meaningful suggestions on increasing adoption through promotion, training, and education. Their understanding of the diffusion process, from the initial decision to explore solar adoption to the installation of a PV array, became evident in each stage of adoption. In addition, all six themes gleaned from my data and presented in the findings reflect the participants' diverse perspectives from across the rural landscape. I have summarized the findings and highlighted relevant literature in an effort to construct a meaningful discussion of my research. Finally, I have drawn conclusions from the findings in an attempt to outline useful strategies to promote solar technology and move adoption forward in rural areas. 


\section{CHAPTER FIVE: DISCUSSION - SUMMARY \& REFLECTIONS}

A discussion of this study's findings centers on the themes developed in the previous chapter and incorporates relevant literature on the topics of renewable energy and solar adoption. The chapter also provides reflections and insights of the findings in a broader philosophical context for the future of solar adoption throughout the Midwest. The insights provide the essential building blocks to theorize on the future of solar adoption in rural America. Residents are quick to associate renewable energy with climate change initiatives and efforts to save the planet, so reflecting on the findings provides an opportunity to challenge this existing culture. Instead, job creation and economic development through measured federal regulation should define efforts to advance solar technology and increase adoption. These non-partisan objectives provide promise that solar innovations can effectively diffuse to a diverse, rural population.

\section{Summary of Findings}

Framed in the theory of diffusion, the findings of this study present an integrated explanation of rich data gathered from participants representing diverse viewpoints of rural solar adoption. The six themes that emerged through the analysis provide a structure for summarizing the findings. When compared with previous literature, the findings can be positioned within the existing body of research on renewable energy. Direct quotes capture participants' thoughts that relate to the findings and further enrich the summary.

While the participants, representing either adopters, installers, or utility companies, expressed varied perspectives on the challenges facing solar adoption, their insights contributed to findings that consistently reappeared in multiple themes. These consistencies coupled with refined theoretical links created integrated relationships 
between categories (Charmaz, 2006). Because similar categories of data supported multiple themes, a clearer view of the key challenges of solar adoption facing rural America emerged from the findings.

In several instances, the findings overlapped from one theme to another. As an example, an overlap in solar technology's visibility occurred between the motivations to adopt, the growth of solar adoption, and the adoption process. The visibility of solar technology in communities motivated adopters and increased solar growth in rural areas. At the same time, this visibility also significantly impacted adopters' awareness, the first stage of adoption. The familiarity of seeing solar technology frequently prompted adopters' interest during the second stage. The visibility of solar technology also affected the attributes of adoption since a PV array's visibility directly relates to the observability, one of the five attributes outlined by Rogers. The reoccurrence of these examples in multiple themes confirms the applicability of the Theory of the Diffusion of Innovations in the solar adoption process.

Comparing the themes developed in this study to those from previous studies provides a benchmark for assessing the relevance of the findings. The themes were relatively consistent with the literature, which mostly outlined motivations for adopting solar technology and the challenges of installing PV arrays. Individuals may be strongly motivated to adopt solar technology; however, if the factors are not favorable, they will not pursue adoption further. Much of the literature also focused on predicting the most likely adopters without fully exploring the factors that influence adoption. The lack of research in exploring factors that prompt an individual to act on their motivations has 
created a void. Understanding these influential factors is necessary to promote more widespread adoption.

The findings of Theme One - Factors and Motivations substantiated the complexity of solar adoption and confirmed several factors that have increased the number of installations. These factors include reducing the price of PV arrays, improving solar technology, minimizing maintenance requirements, and maximizing the support from state and local agencies. The geographic and physical location of a PV array also emerged to factor into the adoption process, impacting the return on investment and power generation, respectfully. The geographic location determines the state and local government support available through rebates, incentives, and regulations. Additionally, utility types vary from one geographic location to another and determine the net metering and energy credit rates paid to solar customers for excess-generation. In terms of physically locating a PV array, adopters often decide between rooftop and ground mounted arrays based on site restrictions and personal preference. Those options assume adopters have a roof suitable for a PV array or land available for a ground-mounted system. If not, utility customers may opt to participate in a community solar program, depending on the availability through their utility company.

Previous studies explored the motivations for adopting solar technology, citing differences in adopters' personalities, behaviors, attitudes, and values (Balcombe, Rigby, \& Azapagic, 2013, 2014; Leenheer, de Nooij, \& Sheikh, 2011). The findings highlighted common demographic factors, including income, age, and education, and confirmed a number of motivations for pursuing solar adoption. While some adopters desired to be self-sustainable and improve the environment, all were motivated to save money. The 
economic consideration of saving money through lower utility bills drives solar adoption, evidenced by the participants' insight. The Engineer maintained, "So really the bottom line is economics. I don't care how green you are, if you can't afford it, you can't afford it. It costs you money. That's the bottom line." Economic benefits continue to motivate the entire range of adopters regardless of their priorities and beliefs.

An increase in energy prices will certainly be a key factor for significant expansion of solar adoption according to the findings. The participants listed energy costs as a contributor to widespread acceptance and adoption of solar technology. They see increases in current monthly power bills as positively affecting the future expansion of solar adoption. The Corporate Farmer projected a direct relationship to increasing energy costs, “...power bills aren’t going to go down. I just think things are going to go nuts. Our rates are going to increase... and being more self-sufficient, you know, if you can produce something yourself, why buy?"

Predicting future energy prices is difficult even though many of the participants strongly voiced their concern over increasing utility rates, an increase most market analyses support. Future utility rates are dependent on the availability of fossil fuels in the U.S. or our government's willingness to continue importing oil. The U.S. has increased its production of oil, natural gas, and other fossil fuels through advancements in technologies such as hydraulic fracturing (fracking). The U.S. continues to rely on other countries with large supplies of these fuels even though domestic production has increased. As Albrecht (2015) explained, the U.S. has paid enormous sums to oilproducing countries, leading to trade concerns. Furthermore, many of these countries maintain non-democratic governments. In turn, the U.S. must fund military actions to 
protect our interest in these countries. These factors cause the continual increase of energy prices and reinforce renewable energy as a sensible alternative to fossil fuels. The findings clearly convey a need to promote solar energy as a renewable option to avoid the instability created by foreign oil dependency and combat the environmental impacts of extracting fossil fuels and generating power from non-renewable resources.

According to the findings, the impact of renewable energy related businesses on local economies can play a significant role in the expansion of solar adoption in rural environments. The positive impact on agribusiness is just one example. Solar technology offers a great upside to farmers; offsetting high utility bills with solar power saves farmers thousands of dollars during peak times of energy use. Additionally, solar adoption can boost local rural economies through job creation. Johnson and Moyer (2012) noted that many states seem motivated to adopt an RPS to stimulate local jobs. In additon to creating employment opportunities, solar development in rural areas can potentially increase personal income and local government revenues (Krannich, Robertson, \& Olson, 2015). Therefore, solar adoption's potential to stimulate economic growth while simultaneously saving adopters money on lower utility bills should be a strong motivator for support by state and local governments.

Even with the possible growth for the rural economy, the findings of Theme Two - Barriers and Challenges reveal several barriers still impeding solar adoption. Affording the upfront cost remains one of the biggest challenges. Wiser, Barbose, and Holt (2011) maintained that the advancement of solar adoption depends on financing options to overcome this obstacle. Krannich et al. (2015) cited pricing and cost issues as principle constraints for solar adoption. Conventional power systems maintain a price advantage 
over still-emerging solar technology because subsidies for fossil fuels do not reflect the environmental impacts of extracting and producing power with oil and natural gas (Rosoff \& Sinclair, 2009). Understanding the payback through rebates, incentives, and utility savings poses an additional challenge for potential adopters when considering the cost implications. Rebates and incentives are inconsistent from state to state and between utility companies, limiting adopters further. Simmons (2011) lamented that up to $40 \%$ of installation costs come from expenses beyond the hardware such as permitting, zoning, and connection fees. These costs often fluctuate from location to location and among utilities (Le, 2013). To overcome the cost implications, a consistent approach at the state, local, and utility level for incentives, regulations, and financing options must be implemented to give solar technology the same price advantage as conventional energy options.

Another barrier identified in previous literature includes the gaps in available product information (Rosoff \& Sinclair, 2009; Shih \& Chou, 2011; Strupeit \& Palm, 2016; Yang, 2010). These barriers align with the findings, which clearly highlighted that solar technology still faces a perception problem, often because of ineffective marketing. A messaging problem impedes solar technology according to the Renewables Advocate:

Then we get that whole perception problem, right? We perceive it's some liberal, usurper plot. I think there's a messaging problem because I think they (adopters) would love it if they really had the chance, and if they were given the option and laws allowed them to take advantage of it.

He advocated more subtle messaging versus "big, splashy marketing” to advance adoption. The Networker added that news outlets often only share the negative stories 
instead of the success stories. Positive messaging to explain the simplicity of PV arrays can combat the common misconceptions that surround solar technology.

Potential adopters still have a misguided perception of solar technology and lack an understanding of the process for adopting and installing an array. The Municipal Utility voiced concern, “Hey solar power, this is free! All's great. What do I have to do? All I have to do is call you (the utility company) and sign me up." According to previous studies, the perception of complexity and risk with solar technology deters individuals from adopting (Karakaya \& Sriwannawit, 2015). An individual often bases his decision to adopt a new technology on his perception of the technology's complexity (Karakaya \& Sriwannawit, 2015). Even more, many rural residents still see solar technology as "the latest snake oil" according to the Installer/Consultant. Until people see an array installed and physically watch it work, they are skeptical. For this reason, improving the perception of solar technology may be addressed most effectively one array at a time. As discussed by the Installer/Consultant, potential adopters are more likely to accept solar technology as a viable option if they see panels producing electricity from the sun for themselves. The findings advance firsthand experience as an effective means for overcoming preconceived ideas about solar technology in advocating a better understanding of the adoption process.

Utility companies face challenges of their own in managing solar energy during the adoption process, which was a surprising result in the findings of Theme ThreeElectric Utilities. Some of their challenges include limiting fee increases for non-solar customers while incurring more expenses and personnel hours to process solar customers' monthly statements. Utility companies stand to incur increased costs while 
losing revenues from an increase in residential-scale PV arrays. These challenges often dictate their hesitancy to support solar technology and engage with potential adopters. In an effort to protect their interests, many utilities have funded lobbying efforts to change regulations and limit the growth of solar adoption (Krannich et al., 2015).

While some literature has addressed regulation changes and inconsistent policies from state to state for utility companies (Fowler \& Breen, 2013; Krannich et al., 2015; Le, 2013; Wiser et al., 2011), few studies have explored the impact that utility types, investor owned, municipal, and cooperative, have on regulations and the renewable incentives offered. The degree to which utilities influence solar adoption was more prevalent throughout the findings than anticipated. Utilities are noticeably impacting the advancement of solar adoption in rural areas in spite of varying degrees of support and differing customer-based priorities.

All of the adopters and installers/consultants expressed unique experiences and frustrations in interacting with utilities. Regardless, the utilities claimed to support solar adoption to the extent that it benefits all of their customers beyond just those who can afford to install an array. The Municipal Utility stressed their willingness to accept solar adoption, “I don't want you to walk away from here saying we're against solar. We're not. We're not against renewables. As far as solar goes, municipal utilities in the State have more solar generation than investor owned and the co-ops combined." The difference in support results largely from varying utility types. Cooperative and municipal utilities have individualized approaches established by their customers on such policies as net metering and power purchase agreements. On the other hand, most states regulate investor-owned utilities under a renewable energy portfolio. The investor-owned 
utilities then prioritize solar energy generation differently depending on the decisions of their leadership. Customer solar generation is often capped, as a result, if the utility does not see the value in increased solar adoption.

The regulation of utility companies at the federal, state, and municipal levels is complex and varies for different geographic locations (Krannich et al., 2015). This complexity along with the challenge of variable energy generation adds considerable cost to the incorporation of renewable energy into an existing conventional power system (Krannich et al., 2015). The utilities argued that integrating solar energy into their energy portfolios creates challenges for balancing energy supplies when PV arrays are not producing at their peak. Utilities need backup capacity readily available to offset this variability in generation and demand (Krannich et al., 2015). Utilities' concern over the variability of customer-generated power combined with efforts to control costs from incorporating renewables limits their support for increased solar adoption. Regardless of the regulations they must meet or their willingness to support increases in residentialscale arrays, the utility companies are playing a key role in the advancement of solar adoption.

Broadening the public's awareness of utilities' impact on the solar adoption process can cultivate a more collaborative relationship between utilities and solar customers. Utility customers would be more empowered to hold utilities accountable for enacting cost increases and complicating grid interconnection policies for residentialscale arrays. Sovacool (2009) stressed, "The lack of public interest in the electricity sector allows utilities and system operators to maintain their control and extract stable profits" (p. 10). According to the findings, utilities have to be involved in advocating 
solar technology to rural residents through increased training and education even though the common perception is utility companies seem to be limiting widespread solar adoption. Foreseeable advancements in energy storage and solar technology more strongly establish the need to train utility companies on the latest solar industry technologies and standards to alleviate uncertainty with solar technology.

The findings of Theme Four - Renewable Portfolio/Energy Standards strongly support the need for more consistent legislation among states to standardize regulations and incentives. According to the Municipal Utility, "It's not a cookie cutter approach. Every state is different, and you're going to see a lot of things." The lack of consistency among states is creating frustration and barriers for potential adopters. It is critical that the policies and regulations have consistency and allow utilities to operate in a competitive yet fair market while maintaining transparency in customers' contributions to renewable power generation and utilities' profit margins. Regardless, the 2016 election reflects a shift towards less government regulation, suggesting many Americans would oppose increased federal intervention to initiate consistency in solar regulations. Even though a more consistent approach could lessen the confusion and challenges of adopting solar technology, rural residents have shown an opposition to government regulations. The current administration's pledge to deregulate federal oversight and increase states' management of energy policies is likely to increase the disparity between utility companies and solar customers. Increased state control over statutes and regulations could further complicate the bureaucracy between the entities involved, including utilities, public service commissions, solar installers, and adopters. 
With no federal renewable portfolio standard, solar adoption has become concentrated in states with policies requiring a higher percentage of renewables for their energy portfolio (Krannich et al., 2015). Individualized RPS policies within these states create varying levels of support for solar adoption and slow the growth of renewable energies (Krannich et al., 2015). Additionally, state-adopted RPS programs allow states to incorporate the easiest and least expensive renewable technologies into their energy portfolio (Wiser et al., 2011). Presently, generating electricity with wind costs less in comparison to solar generated power (Johnson \& Moyer, 2012). While most RPS policies do not dictate any particular renewable technology, they often favor the cheapest option (Wiser et al., 2011). For example, the investor owned utility in Western Missouri favored wind and hydropower because of its availability, which made it a more economical option for the utility. Wiser et al. asserted that states with policies specific to solar adoption offering incentives for residential-scale arrays have experienced a significant increase in PV installations. The findings clearly support this assertion. The Western MO $I O U$ has experienced a drastic increase in the number of solar installations after the $M O$ $P S C$ began requiring the utility to offer solar rebates to meet their RPS requirements.

This increase in adoption illustrates the need for rebates and incentives to keep the cost per watt at a level that a large sector of the population can afford. The Municipal Utility admitted, “... it's a reality that part of the reason these systems are even close to economical is because...folks are taking advantage of the economics of renewable energy tax credits at the federal level." The 70's Solar Consultant added, "It takes a while until people are smart enough that they realize that giving rebates is the cheapest way to get energy. If you want energy on the grid, and you want to do it as clean as possible as you 
can, it's a rebate." If the federal and state governments eliminates these incentives, the advancement of solar technology over the next several years will be slowed greatly. The Installer/Consultant proclaimed, "One day I think solar will make it on its own. Unfortunately it's fed right now with these incentives to help it get started, but I think one day it will get to the point where solar kind of stands on its own." Unfortunately, that "one day" may be much further away than advocates hope if the current administration delivers on its promise to reduce support of renewable energy.

Threats every few years by Congress to discontinue tax credits create uncertainty in the investment potential of PV arrays (Krannich et al., 2015). Policies and incentives need to be more predictable, stable, and consistent; long-term commitments will give potential adopters and industry professionals confidence in solar technology's potential (Krannich et al., 2015). The Surveyor stressed that people want to operate a business based on renewables without worrying about policies changing; he cited net metering laws as an example. Additionally, the ever-changing political direction of energy policies results in fluctuating federal funding for renewable research and development programs thus increasing policy inconsistencies and further slowing the growth of solar technology (Krannich et al., 2015). Liang and Fiorino (2013) advocated stable and predictable projects in research and design to produce more favorable policy outcomes, providing investors with a greater degree of certainty. They added that the federal government's commitment to research and development is critical for innovation progression. Therefore, a commitment at the federal level to continue developing solar technology while instituting consistent policies and regulations for state and local governments can encourage increased solar adoption in all states. 
The findings of Theme Five - Growth of Rural Solar Adoption revealed that rural adopters perceive solar technology and the concept of sustainability differently than citizens living in urban areas. The identification of these differences supports the need for programs and strategies being implemented to move rural solar adoption forward. These include financing programs such as the Property Assessed Clean Energy (PACE) programs and the Rural Energy for America Program (REAP) to make solar technology accessible to a larger rural population. In the meantime, rural utility companies continue exploring solar farms and community solar projects while monitoring the impact that advancing battery backup technologies have on the energy industry.

Even though previous research focused on urban environments, it still provided insight into the social meaning, usability, and behavior change that rural residents assign to the development and deployment of RETs. Rural residents' responses to green building practices also reflect their anticipated acceptance or opposition for more widespread RETs such as solar technology throughout the Midwest. Sovacool (2009) used the example of rural residents' resentment of urban developers who build wind farms in rural areas as an illustration of opposition to RETs. Many residents have concern with technologies such as wind turbines defacing and cluttering the rural landscape (Sovacool \& Watts, 2009). This opposition often ties more closely to preexisting social conflicts than electricity (Sovacool \& Watts, 2009). Hoffman and Henn (2008) argued that the obstacles faced by the green building movement are no longer technological but instead social and psychological factors connected to the idea of green building. Many Americans still associate green building with the hippy culture of the early green movement (Hoffman \& Henn, 2008). Additionally, many conservative minded people 
align green building with the liberally motivated environmental movement (Hoffman \& Henn, 2008). Since a greater percentage of Democrats with a higher than average income live in urban versus rural areas, rural areas may be less likely than urban areas to adopt RETs based on political party affiliation.

The findings on the growth of solar adoption in rural areas are important because of the large amount of energy used by rural homes. Muratori (2015) reported that the energy consumed by rural residents is almost $10 \%$ greater than in urban areas. Higher energy consumption is due to larger houses on average, more exposure to weather, fewer options in energy sources, and various behavior factors such as living habits and spending patterns (Muratori, 2015). Acknowledging that rural residents consume more energy further supports the importance of promoting solar adoption in these areas. The geographic and behavioral differences between densely populated urban centers and rural landscapes should factor into the solution for decreasing the nation's use of fossil fuels. Even the participants like the Engineer, who stressed, "One of the things that seems like it is more pertinent maybe than Midwest versus coast...it's urban versus rural," recognized that the differences between rural and urban areas create unique challenges for rural residents.

Another aspect of solar installations in rural versus urban environments discussed by several participants centered on rural residents' impulse to explore solar technology independently. The Engineer shared:

Again this rural thing...there's a lot of them (rural residents) that pride themselves on tinkering. And you go into your little Northern Tool catalog, they've got 'em for sale right there, inverters and whatever. So I could almost bet money that there 
are people out here who have slapped them on the wood shed and, uh, got 'em running and nobody knows about it.

The $I L-M O I O U$ also noted that Menards now sells a 3-kilowatt array for about $\$ 6,000$, which includes the panels, inverter, and racking system. An individual can have some of the cheapest energy at about $\$ 2$ per watt by installing a system himself. However, the Municipal Utility expressed concern over rural residents experimenting with a panel or two without alerting their utility company. The increased possibility for do-it-yourself solar installs emphasized the importance of educating rural residents on the policies and regulations for grid-connected arrays. Increased training opportunities can ensure the safety and satisfaction of both homeowners and utility personnel.

Education, training, and promotion allow potential adopters to gather information through communication channels as part of the innovation adoption process outlined in Rogers' diffusion theory and discussed in Theme Six - Adoption and Installation. An individual assimilates the information and develops an interest in technology by gaining knowledge. He then forms an opinion about adoption based on that knowledge before deciding to adopt or reject a technological innovation (Kaplan, 1999; Rogers, 1995). Rogers argued that an individual lacking sufficient knowledge will not adopt. Kaplan further maintained that early adopters likely know more about a technology and, therefore, adopt more willingly than laggards, who have little knowledge. Strupeit and Palm (2016) cited Moore (1999) who explained that early adopters are more willing to assume risks and address the complexities of innovations while accepting that most benefits are long-term. The participants classified as innovators precede early adopters and share many of the same characteristics. They gathered as much information as 
possible to make an informed decision and act on their motivations to adopt before others in their community.

Gaining a comprehensive understanding of solar adoption while identifying its diverse barriers provides insight into the process an adopter must traverse; the participants considered countless factors and faced diverse challenges before installing a PV array. Detailing the adoption process highlights the need to increase the knowledge level for all categories of potential adopters. Rural residents, especially those categorized as laggards, even late majority, and possibly early adopters, are less inclined to gather information on their own, so disseminating information becomes even more imperative. The transfer of knowledge promises to advance solar technology more effectively in rural areas and provides an opportunity to reflect on the key findings of this study.

\section{Reflections and Insights}

Because of the complex issue of advancing solar energy, no single approach will completely promote its widespread adoption. This study provides a better understanding of these complexities facing potential solar adopters in rural areas. In fact, I maintain that widespread adoption is not completely realistic at this time. Based on campaign promises, Cabinet appointments, and early actions of the Trump administration, renewable energy is likely facing a decrease in support at the federal level during the next few years. This lack of support could lead to less funding for design and research as with past Republican administrations (Lynn, 2010) and less of the government intervention needed to ensure more consistency in policies and regulations. While recognizing that politics are slowing solar adoption, we must promote educating politicians on the benefits of solar adoption. 
We also have to remain optimistic that advances in energy storage will have a profound impact on the affordability of residential-scale solar arrays.

The political environment cannot be ignored in contemplating the future growth of solar adoption. Rural America is purportedly responsible to a large degree for electing Donald Trump as President of the United States, an individual who has dismissed climate change as a hoax. Asking whether this same rural America considers the future enough to recognize the benefits of diversifying our energy portfolio to include more renewable energy poses a reasonable question. Rural residents have placed their hopes in a leader who promotes practices of the past, so we cannot assume they will prioritize adopting solar technology considering the current rhetoric promoting a rejuvenation in the fossil fuel industry. As Coley and Hess (2012) acknowledged, coal has provided countless jobs and powered our nation's industrial development, but the negative impacts have been well documented.

Since solar power will not likely replace fossil fuels in the immediate future, energy sources combine to form the most likely solution in the meantime. Incorporating solar technology into the energy mix versus expecting it to replace fossil fuels presents the best path forward. The diffusion of technologies does not act as a mere substitution for existing systems according to Sovacool and Watts (2009). The Municipal Utility emphasized, "This (solar) is a piece of the puzzle. This is not the entire puzzle. The solution is a combination of everything: fossil fuels, nuclear power, and renewables - all different kinds of renewables."

The elimination of the partisan debate on solar technology will increase adoption in rural areas. Fundamental differences between the parties have impacted renewable 
energy policies and divided environmental conversations (Hess, Mai, \& Brown, 2106). This division continues impeding solar adoption, but the Buy-American Consultant reasoned that both political parties can support solar adoption for different reasons. Conservatives can appreciate the business growth potential with less government involvement. Liberals can continue promoting the environmental preservation aspect. She summarized:

This is not about whether you're a Conservative or a Liberal. It's not about being a tree hugger necessarily. It's about doing the right thing, for the right reasons. And if you're a Conservative, and you're about less government and you're about growing business and about contributing to your bottom line, hey it fits! If you're an environmentalist, and you're about preserving our earth, hey it fits! So it fits everybody. And for that reason, I don't think it can be stopped.

The Renewables Advocate agreed that solar adoption should not be viewed as having a liberal agenda even though Democrats have consistently supported renewable energy legislation (Coley \& Hess, 2012). Democrats sometimes want to claim coming to renewable energy first and take credit for all of the benefits from renewable energy. The Renewables Advocate maintained, "I think in the past 20 to 30 years, you're seeing renewable energy getting labeled as some sort of liberal idea, and I don't think it is." He believes that it is really an economic issue. Talking about solar adoption from an economic perspective versus an altruistic one accomplishes more. Capitalistic principles can energize solar adoption. Republicans, who believe in free market principles and the benefits of competition in the marketplace, should see renewable energy as a positive impact on the economy. The Renewables Advocate revealed: 
There're a lot of Republicans out there that really get that you're opening up the electric and energy market in a way that it's never been before. I think that some Republicans who really do look at free market principles and look at competition in the marketplace, and they see this as a good thing.

The Renewables Advocate added that if more Republicans increase their knowledge base about the benefits of solar adoption, eventually even a Republican president will not be able to ignore renewable energy.

A strong argument can be made for why Republicans should support renewables even though Coley and Hess (2012) argued Republicans within state government have typically opposed renewable energy policies. States like Missouri can stimulate their economy by attracting more businesses with an interest in solar, wind, biofuel, and other renewable energy. The Renewables Advocate emphasized that bringing industry through renewable energy to Missouri will create jobs, stating, "We've got to make this (solar) corporate. We've got to make this mainstream. It's the only way this is gonna work." Previous research acknowledged that state and local lawmakers along with voters consider economic factors when casting their votes on renewable energy reform (Coley \& Hess, 2012).

While I agree with promoting increased solar development through economic growth, this approach discounts the importance of consistent policies and incentives. The solution cannot be all free market; I maintain that we need minimum federal regulations outlining state statutes for residential-scale solar adoption. The optimal position lies somewhere in the middle of the partisan landscape, neither completely left nor completely right. Increased solar adoption in rural areas depends on federal regulations to 
standardize the policies and incentives among all utility types in every state. As an example, one should consider the widely varying net metering policies and reimbursement rates (retail versus avoided costs) for excess generation from state to state. Even among utility types within a state such as Illinois, investor-owned utilities offer annual energy-credit rollover while most cooperatives limit customers to a three-month carryover of credits.

Free market competition may spark solar development in some deeply conservative states unlikely to pass their own legislation supporting solar programs. However, if legislators in these states feel obligated to protect the interests of rural electric cooperatives and municipals that oppose solar advancement, federal regulations can ensure levelized rebates and incentives. The Renewables Advocate stated, “...there's a lot of them (state legislators) that go to the rural electric cooperative barbecues, and they get fed this line about how it's not good for them. And that's it!"

Increased regulations alone cannot move solar adoption forward in rural areas. Instead, technology needs to continue advancing. Sovacool and Watts (2009) claimed, "It is not the technology that is lacking, but the political will, institutional inertia, and social awareness needed to bring it forward" (p. 107). While I agree with their argument that politics, regulations, and social factors are strongly impacting adoption, improving battery backup technology remains critical. The freedom for homeowners to escape the confines of the utility grid depends on advances in energy storage. Solar adopters could decide whether staying connected to the grid or investing in the freedom to produce and store their own electricity is their best course of action. As the Suburban Co-op 
emphasized, "Now if batteries ever become a reality, game changer - major game changer!"

Developing reliable, more affordable batteries with a longer life span can also relieve power transmission requirements on an aging utility grid. More widespread energy storage and increased renewable energy can positively impact the existing, and arguably outdated, utility grid. Bakke (2016) explained that the existing utility grid was designed to transmit a predictable and regulated amount of power. Because renewable energy's frequent intermittency, the utility grid cannot be adapted easily to accommodate an unpredictable flow. In addition, utility companies must consider the impact to the utility grid from other carbon reducing advancements such as an increase in the number of electric cars on our roadways. The Suburban Co-op proclaimed that transitioning to electric cars will change the capacity and cost recovery from the increased demand at recharging stations. Therefore, considering the upgrades necessary to the existing utility as advancements in energy storage increase solar adoption become imperative.

Realistically, advances in energy storage are coming. The Installer/Consultant exclaimed:

I think once people realize that it (PV array) can make the power harnessing the sun, and that we don't have to burn coal. If you look overseas, and you look at how much solar is overseas. It's coming. It's coming, so it's going to come over here.

With energy storage improvements, the traditional structure of utility services could change drastically. The utility grid as it currently operates may eventually become obsolete. Utility companies should be proactive instead of reactive and get ahead of the 
curve, preparing to store large amounts of energy for solar customers. They can still provide transmission and distribution services for solar energy while charging storage fees to recover lost revenues in energy generation.

I foresee energy storage as a realistic option for investor-owned utilities in large urban areas. These utilities exhibit more forward-thinking approaches for solving energy and environmental concerns. Furthermore, urban citizens tend to be more receptive to progressive ideas. In contrast, many rural residents continue demonstrating apprehension toward solar power and other renewable energies, perceived by many as another green practice supporting a liberal agenda. Unfortunately, the rural mindset does not end with just the customers who use the electricity. It also extends to the municipal and cooperative utilities providing energy from non-renewable sources and those individuals making decisions on energy options. If city council members, as an example, still do not understand how solar energy generation works, they cannot be expected to make informed decisions on renewable energy programs.

Educating rural residents and training utility providers in these communities about solar technology presents an opportunity for a more informed rural population, which increases the likelihood of altering the social meaning and behavior toward solar adoption. As Sovacool (2009) acknowledged, overcoming existing cultural influences can be difficult when changing the acceptance of new technologies. To initiate widespread social acceptance of solar technology in rural areas, consistent policies and incentives must be established through federal regulations, affording a more diverse customer base access to residential-scale solar power. Additionally, advances in storage promise to shift existing cultural and social behaviors because of expanding energy 
options, forcing utility companies to reevaluate their services to an ever-increasing number of solar customers.

\section{Building Blocks for a Theory}

A reflection of the findings provides the necessary insight to theorize a strategic approach needed in the promotion, education, and training of solar PV technology in rural areas. Consideration of the opposing political agendas to incorporate renewable energy further strengthens the argument for a rural solar adoption strategy. Of equal importance, energy storage development could have a profound effect on residentialscale PV arrays. Notwithstanding these advancements, the solar industry must move forward by first promoting solar technology to a receptive audience. Targeting those potential adopters most likely to invest in solar technology can optimize resources for promotion.

The promotion of solar adoption has to start with those most likely to install a PV array. While the Young Adopter was willing to finance his PV array, he was an outlier among the interviewed adopters. Older adults who have available capital to invest without financing a system seem to make up the vast majority of adopters. A potential adopter's upfront capital or his willingness to secure financing limits his motivation to install a PV array. The data indicated key identifiers such as a homeowner living in a neighborhood with PV arrays, an individual visiting solar sites like Missouri S\&T's Solar Village, and a customer inquiring about regulations and available incentives through his utility company. Identifying these potential adopters and providing useful promotional material can increase the likelihood they will pursue adoption and install an array. 
An increase in solar adoption by a group able and willing to invest in renewable energy holds the promise of providing needed visibility to a much larger audience. A sense of hope can prevail. A target audience should not be perceived as limiting; it should be seen as an opportunity - a first step in the eventual acceptance of solar power as a prominent energy source. In such a way, more PV arrays throughout the rural landscape can establish solar technology's credibility, create a social norm surrounding its adoption, provide more opportunities for first-hand experience, and increase the likelihood of future widespread adoption. Telling the story of solar adoption to a target audience provides more promise in the immediate future than holding out hope that vast numbers of Americans will demonstrate a motivation based on environmental stewardship or a willingness to borrow money to install PV arrays.

This approach does not discount the need to include other stakeholders, including installers/consultants, utility companies, and policy makers, in technical assistance and training opportunities. I assert the need to transfer knowledge on innovations in solar technology to this diverse group of stakeholders in an effort to diffuse solar technology further among rural residents. Because government support and available incentives seem erratic and unpredictable, including politicians can ensure government regulations stabilize policy and rebate inconsistencies. Additionally, utility companies, recognizing the potential benefit of advances in energy storage, should support policy changes necessary to encourage solar adoption among rural residents.

Increasing solar adoption in rural America requires 1) targeting an audience most likely to invest in solar technology, 2) making it assessable through first-hand experience, and 3) telling the solar adoption story in a narrative that is relatable to the audience. 
Further, it requires 4) educating a vested group of potential adopters, installers/consultants, utility companies, and policy makers through technical assistance and training opportunities, and 5) minimizing the inconsistencies of policies and incentives through some level of federal government regulation.

\section{Contributions}

This study provides residents, installers/consultants, utility companies, and policy makers with a more comprehensive understanding of residential-scale solar installations. This understanding can support a more focused and effective campaign to encourage adoption in rural areas. It also encourages expanded integration of solar power into utilities' energy portfolios. Because the study employed related behavior concepts of culture, social meaning, usability, and change, the findings provide a more grounded understanding of rural Americans' preconceived ideas on solar adoption. An increase in residential-scale solar generation also points to social implications for communities, potential impacts to local economies, and necessary changes to regulatory oversight.

The study contributes unique findings to existing research on solar adoption that has previously focused on states with large amounts of solar penetration. The majority of existing studies in the field have employed quantitative methods, such as surveys, to collect data on the impediments slowing solar adoptions. The Suburban Co-op argued, "People will say all kinds of things in a survey, but when it comes time to put the money down, they don't do it." He insisted that the proof of knowledge acquisition on solar technology's benefits sways customers to spend money installing an array. Unfortunately, surveys have usually not reflected why adopters have willingly invested in solar technology or what they thought of the experience. Moreover, various methods of 
quantitative research have not provided the necessary insight into what will prompt a larger portion of the rural population to invest in solar power. Conducting qualitative research allowed me to explore the motivations for solar adoption and discover how political and regulatory sanctions are influencing solar adoption. I was able to interpret the participants' unique experiences with solar technology and uncover the reasons interviewed adopters installed PV arrays. Observing participants' environmental behavior directly, I was able to incorporate local knowledge on solar adoption in rural geographies.

The findings are relevant to the larger discussion of renewable energy generation because the data indicates that the geographic location greatly influences solar adoption based on an area's socioeconomic characteristics and social acceptance of RETs. Different geographic locations offer various levels of rebates and incentives, influenced by the utility type in an area. Policies and regulations also vary greatly from location to location. Providing a better understanding of the geographic factors promotes increased solar adoption as a renewable energy source throughout the U.S., including rural areas previously apprehensive to embrace RETs. 


\section{CHAPTER SIX: CONCLUSIONS \& RECOMMENDATIONS}

Key conclusions from this study offer a look toward the future of rural solar adoption. First, much of the rural population currently cannot afford to adopt solar technology regardless of whether environmental stewardship motivates them to improve air quality or reduce their carbon footprint. Solar adoption has to benefit their month-tomonth spending or at least be equal in price to their monthly utility bills. While the participants' displayed varying levels of commitment to a greener lifestyle, they all expressed a desire to save money. The Corporate Farmer did not demonstrate a strong interest in green technologies or a belief in climate change but, instead, installed his array to save money on expensive utility bills from drying grains. The available rebates and grants made his installation more affordable, a critical factor when contemplating the stimulus for solar growth. The Engineer summarized the importance of rebates and incentives, "So obviously if you can get somebody else to pay for it, (it) makes everybody a little greener." Solar generation can undoubtedly improve our environment; nevertheless, reducing rural residents' monthly energy costs through more affordable solar adoption can better their lives.

Next, if solar powered batteries become more affordable and develop as rapidly as other electronic devices, grid connected arrays may eventually be obsolete. Installing stand-alone solar panels may become as common as carrying cellphones in an age when landlines seem outdated. Added to that technological revolution, new battery chargers and portable power packs for automobiles are similar in size to most smart phones. When this small-sized, power storing technology expands to renewable energy, solar technology 
will evolve into a simple and affordable alternative, turning a PV array into a necessity and not just a luxury.

Finally, solar adoption can advance quickly throughout rural areas of the Midwest, assuming an increase in government support and development in energy storage technology. I assert, though, that solar adoption will not progress more quickly in the rural Midwest until potential adopters, politicians, and utility companies understand the usability of PV arrays better. Therefore, disseminating information to a broader audience through education, training, and promotion employing the concept theorized in this study becomes imperative.

\section{Recommendations}

Educating rural residents on solar technology's benefits and simple operation can increase the adoption rate. People have to understand the simplicity of the process. The MO Division of Energy insisted, "At this point, a lot of it may just be education." The Energy Consultant stated that education should start with public education and focus on reducing energy usage. Getting elementary and high schoolteachers on board can expand the discussion to include young people about embracing renewable energy for the longterm benefit of the environment. The Surveyor gave an example of his daughter's elementary school teaching about solar technology with solar charging benches purchased through a grant that the Buy-American Consultant helped write. Installing PV arrays at schools, an untapped market according to the Father-in-law/Farmer, would expose more young people to solar technology. The Energy Consultant even suggested writing kids' books that promote ideas like energy sustainability, environmental stewardship, and resource conservation. 
Many rural residents have no idea how to get started or where to find information, so educating individuals about the regulations and explaining the costs of solar adoption should become a priority. Sovacool and Watts (2009) stressed the importance of distributing information because potential adopters lack knowledge about energy policies, RETs, and existing energy regulations. They argued the possibility of increased renewable energy with adequate policy support, which depends on political leadership. For increased solar integration, the solar industry must also start educating politicians. Both the Networker and the Renewables Advocate maintained that legislators must realize that solar adoption encompasses more than climate change.

This need for education and outreach necessitates a program designed to disseminate information to an engaged audience, including not just politicians but also utility companies, installers/consultants, and potential adopters. All of these entities need easy access to information. Utility companies must engage in the development of outreach programs to ensure they have a stake in promoting solar adoption to their customers. Installers/consultants must employ the most effective ways of promoting solar technology to potential adopters. At the same time, they should engage politicians in discussions to lessen possible resistance for new legislation supporting increased renewable energy.

A technical assistance program offers a format to educate, train, and promote solar adoption in rural areas. One promising method for developing this type of program involves collaborating with the MO Division of Energy. Recognizing the need for solar technical assistance, the MO Division of Energy voiced, "I think one thing you mentioned was technical assistance. I think that may be part of it." Sufficient interest exists within 
the State of Missouri for promoting solar energy and researching the installation of PV systems. This enthusiasm provides great promise for developing a training and outreach center in Missouri.

A solar technology transfer (technical assistance) program could be modeled after a number of technical assistance programs, such as the Local Technical Assistance Program (LTAP) and the Rural Transit Assistance Program (RTAP). Both are federally funded through grants to provide technical assistance and training for local agencies in each state. The Federal Highway Administration funds LTAP to provide training and resources on infrastructure maintenance to city public works departments as well as county road and bridge crews. The Federal Transit Administration funds RTAP to provide training and travel reimbursement to rural transit agencies. Both programs are tailored to meet the needs of local agencies throughout Missouri, but they are part of a larger network of technical assistance centers in each state, which allows for more resource sharing and collaboration.

A solar technology transfer program would allow tailored training for specific geographic locations, a critical consideration according to the findings. Since the geographic location has a noticeable impact on factors, ranging from regulations to rebates, training and resources should be state specific like the LTAP and RTAP programs. Differences in renewable energy policies between Illinois and Missouri were apparent in the data. However, LTAP and RTAP materials are readily shared from one state to another. Therefore, developing a program in Missouri that could easily be adapted to other states according to their Renewable Portfolio Standards and other legislation would benefit several states with large rural populations. 
I manage both the LTAP and RTAP programs through grants to Missouri S\&T, so I am very aware of the impact technical assistance has in disseminating new information and technologies to rural communities. The same format of face-to-face training could be developed for solar installers/consultants, utility companies, and potential adopters. This type of training could also provide small, rural utilities with a resource for training their maintenance personnel. Krannich et al. (2015) acknowledged the importance of developing workforce-development training programs in renewable energy for rural communities.

In addition to providing hands-on training, a solar technology center could provide access to demonstration projects such as Missouri S\&T's Solar Village and Eco Village. Both villages are a collection of six solar-powered homes designed and constructed to compete in previous U.S. Department of Energy Solar Decathlons. Tours of the homes provide educational opportunities for industry professionals and community members interested in solar technology and sustainable living. The homes also serve as student housing and testbeds for a variety of faculty research studies. Projects like the Solar Village and Eco Village offer excellent demonstration opportunities to educate a wide range of interested parties. The findings emphasized the importance of seeing solar technology in-person, reinforcing that demonstration projects provide a key opportunity for increasing solar adoption in rural areas.

Training workshops and demonstrations would also provide excellent materials for promoting solar adoption more effectively. Promotional materials could include printed and online resources with information on pricing, estimated paybacks, technical information, local installers/consultants, and testimonials from satisfied solar adopters. In 
addition, telling success stories of solar adoption in rural areas related to potential adopters' own situations provides meaningful marketing content. As the Installer/Consultant stated, "I think this story needs to be told...I think it's important." Sharing testimonials from satisfied customers can provide an incentive to potential adopters. The Corporate Farmer summarized his happiness, 'I'm glad we did it. I would do it again. It's simple, no maintenance, and it works!" The Installer/Consultant added, "So when you start to think about the energy that you can produce with these arrays and what you can offset...it's been pretty well a no-brainer."

Current news coverage of solar adoption highlights the need for effective promotion. When sources like Fox News falsely report that the solar industry is falling behind Germany because we have less sun ("Solar's Dim Future," 2013), a scientifically false statement, it burdens promoting solar adoption to the masses. Concern about the misrepresentation of solar adoption on news outlets like Fox News, as expressed by the Networker, bolsters the need to produce a factual yet relatable promotional campaign. Providing a consistent message focusing on technical implications and offering limited but useful information targeted to individuals motivated to adopt solar technology could offset this type of adverse publicity. A more likely acceptance of solar technology results from a targeted, receptive audience.

\section{Future Research}

Conducting additional research on the common behaviors and attributes of the adopters investing in solar technology can identify the target audience to produce a more effective campaign for promoting solar adoption. On the other hand, additional data gathered through interviews with nonadopters - individuals who considered adopting 
solar technology but decided against it - could provide more insight into the adopter categories for solar technology. This group of participants could reveal personality differences between nonadopters and adopters. Understanding why nonadopters chose not to pursue solar adoption further could provide insight into the reasons challenges sometimes outweigh benefits for adoption.

Several categories of data emerged beyond my research question and subquestions but provided context on the progression of solar adoption in rural areas. The categories included the importance of developing community solar programs, promoting energy efficiency, conducting energy assessments, and increasing social benefits through solar adoption. I feel strongly that each of these categories warrants further research to provide a more thorough understanding of the challenges solar adoption faces and the direction it is taking.

Several of the participants discussed community solar or mentioned knowing about the program. While community solar programs give more homeowners who cannot afford their own PV array access to renewable energy, it may slow the rate of residentialscale solar adoption. Potential adopters who might otherwise install their own array may opt into a community program instead. Community solar also allows utility companies to incorporate solar power into their energy portfolios without offering customer rebates. The interviewed utilities argued that it enables them to balance the power generated from PV arrays into their energy mix, allowing them to offset non-peak generation periods with nonrenewable energy sources more effectively. Community PV arrays also provide less of a threat for destabilization to an aging utility grid. However, utilities may use community solar simply to maintain control of energy generation. Fully understanding 
the motivations behind utility companies' willingness to develop community solar programs will better position the renewable industry to support or oppose more development. The industry needs to educate potential adopters about the benefits of increased solar generation through community programs and alert them of possible impediments to residential-scale solar adoption. Because of the impact that community solar is already having on the solar energy sector, I propose conducting further research on the topic.

Promoting energy efficiency was important to all of the interviewed utility companies, government agencies, and consultants. Each spoke about conducting energy assessments as a step in the solar adoption process to ensure that correctly sized PV arrays generate only efficiently used energy. The MO Division of Energy maintained, "I mean generally efficiency is thought to be the cheapest form of energy production.... and it helps you size your system right rather than just getting a huge system that is sending energy out into the air." Generating renewable energy only to waste it heating and cooling an inefficient house is not saving resources and promoting environmental stewardship. The Energy Consultant asserted that energy efficiency is potentially the cheapest as well as the cleanest, safest, and most secure source of energy savings. He argued that since buildings consume $75 \%$ of energy production, saving money through energy conservation is critical. Interestingly, none of the interviewed adopters mentioned energy assessments, even the farmers who could benefit by ensuring their grain dryers and other equipment operate efficiently. This topic warrants more research to understand adopters' reluctance to pursue energy assessments. 
While this study focused on the motivations and barriers for solar adoption, it did not reveal whether the interviewed adopters perceived any social benefits for themselves and their communities. Kirkpatrick and Bennear (2014) suggested that these benefits of solar adoption should be determined before making public policy recommendations, specifically related to PACE financing. In the broader context of solar adoption beyond just financing options, exploring the social benefits could strengthen the claim that solar adoption should be a priority at the local, state, and federal levels. Additionally, increased social benefits from solar adoption may improve social equity, one of the three societal values that define sustainability. Social equity relates to the social fairness of a program or policy. Social equity along with economic development and environmental protection assist in the preservation of natural resources. Further, solar adoption may be shown to increase interaction among neighborhoods through the sharing of successes and challenges in adopting solar technology. Greater interest in the actions of others could strengthen community engagement. Surely, these improvements in rural communities would help prompt more public policy for solar adoption. 


\section{Appendix A}

\section{Interview questions for solar adopters:}

1. When did you have your solar panels installed?

2. How are you using them or what are you using them for?

3. What was appealing about solar panels?

4. What first got you interested in installing them?

5. How did you first learn about solar panels?

6. What were your other motivations for installing the solar panel array?

7. Were tax credits/energy credits influential in your decision?

8. Who installed them?

9. What type of solar panel array do you have?

10. What have been the biggest benefits of installing them? 
11. What return do you get for your installation of a solar array? Financial? Personal satisfaction?

12. What was the reaction of your neighbors? Has their opinion change over time? Have any of the installed or are they considering installing solar panels?

13. What do you think the biggest barrier has been that discourages people for installing solar panels/arrays?

14. How does it make you feel in terms of your contribution to helping conserve renewable resources? 


\section{Appendix B}

\section{Interview questions for cooperative utilities:}

1. Can you explain the history and future of your community solar program?

2. What are the benefits to cooperatives for promoting solar adoption among your utility customers?

3. What are the challenges that cooperatives face as more residential-scale solar arrays are installed?

4. How have the changes in incentives, rebates, policies, etc. influenced the support of solar adoption for cooperatives?

5. How are cooperatives addressing the changes that come from grid-tied solar arrays?

6. Are cooperatives planning for a substantial increase in solar production? If so, how?

7. What are some of the biggest challenges/barriers you see facing the adoption of solar PV's in rural areas?

8. What are the some unique challenges that rural areas face in adopting solar that more urban areas may not face?

9. What do you think the biggest barrier has been that discourages people for installing solar panels/arrays?

10. Are cooperatives prioritizing the conservation of renewable resources? 


\section{Appendix C}

\begin{tabular}{|c|c|c|}
\hline \multicolumn{3}{|c|}{ Interview - CH } \\
\hline \multirow[t]{10}{*}{ Themes } & Categories & Codes \\
\hline & Motivations & $\begin{array}{l}\text { Very high utility bills due to } \\
\text { grain dryers was the } \\
\text { motivation }(\mathrm{CH})\end{array}$ \\
\hline & & $\begin{array}{l}\text { Main motivation was cost } \\
\text { savings }(\mathrm{CH})\end{array}$ \\
\hline & & $\begin{array}{l}\text { Reiterating that cost savings } \\
\text { was main motivation }(\mathrm{CH})\end{array}$ \\
\hline & & $\begin{array}{l}\text { Did it for themselves not } \\
\text { others }(\mathrm{CH})\end{array}$ \\
\hline & & $\begin{array}{l}\text { Predicting that solar arrays } \\
\text { will increase }(\mathrm{CH})\end{array}$ \\
\hline & & $\begin{array}{l}\text { Increasing utility rates will } \\
\text { motivate more customers to } \\
\text { install solar }(\mathrm{CH})\end{array}$ \\
\hline & & Had upfront capital $(\mathrm{CH})$ \\
\hline & & $\begin{array}{l}\text { Saying their high utility bill } \\
\text { motivates them }(\mathrm{CH})\end{array}$ \\
\hline & & $\begin{array}{l}\text { Probably wouldn't install } \\
\text { solar otherwise }(\mathrm{CH})\end{array}$ \\
\hline
\end{tabular}




\begin{tabular}{|l|l|l|}
\hline & & $\begin{array}{l}\text { The farm has been in the } \\
\text { family } 130 \text { years }(\mathrm{CH})\end{array}$ \\
\hline & & $\begin{array}{l}\text { Went to college for a while } \\
(\mathrm{CH})\end{array}$ \\
\hline & & $\begin{array}{l}\text { Having the upfront capital } \\
\text { is important }(\mathrm{CH})\end{array}$ \\
\hline & & \\
\hline
\end{tabular}

I think it's the thing of the future. $(\mathrm{CH})$

The important job is having the money to do it. $(\mathrm{CH})$

\begin{tabular}{|l|l|l|}
\hline & Prior knowledge; & $\begin{array}{l}\text { Acknowledging that her son } \\
\text { researching the technology } \\
\text { \& nephews did all of the } \\
\text { background research (CH) } \\
\text { Most of the reading and } \\
\text { research about solar was } \\
\text { done by her grandsons (CH) }\end{array}$ \\
\hline & Net metering, cost & $\begin{array}{l}\text { Willing to waste electricity } \\
\text { so that utility co-op doesn't } \\
\text { get their extra electricity } \\
\text { (CH) }\end{array}$ \\
\hline & & $\begin{array}{l}\text { Excess electricity wiped } \\
\text { clean every 3 months (CH) }\end{array}$ \\
\hline & & \\
\hline
\end{tabular}




\begin{tabular}{|c|c|c|}
\hline 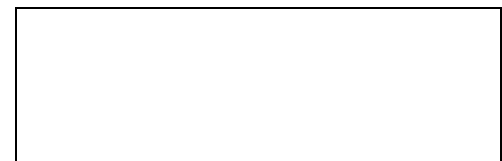 & Challenges; barriers & $\begin{array}{l}\text { Expressing frustration with } \\
\text { co-op }(\mathrm{CH})\end{array}$ \\
\hline & & $\begin{array}{l}\text { Confirming that the solar } \\
\text { installer will know more } \\
\text { about difficulties caused by } \\
\text { co-op }(\mathrm{CH})\end{array}$ \\
\hline & & $\begin{array}{l}\text { Lacking involvement at the } \\
\text { beginning of the process } \\
(\mathrm{CH})\end{array}$ \\
\hline & & $\begin{array}{l}\text { Acknowledging the large } \\
\text { upfront cost }(\mathrm{CH})\end{array}$ \\
\hline & & $\begin{array}{l}\text { Saying their co-op is the } \\
\text { hardest to work with }(\mathrm{CH})\end{array}$ \\
\hline & & $\begin{array}{l}\text { Expressing frustration with } \\
\text { co-op they provided little } \\
\text { help and instruction }(\mathrm{CH})\end{array}$ \\
\hline & & $\begin{array}{l}\text { Lacking necessary } \\
\text { information when they were } \\
\text { ready to turn it on }(\mathrm{CH})\end{array}$ \\
\hline & & $\begin{array}{l}\text { Son wanted it where it } \\
\text { would not be visible, was } \\
\text { ok with it being on the roof } \\
\text { (CH) }\end{array}$ \\
\hline
\end{tabular}




\begin{tabular}{|c|c|c|}
\hline & & $\begin{array}{l}\text { No roofs that would work } \\
(\mathrm{CH})\end{array}$ \\
\hline & & $\begin{array}{l}\text { Co-ops not for it because } \\
\text { they're losing money }(\mathrm{CH})\end{array}$ \\
\hline & & $\begin{array}{l}\text { Upfront cost biggest barrier } \\
\text { for most people }(\mathrm{CH})\end{array}$ \\
\hline & & $\begin{array}{l}\text { Saying utility companies } \\
\text { are against solar }(\mathrm{CH})\end{array}$ \\
\hline & & $\begin{array}{l}\text { Saying solar was entirely } \\
\text { new to her }(\mathrm{CH})\end{array}$ \\
\hline & & $\begin{array}{l}\text { Expressing frustration that } \\
\text { co-op doesn't pay them for } \\
\text { excess electricity generated } \\
(\mathrm{CH})\end{array}$ \\
\hline & & $\begin{array}{l}\text { Changed her mind on how } \\
\text { it looks thought it would } \\
\text { look outrageous }(\mathrm{CH})\end{array}$ \\
\hline & Benefits & $\begin{array}{l}\text { Doesn't mind the look of it } \\
\text { out next to the road }(\mathrm{CH})\end{array}$ \\
\hline & & $\begin{array}{l}\text { Hoping it pays for itself in } 6 \\
\text { years }(\mathrm{CH})\end{array}$ \\
\hline
\end{tabular}




\begin{tabular}{|c|c|c|}
\hline & & $\begin{array}{l}\text { Describing happiness with } \\
\text { small utility bill }(\mathrm{CH})\end{array}$ \\
\hline & & $\begin{array}{l}\text { Acknowledging that solar } \\
\text { helps the environment }(\mathrm{CH})\end{array}$ \\
\hline & & $\begin{array}{l}\text { Expressing satisfaction that } \\
\text { it helps the environment } \\
\text { (CH) }\end{array}$ \\
\hline & & $\begin{array}{l}\text { Being more self-sufficient } \\
\text { is a benefit }(\mathrm{CH})\end{array}$ \\
\hline & & $\begin{array}{l}\text { Deciding still on her } \\
\text { feelings about having the } \\
\text { array }(\mathrm{CH})\end{array}$ \\
\hline & & $\begin{array}{l}\text { Likes that she can't see it } \\
\text { from the house, it is hidden } \\
\text { by a machine shed }(\mathrm{CH})\end{array}$ \\
\hline & $\begin{array}{l}\text { Tax \& other incentives, } \\
\text { benefits, rebates, policies }\end{array}$ & $\begin{array}{l}\text { Mentioning the tax rebate } \\
\text { they will receive }(\mathrm{CH})\end{array}$ \\
\hline & & $\begin{array}{l}\text { Further describing the tax } \\
\text { break }(\mathrm{CH})\end{array}$ \\
\hline & & $\begin{array}{l}\text { Doesn't know of } \\
\text { other incentives }(\mathrm{CH})\end{array}$ \\
\hline & & \\
\hline
\end{tabular}




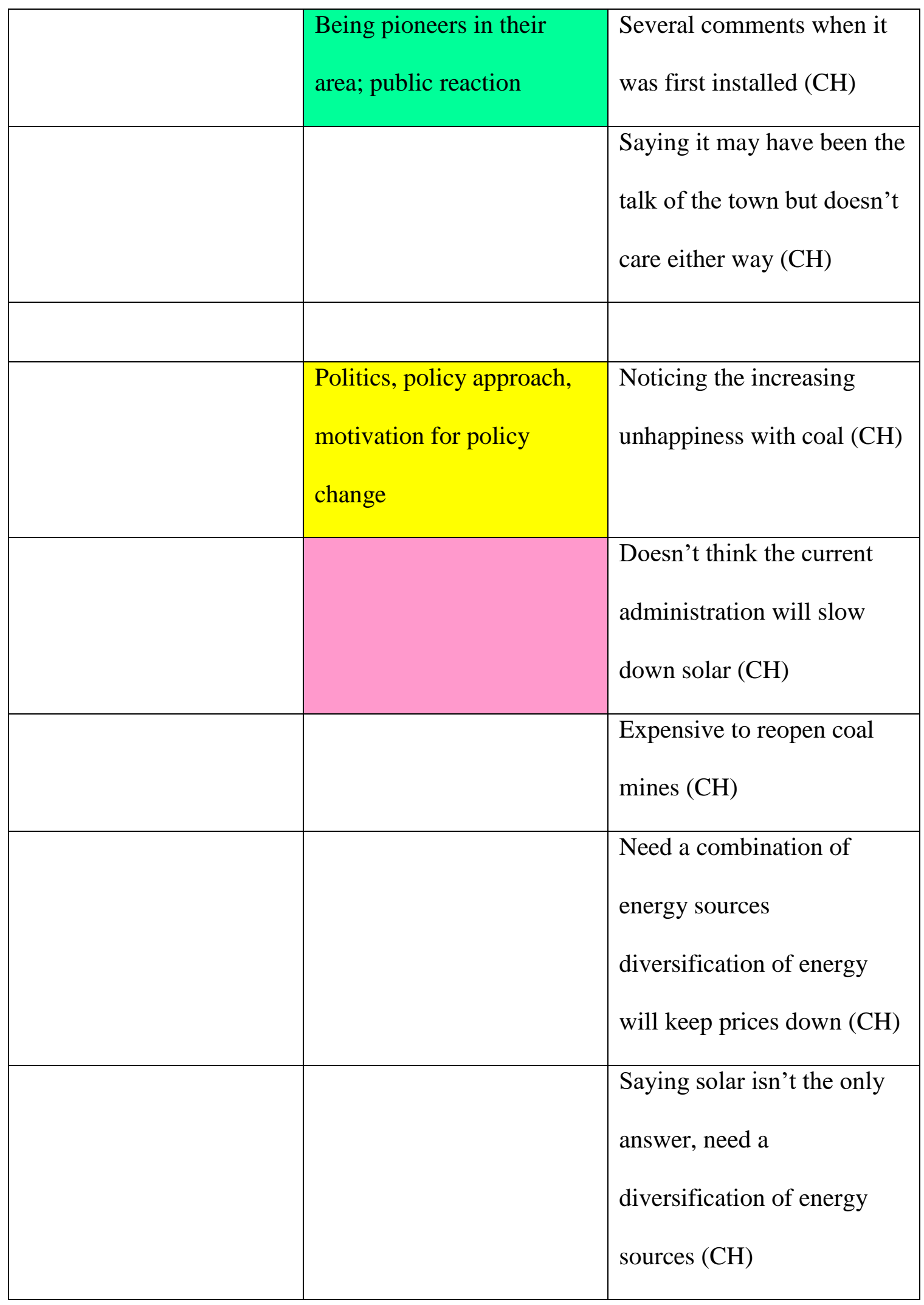




\section{Appendix D}

\begin{tabular}{|c|c|c|}
\hline \multicolumn{3}{|c|}{ Category - Solar farm developments } \\
\hline Themes & Subcategories & Codes \\
\hline & & $\begin{array}{l}\text { Receiving interest from out- } \\
\text { of-state company wanting to } \\
\text { develop a solar farm to sell } \\
\text { electricity on the grid } \\
\text { (Roger) }\end{array}$ \\
\hline & & $\begin{array}{l}\text { Supplementing burning coal } \\
\text { with solar field may be } \\
\text { necessary to get their costs } \\
\text { down (JC) }\end{array}$ \\
\hline & & $\begin{array}{l}\text { Company in AZ wanting to } \\
\text { lease } 200-400 \text { acres a } 20 \\
\text { year lease for solar farms } \\
\text { (JC) }\end{array}$ \\
\hline & & $\begin{array}{l}\text { Farmers, landowners been } \\
\text { getting letters from the } \\
\text { company (JC) }\end{array}$ \\
\hline & & $\begin{array}{l}\text { Wanting to build big solar } \\
\text { farm but typically no benefit } \\
\text { to user but no more cost }\end{array}$ \\
\hline
\end{tabular}




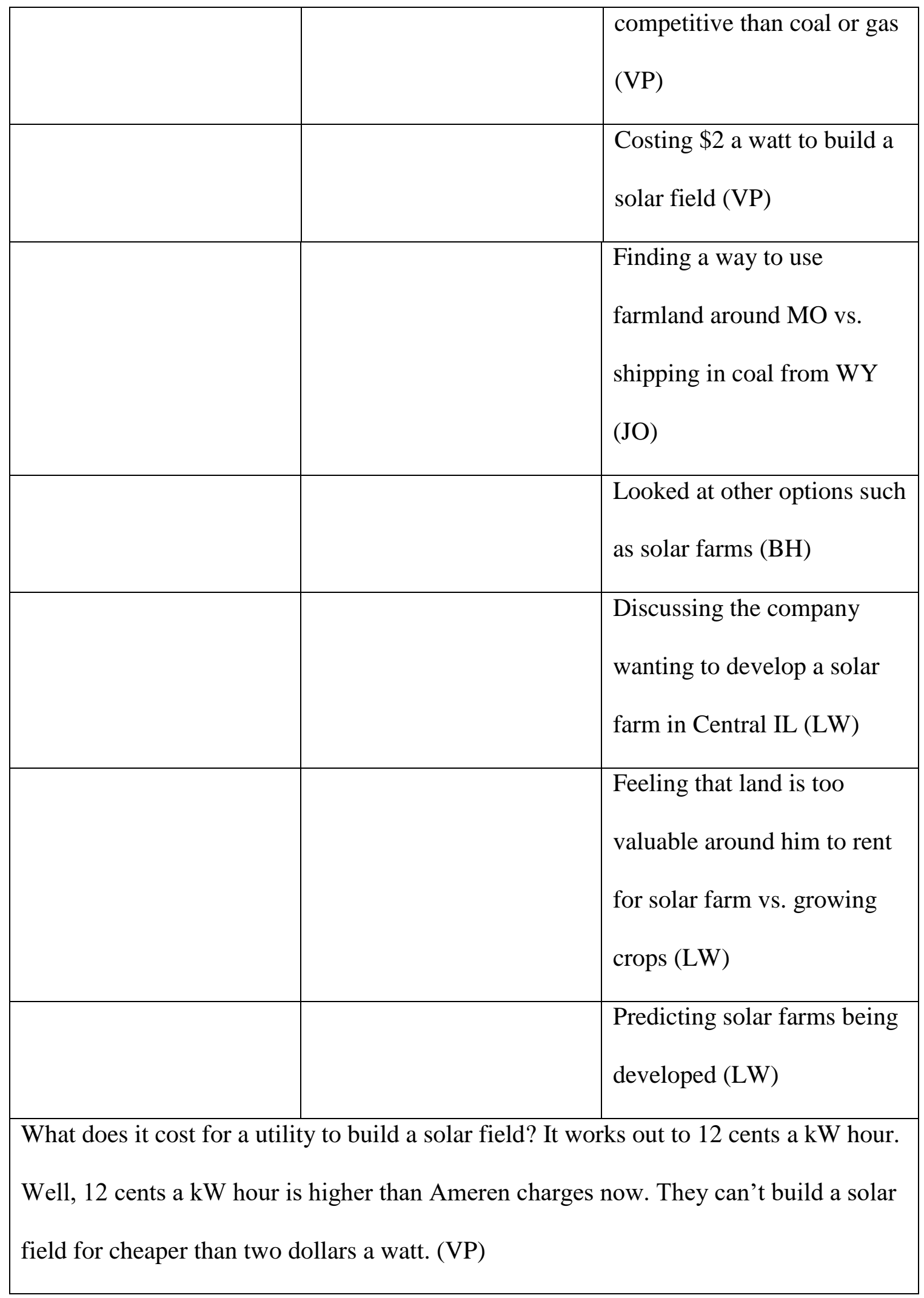




\section{Appendix E}

\begin{tabular}{|l}
\hline Factors and Motivations \\
\hline Theme \\
Multiple factors, benefits, and familiarity \\
with solar contribute to an individual's \\
motivation to adopt solar
\end{tabular}

- Inconsistent adoption rates in various locations due to multiple factors: impact of utilities and regulations, upfront capital necessary or willingness to finance, falling price of panels, improved technology, easy maintenance, and installation process

- Personal motivations and accessing benefits encourage solar adoption: saving money through lower utility bills, taking advantage of state $\&$ federal tax credits, receiving energy credits \& rebates, having a strong return on
Categories \& Subcategories

Factors

Having a cooperative utility

Easing regulations

Educating people/public

Having upfront capital

Being able to finance or get grant

Lowering costs of solar arrays

Improving PV technology/increasing

production

Requiring very little maintenance

Having independent spirit

Being able to self-install

Getting support from

installers/consultants

Having latest technologies/gadgets

Misc. Factors

Additional markets

Being in a rural area

Motivations

Saving money 


\begin{tabular}{|c|c|}
\hline \multirow{2}{*}{$\begin{array}{l}\text { investment, producing power for } \\
\text { self-sufficiency, and contributing }\end{array}$} & Having lower utility bills \\
\hline & Receiving a tax rebate \\
\hline \multirow[t]{2}{*}{ to environmental stewardship } & Investing in the future \\
\hline & Being influenced by others \\
\hline \multirow{3}{*}{$\begin{array}{l}\text { - Solar adopters motivated by } \\
\text { familiarity gained through: } \\
\text { reading, researching \& studying }\end{array}$} & Being self-sufficient/sustainable \\
\hline & Going without power in the past \\
\hline & Impacting the environment positively \\
\hline \multirow{2}{*}{$\begin{array}{l}\text { PV products, seeing systems } \\
\text { firsthand, knowing about other }\end{array}$} & Having personal reasons \\
\hline & Appealing to farmers \\
\hline renewables, and experimenting & Benefits \\
\hline \multirow[t]{12}{*}{ with solar } & Saving money \\
\hline & Having a quick payoff \\
\hline & Stimulating economy \& creating jobs \\
\hline & Generating own power \\
\hline & Being self-sufficient/sustainable \\
\hline & Receiving RECs \& rebates \\
\hline & $\begin{array}{l}\text { Requiring little maintenance/being } \\
\text { reliable }\end{array}$ \\
\hline & Being easy \& quick to install \\
\hline & Helping the environment \\
\hline & Physical appearance not distracting \\
\hline & No negative drawbacks \\
\hline & Overall satisfaction \\
\hline
\end{tabular}




\begin{tabular}{|l|l|}
\hline \multirow{5}{*}{} & Misc. benefits \\
\cline { 2 - 2 } & Prior knowledge, researching the \\
& technology \\
\cline { 2 - 2 } & Reading \& doing research \\
\cline { 2 - 3 } & Referencing various sources \\
\cline { 2 - 3 } & Hearing about solar \\
\cline { 2 - 3 } & Seeing solar/other systems firsthand \\
\cline { 2 - 3 } & Knowing about other renewables \\
\cline { 2 - 3 } & Having related experience \\
\cline { 2 - 3 } & Studying products, etc. \\
\hline & Experimenting \& installing \\
\hline
\end{tabular}

\section{Barriers and Challenges}

Theme

Diverse barriers present challenges for an

individual to adopt solar

- Affording the upfront cost and

overcoming various barriers make

it challenging to consider solar:

state, local, and utility regulations;

available rebates and incentives;

insurance requirements; impact to

energy industry; attitude toward
Categories \& Subcategories

Challenges; barriers

Utilities

Challenges for utilities

Cost

Physical limitations

Regulations

Lack of rebates \& incentives

Insurance increase

Impact to energy industry 


\begin{tabular}{|c|c|}
\hline and understanding of solar; and & Complacency \\
\hline \multirow[t]{2}{*}{ installation constraints } & Lack of understanding \\
\hline & Complexity of the process \\
\hline \multirow{3}{*}{$\begin{array}{l}\text { Lack of support in rural areas } \\
\text { impacted by level of technical } \\
\text { support, opportunities, availability }\end{array}$} & Solar equipment \\
\hline & Lack of installers/consultants \\
\hline & Challenges for installers \\
\hline of resources, and socioeconomic & Negative attitude by others \\
\hline \multirow[t]{2}{*}{ status of the region } & Competing priorities \\
\hline & Lack of support in rural areas \\
\hline \multirow{13}{*}{$\begin{array}{l}\text { Current political environment, } \\
\text { threats of increased deregulation, } \\
\text { and concerns of adverse effects of }\end{array}$} & Rural context, solar friendly areas \\
\hline & Rural demographics \\
\hline & Rural barriers \\
\hline & Politics, policy approach, \\
\hline & motivation for policy change \\
\hline & Current administration \\
\hline & Impact on coal \& fossil fuel \\
\hline & Impact on non-adopters \\
\hline & Diversifying energy \\
\hline & Regulations/deregulation \\
\hline & Political preferences \\
\hline & Impact of political preference \\
\hline & History of oil embargo \\
\hline
\end{tabular}




\begin{tabular}{|c|c|}
\hline Electric Utilities & \\
\hline Theme & Categories \& Subcategories \\
\hline Multiple utility types create inconsistent & Utility impact, networking, utility pool, \\
\hline statutes and differing installation costs for & utility structure \\
\hline an individual to adopt solar & Utility structure, power agreements, PSC \\
\hline - Explaining policy differences & Co-ops \\
\hline between municipal, cooperative, & Investor-owned utilities \\
\hline and investor-owned utilities and & Municipal utilities \\
\hline how they are impacted by state & Utilities \& renewable energy/solar \\
\hline statues & Energy portfolio, changes by some in \\
\hline - Cost of energy and economics & solar market \\
\hline of serving customers determines & Cost, economics \\
\hline percentage of renewables & \\
\hline - Utilities' energy portfolios & Scheduling, usage \\
\hline impact scheduling power usage and & \\
\hline willingness to promote solar & \\
\hline
\end{tabular}

\section{Renewable Portfolio/Energy Standards}

\begin{tabular}{|l|l|}
\hline Theme & Categories \& Subcategories \\
\hline Renewable portfolio/energy standard & Renewable Portfolio Standards, \\
dictates state's statutes and regulations for & regulation \\
\cline { 2 - 2 } including renewables & \\
\cline { 2 - 2 } & Proposition C \\
\hline
\end{tabular}




\begin{tabular}{|c|c|}
\hline - $\quad$ Explaining differences state to & Renewable Portfolio Standards \\
\hline \multirow[t]{2}{*}{ state in incentives and rebates } & Renew Missouri \\
\hline & Public Service Commission, regulation \\
\hline \multirow{3}{*}{$\begin{array}{l}\text { Exploring utility approaches to } \\
\text { solar: net metering, cost recovery, } \\
\text { and avoided costs }\end{array}$} & Statutes, rules/regulations \\
\hline & Tax \& other incentives, benefits, rebates, \\
\hline & policies \\
\hline \multirow{3}{*}{$\begin{array}{l}\text { - Offsetting challenges of } \\
\text { Renewable Energy Credits with }\end{array}$} & General thoughts on incentives, rebates \\
\hline & Benefits of incentives, rebates \\
\hline & Challenges in incentives, rebates \\
\hline benefits and operating REC & Differences state to state \\
\hline \multirow[t]{11}{*}{ program } & Challenges \\
\hline & Co-ops \& rebates \\
\hline & Net metering, cost recovery, avoided \\
\hline & costs \\
\hline & Net metering general information \\
\hline & Pushback on net metering \\
\hline & Net metering limits/terms \\
\hline & Credit for excess generation \\
\hline & Avoided cost \\
\hline & $\begin{array}{l}\text { Renewable Energy Credits (RECs or } \\
\text { SRECs) }\end{array}$ \\
\hline & Thoughts on Renewable Energy Credits \\
\hline
\end{tabular}




\begin{tabular}{|l|l|}
\hline \multirow{2}{*}{} & Benefits of RECs \\
\cline { 2 - 2 } & Challenges of RECs \\
\cline { 2 - 2 } & Managing personal RECs \\
\cline { 2 - 2 } & Operation of REC program \\
\hline
\end{tabular}

\begin{tabular}{|c|c|}
\hline \multicolumn{2}{|l|}{ Growth of Rural Solar Adoption } \\
\hline Theme & Categories \& Subcategories \\
\hline \multirow{3}{*}{$\begin{array}{l}\text { Growth of solar in rural areas dependent on } \\
\text { increased visibility, finance and grant } \\
\text { program availability, and improved }\end{array}$} & Rural context \\
\hline & $\begin{array}{l}\text { Encouraging solar in rural areas, benefits } \\
\text { in rural areas }\end{array}$ \\
\hline & Rural areas with solar \\
\hline - Rural solar adoption increased & Being pioneers in their area, public \\
\hline \multirow{2}{*}{$\begin{array}{l}\text { by visibility of existing arrays, } \\
\text { promotion \& education, positive }\end{array}$} & reaction, promotion, education, \\
\hline & perception \\
\hline public reaction $\&$ perception, and & Visibility of panels \\
\hline interest in new technologies & Reaction from others \\
\hline & $\begin{array}{l}\text { Telling \& talking to others about solar, } \\
\text { educating others, promoting }\end{array}$ \\
\hline $\begin{array}{l}\text { Solar available to more people } \\
\text { through grant \& loan programs, }\end{array}$ & Relating solar to other technologies \\
\hline \multirow{2}{*}{$\begin{array}{l}\text { community solar \& solar farm } \\
\text { developments, and power purchase }\end{array}$} & Influence of renewable energy \\
\hline & Growing solar businesses \\
\hline agreements & Community solar \\
\hline
\end{tabular}


- Improvements in battery technology can greatly impact solar diffusion
Examples of community solar projects

Questions about community solar

Supporting community solar

Benefits of community solar

Solar farm developments

Financing, grants

PACE

REAP grants

Other loan programs - Green Sky, etc.

Power purchase agreement (PPA)

Property assessed clean energy

Challenges, installation

Battery backup

Cost of batteries

Cost of batteries

Battery backup being a game changer

Grid tied vs. battery backup

Benefits of battery backup

Challenges, installation 


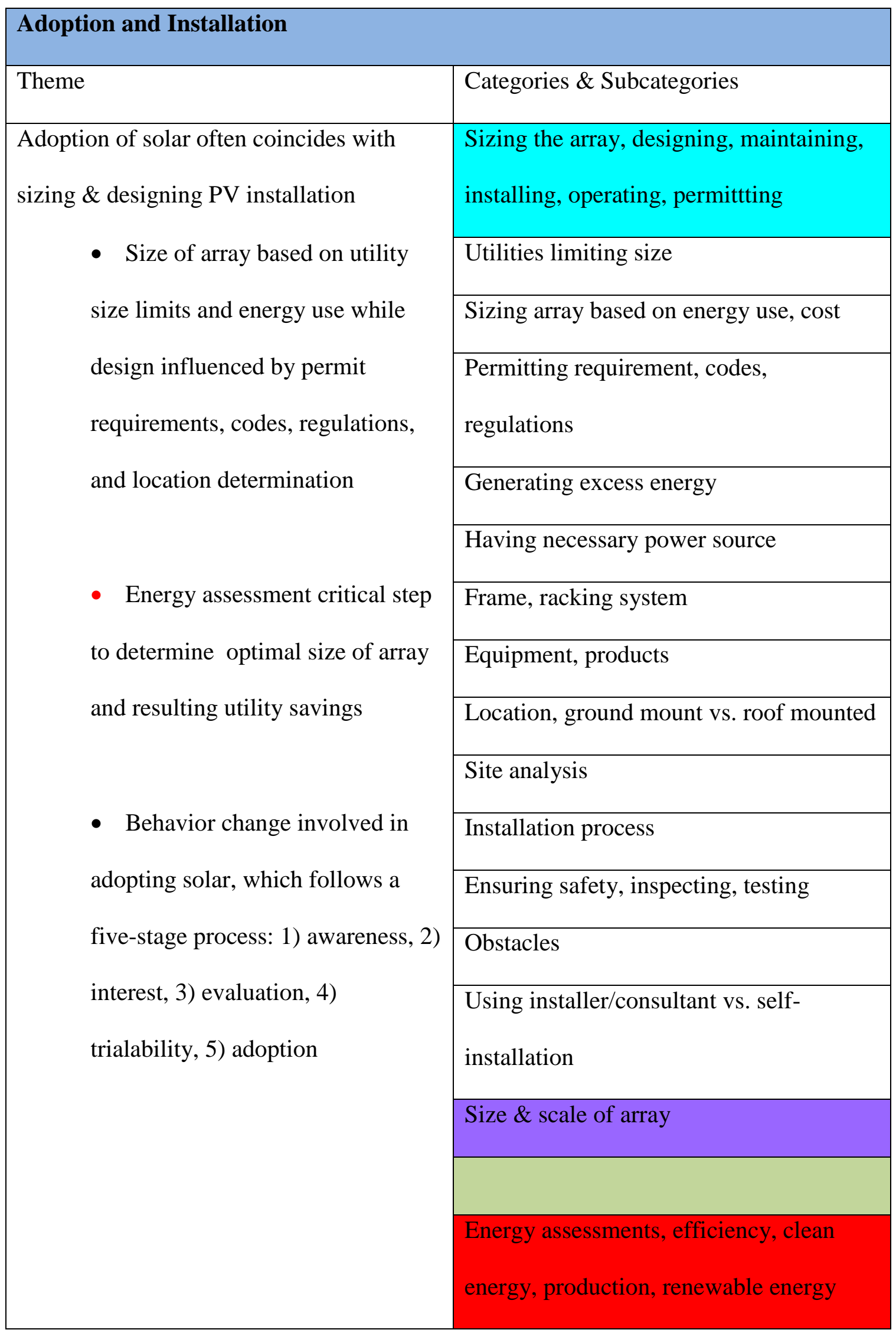




\begin{tabular}{|l|l|}
\hline \multirow{2}{*}{} & Need for energy efficiency \\
\cline { 2 - 2 } & Methods of energy efficiency \\
\cline { 2 - 2 } & Energy efficiency programs \\
\cline { 2 - 2 } & Behavior change, adoption stages \\
\cline { 2 - 2 } & \\
\hline
\end{tabular}




\section{References}

Albrecht, D. E. (Ed.). (2015). U.S. energy production and consumption: An overview. In D. E. Albrecht (Ed.), Our energy future: Socioeconomic implications and policy options for rural America (pp. 1-18). New York, NY: Routledge.

Altman, I., \& Chemers, M. M. (1980). Cultural aspects of environment-behavior relationships. Handbook of Cross-Cultural Psychology, 5, 355-395.

Bakke, G. (2016). The grid: The fraying wires between Americans and our energy future. New York, NY: Bloomsbury Publishing.

Balcombe, P., Rigby, D., \& Azapagic, A. (2013). Motivations and barriers associated with adopting microgeneration energy technologies in the UK. Renewable and Sustainable Energy Reviews, 22, 655-666.

Balcombe, P., Rigby, D., \& Azapagic, A. (2014). Investigating the importance of motivations and barriers related to microgeneration uptake in the UK. Applied Energy, $130,403-418$.

Balfour, J., Shaw, M., \& Jarosek, S. (2013). Introduction to photovoltaics. Burlington, MA: Jones \& Bartlett Learning.

Balint, P. J. (2006). Bringing solar home systems to rural El Salvador: Lessons for small NGOs. Energy Policy, 34, 721-729.

Bazen, E. F., \& Brown, M. A. (2009). Feasibility of solar technology (photovoltaic) adoption: A case study on Tennessee's poultry industry. Renewable Energy, 34(3), 748-754.

Berger, R. (2015). Now I see it, now I don’t: Researcher's position and reflexivity in qualitative research. Qualitative Research, 15(2), 219-234. 
Bott, E. (2010). Favourites and others: Reflexivity and the shaping of subjectivities and data in qualitative research. Qualitative Research, 10(2), 159-173.

Bowman, T., \& Thompson, J. (2009). Barriers to implementation of low-impact and conservation subdivision design: Developer perceptions and resident demand. Landscape and Urban Planning, 92(2), 96-105.

Brecha, R. J., Mitchell, A., Hallinan, K., \& Kissock, K. (2011). Prioritizing investment in residential energy efficiency and renewable energy - a case study for the U.S. Midwest. Energy Policy, 39, 2982-2992.

Brown, J. P., Weber, J. G., \& Wojan, T. R. (2013). Emerging Energy Industries and Rural Growth (ERR-159). U.S. Department of Agriculture, Economic Research Service. Retrieved from www.ers.usda.gov/publications/err-economic-research$\underline{\text { report/err159.aspx }}$

Campbell, S. (1996). Green cities, growing cities, just cities?: Urban planning and the contradictions of sustainable development. Journal of the American Planning Association, 62, 296-312.

Charmaz, K. (2006). Constructing grounded theory: A practical guide through qualitative analysis. Thousand Oaks, CA: SAGE.

Chase, P. G. (2006). The emergence of culture: The evolution of a uniquely human way of life. New York, NY: Springer.

Chaurey, A., \& Kandpal, T.C. (2010). Assessment and evaluation of PV based decentralized rural electrification: An overview. Renewable and Sustainable Energy Reviews, 14, 2266-2278. 
Clifton, J., \& Boruff, B. J. (2010). Assessing the potential for concentrated solar power development in rural Australia. Energy Policy, 38, 5272-5280.

Coley, J. S., \& Hess, D. J. (2012). Green energy laws and Republican legislators in the United States. Energy Policy, 48, 576-583.

Cooper, I. (2006). Cultural and social aspects of sustainable architectures.

Building Research \& Information, 34(1), 82-86.

Creswell, J. W. (2013). Qualitative inquiry \& research design: Choosing among five approaches. Thousand Oaks, CA: SAGE.

Creswell, J. W. (2014). Research design: Qualitative, quantitative, and mixed methods approaches. Thousand Oaks, CA: SAGE.

Crotty, M. (1998). The foundations of social research: Meaning and perspective in the research process. Thousand Oaks, CA: SAGE.

D’Agostino, A. L., Sovacool, B., Trott, K., Ramos, C. R., Saleem, S., \& Ong, Y. (2011). What's the state of energy studies?: A content analysis of three leading journals from 1999 to 2008. Energy, 36, 508-519.

Denholm, P., \& Margolis, R. M. (2008). Land-use requirements and the per-capita solar footprint for photovoltaic generation in the United States. Energy Policy, 36(9), 3531-3543.

De Young, R. (2011). Motives for living lightly. Adapted from De Young, R. (1991). Some psychological aspects of living lightly: Desired lifestyle patterns and conservation behavior. Journal of Environmental Systems, 20, 215-227.

De Young, R., \& Monroe, M. C. (1996). Some fundamentals of engaging stories. Environmental Education Research, 2(2), 171-187. 
Dietz, T., Fitzgerald, A., \& Shwom, R. (2005). Environmental values. Annual Review of Environment and Resources, 30, 335-371.

Dietz, T., Garderner, G. T., Gilligan, J., Stern, P. C., \& Vandenbergh, M. P. (2009). Household actions can provide a behavioral wedge to rapidly reduce US carbon emissions. Proceedings of the National Academy of Sciences of the United States of America, 106(44), 18452-18456.

Dono, J., Webb, J., \& Richardson, B. (2010). The relationship between environmental activism, pro-environmental behaviour and social identity. Journal of Environmental Psychology, 30, 178-186.

Duke, R. D., Jacobson, A., \& Kammen, D. M. (2002). Photovoltaic module quality in the Kenyan solar home systems market. Energy Policy, 30, 477-499.

Faiers, A., \& Neame, C. (2006). Consumer attitudes towards domestic solar power systems. Energy Policy, 34, 1797-1806.

Faiers, A., Neame, C., \& Cook, M. (2007). The adoption of domestic solar-power systems: Do consumers assess product attributes in a stepwise process? Energy Policy, $35,3418-3423$.

Farmer, G. (2013). Re-contextualising design: three ways of practicing sustainable architecture. Design, 17(20), 107-119.

Fazio, R., \& Zanna, M. (1981). Direct experience and attitude-behavior consistency. Advances in Experimental Social Psychology, 14, 161-202.

Findlay, L. (2002). Negotiating the swamp: The opportunity and challenge of reflexivity in research practice. Qualitative Research, 2(2), 209-230. 
Fowler, L., \& Breen, J. (2013). The impact of political factors on states' adoption of renewable portfolio standards. The Electricity Journal, 26(2), 79-94.

Geertz, C. (1973). The interpretation of cultures. New York, NY: Basic Books, Inc.

Gerdes, J. (2017, December 27). Trump administration reverses course on PACE financing. Green Tech Media. Retrieved from https://www.greentechmedia.com/articles/read/trump-administration-reverses-course-onpace-financing

Golding, S. (2012). Rural identities and the politics of planning: The case of a midwestern destination county. Society \& Natural Resources: An International Journal, $25,1028-1042$.

Gonzales, R. (2018, January 22). Trump slaps tariffs on imported solar panels and washing machines. National Public Radio Inc. (US). Retrieved from https://www.npr.org/sections/thetwo-way/2018/01/22/579848409/trump-slaps-tariffs-onimported-solar-panels-and-washing-machines

Goodenough, W. (1971). Culture, language, and society. Reading, MA: AddisonWesley.

Groat, L., \& Wang, D. (2013). Architectural research methods. Hoboken, NJ: John Wiley \& Sons, Inc.

Guy, S., \& Farmer, G. (2001). Reinterpreting sustainable architecture: The place of technology. Journal of Architectural Education, 54(3), 140-148. 
Hess, D. J., Mai, Q. D., \& Brown, K. P. (2016). Red states, green laws: Ideology and renewable energy legislation in the United States. Energy Research \& Social Science, $11,19-28$.

Hoffman, A. J., \& Henn, R. (2008). Overcoming the social and psychological barriers to green building. Organization \& Environment, 21(4), 390-419.

Hughes, T. P. (1983). Networks for power: Electrification of Western society, 1880-1930. Baltimore, MD: The Johns Hopkins University Press.

Ilyinichna, I., \& Valeryevna, Y. (2015). Sociological methods for sustainable urban design. Applied Mechanics and Materials, 737, 909-912.

Islam, T. (2014). Household level innovation diffusion model of photo-voltaic (PV) solar cells from stated preference data. Energy Policy, 65, 340-350.

Johnson, S. D., \& Moyer, E. J. (2012). Feasibility of U.S. renewable portfolio standards under cost caps and case study for Illinois. Energy Policy, 49, 499-514.

Kamalapur, G. D., \& Udaykumar, R. Y. (2011). Rural electrification in India and feasibility of Photovoltaic Solar Home Systems. Electrical Power and Energy Systems, 33, 594-599.

Kaplan, A. W. (1999). From passive to active about solar electricity: Innovation decision process and photovoltaic interest generation. Technovation, 19, 467-481.

Karakaya, E., \& Sriwannawit, P. (2015). Barriers to the adoption of photovoltaic systems: The state of the art. Renewable and Sustainable Energy Reviews, 49, 60-66.

Kearney, A. R. (1994). Understanding global change: A cognitive perspective on communicating through stories. Climatic Change, 27, 419-441. 
Kirkpatrick, A. J., \& Bennear, L. S. (2014). Promoting clean energy investment: An empirical analysis of property assessed clean energy. Journal of Environmental Economics and Management, 68, 357-375.

Koranda, C., Chong, W., Kim, C., Chou, J. S., \& Kim, C. (2012). An investigation of the applicability of sustainability and lean concepts to small construction projects. Journal of Civil Engineering, 16(5), 699-707.

Krannich, R. S., Robertson, P. G., \& Olson, S. K. (2015). Renewable energy in the United States: Trends, prospects, and implications for rural development. In D. E. Albrecht (Ed.), Our energy future: Socioeconomic implications and policy options for rural America (pp. 125-146). New York, NY: Routledge.

Krasko, V. A., \& Doris, E. (2013). State distributed PV policies: Can low cost (to government) policies have a market impact? Energy Policy, 59, 172-181.

Kwok, A. G., \& Grondzik, W. T. (2011). The Green Studio Handbook. New York, NY: Taylor \& Fancis.

Labay, D. G., \& Kinnear, T. C. (1981). Exploring the consumer decision process in the adoption of solar energy systems. Journal of Consumer Research, 8, 271-278.

Lang, J. (1987). Creating architectural theory: The role of the behavioral sciences in environmental design. New York, NY: Van Nostrand Reinhold.

Liang, J., \& Fiorino, D. J. (2013). The implications of policy stability for renewable energy innovation in the United States. The Policy Studies Journal, 41(1), 97118. 
Le, M. (2013, January 8). Finding solutions to solar's soft cost dilemma.

Department of Energy. Retrieved from http://energy.gov/articles/finding-solutions-solars$\underline{\text { soft-cost-dilemma }}$

Leenheer, J., de Nooij, M., \& Sheikh, O. (2011). Own power: Motives of having electricity without the energy company. Energy Policy, 39, 5621-5629.

Lutzenhiser, L. (1990). Explaining consumption: The promises and limitations of energy and behavior research. In Proceedings of the American Council for an Energy Efficient Ecomony 1990 Summer Study on Energy Efficiency in Buildings (pp. 2.1012.110). Washington, DC: ACEEE Press.

Lynn, P. A. (2010). Electricity from sunlight: An introduction to photovoltaics. Chichester: Wiley.

Marcuse, P. (1998). Sustainability is not enough. Environmental and Urbanization, 10(2), 103-111.

Masini, A., \& Menichetti, E. (2013). Investment decisions in the renewable energy sector: An analysis of non-financial drivers (June 21, 2012). Technological Forecasting and Social Change, 80(3), 510-524. (HEC Paris Research Paper No. 976/2013). Retrieved from: https://ssrn.com/abstract=2247461

Maxwell, J. A. (2005). Qualitative research design: An interactive approach. Thousand Oaks, CA: SAGE.

McKenzie-Mohr, D. (2000). Fostering sustainable behavior through communitybased social marketing. American Psychologist, 55(5), 531-537.

Merriam, S. B. (2009). Qualitative research: A guide to design and implementation. San Francisco, CA: Jossey-Bass. 
Midgely, D., \& Dowling, G. (1978). Innovativeness: The concept and its measurement. The Journal of Consumer Research, 4, 229-242.

Miller, M. (2010, July 19). Solar power gaining support, use as alternative energy source. Southeast Missourian. Retrieved from http://www.semissourian.com/story/1796122.html

Moore, G. A. (1999). Crossing the chasm: Marketing and selling high-tech products to mainstream customers. New York, NY: Harper Business.

Moore, S., \& Wilson, B. (2009). Contested construction of green building codes in North America: the case of the alley flat initiative. Urban Studies, 46(12), 2617-2641.

Mulvaney, K., Woodson, P., \& Prokopy, L. (2013). Different shades of green: A case study of support for wind farms in the rural Midwest. Environmental Management, $51,1012-1024$.

Munday, M., Bristow, G., \& Cowell, R. (2011). Wind farms in rural areas: How far do community benefits from wind farms represent a local economic development opportunity? Journal of Rural Studies, 27, 1-12.

Murarolli, M. (2014). Exploring the relative impacts of different motivations to adopt green housing features (Unpublished doctoral dissertation). University of Missouri, Columbia.

Muratori, M. (2015). Rural energy use and the challenges for energy conservation and efficiency. In D. E. Albrecht (Ed.), Our energy future: Socioeconomic implications and policy options for rural America (pp. 147-162). New York, NY: Routledge.

Net Metering. (n.d.). Retrieved February 02, 2017, from http://www.seia.org/policy/distributed-solar/net-metering 
Noble, E. (2012). The impact and cost-effectiveness of the Missouri Solar Rebate (Master's thesis). Duke University. Retrieved from http://dukespace.lib.duke.edu/dspace/handle/10161/5284

Obi, M., \& Bass, R. (2016). Trends and challenges of grid-connected photovoltaic systems - A review. Renewable and Sustainable Energy Reviews, 58, 1082-1094.

Ozaki, R. (2009). Adopting sustainable innovation: What makes consumers sign up to green electricity? Business Strategy and the Environment, 20, 1-17.

Owen, C., \& Dovey, K. (2008). Fields of sustainable architecture. The Journal of Architecture, 13(1), 9-21.

Painuly, J. P. (2000). Barriers to renewable energy penetration; a framework for analysis. Renewable Energy, 24, 73-89.

Parnell, R., \& Larsen, O. P. (2005). Informing the development of domestic energy efficiency initiatives: An everyday householder-centered framework. Environment and Behavior, 37(6), 787-807.

Pascale, A., Urmee, T., Whale, J., \& Kumar, S. (2016). Examining the potential for developing women-led solar PV enterprises in rural Myanmar. Renewable and Sustainable Energy Reviews, 57, 576-583.

Patton, M. Q. (1990). Qualitative evaluation and research methods. Newbury Park, CA: SAGE Publications, Inc.

Rapoport, A. (1980). Cross-cultural aspects of environmental design. In I. Altman, A. Rapoport, \& J. Wohwill (Eds.), Environment and culture (pp. 7-46). New York, NY: Plenum. 
Rebane, K. L., \& Barham, B. L. (2011). Knowledge and adoption of solar home systems in rural Nicaragua. Energy Policy, 39, 3064-3075.

Reddy, S., \& Painuly, J. P. (2004). Diffusion of renewable energy technologies barriers and stakeholders' perspectives. Renewable Energy, 29, 1431-1447.

Rogers, E. M. (1995). Diffusion of innovations. New York, NY: The Free Press.

Rosoff, L., \& Sinclair, M. (2009, August). Smart solar marketing strategies. Clean Energy Group and SmartPower. Retrieved from

https://www.cesa.org/assets/Uploads/Resources-pre-8-16/CEG-Solar-Marketing-Report2009.pdf

Shih, L. H., \& Chou, T. Y. (2011). Customer concerns about uncertainty and willingness to pay in leasing solar power systems. International Journal of Science \& Technology, 8, 523-532.

Simmons, G. (2011, December 1). Rooftop solar challenge to cut solar's red tape. Department of Energy. Retrieved from energy.gov/articles/rooftop-solar-challenge-cut$\underline{\text { solars-red-tape }}$

Solar Energy Industries Association (SEIA). U.S. solar market insight: 2011 year in review. SEIA/GTM Research.

Solar's dim future [Video file]. (2013, February 7). Retrieved from https://www.youtube.com/watch?v=jJN0B2RIIMI

Sovacool, B. (2014). Energy studies need social science. Nature, 511, 529-530.

Sovacool, B. (2009). Rejecting renewable: The socio-technical impediments to renewable electricity in the United States. Energy Policy, 37, 4500-4513. 
Sovacool, B. K., \& Ratan, P. (2012). Conceptualizing the acceptance of wind and solar electricity. Renewable and Sustainable Energy Reviews, 16, 5268-5279.

Sovacool, B. K., \& Watts, C. (2009). Going completely renewable: Is it possible (let alone desirable)? The Electricity Journal, 22(4), 95-111.

Stone, J. (1994). SOLAR 2000: The next critical step towards large-scale commercialization of photovoltaics in the United States. Solar Energy Materials and Solar Cells, 34, 41-49.

Strupeit, L., \& Palm, A. (2016). Overcoming barriers to renewable energy diffusion: Business models for customer-site solar photovoltaics in Japan, Germany and the United States. Journal of Cleaner Production, 123, 124-136.

Stryker, S., \& Burke, P. (2000). The past, present, and future of an identity theory. Social Psychology Quarterly, 63(4), 284-297.

Sueyoshi, T., \& Goto, M. (2014). Photovoltaic power stations in Germany and the United States: A comparative study by data envelopment analysis. Energy Economics, 42, 271-288.

Touryan, K. (1999). Renewable energy: Rapidly maturing technology for the $21^{\text {st }}$ century. Journal of Propulsion and Power, 15(2), 163-174.

Tucker, L. (2008, May 28-June 1). Sustainable environments: $18^{\text {th }}$ and $19^{\text {th }}$ century sustainable design technologies in the eastern U.S. Linking Differences/Defining Actions. Paper presented at EDRA 39, Boca del Rio, Veracruz, Mexico (pp. 284-286).

Wiser, R., Barbose, G., \& Holt, E. (2011). Supporting solar power in renewables portfolio standards: Experience from the United States. Energy Policy, 39, 3894-3905. 
Woodruff, A., Hasbrouck, J., \& Augustin, S. (2008, April 5-10). A bright green perspective on sustainable choices. CHI Proceedings at Green Day, Florence, IT (pp. 313-322).

Yang, C.-J. (2010). Reconsidering solar grid parity. Energy Policy, 38, 32703273.

Zahran, S., Brody, S., Vedlitz, A., Lacy, M., \& Schelly, C. (2008). Greening local energy: Explaining the geographic distribution of household solar energy use in the United States. Journal of the American Planning Association, 74(4), 419-434.

Zia, A., \& Todd, A. M. (2010). Evaluating the effects of ideology on public understanding of climate change science: How to improve communication across ideological divides? Public Understanding of Science, 19(6), 743-761. 


\section{VITA}

Heath Pickerill was born on July 3, 1971 in Litchfield, Illinois but grew up in the small town of Raymond. From a young age, he demonstrated a desire to develop his artistic ability along with a quest for learning. Throughout high school, he expressed an interest in pursuing a career in architecture but continued cultivating his passion for art. Upon graduating from Lincolnwood High School in Raymond in 1990 as his class valedictorian, he attended Millikin University in Decatur, Illinois on both art and academic scholarships. However, working for a small architecture and engineering firm during his first summer in college made becoming an architect more appealing than earning an art degree. He transferred to the University of Illinois at Urbana-Champaign where he completed his Bachelor of Science in Architectural Studies in May 1995. He returned to the University of Illinois after interning for one year for an architecture firm in Springfield, Illinois. He graduated in May 1998 with two masters' degrees, a Master of Architecture and a Master of Science in Civil Engineering.

After graduation, Heath accepted a position as an intern architect with Woolpert, Inc. in Belleville, Illinois where he worked for five years. In 2003, he moved to Rolla, Missouri and began working at Fort Leonard Wood as a project manager, first for the Directorate of Public Works and then the U.S. Army Corps of Engineers. He began teaching as an adjunct professor in the Architectural Engineering program at Missouri S\&T in August 2005 while still working at Fort Leonard Wood. He was named director of the Missouri Local Technical Assistance Program located at Missouri University of Science and Technology (Missouri S\&T) in June 2007. He has continued teaching construction management courses at Park University's Fort Leonard Wood campus since 
his early days of living in Missouri. Recently, he also started teaching for their online Bachelor of Science in Construction Management program.

A few of his professional affiliations include the National Local Technical Assistance Program Association, the Missouri Coalition for Roadway Safety Infrastructure Subcommittee, the Transportation Engineers Association of Missouri board of directors, and Missouri Association of County Transportation Officials. In addition, he serves as the lead faculty advisory for the Missouri S\&T Solar House Design Team. He enjoys balancing his involvement in various organizations with his administrative responsibilities as well as teaching and advising opportunities. He remains passionate about sharing his knowledge of architecture, renewable energy, and project delivery methods. 